
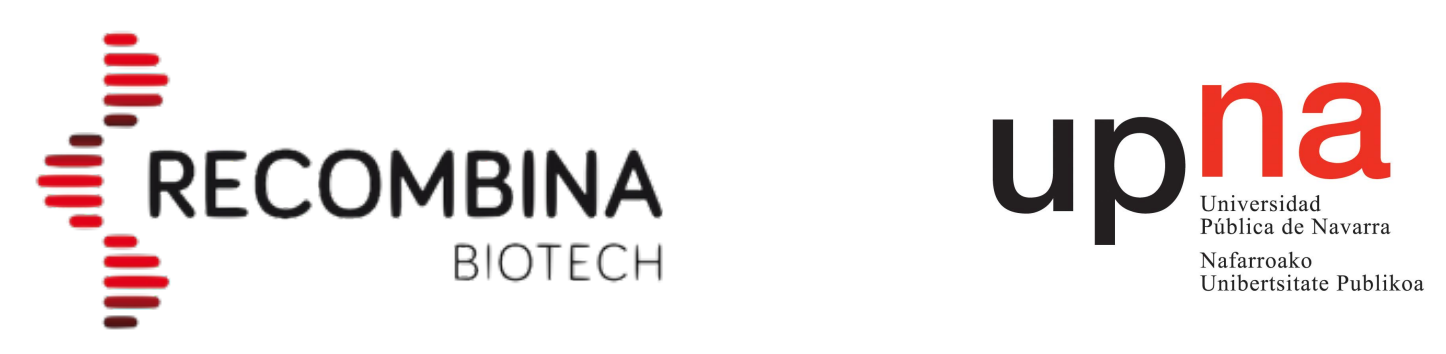

\title{
Novel strategies for treating biofilm and MRSA associated infections.
}

\author{
Memoria presentada por \\ JUANA MARÍA PRIETO MARISCAL \\ para optar al grado de Doctor por la Universidad Pública de Navarra
}

Director:

Dra. Cristina Latasa Osta

Tutor:

Prof. Iñigo Lasa Uzcudun

Pamplona - Iruña, 2020 
upna

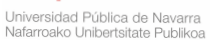


Dra. CRISTINA LATASA OSTA, socia de Recombina SL, con experiencia como investigadora reconocida por la Universidad Pública de Navarra.

INFORMA:

Que la presente memoria de Tesis Doctoral "Novel strategies for treating biofilm and MRSA associated infections" elaborada por Doña JUANA MARÍA PRIETO ha sido realizada bajo su dirección y que cumple las condiciones exigidas por la legislación vigente para optar al grado de Doctor.

Y para que así conste, firman la presente en Pamplona, a 23 de octubre de 2020.

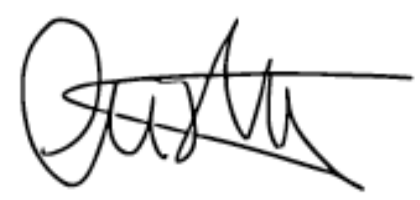

Fdo. Cristina Latasa Osta 
El presente trabajo ha sido realizado gracias a las ayudas concedidas por el Ministerio de Asuntos Económicos y Transformación Digital y el Centro para el Desarrollo Tencológico Industrial. Más concretamente, la tesis presentada ha sido financiada por los siguientes proyectos:

- "Nuevas estrategias para el control de infecciones nosocomiales- RTC2015-318". Convocatoria Retos Colaboración - Ministerio de Asuntos Económicos y Transformación Digitial (MINECO).

- "NEO016RECOMBINA SNEO-20161233". Convocatoria NEOTEC - Centro para el Desarrollo Tecnológico Industrial (CDTI).

El capítulo II de este documento está publicado en la revista Scientific Reports:

Prieto, J.M., Rapún-Araiz, B., Gil, C. et al. Inhibiting the two-component system GraXRS with verteporfin to combat Staphylococcus aureu infections. Sci Rep 10, 17939 (2020). https://doi.org/10.1038/s41598-020-74873-5 
AGRADECIMIENTOS 
"Everything should be as simple as possible, but not simpler."

Albert Einstein 
Antes de terminar de escribir este documento me gustaría dedicar unas palabras de agradecimiento.

En primer lugar agradecer a mi directora Cristina Latasa y mi tutor Iñigo Lasa la oportunidad que me dieron para poder hacer esta tesis. Una tesis no tan al uso, al realizarla desde una empresa, pero donde he aprendido que para conseguir las cosas hay que trabajar y esforzarse mucho.

No puedo olvidarme de mis compañeras de Recombina, Mari, Leire y CristinaP que habéis estado ahí apoyándome y echándome una mano siempre que la he necesitado. También darle las gracias a Nacho por apoyar este proyecto dandome esta oportunidad.

También quiero agradecer a Carmen y Bea, por su gran esfuerzo y ayuda en los ensayos de ratones y sus numerosas repeticiones.

A mis amigas: Maite, Natalia, Bea, Inés, Aroa y Ronces, porque aunque todas hemos tenido nuestros problemas y distintas dificultades, no me ha faltado una palabra de aliento en los momentos malos o una celebración en los buenos.

A mis hermanas y "hermanos": Manoli, Eduardo, Filo, JLuis y Nati, hay una cosa que siempre he tenido clara, pero con cada día de esta tesis lo voy teniendo más claro, siempre vamos a estar unidas, pase lo que pase.

A mis sobrinos: Lucía, Irune, Daniel, Asier, Enaitz y Odei, porque sois la alegría de mi jardín, porque sin mis bichitos las cosas serían muuucho mucho más difíciles. ¡Gracias por quererme tanto y dejarme quereros tanto!

A mi familia política, Lucía y Antonio, igracias por vuestro apoyo día a día!

¡A mis padres!, GRACIAS, GRACIAS y GRACIAS. Y por muy grande o muchas veces que lo escriba nunca sería suficiente, vosotros me habéis enseñado que quien algo quiere, algo le cuesta; que aunque el agotamiento parezca apoderarse de uno mismo, siempre hay que seguir luchando y tirando 
hacia adelante. Nunca me habéis dejado venirme abajo y me habéis enseñado a gestionar emociones y enfados. Por que por muchas piedras que haya tenido en el camino, siempre me habéis dado el empujón para seguir caminando. Vosotros no entendíais mis palabras cuando os contaba mis experimentos y sobretodo tu mamá, has estado preguntando un día tras otro por cada uno de mis experimentos. Porque no sabías si el resultado era bueno o malo, pero siempre me lo hacías ver con buenos ojos. Gracias a los dos por desearme y darme lo mejor con todas vuestras fuerzas.

Por último, a mi marido, Raúl. Gracias por tu apoyo, tu cariño, tus palabras, tus tonterías y tus ánimos. Se nos han juntado etapas muy bonitas y complicadas, pero tu has estado ahí dándome la mano para que no me pudiese perder ni caer. Has tenido que aprender de microbiología de forma exprés todo lo que no pudieron enseñarte en el colegio-instituto, pero siempre lo entendías y sabías hacerme un símil de pinturas y pinceles. Has conseguido que las cosas tuviesen otro color al estar a mi lado. GRACIAS, cariño, te quiero. 
“Un poco más de persistencia, un poco más de esfuerzo, y lo que parecía irremediablemente un fracaso, puede convertirse en un éxito glorioso"

Elbert Hubbard 


\section{TABLE OF CONTENTS:}

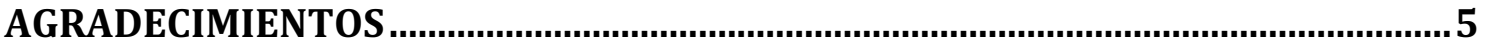

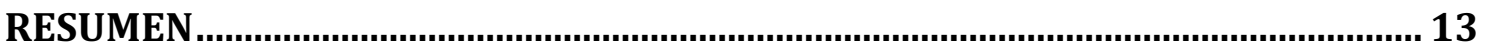

SUMMARY

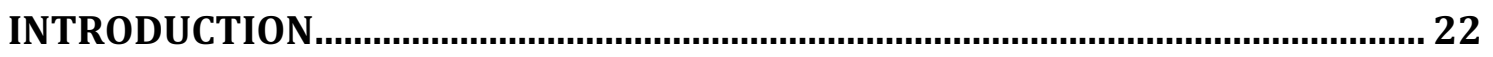

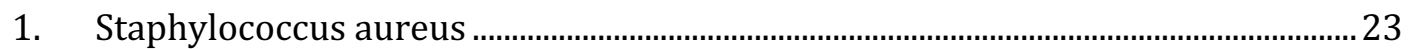

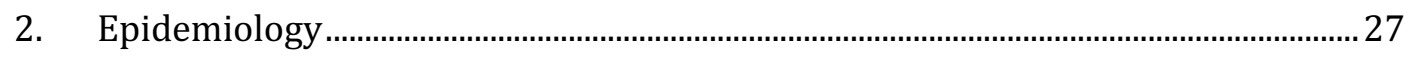

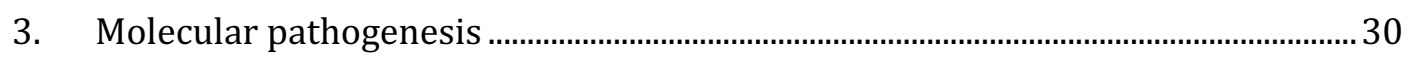

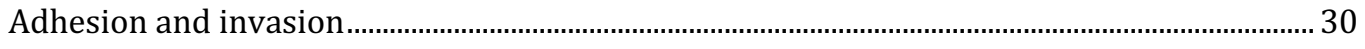

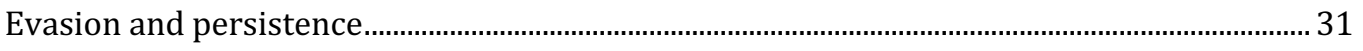

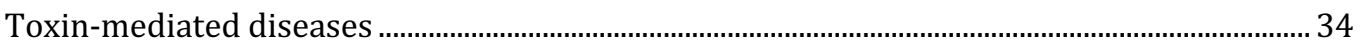

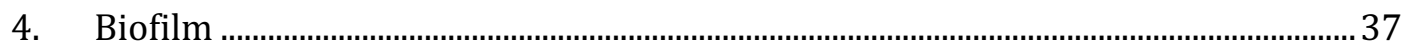

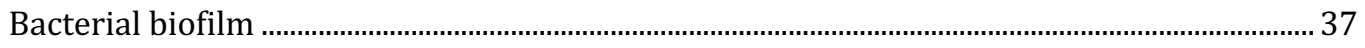

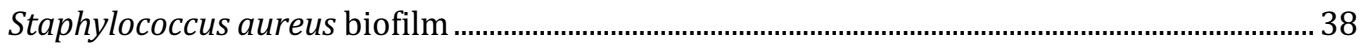

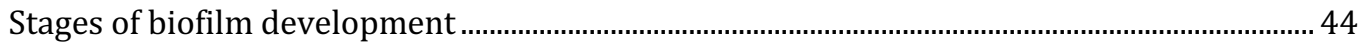

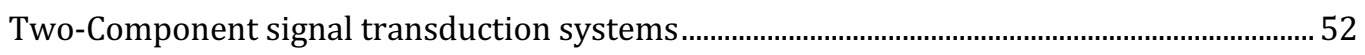

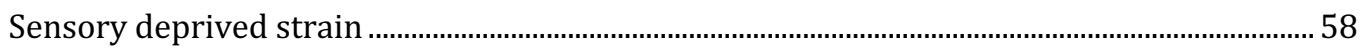

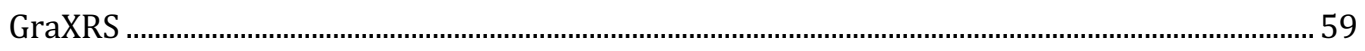

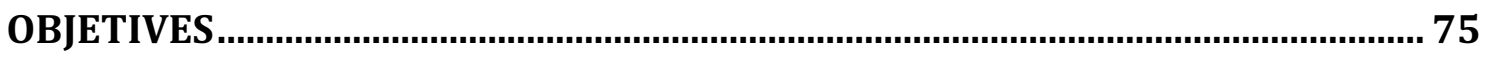

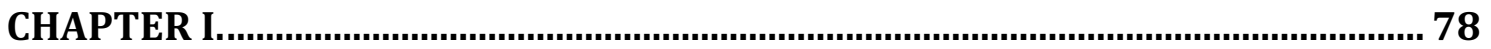

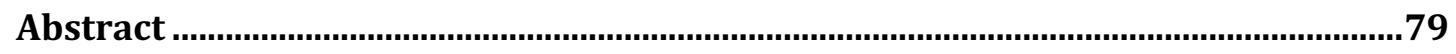

Introduction

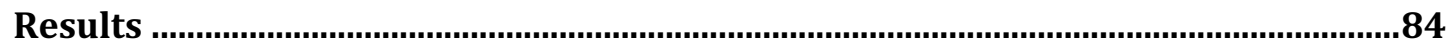


High Throughput Screening platform

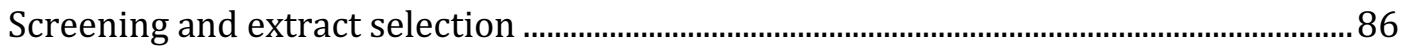

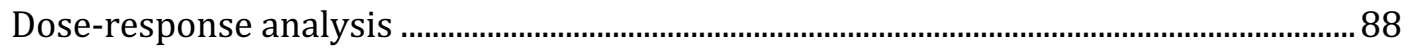

Batch reproducibility analysis ......................................................................................... 90

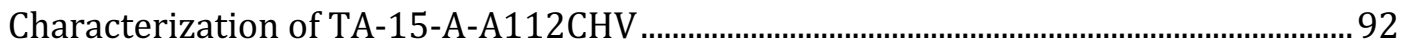

PIA/PNAG specificity:_........................................................................................................................... 92

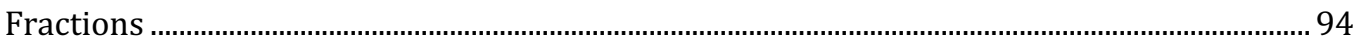

Preliminary approach for understanding the molecular mechanisms underlaying

PIA/PNAG-specific lethal effects .......................................................................................................... 96

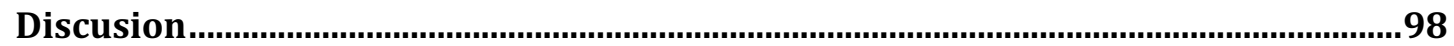

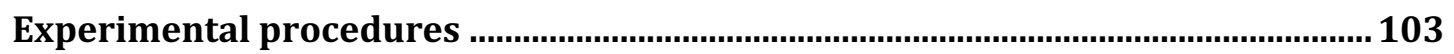

Bacterial strains, plasmids and culture media..................................................................... 103

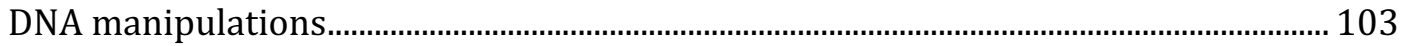

Compounds and extracts libraries ………..................................................................... 103

PIA/PNAG-dependent biofilm quantification assay ........................................................... 104

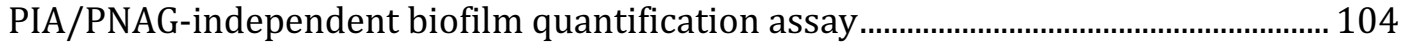

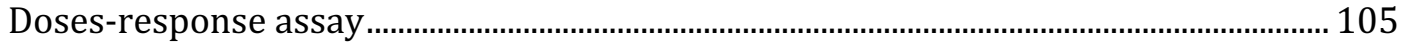

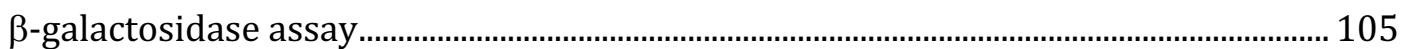

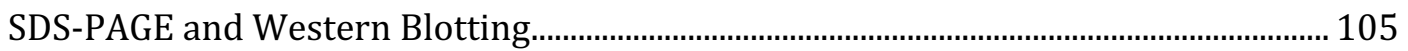

PIA/PNAG quantification ........................................................................................................ 106

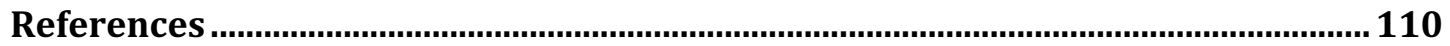

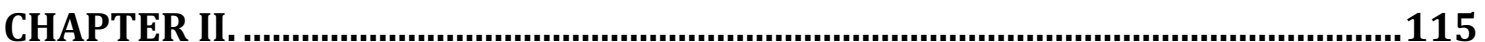

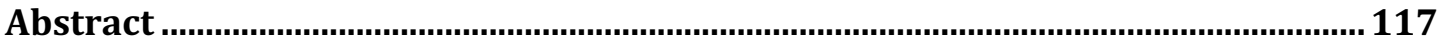

Introduction 
Design and validation of a GraXRS-focused screening platform.

Primary and secondary screenings .

In vitro effect of selected compounds: Phagocytosis and killing of $S$. aureus by human PMNs

Effect of Verteporfin in a murine model of wound infection

Exploring the mechanistic basis of verteporfin

Discussion

Material and Methods

Bacterial strains, plasmids, oligonucleotides and culture media 140

DNA manipulations.

Allelic exchange of chromosomal genes. 140

Reporter plasmid construction

High throughput beta-galactosidase-based screening

Phagocytosis and killing of $S$. aureus by human PMNs

Mouse infections models

Statistical analysis

References.

FUTURE PROSPECTS.

CONCLUSIONES

CONCLUSIONS

ANEXO I 
upna 
A lo largo de los últimos años el desarrollo de nuevas moléculas con actividad antibiótica ha sufrido un drástico descenso. La práctica totalidad de los antibióticos que se utilizan actualmente fueron descubiertos entre las décadas de los 30 y 90, habiéndose comercializado únicamente cuatro clases de nuevos antibióticos en los últimos 30 años. Este factor, sumado al aumento exponencial de la prevalencia de infecciones asociadas a bacterias resistentes a antibióticos, nos ha sumido en lo que se conoce como "era post-antibiótica". Este escenario contempla incluso que infecciones que hasta el momento han sido controladas con tratamientos sencillos podrían poner en riesgo la vida del paciente por la ausencia de alternativas terapéuticas. En diciembre de 2014, en la revisión anual de resistencias antibióticas, el economista Jim O'Neil predijo que, si no se toman medidas, en el año 2050 las enfermedades por microorganismos multiresistentes ocasionarán la muerte de 10 millones de personas en el mundo al año. Esta situación ha convertido la necesidad de desarrollar nuevas técnicas y aproximaciones terapéuticas para el control de infecciones causadas por bacterias multi-resistentes en una prioridad a nivel mundial. Especialmente preocupantes son las infecciones causadas por el grupo de patógenos denominado ESKAPE (Entereococcus faecium, Staphylococcus aureus,

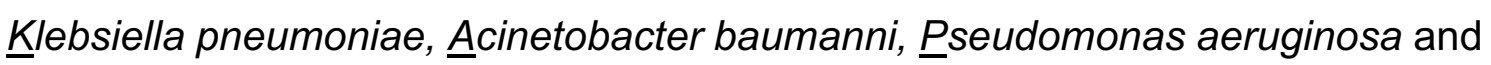
Enterobacter species).

S. aureus tiene un gran peso específico en el problema sanitario y económico que suponen las bacterias ESKAPE ya que, pese a que se trata de una especie comúnmente asociada a la microbiota humana, este microorganismo es el agente etiológico de muy diversas enfermedades. Esto es en gran parte debido a su extrema capacidad adaptativa, en la que la formación de biopelículas de 
diversa naturaleza, capaces de proteger a la bacteria frente al sistema inmune y el efecto de los antimicrobianos, tiene un papel crucial.

En esta tesis hemos trabajado en dos estrategias, un cribado fenotípico y otro frente a una diana específica, que podrían ayudar a ampliar las alternativas terapéuticas frente a $S$. aureus. En el primer capítulo, nos hemos centrado en la capacidad de esta bacteria para formar biofilms, y en el problema que esto implica. En nuestro intento de afrontar el problema con un abordaje diferente, nos hemos basado en el hecho de que la producción del biofilm, en especial el compuesto por el polisacárido PIA/PNAG, en muchas ocasiones es una ventaja para la bacteria, pero en otras puede ser su propio "talón de Aquiles". Con el objetivo de encontrar un compuesto capaz de incrementar los efectos negativos colaterales de la producción del biofilm e inhibir de forma selectiva a aquellas bacterias capaces de producir el polisacárido PIA/PNAG, hemos realizado un cribado a gran escala (HTS), en colaboración con la empresa Biomar, de compuestos y extractos procedentes de fermentaciones de microorganismos marinos. Los resultados han revelado la existencia de una sub-fracción (SF8) compuesta por tres moléculas que presenta una actividad inhibitoria específica sobre aquellas cepas que han iniciado el proceso de formación del biofilm polisacarídico. Además, los resultados obtenidos hasta la fecha sugieren que el efecto inhibidor de SF8 está mediado por una regulación de IcaC a nivel post transcripcional y la represión de proteína A, así como de otras proteínas de alto peso molecular.

En el segundo capítulo, nos hemos fijado un objetivo alternativo para "desarmar" a $S$. aureus, centrándonos en la participación del sistema de dos componentes (TCS) GraXRS en la capacidad de S. aureus para contrarrestar las barreras del sistema inmune innato del huésped. Con el objetivo de encontrar un medicamento en uso, capaz de bloquear GraXRS y hacer más susceptible a la 
bacteria, hemos realizado un HTS con una colección de 1280 medicamentos aprobados por la agencia FDA cuyas patentes han expirado, utilizando una cepa reportera defectiva en todos los TCS no esenciales excepto GraXRS. El medicamento Vertepofin, cuya indicación aceptada es el tratamiento de la degeneración macular, es capaz de bloquear este TCS, mejorando la actividad anti-bacteriana mediada por las células polimorfonucleares. Su administración tópica en un modelo murino es capaz de reducir significativamente la carga bacteriana. Asimismo, se ha reforzado la conexión entre el sistema GraXRS y la señalización mediada por condiciones redox, ya que en nuestro cribado observamos que las moléculas antioxidantes y redox-activas son capaces de reducir la expresión del regulón GraXRS. El análisis del mecanismo molecular sugiere que el residuo redox-activo C227 de GraS participa en la inhibición ejercida por este fármaco. Teniendo en cuenta estos resultados, sugerimos incluir el fármaco Vertepofin en la lista de compuestos cuya indicación puede reconvertirse para sensibilizar a $S$. aureus y por tanto ser útil para combatir infecciones persistentes o resistentes a los antibióticos. 
In the course of recent years both development and commercialization of new antimicrobial drugs have undergone a very significant decline. Virutally all the antibiotics that are currently being used in clinics were discovered between 30's and 90's decades and only four new types of antimicrobial drugs have been brought into the market during the last 30 years. Such a premise, together with the fact that we are witnessing an exponential growth of infections associated to antibiotic-resistant bacteria, has plung us into in what is referred to as "postantibiotic era". This scenario could turn common easy-to-cure infections into lifethreatening diseases due to the lack of therapeutical alternatives; Actually, during the Annual Revision of Antibotic Resistance of 2014, it was predicted that, if community is not willing to undertake corrective measures, 10 million people could die from infectious diseases per year by 2050 . Thus, development of novel techniques and alternative therapeutical approaches to combat resistant bacteria, specially those belonging to the ESKAPE family (Enterococcus facecium, Staphylococcus aureus, Klebsiella pneumoniae, Acinetobacteri baumanni, Pseudomonas aureuginosa and Enerobacter) are of major importance and extraordinary priority worldwide.

S. aureus poses a particular threat to economy and public health, since, though it is commonly associated to our normal microbiota, this species can be the ethiologic agent of a very wide range of diseases. This is mostly due to its impressive adaptative capacity, which mainly relies on an extraordinary network of signalling pathways for sensing and responding to environmental changes and the capacity to form biofilms that protect bacteria from the action of antimicrobials and the immune system.

In this thesis, we have applied a phenotypic (chapter I) and a target-focused (Chapter II) screening approaches, with the objective of finding molecules that 


\section{Summary}

could somehow broaden the therapeutical alternatives against $S$. aureus. The first chapter is focused on the contradictory nature of PIA/PNAG, the major component of polysaccharidic staphylococcal biofilms. Though the production of this polymer protects bacteria and entails an unquestionable evolutionary advantage, it might also have some side effects in terms of bacterial fitness, which could be indeed enhanced or exploited to generate a lethal outcome. In collaboration with the spanish company Biomar, and with the hope of finding a molecule capable of targetting this bacterial "Achilles heel", we have perfomed a High-Troughput-Screening (HTS) with a library of extracts and compounds of marine origin. Our results have revealed that a subfraction proceeding from the fermentation of a marine species, composed by three active compounds, exerts a specific inhibitory effect on those bacteria that had entered into the biofilm lifestyle and are producing PIA/PNAG as a part thereof. Up to date, analysis suggest that the mechanisms underlaying this inhibition are, at least in part, mediated by a post transcriptional inactivation of icaC protein and repression of Protein A and other high-molecular-weight proteins.

The second chapter is focused on the GraXRS Two Component System (TCS) as an alternative target for disarming $S$. aureus, since this pathway is crucial for bacterial resilience against the barriers of the host's innate immune system and thus has a pivotal role in $S$. aureus virulence. With the aim of finding new molecules capable of blocking GraXRS activity, we have screened 1280 offpatent FDA-approved drugs using a reporter strain lacking all non-essential TCSs but GraXRS. We have found that Vertepofin, a drug that is normally prescribed to treat macular degeneration, inhibits this TCS and it is indeed very efficient in enhancing PMN-mediated bacterial killing. Besides, the topical administration of this drug in a murine model significantly reduces the bacterial load. Likewise, the connection between the GraXRS signaling pathway and redox signalling has been strengthened by our findings, since we have observed that active 
antioxidant and redox molecules are capable of reducing the expression of the GraXRS regulon. The analysis of molecular mechanisms underlaying Verterporfin effect suggest that the active C227 redox residue of GraS participates in the inhibition exerted by this drug. We therefore believe that it might be worth considering the drug Vertepofin as a candidate for sensitizing $S$. aureus and combating persistent or antibiotic-resistant infections. 


\section{Staphylococcus aureus}

Staphylococcus aureus is a gram-positive spherical bacterium, usually arranged in grape-like irregular clusters (see figure 1), which is commonly described as a non-motile, non-sporulated, facultative anaerobic microorganism. Relevant characteristics shown by this species also include a relatively high resistance to drying, extreme temperatures (up to $50^{\circ} \mathrm{C}$ for 30 minutes), a wide $\mathrm{pH}$ range $(4,8-9,4)$ and high-salt concentrations (up to $9 \%$ of sodium chloride), but a moderate susceptibility to certain chemicals like hexachlorophene, chlorhexidine or povidone-iodine instead. Regarding S. aureus major biochemical features, worth mentioning are its capacities to metabolize mannitol, glucose, xylose, lactose, sucrose, maltose and glycerol (Crossley et al., 2009; Somerville and Proctor, 2009; Brooks et al., 2013).

Most strains of Staphylococcus aureus are capable of producing the golden coloured carotenoid pigment staphyloxanthin, which acts as a virulence factor mainly due to its antioxidant properties that counteract the action of the reactive oxygen species produced by the host immune system. In addition, S. aureus is capable of producing surface polysaccharides that are important components of the staphylococcal cell envelope. These glycopolymers include capsular polysaccharide (CP), cell wall teichoic acid (WTA), and polysaccharide intercellular adhesin/poly- $\beta(1-6)-N$-acetylglucosamine (PIA/PNAG) and play distinct roles in $S$. aureus colonization and pathogenesis. Besides, colonies of $S$. aureus are $\beta$-hemolytic due to the production of several hemolysins, including $\alpha$ hemolysin, $\beta$-hemolysin, $\gamma$-hemolysin and $\delta$-hemolysin, which contribute to host cell damage. (Pelz et al., 2005; Clauditz et al., 2006; Somerville and Proctor, 2009; Brooks et al., 2013). 


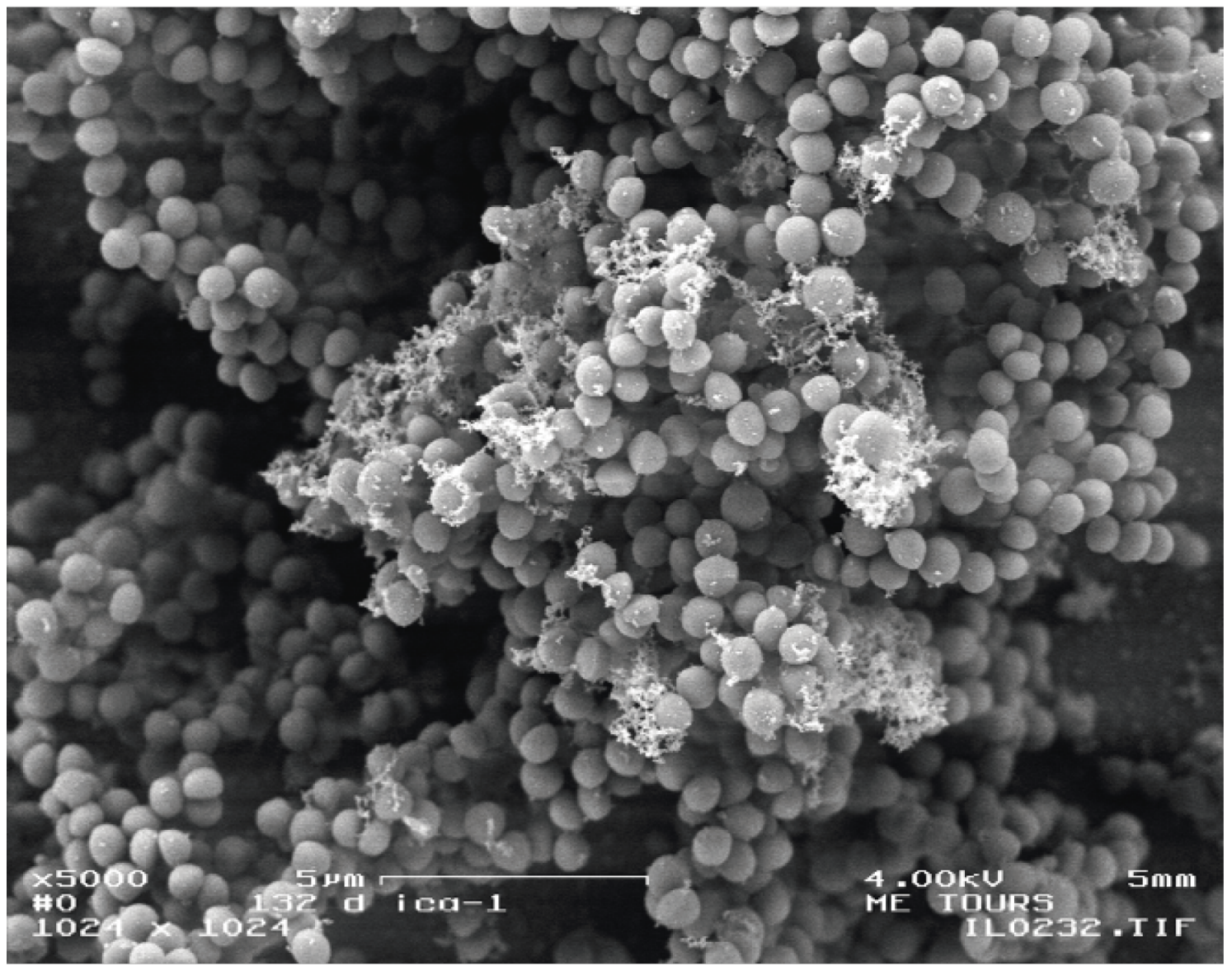

Figure 1. Scanning electron micrograph (SEM) of Staphylococcus aureus. Magnified 5000x. 


\section{Phylogeny}

From a phylogenetic point of view, the species $S$. aureus is a member of the phylum Firmicutes, class Bacilli, order Bacillales, family Staphylococcaceae and genus Staphylococcus.

The genus Staphylococcus was initially classified on the basis of the colony colour, referring to the orange-yellow staphylococci as S. aureus, the white colonies as $S$. albus and the lemon-coloured species as S. citreus. However, pigment as the sole criterion for species classification was unsatisfactory, mainly because it was not a genetically stable character in many strains (Kloos, 1980). Afterwards, various molecular DNA-based methods requiring the use of several species-specific PCR primers, hybridization probes, multiple restriction enzymes, 16S rRNA gene sequencing, PCR restriction fragment length polymorphism (PCR-RFLP) and PCR-RFLP analysis of the 23S rRNA gene with two restriction enzymes were developed. However these conventional molecular typing approaches frequently struggle to discriminate between isolates in health-care environments (Ghebremedhin et al., 2008). Nowadays, technological advances have turned whole genome sequencing (WGS) into the most promising method when it comes to distinguish clonal isolates. This method enables the entire genome of isolates to be compared, which enhances resolution significantly (Humphreys and Coleman, 2019). The affordability and increasing availability of WGS in recent years has enabled a more detailed study of previously undocumented transmission, as well as the overall and detailed analysis or the evolutionary route of resistance genes in S. aureus strains (Kuroda et al., 2001; John et al., 2019).

Apart from phylogenetic findings and classifications, in a simplified but more useful and well-accepted scheme, staphylococci are divided into two main groups on the basis of their ability to clot blood plasma (coagulase reaction). The first one, the coagulase-negative staphylococci (CoNS) group, represents a regular part of the microbiota of the skin and mucous membranes of humans and animals. The second one, the coagulase-positive staphylococci (CoPS) group, 
Introduction

consists of the most pathogenic staphylococcal species, where the major human pathogen is $S$. aureus. The genus consists of 47 species, 38 of which fulfil the categorization of coagulase-negative species, one of them includes both a coagulase-negative and positive subspecies, and the remaining species belong to the coagulase-positive group (Brooks et al., 2013; Becker et al., 2014). 


\section{Epidemiology}

$S$. aureus is a frequent component of the human microbiota. Colonization commonly occurs after born and persists throughout life in a significant proportion of the population (approximately $20 \%$ of individuals are persistently colonized and $30 \%$ are transiently colonized), being the anterior nares, the throat, and the perineum the niches from which $S$. aureus can be cultured (Wertheim et al., 2005).

S. aureus normally behaves like a commensal microbe that colonizes the host without causing disease but might turn into a dangerous pathogen due to its versatile and resilient nature. Indeed, S. aureus is capable of infecting almost every tissue and organ system in the human body, leading to diverse serious clinical conditions. Acute infections, such as bacteraemia and skin abscesses, are generally caused by planktonic cells and associated to the production of secreted toxins and exo-enzymes, while chronic infections, such as osteomyelitis, endocarditis, septicaemia and pneumonia, are normally associated to the biofilm or community lifestyle, which permits attachment and persistence on host tissues (like bone and heart valves) or on implanted materials (catheters, prosthetics joints or pacemakers, to name a few). Penetration into deeper tissue often occurs through invasive procedures like the introduction of catheters or artificial prostheses that are carried out in healthcare settings. Various host factors predispose to infection; These factors include loss of the normal skin barrier, presence of underlying disease (type 1 diabetes e.g.), acquired immunodeficiency syndrome or defects in neutrophils function. S. aureus-related infections are associated with increasing morbidity and mortality, longer hospital stays and often required surgical removal of infected devices, resulting in an expensive annuals cost (Sibbald et al., 2006; Verbrugh, 2009; Lister and Horswill, 2014; Haag and Bagnoli, 2015; Al-Mebairik et al., 2016; Moormeier and Bayles, 2017). The incidence of $S$. aureus bacteremia (SAB), in particular those cases associated to methicillin-resistant $S$. aureus (MRSA) strains increased dramatically in the period between 1960 to 2000 (Tong et al., 2015). Even though 
the prevalence has decreased in recent years, MRSA remains as one of the most important nosocomial pathogens, and noticeably, MRSA infections have emerged in the community. In Spain, S. aureus is, after Escherichia coli, the most frequent etiologic agent causing both nosocomial infections $(10,06 \%$ of total hospital-acquired infections and $14,55 \%$ of hospital-acquired bacteremia) and community-acquired infections (8,94\% of total community infections and $11,37 \%$ of community acquired bacteremia) (EPINE-EPPS, 2019).

The problem associated to staphylococcal infections is enhanced by the amazing ability of $S$. aureus to develop resistance to antibiotics. Infections caused by this pathogen were initially treated with penicillin since its introduction in the 1940s, but the appearance and rapid spread of methicillin-resistant S. aureus (MRSA) strains has eliminated the use of $\beta$-lactams as a treatment option. Actually, the phenomenon of antibiotic resistance was observed very soon. In 1961 the first MRSA strain was isolated, just 1 year after the introduction of methicillin. Vancomycin has long been a last resort antibiotic for multiple-drugresistant S. aureus strains, but in 1996 a strain showing reduced sensitivity towards vancomycin was isolated, designated vancomycin intermediately resistant S. aureus (VISA). A few years later, in 2002, the first vancomycin resistant S. aureus (VRSA) emerged (Sibbald et al., 2006; Assis et al., 2017). As a result, $S$. aureus is nowadays considered as part of a dangerous group of bacteria that escape the lethal action of antibiotics. The group is composed by Enterococcus faecium, Śtaphylococcus aureus, Klebsiella pneumoniae, Acinetobacter baumanni, $\underline{P}$ seudomonas aeruginosa and Enterobacter species and is referred to as "the ESKAPE bugs" (Rice, 2008).

Finally, worth mentioning is the fact that, apart from being a notorious human pathogen, S. aureus causes an array of infections with great economic livestock animals including cows, sheep, goats, poultry and rabbits. For instance, intramammary infection of dairy cows leading to mastitis, is a major economic burden on the global diary industry. The disease also affects small ruminants, which is a particular problem in regions that produce sheep and goat cheeses 
Introduction

and is also considered a major cause of lameness in the poultry industry, causing skeletal infections in commercial broiler chickens. Furthermore, this pathogen might cause skin abscesses, mastitis and septicaemia in rabbits (Fitzgerald, 2012). 


\section{Molecular pathogenesis}

As mentioned earlier, S. aureus is recognized as a commensal colonizer of the skin and mucosa surface and also as an important pathogen. The success of $S$. aureus as both colonizer and pathogen and moreover to cause a wide range of infections in human and animals is largely due to its ability to adapt to different environment and to the extensive repertoire of mechanisms for virulence the bacterium is provide with. These virulence factors vary in their presence and specificity between clones and might be classified attending several criterions; In this thesis they are divided according to their mechanism of action: (1) adhesion and invasion; (2) Evasion and persistence; and (3) Toxins (Foster, 2004; Sibbald et al., 2006; Gordon and Lowy, 2008; Al-Mebairik et al., 2016). Each group is described below, summarized in table 1 and illustrated in figure 2 .

\section{Adhesion and invasion}

The first step of $S$. aureus colonization involves bacterial adherence to host epithelial cells. This adhesion is mediated by surface proteins that are covalently attached to peptidoglycan, which are known as cell wall anchored (CWA) proteins. The precise repertoire of CWA proteins on the surface varies among strains and depends on growth conditions, but it is accepted that $S$. aureus can express up to 24 CWA proteins. The MSCRAMM (microbial surface component recognizing adhesive matrix molecules) protein family is also related to the attachment to components of the host extracellular matrix (ECM) such as fibrinogen, fibronectin and collagen. Through the acronym MSCRAMM was originally applied to surface proteins that mediate attachment to components of the host ECM, it is worth noting that many bacterial surface proteins are not MSCRAMM, while some MSCRAMM have additional functions other than promoting adhesion. MSCRAMM family includes clumping factor (clfA and clfB), collagen adhesin (cna), extracellular adherence protein (Eap), fibronectinbindings proteins (FnBPA and FbBPB), biofilm associated protein (Bap), Ironregulated surface determinant protein $A$ (IsdA) or $S$. aureus surface protein $G$ 
(SasG). (Cucarella et al., 2002; Vergara-Irigaray, Valle, Merino, Latasa, Garcia, Mozos, et al., 2009; Foster et al., 2014; Al-Mebairik et al., 2016).

ECM adhesion step is a prerequisite for the internalization into nonprofessional phagocytic cells (NPPCs) like epithelial cells, endothelial cells, fibroblasts and osteoblasts. FnBPs can bind Fn molecules, and thus cluster $\alpha 5 \beta 1$ integrins on the cell surface to trigger the efficient intracellular signalling required for internalization. The signalling pathway of staphylococci internalization involves focal adhesion kinases (FAKs) and activated Src that subsequently recruit cortactin to promote actin polymerization and mobilize the endocytic machinery. Downstream of the FAK-Src pathway, the activation of PI3K and Akt is also important for the internalization of $S$. aureus. This internalization mechanism appears to be an active process on the cellular side, but $S$. aureus could also stimulate its own uptake by upregulating $\beta 1$ integrin expression in the host cell via $\alpha$-haemolysin secretion (Foster et al., 2014; Goldmann et al., 2016; Josse et al., 2017).

\section{Evasion and persistence}

The innate immune system represents a first-line defence against invading pathogens and consists of three major effector mechanisms: (i) complement system, (ii) phagocytosis and (iii) antimicrobial peptides and enzymes production. The importance of these three effector mechanisms is different depending on the site of infection and on bacterial characteristics. Nevertheless, S. aureus has plenty of mechanisms to evade host innate immunity.

- $\quad$ Complement system represent the most "primitive" line of defence against infectious agents. The role of the complement system is to enhance binding and uptaking processes by phagocytic immune cells. S. aureus fights this mechanism by producing Staphylococcus protein A (SpA) (Forsgren and Sjöquist, 1966) and Staphylococcus binder of immunoglobulin (Sbi), two proteins that bind $\lg G$ in the wrong orientation, thereby blocking Fc receptor-mediated phagocytosis (Zhang et al., 1998). 
Besides that, $S$. aureus also produces cna (inhibits activation of the lectin pathway)(Kang et al., 2013), Aureolysin (Aur, inhibits the de the deposition of C3 on the bacterial surface) (Laarman et al., 2011), Eap (blocks the formation of lectin)(Woehl et al., 2014), Staphylococcus complement inhibitor (SCIN, blocks C3b deposition and $\mathrm{C} 5 \mathrm{a}$ production)(Suzan H M Rooijakkers et al., 2005), Staphylokinase (SAK, remove opsonins IgG and C3b from the surface), SSL7 (interference with the production of C5a)(S.H.M. Rooijakkers et al., 2005), Extracellular fibrinogen-binding protein (Efb, blocks C3 and C5 convertases) and its homologue extracellular complement-binding protein (Ecb, blocks C3 and C5 convertases and can build a "capsule-like" shield to prevent recognition of opsonins by FcR or CR)(Jongerius et al., 2010; de Vor et al., 2020).

- Phagocytosis: neutrophils are the most important effector cells in staphylococcal infections. They are recruited to the tissue by chemoattractants that are locally produced following infection by the bacterium (formylated peptides, leukotriene and platelet-activating factor) (Schiffmann et al., 1975). S. aureus secrets proteins like chemotaxis inhibitory protein of Staphylococcus (CHIPS) (de Haas et al., 2004).that evade priming and activation of neutrophils by blocking the interaction of chemoattractants with their neutrophil receptor, Moreover, FRP-like 1 inhibitory protein (FLIPr) and FLIPr-like block FPR1, FPR2, multiple FcRs and inhibit antibody-mediated phagocytosis (Stemerding et al., 2013).

- Antimicrobial peptides and enzymes: after phagocytosis, bacteria are subjected to high levels of reactive oxygen species (ROS), reactive nitrogen species (RNS) and degranulation of antimicrobial products (lactoferrin, lysozyme, antimicrobial peptides (AMPs) and neutrophil serine proteases) in the phagosome. As response, S. aureus induces the expression of a large number of antioxidant enzymes like catalases, staphyloxantin or superoxide dismutase and uses different strategies to 
avoid antimicrobial peptides (which target negatively charged bacteria), altering its surface charges or even degrading (Aur) and neutralizing (SAK) them (Liu, 2009).

Persistence is also a clinically relevant mechanism, allowing bacterial resilience against host defences or antibiotics. The capacity to persist on the host shown by $S$. aureus mainly lies in its ability to form small colony variants (SCVs) and display an aggregative behaviour known as biofilm. SCVs constitute a slowgrowing auxotrophic subpopulation of bacteria with distinctive phenotypic and pathogenic traits that contribute to persistent and recurrent infections. In vitro assays have shown that SCVs are able to "hide" in host cells without causing significant host-cell damage, remaining protected from antibiotics and host defences. They can later revert to the more virulent wild-type phenotype, possibly resulting in recurrent infection (Gordon and Lowy, 2008; Liu, 2009; Melter and Radojevič, 2010).

Furthermore, $S$. aureus is capable of assembling sessile microbial communities known as biofilms. Within these multicellular structures, bacteria are attached to a surface or to other cells and embedded in a protective extracellular polymeric matrix. The composition of the scaffold varies amongst strains, but generally contain host factors, polysaccharides, proteins and extracellular DNA. Biofilms play an important role during infection, "sheltering" bacteria against several clearance mechanisms. Thus, biofilm matrixes can impede the access of certain types of immune elements like macrophages or antibodies and generate tolerance towards antibacterial agents. Beyond offering resistance to clearance mechanisms, biofilms are important in chronic diseases progression since individual cells can disperse from previously stablished scaffolds and either seed new sights of infection or mediate an acute process (Vuong et al., 2004; Lister and Horswill, 2014). Following section describes further details regarding $S$. aureus biofilm. 


\section{Toxin-mediated diseases}

Toxins are key virulence factors defined as molecules that increase the potential of a pathogen to cause disease through a direct interference with the host. The main $S$. aureus toxins can be divided into three major groups.

First group includes the pore forming toxins (PFTs), which by itself or in association with a receptor of host cell are able to produce a transmembrane channel. The PFTs group includes hemolysin- $\alpha$, hemolysin- $\beta$, leukotoxins (LukDE, LukAB, Panton-Valentine leukocidin PLV) and phenol-soluble modulins (PSMs) (Grumann et al., 2014).

The second group refers to exfoliative toxins (ETs), also known as epidermolytic toxins. ETs are extremely specific serine proteases secreted by $S$. aureus, which recognize and hydrolyse desmosome cadherins in the superficial layers or the skin. ETs include exfoliative toxin A/B/C/D (ETA, ETB, ETC, ETC) (Bukowski et al., 2010; Mariutti et al., 2017).

The third and last group comprises toxins known as superantigens (SAgs). These toxins activate a large fraction of $\mathrm{T}$ lymphocytes simultaneously by directly cross-linking certain $\mathrm{T}$ cell receptors in an $\mathrm{MCH}$-independent manner. There are more than 23 staphylococcal SAgs toxins as toxic shock syndrome toxin (TSST1), staphylococcal enterotoxins (SEA to SEE, SEG to SEJ, SEL to SEQ and SER to SET) and staphylococcal superantigen-like toxins (SEIK to SEIQ, SEU to SEIX) (Proft and Fraser, 2003; Grumann et al., 2011; Grumann et al., 2014; Otto, 2014). 
Table 1. Summary of Staphylococcus aureus virulence factors.

\begin{tabular}{|c|c|c|}
\hline $\begin{array}{c}\text { Mechanism of } \\
\text { action }\end{array}$ & Virulence Factor & References \\
\hline $\begin{array}{c}\text { Adhesion and } \\
\text { invasion }\end{array}$ & $\begin{array}{l}\text { ClfA, ClfB, FnbA, FnbB, Bap, } \\
\text { SasG, Cna, Sdr, SraPBbp, } \\
\text { Eap FnBPA, FnbPB IsdA, } \\
\text { WTA }\end{array}$ & $\begin{array}{l}\text { (Cucarella et al., 2002; Vergara-Irigaray, Valle, } \\
\text { Merino, Latasa, Garcia, Mozos, et al., 2009; } \\
\text { Foster et al., 2014; Al-Mebairik et al., 2016; } \\
\text { Goldmann et al., 2016; Josse et al., 2017) }\end{array}$ \\
\hline $\begin{array}{l}\text { Evasion and } \\
\text { persistence }\end{array}$ & $\begin{array}{l}\text { SpA, Sbi, can, Aur, SCIN, } \\
\text { SAK, SSL7, Efb, Ecb, CHIP, } \\
\text { FLIPr, FLIPr-like Eap, } \\
\text { staphyloxantin, katG, mprF, } \\
\text { DIt operon, Coa, capsule, } \\
\text { SCVs, IcaACBD, IcaR, Rbf }\end{array}$ & $\begin{array}{l}\text { (Forsgren and Sjöquist, 1966; Zhang et al., } \\
\text { 1998; Suzan H M Rooijakkers et al., 2005; Liu, } \\
\text { 2009; Jongerius et al., 2010; Laarman et al., } \\
\text { 2011; Zecconi and Scali, 2013; Stemerding et } \\
\text { al., 2013; Kang et al., 2013; Woehl et al., 2014; } \\
\text { McGuinness et al., 2016) }\end{array}$ \\
\hline Toxins & $\begin{array}{c}\text { PSMs, ETA, ETB, ETC, ETD, } \\
\text { SEAs, TSST, Hla, Hlb, PVL, } \\
\text { LukDE, LukAB, SEs }\end{array}$ & $\begin{array}{l}\text { (Proft and Fraser, 2003; Sibbald et al., 2006; } \\
\text { Gordon and Lowy, 2008; Bukowski et al., 2010; } \\
\text { Grumann et al., 2011; Grumann et al., 2014; } \\
\text { Otto, 2014; Mariutti et al., 2017) }\end{array}$ \\
\hline
\end{tabular}




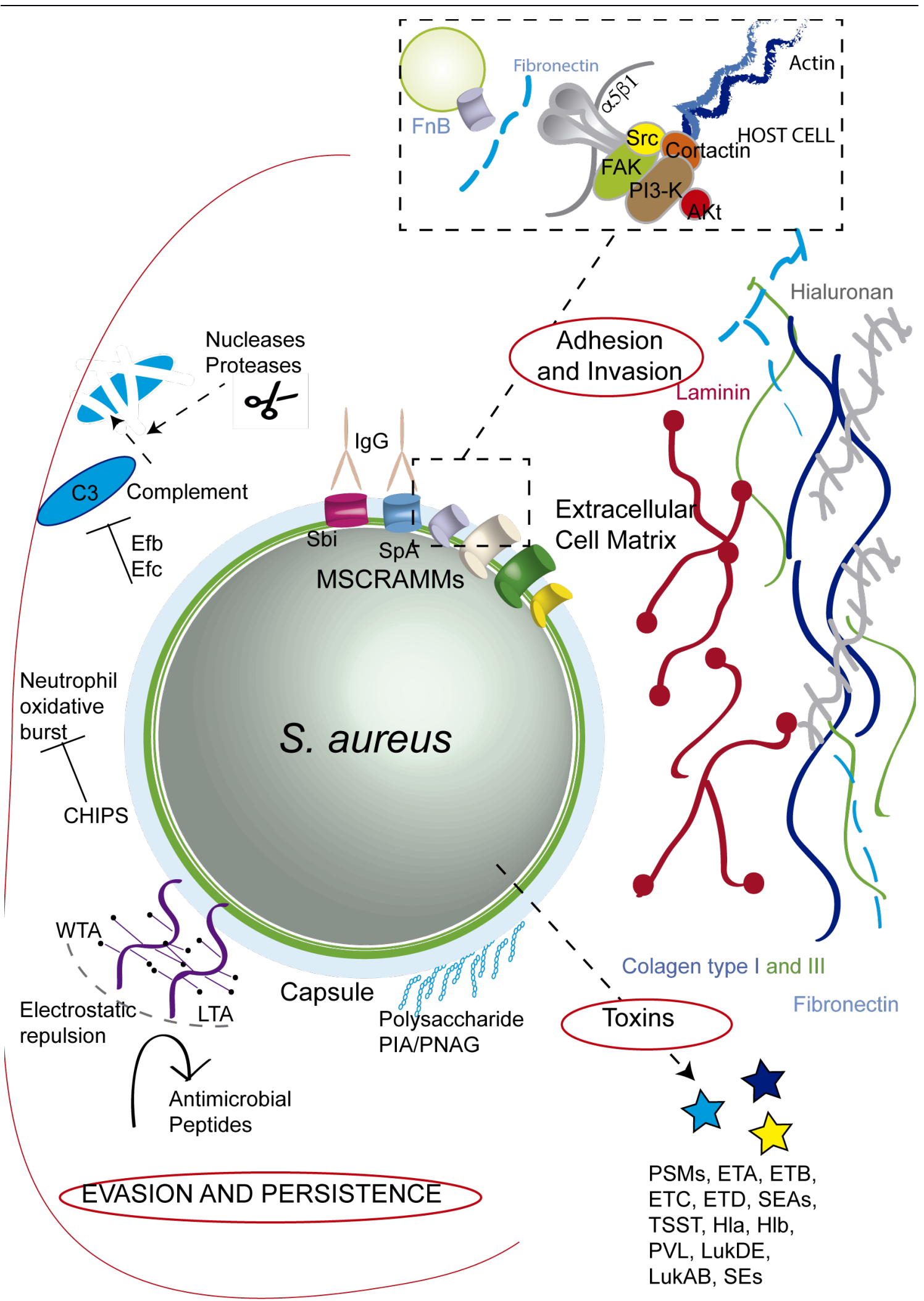

Figure 2. Schematic diagram of $S$. aureus virulence factors. Illustrated acording to the three main groups: adhesion and invasion, evasion and persistence and toxins. 


\section{Biofilm}

\section{Bacterial biofilm}

In the $17^{\text {th }}$ century, Antonie van Leeuwenhoek observed swarming "animalcules" deposited on living and dead matter for the first time. These "animalcules" in the tartar on his own teeth were indeed bacteria of the dental plaque, and represent the first documented evidence of the biofilm concept; (Percival et al., 2011). The exhaustive observation of this particular microbial structure awaited the invention of the electron microscopy.

In general terms, biofilms are defined as a communities of microorganisms attached to biotic or abiotic surfaces, embedded by a matrix of extracellular polymers, acting as an independent functioning and homeostatically-regulated ecosystems (Percival et al., 2000; Sadekuzzaman et al., 2015; Jamal et al., 2018). Now it is well recognized that almost all microorganisms in nature, under the appropriate conditions, have the ability to grow as part of a sessile biopolymer-enshrouded community referred to as biofilm. Biofilms communities differ from their planktonic (freely suspended) counterparts in terms of gene expression and protein production. The communication between neighbouring bacteria mainly occurs via quorum sensing, a social language and behaviour that enables interactions within bacterial communities. Sometimes interactions can be beneficial (metabolic cooperation, attachment allowing), but other times the relationship might be based on the competition for resources or natural nutrients (Elias and Banin, 2012).

There is a wide range of microbial biofilms depending on whether they are composed by single or multiple species, or according to the matrix composition, which is highly complex and might suffer great variations depending on environmental conditions (Donlan, 2002). Biofilm formation is a phenomenon that occurs in both ecological and clinical environments and leads to the development of beneficial communities or inconvenient disease-associated biofilms formed on medical devices (Costerton et al., 1981). In humans, an estimated $65 \%$ of all hospital infections are associated to biofilms. Once established, these infections 
Introduction

are very difficult to eradicate due to their resilience to removal by host defense mechanisms and antimicrobials (Percival et al., 2011). The biofilm-producing pathogen Staphylococcus aureus has become specially notorious for causing chronic infections associated to the biofilms formed on indwelling medical devices (Moormeier and Bayles, 2017).

\section{Staphylococcus aureus biofilm}

As it has just been stated, the capacity of $S$. aureus to form biofilms is an important virulence factor when it comes to device-related infections. Biofilm plays a relevant role by providing defense against several clearance mechanisms. The biofilm matrix can impede the access of certain types of immune defense, such as macrophages, which display incomplete penetration into the biofilm matrix (frustrated phagocytosis). Additionally, biofilm cells display increased tolerance to antibiotics, due to the presence of a diffusion barrier that slows down the infiltration of some antimicrobial agents but also because of the low metabolic rates of some cells, known as physiologically dormant or persister cells. Beyond offering resistance to clearance mechanisms, biofilm also plays an important role in the progression of chronic diseases since, following the establishment of a biofilm, individual cells can disperse from the original biofilm and either seed new colonization spots or mediate an acute infection process or even sepsis (dispersal model) (Lister and Horswill, 2014).

S. aureus can produce a multilayer biofilm embedded within a highly heterogenous glycocalyx or slime layer (see figure 3). Initially, it was thought that the slime was a mixture of teichoic acids (80\%) and proteins $(20 \%)$ (Hussain, 1993). In 1995, Mack et al. isolated the Polysaccharide Intercellular Antigen (PIA/PNAG) from staphylococcal extracellular matrix (Mack et al., 1996), also known as polymeric $N$-acetyl glucosamine (PNAG) (Maira-Litran et al., 2002). In general terms, Staphylococcus biofilms can be classified depending on the composition of the biofilm matrix as PIA/PNAG-dependent or PIA/PNAGindependent biofilm. 
(a)

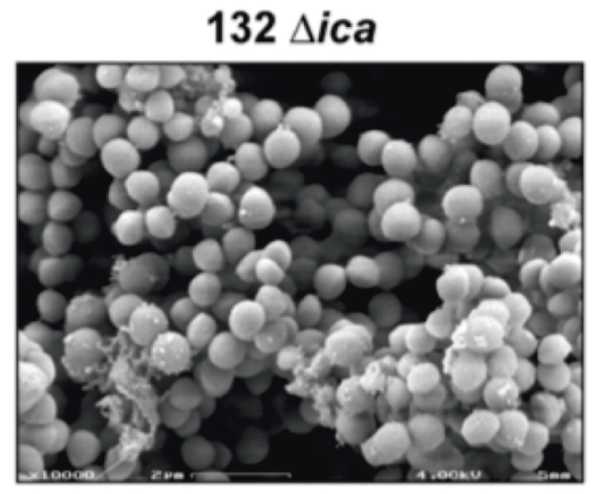

(c)

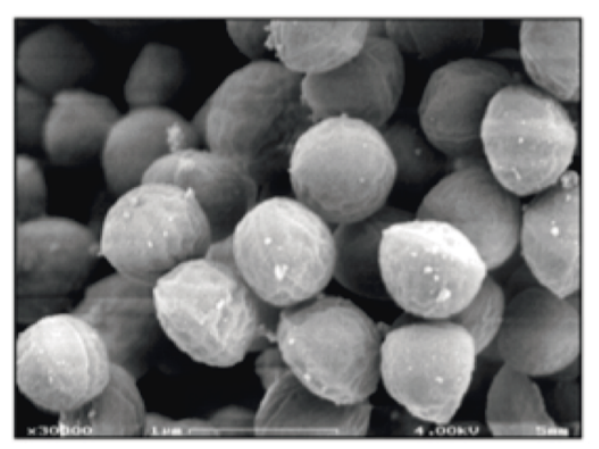

TSB-gluc

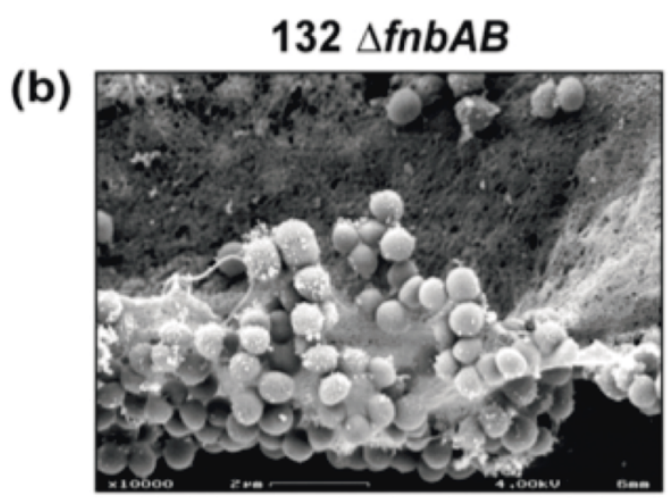

(d)

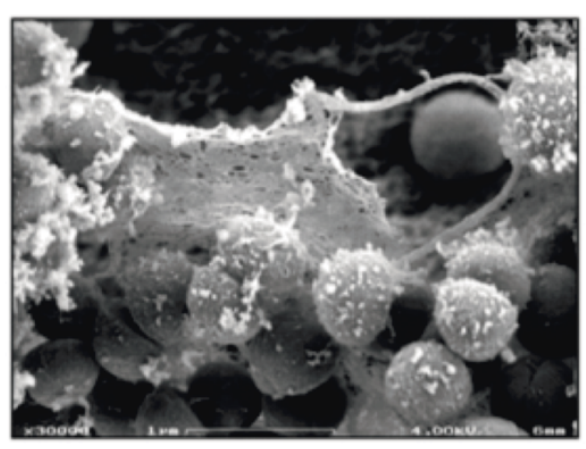

TSB-NaCl

Figure 3. Scanning electron micrographs. $(a, c)$ proteinaceous biofilm developed by the $S$. aureus strain $132 \Delta$ ica mutant and (b, d) PIA/PNAG-dependent biofilm developed by the strain $132 \triangle \mathrm{fnbAB}$ mutant at $\times 10,000(a, b)$ and $\times 30,000(c, d)$ magnifications. (Vergara-Irigaray et al., 2009) 


\section{- PIA/PNAG-independent biofilm matrix}

$S$. aureus can produce a biofilm matrix in which proteins usually take the responsibility for mediating cell-to-cell interactions and multicellular behaviour. The molecular mechanisms underlaying the production of protein-based biofilm matrix remain to be fully understood so far, probably because regulatory schemes behind biofilm formation might not be the same for all strains and the same strains may have multiple mechanisms depending on the environmental signals. In any case, increasing number of studies indicate that proteinaceous scaffolds are more common than previously anticipated (O'Gara, 2007; Taglialegna et al., 2016).

Research groups leaded by J. Penades and I. Lasa described the biofilmassociated protein (Bap), an essential protein for both initial adherence and intercellular accumulation during PIA/PNAG-independent biofilm formation (Cucarella et al., 2001). Although bap gene is present in only $5 \%$ of bovine isolates and appears to be absent in human clinical isolates of $S$. aureus (Cucarella et al., 2004), this protein is member of a group of over 100 surface proteins with conserved structural and functional characteristics from several bacterial species (Lasa and Penadés, 2006; Latasa et al., 2006). Bacterial cell surface-anchored proteins can assemble the matrix scaffold through homophilic interactions between identical molecules expressed on neighbour cells or through heterophilic interactions with other surface proteins or even with nonproteinaceous cell wall structures (Conrady et al., 2008; Herman-Bausier et al., 2015). Another strategy by which proteins can contribute to the formation of the matrix is through polymerization into functional amyloids fibers. Secreted proteins can assemble to form insoluble fibers, which constitute a strong platform able to mediate interactions between the neighbour cells and surfaces. Acting as a sensor, Bap is constitutively expressed and processed. When the $\mathrm{pH}$ of the medium becomes acidic and the concentration of calcium is low, the resulting fragments form insoluble amyloid-like aggregates, and when calcium concentration increases, metal-coordinated Bap adopts a more stable 
conformation (Taglialegna et al., 2016). Besides, S. aureus produces extracellular fibers in biofilm communities that consist of small peptides called phenol soluble modulins (PSMs). The accumulation of PSM peptides in fibers modulates their ability to disperse biofilms. Thus, PSMs fulfill dual and opposing roles that are modulated by amyloid-like aggregation (Schwartz et al., 2012).

Furthermore, a substantial number of staphylococcal molecules have been subsequently associated to PIA/PNAG-independent biofilms. As stated before, microbial surface components recognizing adhesive matrix molecules (MSCRAMM) are peptidoglycan covalently linked adhesins containing the Cterminal sorting signal LPXTG motif. Among the MSCRAMMs, fibronectin (Fn)binding proteins $A$ and $B$ (FnBPA and FnBPB) have been identified as key molecules in proteinaceous biofilms (Vergara-Irigaray, Valle, Merino, Latasa, Garcia, Mozos, et al., 2009), while the S. aureus surface protein G (SasG) is involved in the biofilm accumulation (Corrigan et al., 2007); and Protein A (spa), another LPXTG protein, has also been associated with biofilm formation due to promotion of intercellular aggregation (Merino et al., 2009). SraP (Serine-rich adhesin for binding to platelets) protein also contributes to biofilm formation by mediating attachment to a variety of host cells or bacteria themselves (Foster et al., 2014).

Another important component of the staphylococcal biofilm is extracellular DNA (eDNA). The autolysis of a subpopulation of the biofilm cells and subsequent genomic DNA release must also occur early in cell attachment for proper biofilm formation. Due to the negative charge of the DNA polymer, eDNA potentially acts as an electrostatic polymer that anchor cells to a surface, to host factors, and to each other (Archer et al., 2011; Lister and Horswill, 2014).

\section{- PIA/PNAG-dependent biofilm matrix}

Although multiple bacterial and external factors influence attachment and accumulation, production of an extracellular polysaccharide adhesin by icaADBC operon-encoded enzymes, termed polysaccharide intercellular adhesin (PIA/PNAG) or polymeric $N$-acetyl-glucosamine (PNAG), is currently the best 
Introduction

understood mechanism underlaying biofilm formation in staphylococci (Mack et al., 1996; Maira-Litran et al., 2002).

PIA/PNAG is composed of $\beta-1,6$-linked $N$-acetylglucosamine polymer. The first two genes of the ica $A D B C$ operon, ica $A$ and icaD respectively, exert a primary role in the exopolysaccharide synthesis. icaA encodes for a transmembrane enzyme with $N$-acetylglucosaminyl transferase activity, necessary for the synthesis of the poly- $N$-acetylglucosamine polymer, ica $D$ gene co-expression is also requiring for optimal activity (oligomers longer than 20 glucosamine units). Conversely, the product of the icaC gene appears to translocate the poly- $N$-acetylglucosamine polymer to the bacterial cell surface, while ica $B$ product operates the deacetylation of the molecule. Deacetylation is relevant for the structural development of the exopolysaccharide-based biofilm, since such process permits the fixation of the polymer to the outer bacterial surface (Gerke et al., 1998). figure 4 illustrates PIA/PNAG synthesis process.

The negative regulator termed intercellular adhesin locus regulator (icaR) gene governs the expression of the ica locus under the influence of SarA and the stress $\sigma^{\mathrm{B}}$ (Cerca et al., 2008). 


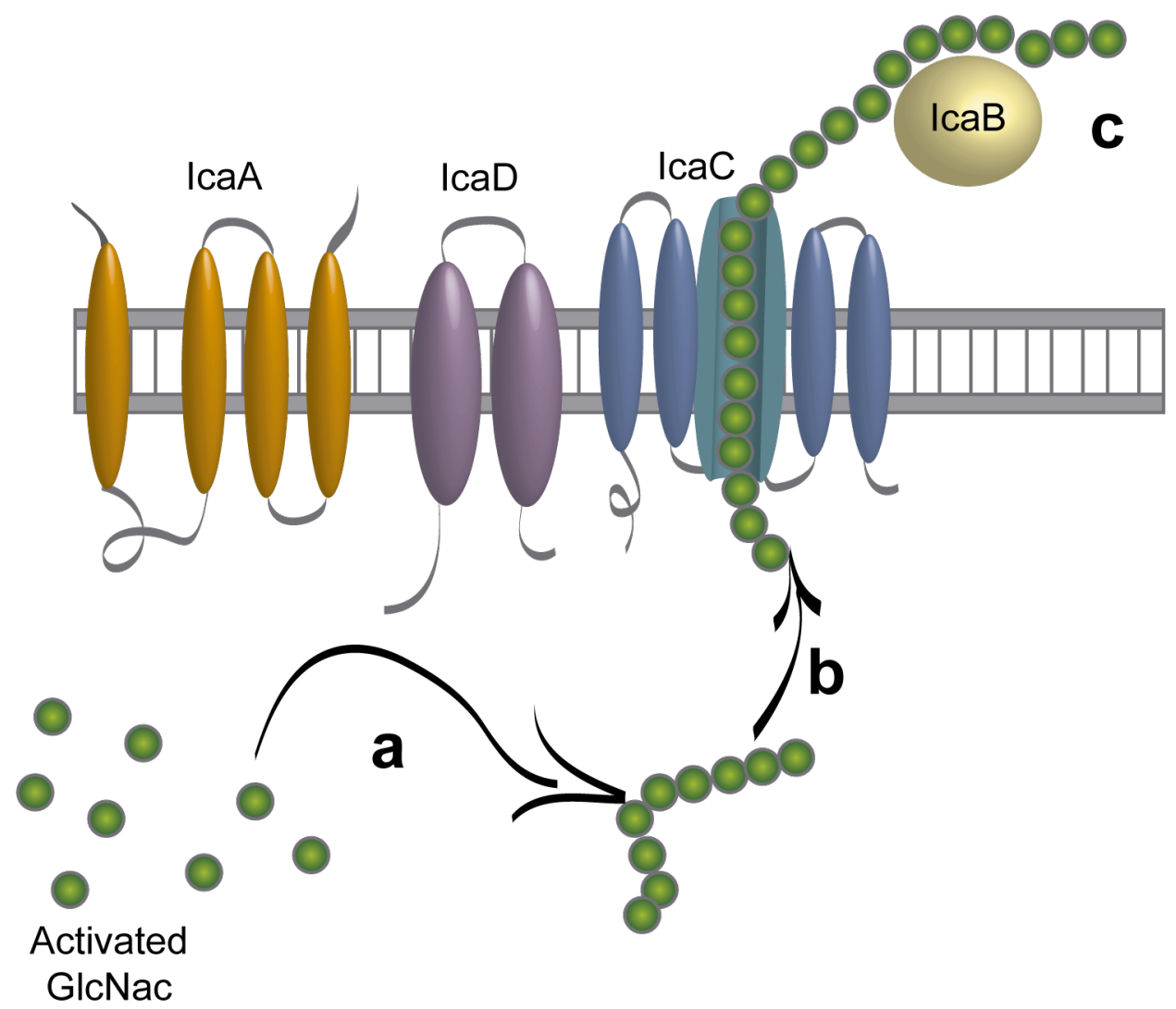

Figure 4. The exopolysaccharide PIA/PNAG synthesis by icaADBC locus encodes enzymes. a) $\mathrm{N}$-acetylglucosaminyl transferase activity of IcaA and IcaD enzymes. b) poly- $\mathrm{N}$-acetylgucosamine polymer translocation to the bacterial cell surface by IcaC. c) Deacetylation of the molecule by IcaB. 


\section{Stages of biofilm development}

While the biofilm matrix composition varies amongst bacterial species and even in the same species or the same strains under different environmental conditions, a basic model of biofilm formation is widely recognized. The model consist of three sequential stages: (i) attachment, (ii) accumulation/maturation and (iii) detachment/dispersal (O'Toole et al., 2000). Different stages are described below and illustrated in figure 5 .

\section{i. Attachment}

To initiate biofilm formation, planktonic $S$. aureus cells first attach to a surface. The microorganism must be brought into close proximity to the surface, driven either randomly by a stream of fluid flowing over a surface as occurs for non-motile bacteria, or in a directed fashion via chemotaxis, twitching (pili) or swimming (flagella) motility. Once bacteria reached the surface, adhesion occurs through a variety of CWA proteins or surface molecules, which are specific for different host matrix substrates, through their appendages (like pili or flagella) or through other physical forces between cell and surface (like van der Waal's forces, electrostatic interactions or hydrophobic interactions) (O'Toole et al., 2000).

\section{ii. Maturation}

The following stage is the proliferation and maturation of the biofilm. This process begins once irreversible attachment to the surface occurs and as long as a sufficient nutrient source existed. In this phase, bacteria replicate and synthesize extracellular polymeric substances comprising polysaccharides and proteins that form the extracellular matrix and maintain bacteria interacting with each other. At this moment, channels and mushroom-shaped structures are formed to facilitate nutrient delivery and oxygen circulation to deeper layers of the biofilm and waste removal. Cell-tocell communication via quorum sensing is an important process at this stage (O'Toole et al., 2000; Le et al., 2014). 
iii. Dispersal

Finally, to conclude the cycle, some bacteria detach from the biofilm and initiate the colonization of new niches. Three different dispersal strategies can be observed: swarming dispersal, clumping dispersal and surface dispersal. Mechanic forces, surfactant molecules (PSMs) and enzymes that degrade biofilm matrix molecules such as nucleases and proteases also stimulate this process. All of these dynamic detachment events could succeed in dispersing biofilm bacteria to new surfaces or to a susceptible host (Hall-Stoodley and Stoodley, 2005; Le et al., 2014). 


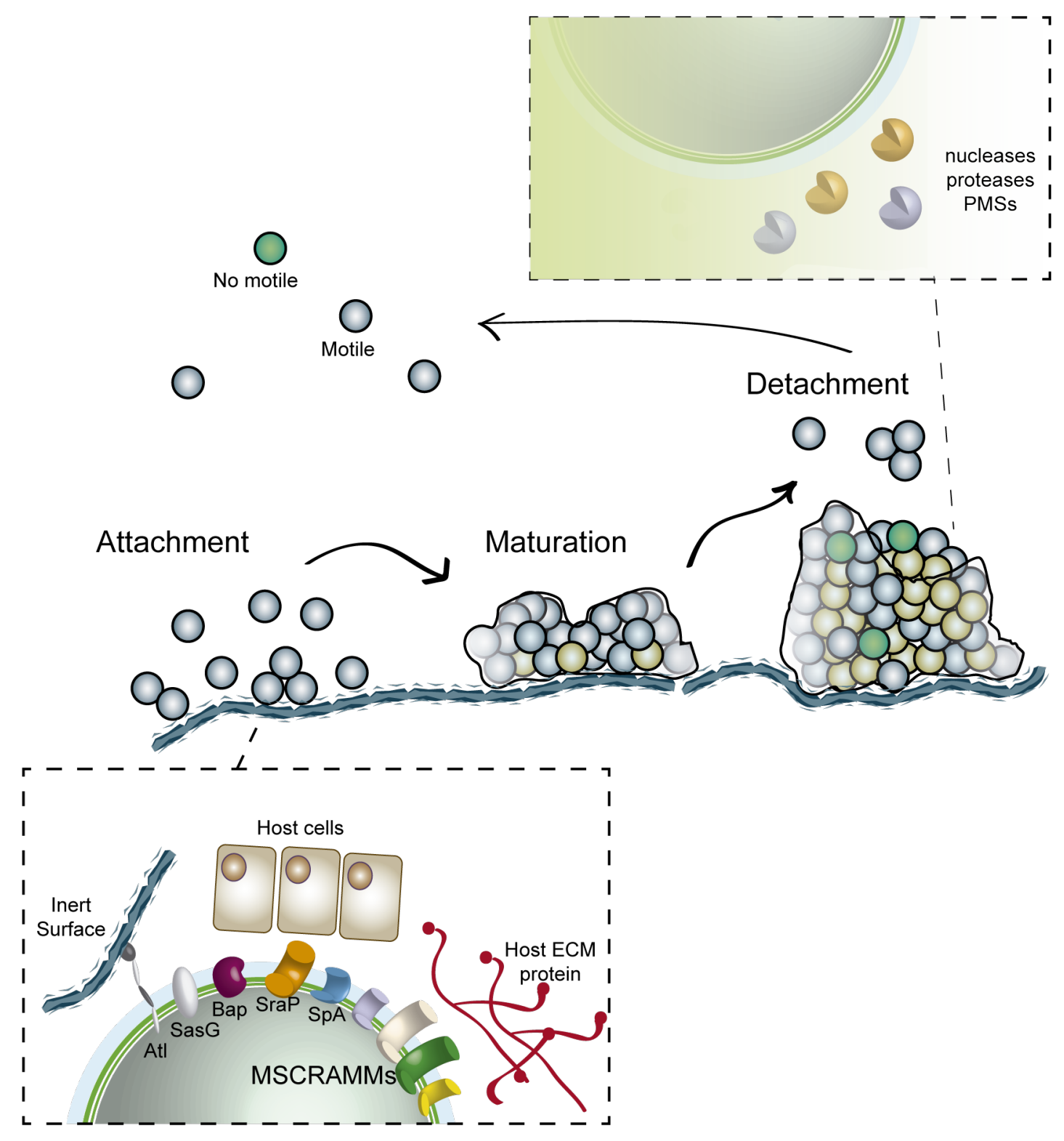

Figure 5. Biofilm life cycle. Biofilm formation follows sequentially steps of attachment, maturation and final detachment to re-enter into planktonic mode. 


\section{Biofilm regulation}

A fine control of sessile and planktonic phenotypes is highly required to explain a well-coordinated and effective action in biofilm formation and disruption. Mechanisms for biofilm formation are enabled by stimuli from density of bacterial cells belonging to the same group and sharing the same pheromone system (termed as quorum sensing QS) and also from environmental stimuli, including presence of oxygen, glucose, ethanol, salts, certain antibiotics, osmolarity and temperature. The expression of biofilm phenotype is considered as a very complex process, in part because there is a multiplicity of factors that contribute to the biofilm extracellular matrix, but also because the biofilm production derives from a complicated equilibrium of production of extracellular polymeric substances and enzymatic reactions. So much so, and though it is assumed that environmental signals determine the biofilm composition, the molecular determinant underlying the choice of either a polysaccharide or protein-based biofilm matrix is not well understood; (Vergara-Irigaray, Valle, Merino, Latasa, Garcia, Mozos, et al., 2009; Arciola et al., 2015).

Focusing on the regulation of polysaccharidic biofilms (see figure 6), different mechanisms are known. As previously mentioned, PIA/PNAG is the principal component of this kind of biofilm. The production of this polysaccharide is regulated by environmental factors, such as the presence of glucose, $\mathrm{NaCl}$, ethanol, osmolarity, temperature or antibiotics. Under anaerobic conditions, for instance, ica operon is upregulated by the staphylococcal respiratory response regulator SrrAB via binding a DNA sequence upstream of icaADBC operon. Specially notable is the strong negative regulation conferred by $i c a R$, a gene that encodes a transcriptional repressor with a central role in the environmental regulation of ica operon expression. Modification of the bacterial environment by the addition of $\mathrm{NaCl}$ or ethanol to the growth medium can activate the ica operon via separate regulatory pathways in an icaR-dependent manner. IcaR interacts with icaADBC promoter and inhibits the access of the ribosome to the Shine- 
Dalgarno (SD) region. This process occurs after a complex post-transcriptional modulation mechanism which control icaR expression and subsequently PIA/PNAG production. (O'Gara, 2007; Mozos et al., 2013). Apart from IcaR, putative binding sequences for TcaR (teicoplanin-associated locus regulator) have been identified in the promoter region of the ica operon, suggesting that this marR-type protein functions as a direct repressor of PIA/PNAG production.

An alternative regulatory mechanism involves phase variation of the poly- $N-$ acetylglucosamine expression. Phase variation functions as a reversible on/off switch for a particular gene, that could be led by a slipped-strand mispairing mechanism. This slipped-strand mispairing occurs during DNA replication when there is mispairing between mother and daughter DNA strands in regions that contain simple nucleotide repeats, resulting in the addition or subtraction of one or more repeats that can bring about a change in transcriptional efficiency or shift the reading frame to alter or halt translation. Brooks et al., found that a RecAindependent expansion or contraction of a 4-nt tandem "ttta" repeat shifts the reading frame of $i c a C$, leading to a premature stop codon, truncating the protein at 303 amino acids; 47 amino acids shorter than full-length protein. This mutation results in the complete inhibition of PIA/PNAG production (PIA/PNAG-negative phenotype) (Brooks and Jefferson, 2014). Additionally, it has also been observed in some S. aureus strains, that the insertion sequence IS256 contributes to the production of biofilm-negative variants through insertion/excision events into icaC and the sarA genes (Archer et al., 2011; Kleinert et al., 2017).

In the case of proteinaceous biofilms (see figure 6), development control is an intricate network of overlapping circuits involving two-component systems (TCS) and transcriptional and post-transcriptional, including RNA molecules. The accessory gene regulator (Agr) system plays an important role modulating of the expression of different virulence-associated genes. The main Agr effector molecule, RNAIll, downregulates genes that encode cell surface proteins (Spa, FnBPA, SasG, Coa) and upregulates exoproteins (PSMs, proteases and $\mathrm{Hla}$ ) (Novick, 2003). Rot (repressor of toxins) is another key player within the biofilm 
regulatory network promoting biofilm upregulation by proteases repression. Rot is regulated by Agr in presence of RNAIII (Mootz et al., 2015). The staphylococcal accessory regulator (SarA) protein is a global transcriptional regulator with a profound impact on ica-independent biofilm production indirectly via agr-positive regulation (Rice et al., 2006). Also Sigma factor B (Sig B) has a role in biofilm production by SarA and Agr-RNAIII regulation (Gotz, 2002; Valle et al., 2003). Furthermore, there are other two-component systems that collaborates in the regulation of the biofilm formation, such as SaeRS (downregulates proteases in synergy with SarA), WalKR (upregulates both LytM and AtIA autolysis) and ArIRS (decreasing protease activity) (Toledo-Arana et al., 2005; Dubrac et al., 2007; Mrak et al., 2012). 


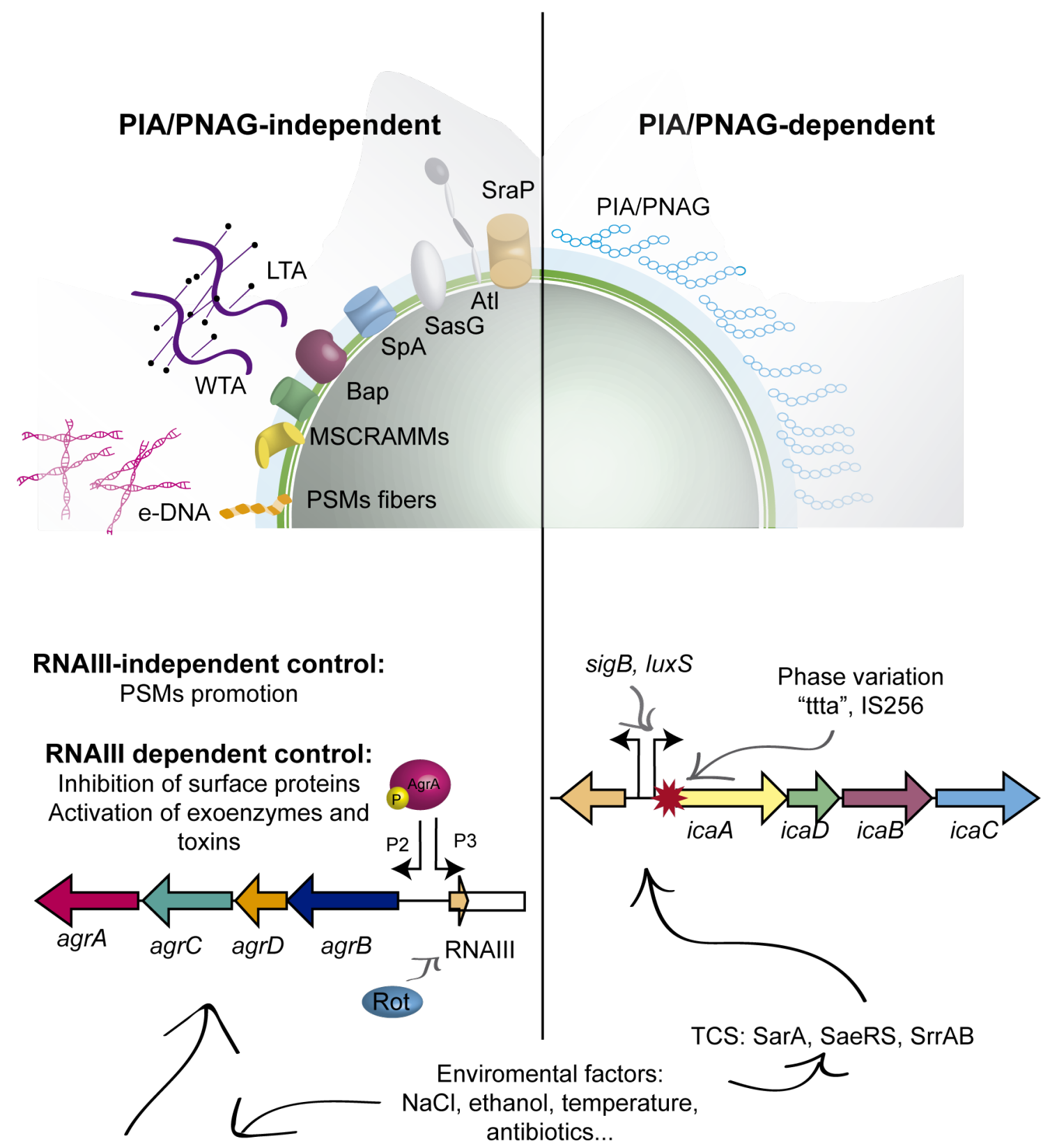

Other TCS: SarA, SaeRS,

WalKR, ArIRS

Figure 6. The regulation of biofilm formation. Schematic diagram of PIA/PNAG-independent (left side) and PIA/PNAG-dependent (right side) biofilm regulation. 


\section{Signal transduction system of S. aureus}

In nature, bacteria are subjected to changes in local $\mathrm{pH}$, osmotic pressure, temperature, redox potential, nutrient availability or exposure to toxic chemicals, to name but a few conditions. Focusing on $S$. aureus, this species shows an amazing ability to adapt to distinct environments, being able to survive in a wide range of niches and can thus cause a diverse spectrum of human diseases and animal infections. To successfully cope with selective pressure, bacteria have evolved simple but highly efficient signal transduction systems to regulate gene expression and respond accordingly. Thus, this capacity of coordinated expression of genes in response to environmental cues is a key factor that has determined the evolutionary success of this pathogen (Cheung et al., 2004; Dubrac and Msadek, 2008; Capra and Laub, 2012; Mattos-Graner and Duncan, 2017; Villanueva et al., 2018).

$S$. aureus utilizes three major classes of signal transduction systems:

a) Diguanylate cyclase and phosphodiesterase, which transmit internal or external signals by modifying the cyclic diguanylate (c-di-GMP) levels. Diguanylate cyclase are characterized by the presence of the GGDEF domain and they are responsible for the synthesis of c-di-GMP. Phosphodiesterases contain the EAL domain and they are responsible for the degradation of this molecule. The signalling molecule c-di-GMP, is a global regulator that play a role in process like biofilm formation, motility and by modulating the function of c-diGMP binding molecules, proteins or RNA. S. aureus genome presents only one conserved domain GGDEF (GdpS) and a second protein with highly modified GGDEF domain (GdpP) but with phosphodiesterase activity. There is no evidence of any $S$. aureus genome encoding an EAL domain protein. (Karaolis et al., 2005; Römling and Amikam, 2006; Jenal and Malone, 2006; Holland et al., 2008; Corrigan et al., 2011).

b) Proteins kinases/phosphatases, which upon receiving a stimulus bind and modify the phosphorylation status of target specific genes (Liebeke et al., 2010). 
c) Two-component signal transduction systems, which are composed by a sensor located on the membrane and a cytosolic receptor protein that triggers the bacterial response (Stock et al., 2000). This mechanism is exposed in the following section.

\section{Two-Component signal transduction systems}

Two-component signal transduction systems or two-component systems (TCSs) are the predominant means by which bacteria sense and respond to environmental stimuli. In their most basic form, TCSs systems comprise a receptor membrane-bound protein, referred to as histidine kinase $(\mathrm{HK})$, that sense a specific signal and translates that input into a desired output; and its cytosolic response regulator $(\mathrm{RR})$ protein, required for inducing transcriptional adaptation. Upon receiving a stimulus, the HK catalyses an autophosphorylation reaction on a conserved histidine residue. This phosphoryl group is then transferred to a conserved aspartate on a cognate RR. Phosphorylation of the regulator usually drives a conformational change that activates its output response (see figure 7). In some cases, input signals may promote the phosphatase state rather than stimulating autophosphorylation (Yang and Inouye, 1993; Jin and Inouye, 1993; Casino et al., 2010; Capra and Laub, 2012).

HK contains two highly conserved domains, the dimerization and histidine phosphotransferase (DHp) domain, which harbor the conserved histidine that is the site of both autophosphorylation and phosphotransfer reactions, and the catalytic and ATP biding (CA) domain. In addition, all HK are identified by unique signature sequence called $\mathrm{H}, \mathrm{N}, \mathrm{G} 1, \mathrm{~F}$ and $\mathrm{G} 2$ boxes. The conserved amino acids of the $N, G 1, F$ and $\mathrm{G} 2$ boxes border the unique ATP-binding pocket and compose the transmitter domain. The most conserved residues are those used to anchor ATP within the binding site: an Asp in the G1 box and an Asn in the N box (Dutta et al., 1999; Galperin, 2005; Wilke and Carlson, 2013).

$\mathrm{RR}$ are typically multidomain proteins, consisting of a well-conserved receiver or regulatory domain (at the $\mathrm{N}$-terminal) and a variable effector domain (at the $\mathrm{C}$ terminal). The conserved regulatory domain catalyzes the transfer of a 
Introduction

phosphoryl group from its cognate HK to one of its own aspartic acid residues.

This phosphorylation promotes a stabilizing conformation capable of promoting activity of the effector domain. The variable effector domain elicits the specific output response of the system, most commonly transcriptional regulation (Gao et al., 2007; Capra and Laub, 2012). 
Signal or stimuli

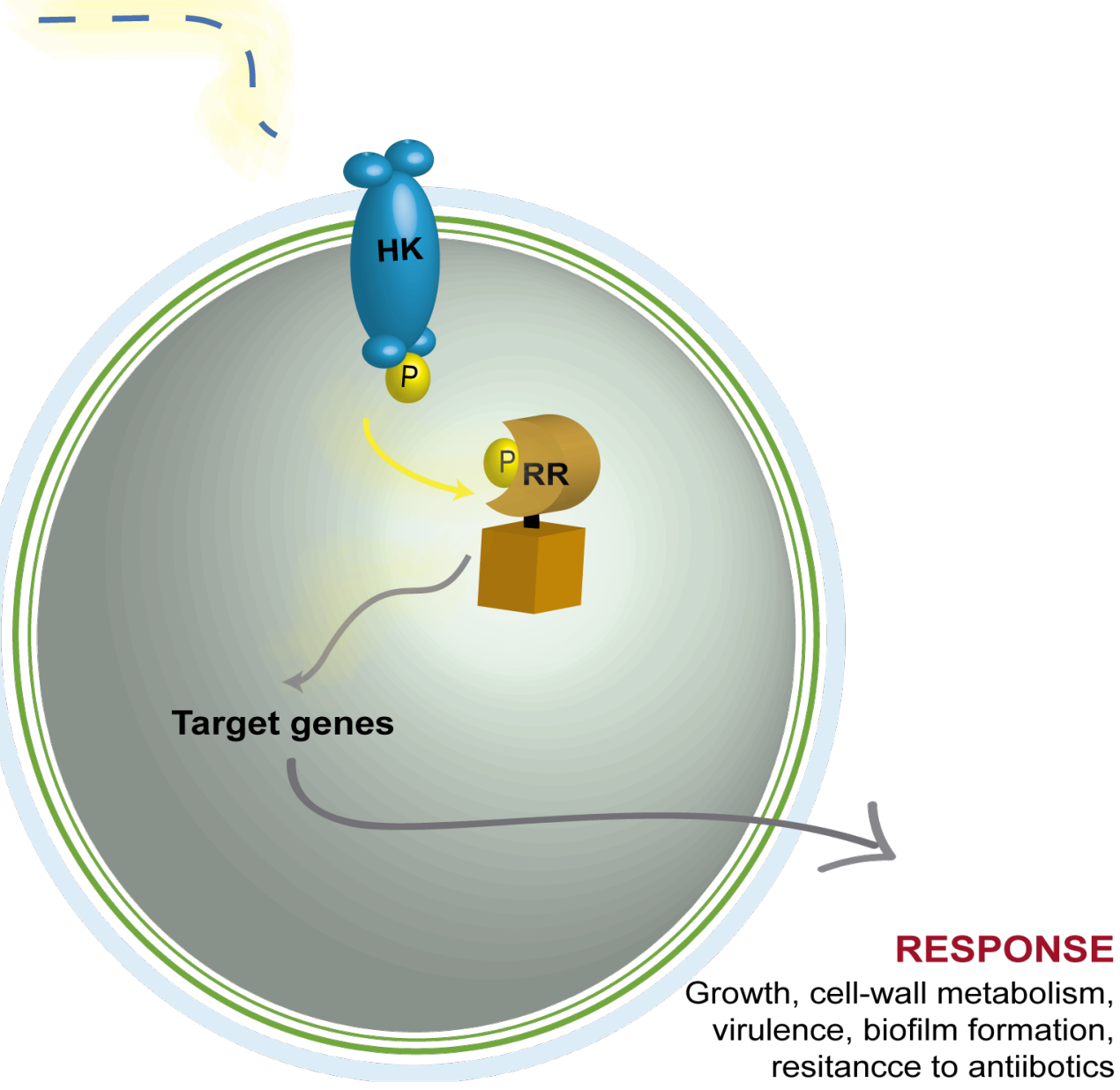

Figure 7. Overview of general two-component systems. In response to stimuli, HK auto-phosphorylates and transfers the phosphoryl group to the RR, which regulates target genes and effects changes in cellular physiology. 


\section{TCS in S. aureus}

Most clinically relevant bacterial species usually contain multiple twocomponent HK-RR pairs. The sum of TCSs is proportional to the genome size, the diversity of environment in which the organism lives, and the complexity of the cellular differentiation. The number of TCSs seems to expand primarily through a mechanism of gene duplication and subsequent accumulation of mutations that insulate the new pathways from the existing TCS pathways. The final consequence of this evolutionary process is that bacteria gain the capacity to colonize new niches or improve the efficiency to grow under the condition of the niche they are colonizing (Galperin, 2005; Capra and Laub, 2012; Villanueva et al., 2018).

S. aureus is a versatile pathogen that also presents several TCS. Most strains encode 16 TCS but might also harbor an additional TCS when the mec element, linked to the induction of methicillin resistance, is present in the chromosome (see table 2). These TCSs are involved in sensing a diverse array of environmental stimuli and contribute to the ability of $S$. aureus to adapt to the diverse environments it encounters during its life cycle.

Even though our understanding of staphylococcal gene regulation by TCS has made significant progress in the last decade, there are many issues that remain to be understood. Current knowledge about the genes affected by most of the TCS is the result of studying mutants in the respective sensor kinase, response regulator and auxiliary genes. Nevertheless, the precise nature of signal(s) that are sensed and their relevance to bacterial physiology for most $S$. aureus TCSs have not been fully uncovered.

Although we have still not reached the point where the function of two TCSs is totally deciphered, S. aureus TCS are commonly grouped according to their major function (Haag and Bagnoli, 2015):

- Regulation of virulence gene expression: two TCS, agrCA and saeRS, are known as global regulators of virulence-related gene expression. 
- Response to AMPs and cell wall damage: Antimicrobial peptides (AMPs) interact with microbial membranes, leading to cell lysis or formation of transient pores, though which AMPs are transported into the cell. $S$. aureus contains three TCS, vraSR, graXRS and braRS, that mediate the response to the exposure to AMPs.

- Cell wall metabolism, autolysis and cell death: bacterial growth and replication requires an exquisite control to coordinate DNA replication machinery, cell wall biosynthesis and remodeling. $S$. aureus employs three TCSs, arlRS, IytSR and the crucial walkRK, to regulate cell wall metabolism.

- Respiration, fermentation and nitrate metabolism: S. aureus is a facultative anaerobe that can grow without oxygen using either anaerobic respiration with nitrate as the terminal electron acceptor or by fermenting carbohydrates. Three TCS of $S$. aureus synchronize the response to environmental oxygen levels in order to fine-tune respiratory activity and divert energy fluxes into different metabolic pathways; These are srrAB, nreCBA and airRS.

- Nutrient sensing and metabolism: the availability of nutrients and micronutrients is a key determinant of the microenvironment in which a bacterium resides and is essential for bacterial metabolism and survival. $S$. aureus harbors three TCS responsible for nutrient sensing and metabolism regulation. These are $h s s S R, k d p D E$ and phoRP. 
Table 2. TCSs of S. aureus.

\begin{tabular}{|c|c|c|c|c|}
\hline & Name & $\begin{array}{l}\text { Alternative } \\
\text { name }\end{array}$ & Genes (MW2) & Major function \\
\hline TCS1 & walKR & $\begin{array}{l}\text { yycFG, } \\
\text { vicRK, } \\
\text { micAB }\end{array}$ & $\begin{array}{c}\text { walR/walk } \\
\text { MW0020 M0021 }\end{array}$ & Bacterial cell composition \\
\hline TCS2 & $\operatorname{tcs} 2^{*}$ & & * & Kdp-like, potassium transport \\
\hline TCS3 & $\operatorname{tcs} 3$ & & $\begin{array}{l}\text { MW0200 } \\
\text { MW0199 } \\
\text { MW0198 }\end{array}$ & Unknown function \\
\hline TCS4 & lytSR & & lytR/lytS & Murein hydrolase activity \\
\hline TCS5 & $\operatorname{graXRS}$ & aspRS & $\begin{array}{l}\text { graX } \\
\text { graR } \\
\text { graS }\end{array}$ & CAMP sensing and virulence \\
\hline TCS6 & saePQRS & & $\begin{array}{l}\text { saeP } \\
\text { saeQ } \\
\text { saeR } \\
\text { saeS }\end{array}$ & $\begin{array}{l}\text { Secreted factors mostly involved in } \\
\text { immune evasion }\end{array}$ \\
\hline TCS7 & tcs 7 & & $\begin{array}{l}\text { MW1206 } \\
\text { MW1207 } \\
\text { MW1208 } \\
\text { MW1209 }\end{array}$ & $\begin{array}{l}\text { Specific to staphylococci, unknown } \\
\text { function }\end{array}$ \\
\hline TCS8 & arlRS & & $\begin{array}{l}\text { arlR } \\
\text { arlS }\end{array}$ & $\begin{array}{l}\text { Adhesion, autolysis, multidrug } \\
\text { resistance and virulence genes }\end{array}$ \\
\hline TCS9 & srrAB & $\begin{array}{l}\text { srhSR, } \\
\text { resED }\end{array}$ & $\begin{array}{l}\text { scpA } \\
\text { scpB } \\
\text { rluB } \\
\text { srrA } \\
\text { srrB } \\
\end{array}$ & Aerobic and anaerobic respiration \\
\hline TCS10 & phoPR & & $\begin{array}{l}\text { phoP } \\
\text { phoR }\end{array}$ & Phosphate assimilation \\
\hline TCS11 & yhsSR & yheSR & $\begin{array}{l}\text { yhcS } \\
\text { yhcR }\end{array}$ & Oxygen sensing \\
\hline TCS12 & vraSR & & $\begin{array}{c}\text { MW1827 } \\
\text { yvqF } \\
\text { vraS } \\
\text { vraR } \\
\end{array}$ & Cell wall biosynthesis \\
\hline TCS13 & $\operatorname{agrBDCA}$ & & $\begin{array}{l}\text { agrB } \\
\text { agrD } \\
\text { agrC } \\
\text { agrA } \\
\end{array}$ & $\begin{array}{l}\text { Exo- and cell protein synthesis, } \\
\text { quorum sensing }\end{array}$ \\
\hline TCS14 & $k d p D E$ & & $\begin{array}{l}\mathrm{kdpD} \\
\mathrm{kdpE}\end{array}$ & Potassium transport \\
\hline TCS15 & $h s s R S$ & & $\begin{array}{l}\text { hssR } \\
\text { hssS }\end{array}$ & heme sensing \\
\hline TCS16 & nreABC & & $\begin{array}{c}\text { narG } \\
\text { narH } \\
\text { narJ } \\
\text { narl } \\
\text { nreA } \\
\text { nreB } \\
\text { nreC }\end{array}$ & $\begin{array}{l}\text { Nitrogen assimilation/oxygen } \\
\text { regulatory protein NreC }\end{array}$ \\
\hline TCS17 & braRS & $\begin{array}{l}\text { nsaRS, } \\
\text { bceRS }\end{array}$ & $\begin{array}{c}\text { MW2546 } \\
\text { braR } \\
\text { braS }\end{array}$ & Bacitracin efflux/influx/sensing \\
\hline
\end{tabular}

* System present in some S. aureus strains, which carry SCCmec element. 


\section{Sensory deprived strain}

Given the uncertainty surrounding several TCS function, in a previous study a genetic reductionist approach was applied on two genetically unrelated $S$. aureus strains in order to generate mutant derivatives that lack the whole TCS signaling network. The process involved the sequential deletion of the 15 nonessential TCSs of $S$. aureus except walKR TCS, whose complete deletion is lethal. The results obtained in such work demonstrated that $S$. aureus remains viable after the deletion of the 15 non-essential TCSs and might be even deprived from all of them, including WalK, under non-replicating conditions. Besides, the experiments carried out with this unique strain, referred to as $\Delta \mathrm{XV}$, and its TCSrestored derivatives, confirmed the concept of TCSs as self-sufficient modules that confer a specific advantage under particular environmental conditions (Villanueva et al., 2018).

More deeply, phenotypic analysis of the $\Delta \mathrm{XV}$ mutant strain revealed indistinguishable growth levels at 37 and $44^{\circ} \mathrm{C}$ in comparison to those showed by the wild type strain, and similar metabolic capacities. However, $\Delta \mathrm{XV}$ strain lost the capacity to reduce nitrite, showed a slight growth arrest at $28^{\circ} \mathrm{C}$, a decreased capacity to survive in the environment and higher sensitivity to detergents. Moreover, in the absence of TCSs, $S$. aureus is unable to invade eukaryotic cells and colonize organs, rendering the bacteria avirulent in a mouse infection model (Villanueva et al., 2018).

The TCS-deficient strain is an extremely useful tool, which will allow the study of TCS function without counteracting or "hindering" effects exerted by other TCSs. With the help of $\triangle \mathrm{XV}$, every TCS might be individually analyzed and thus determine the specific signal recognized by the TCS and the precise relevance of the TCS to bacterial physiology. Besides, this strain will be really useful to identify the regulon of each TCS or in the hard work of finding antimicrobials that specifically block TCS functions. In this thesis we will focus on TCS5 (graXRS). 


\section{GraXRS}

The GraXRS (for Glycopeptide-resistance-associated) TCS might also be referred to as antibiotic peptide sensor (ApsRS). GraXRS was identified by Cui et. al. in 2005 while studying the transcriptomic profiles of $S$. aureus strains showing different degrees of vancomycin resistance. Thus, expression of graS gene was significantly higher in strains that showed increased resistance to the antibiotic. Furthermore, it was observed that overexpression of graS in vancomycin sensitive strains increased the resistance to this antibiotic. As a result, GraXRS was linked with resistance to vancomycin (Cui et al., 2005).

GraXRS is also connected with control of resistance to cationic antimicrobial peptides (CAMPs) through the synthesis of enzymes that increase bacterial cell surface positive charge, by D-alanylation of teichoic acids and lysylination of phosphatidylglycerol, leading to electrostatic repulsion of CAMPs. GraXRS requires the $\mathrm{ABC}$ transporter vraFG for conferring resistance to CAMPs (Falord et al., 2012).

Recently, GraXRS has also been associated to virulence and cell-wall metabolism. Transcriptomic approaches have revealed that, in contrast to many TCSs, GraXRS does not regulate its own expression, but affects the expression levels of 248 genes, some of which are major regulators of virulence gene expression, colonization factors and exotoxin-encoding genes. Modification of teichoic acid with D-alanine by the products of the dlt operon protects $\mathrm{S}$. aureus against major antimicrobial host defense molecules such as defensins. Furthermore, acidic exposure, as inside macrophage phagolysosomes, evokes GraS signaling, which in turn elicits an adaptive response that endows the bacteria with increased resistance to antimicrobial effectors so that $S$. aureus can regulate with GraXRS its surface properties in order to overcome innate host defense (Meehl et al., 2007; Kraus et al., 2008; Falord et al., 2011; Flannagan et al., 2018).

The graXRS genes are located immediately upstream of the ABC transporter genes vraF and vraG, being one of four TCS system loci that are in proximity to 
$A B C$ transporter genes (see figure $8 \mathrm{~A}$ ). Interestingly, this close relationship between TCS and ABC transporter was only observed in firmicutes. The GraXRS system shows high similarity to the BceRS TCS of Bacillus subtilis, similar to its S. aureus homolog, the bceRS genes, that also are located immediately upstream of the ABC transporter system (Falord et al., 2011; Falord et al., 2012; Haag and Bagnoli, 2015). So, it can be said that GraXRS is a five-component signal transduction system, whose components are described below.

The membrane-bound HK, GraS, is a 346 amino acid protein that consists of a membrane bound domain (spanning 1-63 residues) and a cytoplasmic domain referred to as kinase domain (spanning residues 110-346), that harbors the catalytic domain (residues 181 to 346 ). The cytoplasmic domain of GraS does not have autokinase activity (Muzamal et al., 2014).

The second component of GraXRS is the cytosolic protein that acts as its cognate RR. GraR is a 224 amino acid protein that present a conserved aspartate residue at position 51. This residue is essential for its activity (Falord et al., 2012). A highly conserved ten-base-pair palindromic sequence (5' ACAAATTTGT 3') located upstream from GraR-regulated genes was shown to be essential for transcriptional regulation and induction by GraR, suggesting that this could be a likely GraR binding site (Falord et al., 2011; Falord et al., 2012).

The third component, GraX, is the auxiliary protein. GraX is a cytosolic protein with 308 amino acids that contains a weakly hydrophobic putative transmembrane segment (residues 216 to 236) and a suggested extracellular C terminus. GraX play a role as a bridge protein between its HK (GraS) and RR (GraR), interacting with GraS (see figure 8B) (Falord et al., 2012; Muzamal et al., 2014).

Finally, the ABC transporter proteins VraF and VraG are 254 and 630 amino acids proteins respectively, located immediately upstream of the graXRS genes which are required for conferring CAMPs resistance (see figure 8B) (Kuroda et al., 2000; Muzamal et al., 2014). 
A

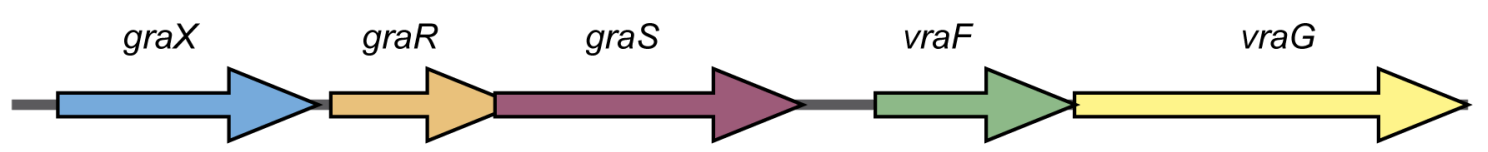

B

CAMP

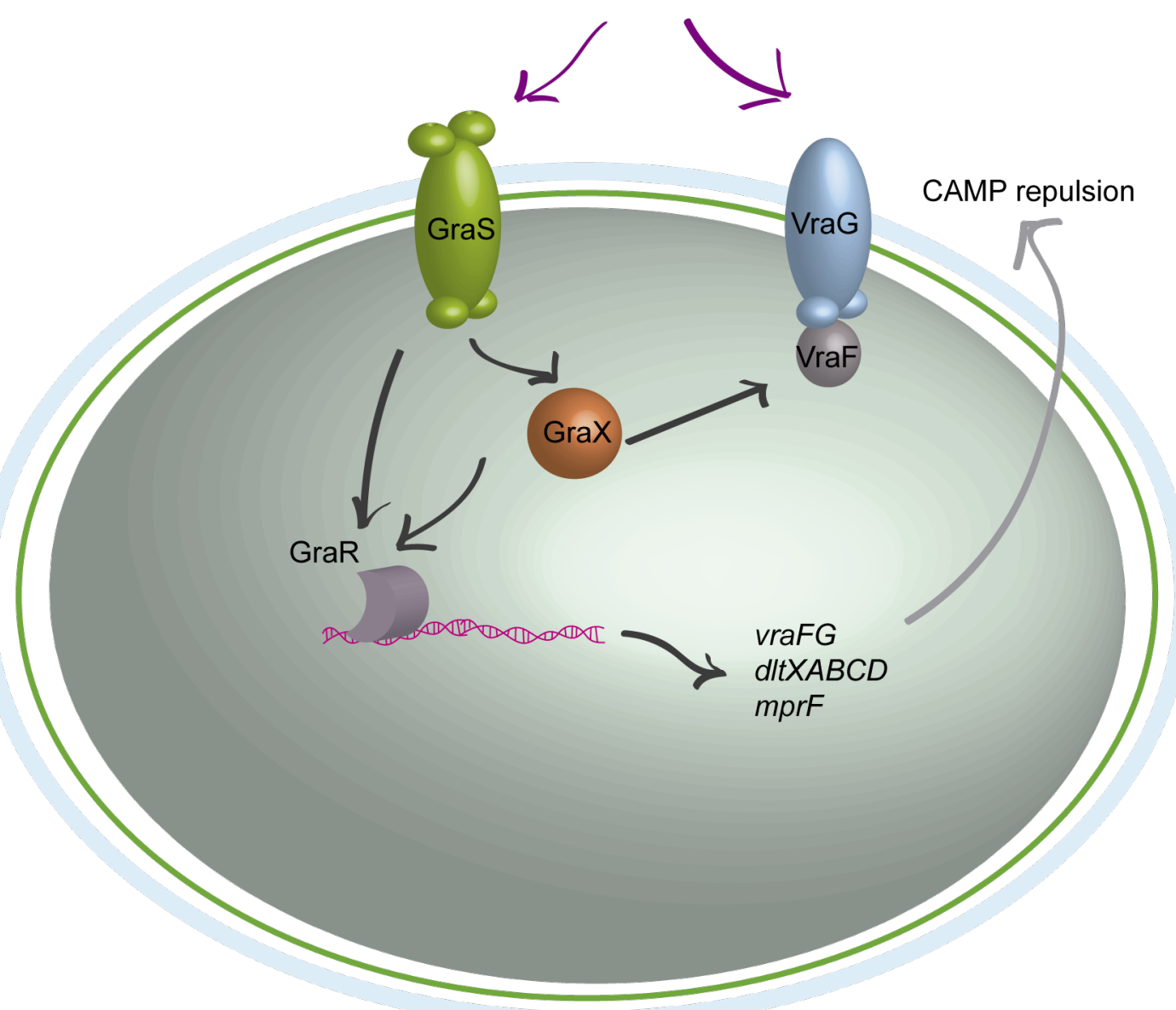

Figure 8. GraXRS TCS. A) The graXRS and vraFG locus of $S$. aureus MW2. B) GraXRS signal transduction network. GraS and VraG sense the stimuli (CAMPS) and the signal is transduced to GraS through a mechanism that likely involves interaction between VraG and GraS. Activation of the GraSR systems leads to increaed transcription of the vraFG operon, dltXABCD operon and mprF gene, generating a response (CAMP resistance by repulsion). 


\section{References}

Al-Mebairik, N. F., El-kersh, T. A., Al-Sheikh, Y. A., Marie, M. A. M., Ali, M., Marie, M. A. M., ... Marie, M. A. M. (2016). A review of virulence factors, pathogenesis, and antibiotic resistance in Staphylococcus aureus. Reviews in Medical Microbiology, 27(2), 50-56. https://doi.org/10.1097/MRM.0000000000000067

Archer, N. K., Mazaitis, M. J., Costerton, J. W., Leid, J. G., Powers, M. E., \& Shirtliff, M. E. (2011). Staphylococcus aureus biofilms. Virulence, 2(5), 445459. https://doi.org/10.4161/viru.2.5.17724

Arciola, C. R., Campoccia, D., Ravaioli, S., \& Montanaro, L. (2015). Polysaccharide intercellular adhesin in biofilm: structural and regulatory aspects. Cellular and Infection Microbiology, 5(February), 1-10. https://doi.org/10.3389/fcimb.2015.00007

Assis, L. M., Nedeljković, M., \& Dessen, A. (2017). New strategies for targeting and treatment of multi-drug resistant Staphylococcus aureus. Drug Resistance Updates, 31, 1-14. https://doi.org/10.1016/j.drup.2017.03.001

Becker, K., Heilmann, C., \& Peters, G. (2014). Coagulase-negative staphylococci. Clinical Microbiology Reviews, 27(4), 870-926. https://doi.org/10.1128/cmr.00109-13

Brooks, G. F., Carroll, K. C., Butel, J., Morse, S. A., \& Mietzner, T. (2013). Medical Microbiology. Jawetz, Melnick, \& Adelberg's Medical Microbiology. https://doi.org/10.1017/CBO9781107415324.004

Brooks, J. L., \& Jefferson, K. K. (2014). Phase Variation of Poly-NAcetylglucosamine Expression in Staphylococcus aureus. PLoS Pathogens, 10(7), e1004292. https://doi.org/10.1371/journal.ppat.1004292

Bukowski, M., Wladyka, B., \& Dubin, G. (2010). Exfoliative Toxins of Staphylococcus aureus. Toxins, 2(5), 1148-1165. https://doi.org/10.3390/toxins2051148

Capra, E. J., \& Laub, M. T. (2012). Evolution of Two-Component Signal Transduction Systems. Annual Review of Microbiology, 66(1), 325-347. https://doi.org/10.1146/annurev-micro-092611-150039

Casino, P., Rubio, V., \& Marina, A. (2010). The mechanism of signal transduction by two-component systems. Current Opinion in Structural Biology, 20(6), 763-771. https://doi.org/10.1016/j.sbi.2010.09.010

Cerca, N., Brooks, J. L., \& Jefferson, K. K. (2008). Regulation of the Intercellular Adhesin Locus Regulator (icaR) by SarA, B, and IcaR in Staphylococcus aureus. Journal of Bacteriology, 190(19), 6530-6533. https://doi.org/10.1128/JB.00482-08 
Cheung, A. L., Bayer, A. S., Zhang, G., Gresham, H., \& Xiong, Y.-Q. (2004). Regulation of virulence determinants in vitro and in vivo in Staphylococcus aureus. FEMS Immunology \& Medical Microbiology, 40(1), 1-9. https://doi.org/10.1016/s0928-8244(03)00309-2

Clauditz, A., Resch, A., Wieland, K.-P. P., Peschel, A., \& Gotz, F. (2006). Staphyloxanthin Plays a Role in the Fitness of Staphylococcus aureus and Its Ability To Cope with Oxidative Stress. Infection and Immunity, 74(8), 4950-4953. https://doi.org/10.1128/iai.00204-06

Conrady, D. G., Brescia, C. C., Horii, K., Weiss, A. A., Hassett, D. J., \& Herr, A. B. (2008). A zinc-dependent adhesion module is responsible for intercellular adhesion in staphylococcal biofilms. Proceedings of the National Academy of Sciences, 105(49), 19456-19461. https://doi.org/10.1073/pnas.0807717105

Corrigan, R. M., Abbott, J. C., Burhenne, H., Kaever, V., \& Gründling, A. (2011). c-di-AMP Is a New Second Messenger in Staphylococcus aureus with a Role in Controlling Cell Size and Envelope Stress. PLoS Pathogens, 7(9), e1002217. https://doi.org/10.1371/journal.ppat.1002217

Corrigan, R. M., Rigby, D., Handley, P., \& Foster, T. J. (2007). The role of Staphylococcus aureus surface protein SasG in adherence and biofilm formation. Microbiology, 153(8), 2435-2446. https://doi.org/10.1099/mic.0.2007/006676-0

Costerton, J. W., Irvin, R. T., \& Cheng, K. J. (1981). The Bacterial Glycocalyx in Nature and Disease. Annual Review of Microbiology, 35(1), 299-324. https://doi.org/10.1146/annurev.mi.35.100181.001503

Crossley, K. B., Jefferson, K. K., Archer, G. L., \& Fowler, V. G. (Eds.). (2009). Staphylococci in Human Disease. Oxford, UK: Wiley-Blackwell. https://doi.org/10.1002/9781444308464

Cucarella, C., Tormo, M. A., Ubeda, C., Trotonda, M. P., Monzon, M., Peris, C., ... Penades, J. R. (2004). Role of Biofilm-Associated Protein Bap in the Pathogenesis of Bovine Staphylococcus aureus. Infection and Immunity, 72(4), 2177-2185. https://doi.org/10.1128/IAI.72.4.2177-2185.2004

Cucarella, Carme, Solano, C., \& Valle, J. (2001). Bap, a Staphylococcus aureus surface protein involved in biofilm formation. Journal of Bacteriology, 183(9), 2888-2896. https://doi.org/10.1128/jb.183.9.2888

Cucarella, Carme, Tormo, M. Á., Knecht, E., Amorena, B., Lasa, I., Foster, T. J., ... Penadés, J. R. (2002). Expression of the biofilm-associated protein interferes with host protein receptors of Staphylococcus aureus and alters the infective process. Infection and Immunity, 70(6), 3180-3186. https://doi.org/10.1128/iai.70.6.3180-3186.2002

Cui, L., Lian, J.-Q., Neoh, H. -m., Reyes, E., \& Hiramatsu, K. (2005). DNA Microarray-Based Identification of Genes Associated with Glycopeptide 
Resistance in Staphylococcus aureus. Antimicrobial Agents and Chemotherapy, 49(8), 3404-3413. https://doi.org/10.1128/AAC.49.8.34043413.2005

de Haas, C. J. C., Veldkamp, K. E., Peschel, A., Weerkamp, F., Van Wamel, W. J. B., Heezius, E. C. J. M., ... van Strijp, J. A. G. (2004). Chemotaxis Inhibitory Protein of Staphylococcus aureus, a Bacterial Antiinflammatory Agent. Journal of Experimental Medicine, 199(5), 687-695. https://doi.org/10.1084/jem.20031636

de Vor, L., Rooijakkers, S. H. M., \& van Strijp, J. A. G. (2020). Staphylococci evade the innate immune response by disarming neutrophils and forming biofilms. FEBS Letters. https://doi.org/10.1002/1873-3468.13767

Donlan, R. M. (2002). Biofilms: Microbial Life on Surfaces. Emerging Infectious Diseases, 8(9), 881-890. https://doi.org/10.3201/eid0809.020063

Dubrac, S., Boneca, I. G., Poupel, O., \& Msadek, T. (2007). New Insights into the WalK/WalR (YycG/YycF) Essential Signal Transduction Pathway Reveal a Major Role in Controlling Cell Wall Metabolism and Biofilm Formation in Staphylococcus aureus. Journal of Bacteriology, 189(22), 8257-8269. https://doi.org/10.1128/JB.00645-07

Dubrac, Sarah, \& Msadek, T. (2008). Tearing Down the Wall: Peptidoglycan Metabolism and the WalK/WaIR (YycG/YycF) Essential Two-Component System. In Springer (Ed.), Bacterial Signal Transduction: Networks and Drug Targets (Advances i, pp. 214-228). New York, NY: Springer New York. https://doi.org/10.1007/978-0-387-78885-2_15

Dutta, R., Qin, L., \& Inouye, M. (1999). Histidine kinases: diversity of domain organization. Molecular Microbiology, 34(4), 633-640. https://doi.org/10.1046/j.1365-2958.1999.01646.x

Elias, S., \& Banin, E. (2012). Multi-species biofilms: living with friendly neighbors. FEMS Microbiology Reviews, 36(5), 990-1004. https://doi.org/10.1111/j.1574-6976.2012.00325.x

EPINE-EPPS. (2019). Prevalencia de infecciones (relacionadas con la asistencia sanitaria y comunitarias) y uso de antimicrobianos en hospitales de agudos. Madrid: Sociedad Española de Medicina Preventiva, Salud Pública e Higiene, 1,0.

Falord, M., Karimova, G., Hiron, A., \& Msadek, T. (2012). GraXSR Proteins Interact with the VraFG ABC Transporter To Form a Five-Component System Required for Cationic Antimicrobial Peptide Sensing and Resistance in Staphylococcus aureus. Antimicrobial Agents and Chemotherapy, 56(2), 1047-1058. https://doi.org/10.1128/AAC.05054-11

Falord, M., Mäder, U., Hiron, A., Débarbouillé, M., \& Msadek, T. (2011). Investigation of the Staphylococcus aureus GraSR regulon reveals novel links to virulence, stress response and cell wall signal transduction 
$\begin{array}{llll}\text { pathways. } & \text { PLoS } & \text { ONE, } & \text { e21323. }\end{array}$

https://doi.org/10.1371/journal.pone.0021323

Fitzgerald, J. R. (2012). Livestock-associated Staphylococcus aureus: origin , evolution and public health threat. Trends in Microbiology, 20(4), 192-198. https://doi.org/10.1016/j.tim.2012.01.006

Flannagan, R. S., Kuiack, R. C., McGavin, M. J., \& Heinrichs, D. E. (2018). Staphylococcus aureus Uses the GraXRS Regulatory System To Sense and Adapt to the Acidified Phagolysosome in Macrophages. MBio, 9(4), 561. https://doi.org/10.1128/mBio.01143-18

Forsgren, A., \& Sjöquist, J. (1966). "Protein A" from S. aureus. The Journal of Immunology, 97(6), 822 LP - 827. Retrieved from http://www.jimmunol.org/content/97/6/822.abstract

Foster, T. J. (2004). The Staphylococcus aureus "superbug." Journal of Clinical Investigation, 114(12), 1693-1696. https://doi.org/10.1172/JCl23825

Foster, T. J., Geoghegan, J. A., Ganesh, V. K., \& Höök, M. (2014). Adhesion, invasion and evasion: the many functions of the surface proteins of Staphylococcus aureus. Nature Reviews Microbiology, 12(1), 49-62. https://doi.org/10.1038/nrmicro3161

Galperin, M. Y. (2005). A census of membrane-bound and intracellular signal transduction proteins in bacteria: Bacterial IQ, extroverts and introverts. $B M C$ Microbiology, 5, 35. https://doi.org/10.1186/1471-2180-5-35

Gao, R., Mack, T. R., \& Stock, A. M. (2007). Bacterial response regulators: versatile regulatory strategies from common domains. Trends in Biochemical Sciences, 32(5), 225-234. https://doi.org/10.1016/j.tibs.2007.03.002

Gerke, C., Kraft, A., Süßmuth, R., Schweitzer, O., \& Götz, F. (1998). Characterization of the $\mathrm{N}$-Acetylglucosaminyltransferase Activity Involved in the Biosynthesis of the Staphylococcus epidermidis Polysaccharide Intercellular Adhesin. Journal of Biological Chemistry, 273(29), 1858618593. https://doi.org/10.1074/jbc.273.29.18586

Ghebremedhin, B., Layer, F., Konig, W., \& Konig, B. (2008). Genetic Classification and Distinguishing of Staphylococcus Species Based on Different Partial gap, 16S rRNA, hsp60, rpoB, sodA, and tuf Gene Sequences. Journal of Clinical Microbiology, 46(3), 1019-1025. https://doi.org/10.1128/jcm.02058-07

Goldmann, O., Tuchscherr, L., Rohde, M., \& Medina, E. (2016). a-Hemolysin enhances Staphylococcus aureus internalization and survival within mast cells by modulating the expression of $\beta 1$ integrin. Cellular Microbiology, 18(6), 807-819. https://doi.org/10.1111/cmi.12550

Gordon, R. J., \& Lowy, F. D. (2008). Pathogenesis of Methicillin-Resistant Staphylococcus aureus Infection. Clinical Infectious Diseases, 46(S5), S350- 
- S359. https://doi.org/10.1086/533591

Gotz, F. (2002). Staphylococcus and biofilms. Molecular Microbiology, 43(6), 1367-1378. https://doi.org/10.1046/j.1365-2958.2002.02827.x

Grumann, D., Nübel, U., \& Bröker, B. M. (2014). Staphylococcus aureus toxins Their functions and genetics. Infection, Genetics and Evolution, 21, 583592. https://doi.org/10.1016/j.meegid.2013.03.013

Grumann, D., Ruotsalainen, E., Kolata, J., Kuusela, P., Järvinen, A., Kontinen, V. P., ... Holtfreter, S. (2011). Characterization of Infecting Strains and Superantigen-Neutralizing Antibodies in Staphylococcus aureus Bacteremia. Clinical and Vaccine Immunology, 18(3), 487-493. https://doi.org/10.1128/CVI.00329-10

Haag, A. F., \& Bagnoli, F. (2015). The Role of Two-Component Signal Transduction Systems in Staphylococcus aureus Virulence Regulation. In Life Science Journal (Vol. 6, pp. 145-198). https://doi.org/10.1007/82_2015_5019

Hall-Stoodley, L., \& Stoodley, P. (2005). Biofilm formation and dispersal and the transmission of human pathogens. Trends in Microbiology, 13(1), 7-10. https://doi.org/10.1016/j.tim.2004.11.004

Herman-Bausier, P., El-Kirat-Chatel, S., Foster, T. J., Geoghegan, J. A., \& Dufrêne, Y. F. (2015). Staphylococcus aureus Fibronectin-Binding Protein A Mediates Cell-Cell Adhesion through Low-Affinity Homophilic Bonds. MBio, 6(3), e00413-15. https://doi.org/10.1128/mBio.00413-15

Holland, L. M., O'Donnell, S. T., Ryjenkov, D. A., Gomelsky, L., Slater, S. R., Fey, P. D., ... O'Gara, J. P. (2008). A Staphylococcal GGDEF Domain Protein Regulates Biofilm Formation Independently of Cyclic Dimeric GMP. Journal of Bacteriology, 190(15), 5178-5189. https://doi.org/10.1128/JB.00375-08

Humphreys, H., \& Coleman, D. C. (2019). Contribution of whole-genome sequencing to understanding of the epidemiology and control of meticillinresistant Staphylococcus aureus. Journal of Hospital Infection, 102(2), 189199. https://doi.org/10.1016/j.jhin.2019.01.025

Hussain, M. (1993). The slime of coagulase-negative staphylococci: Biochemistry and relation to adherence. FEMS Microbiology Letters, 104(3-4), 191-207. https://doi.org/10.1016/0378-1097(93)90596-T

Jamal, M., Ahmad, W., Andleeb, S., Jalil, F., Imran, M., Nawaz, M. A., ... Kamil, M. A. (2018). Bacterial biofilm and associated infections. Journal of the Chinese Medical Association, 81(1), 7-11. https://doi.org/10.1016/j.jcma.2017.07.012

Jenal, U., \& Malone, J. (2006). Mechanisms of Cyclic-di-GMP Signaling in Bacteria. Annual Review of Genetics, 40(1), 385-407. https://doi.org/10.1146/annurev.genet.40.110405.090423 
Jin, T., \& Inouye, M. (1993). Ligand Binding to the Receptor Domain Regulates the Ratio of Kinase to Phosphatase Activities of the Signaling Domain of the Hybrid Escherichia coli Transmembrane Receptor, Taz1. Journal of Molecular Biology, 232(2), 484-492. https://doi.org/10.1006/jmbi.1993.1404

John, J., George, S., Nori, S. R. C., \& Nelson-Sathi, S. (2019). Phylogenomic Analysis Reveals the Evolutionary Route of Resistant Genes in Staphylococcus aureus. Genome Biology and Evolution, 11(10), 2917-2926. https://doi.org/10.1093/gbe/evz213

Jongerius, I., Garcia, B. L., Geisbrecht, B. V., van Strijp, J. A. G., \& Rooijakkers, S. H. M. (2010). Convertase Inhibitory Properties of Staphylococcal Extracellular Complement-binding Protein. Journal of Biological Chemistry, 285(20), 14973-14979. https://doi.org/10.1074/jbc.M109.091975

Josse, J., Laurent, F., \& Diot, A. (2017). Staphylococcal Adhesion and Host Cell Invasion: Fibronectin-Binding and Other Mechanisms. Frontiers in Microbiology, 8(DEC), 1-8. https://doi.org/10.3389/fmicb.2017.02433

Kang, M., Ko, Y.-P., Liang, X., Ross, C. L., Liu, Q., Murray, B. E., \& Höök, M. (2013). Collagen-binding Microbial Surface Components Recognizing Adhesive Matrix Molecule (MSCRAMM) of Gram-positive Bacteria Inhibit Complement Activation via the Classical Pathway. Journal of Biological Chemistry, 288(28), 20520-20531. https://doi.org/10.1074/jbc.M113.454462

Karaolis, D. K. R., Rashid, M. H., Chythanya, R., Luo, W., Hyodo, M., \& Hayakawa, Y. (2005). c-di-GMP (3'-5'-Cyclic Diguanylic Acid) Inhibits Staphylococcus aureus Cell-Cell Interactions and Biofilm Formation. Antimicrobial Agents and Chemotherapy, 49(3), 1029-1038. https://doi.org/10.1128/AAC.49.3.1029-1038.2005

Kleinert, F., Kallies, R., Hort, M., Zweynert, A., Szekat, C., Nagel, M., \& Bierbaum, G. (2017). Influence of IS256 on Genome Variability and Formation of SmallColony Variants in Staphylococcus aureus. Antimicrobial Agents and Chemotherapy, 61(8). https://doi.org/10.1128/AAC.00144-17

Kloos, W. E. (1980). Natural Populations of the Genus Staphylococcus. Annual Review of Microbiology, 34(1), 559-592. https://doi.org/10.1146/annurev.mi.34.100180.003015

Kraus, D., Herbert, S., Kristian, S. A., Khosravi, A., Nizet, V., Götz, F., \& Peschel, A. (2008). The GraRS regulatory system controls Staphylococcus aureus susceptibility to antimicrobial host defenses. BMC Microbiology, 8(1), 85. https://doi.org/10.1186/1471-2180-8-85

Kuroda, M., Kuwahara-Arai, K., \& Hiramatsu, K. (2000). Identification of the Upand Down-Regulated Genes in Vancomycin-Resistant Staphylococcus aureus Strains Mu3 and Mu50 by cDNA Differential Hybridization Method. Biochemical and Biophysical Research Communications, 269(2), 485-490. https://doi.org/10.1006/bbrc.2000.2277 
Kuroda, M., Ohta, T., Uchiyama, I., Baba, T., Yuzawa, H., Kobayashi, I., ... Hiramatsu, K. (2001). Whole genome sequencing of meticillin-resistant Staphylococcus aureus. The Lancet, 357(9264), 1225-1240. https://doi.org/10.1016/S0140-6736(00)04403-2

Laarman, A. J., Ruyken, M., Malone, C. L., van Strijp, J. A. G., Horswill, A. R., \& Rooijakkers, S. H. M. (2011). Staphylococcus aureus Metalloprotease Aureolysin Cleaves Complement C3 To Mediate Immune Evasion. The Journal of Immunology, 186(11), 6445-6453. https://doi.org/10.4049/jimmunol.1002948

Lasa, I., \& Penadés, J. R. (2006). Bap: A family of surface proteins involved in biofilm formation. Research in Microbiology, 157(2), 99-107. https://doi.org/10.1016/j.resmic.2005.11.003

Latasa, C., Solano, C., Penadés, J. R., \& Lasa, I. (2006). Biofilm-associated proteins. Comptes Rendus Biologies, 329(11), 849-857. https://doi.org/10.1016/j.crvi.2006.07.008

Le, K. Y., Dastgheyb, S., Ho, T. V., \& Otto, M. (2014). Molecular determinants of staphylococcal biofilm dispersal and structuring. Frontiers in Cellular and Infection Microbiology, 4(November), 1-7. https://doi.org/10.3389/fcimb.2014.00167

Liebeke, M., Meyer, H., Donat, S., Ohlsen, K., \& Lalk, M. (2010). A Metabolomic View of Staphylococcus aureus and Its Ser/Thr Kinase and Phosphatase Deletion Mutants: Involvement in Cell Wall Biosynthesis. Chemistry \& Biology, 17(8), 820-830. https://doi.org/10.1016/j.chembiol.2010.06.012

Lister, J. L., \& Horswill, A. R. (2014). Staphylococcus aureus biofilms: recent developments in biofilm dispersal. Frontiers in Cellular and Infection Microbiology, 4(December), 178:1-9. https://doi.org/10.3389/fcimb.2014.00178

Liu, G. Y. (2009). Molecular Pathogenesis of Staphylococcus aureus Infection. Pediatr Res, 65, 71-77. https://doi.org/10.1203/pdr.0b013e31819dc44d.molecular

Mack, D., Fischer, W., Krokotsch, A., Leopold, K., Hartmann, R., Egge, H., \& Laufs, R. (1996). The intercellular adhesin involved in biofilm accumulation of Staphylococcus epidermidis is a linear beta-1,6-linked glucosaminoglycan: purification and structural analysis. Journal of Bacteriology, 178(1), 175-183. https://doi.org/10.1128/jb.178.1.175183.1996

Maira-Litran, T., Kropec, A., Abeygunawardana, C., Joyce, J., Mark III, G., Goldmann, D. A., ... Pier, G. B. (2002). Immunochemical Properties of the Staphylococcal Poly-N-Acetylglucosamine Surface Polysaccharide. Infection and Immunity, 70(8), 4433-4440. https://doi.org/10.1128/iai.70.8.4433-4440.2002 
Mariutti, R. B., Tartaglia, N. R., Seyffert, N., Castro, T. L. de P., Arni, R. K., Azevedo, V. A., ... Nishifuji, K. (2017). Exfoliative Toxins of Staphylococcus aureus. In The Rise of Virulence and Antibiotic Resistance in Staphylococcus aureus. InTech. https://doi.org/10.5772/66528

Mattos-Graner, R. O., \& Duncan, M. J. (2017). Two-component signal transduction systems in oral bacteria. Journal of Oral Microbiology, 9(1), 1400858. https://doi.org/10.1080/20002297.2017.1400858

McGuinness, W. A., Kobayashi, S. D., \& Deleo, F. R. (2016). Evasion of Neutrophil Killing by Staphylococcus aureus. Pathogens, 5(1), 32. https://doi.org/10.3390/pathogens5010032

Meehl, M., Herbert, S., Gotz, F., \& Cheung, A. (2007). Interaction of the GraRS Two-Component System with the VraFG ABC Transporter To Support Vancomycin-Intermediate Resistance in Staphylococcus aureus. Antimicrobial Agents and Chemotherapy, 51(8), 2679-2689. https://doi.org/10.1128/AAC.00209-07

Melter, O., \& Radojevič, B. (2010). Small colony variants of Staphylococcus aureus - review. Folia Microbiologica, 55(6), 548-558. https://doi.org/10.1007/s12223-010-0089-3

Merino, N., Toledo-Arana, A., Vergara-Irigaray, M., Valle, J., Solano, C., Calvo, E., ... Lasa, I. (2009). Protein A-mediated multicellular behavior in Staphylococcus aureus. Journal of Bacteriology, 191(3), 832-843. https://doi.org/10.1128/jb.01222-08

Moormeier, D. E., \& Bayles, K. W. (2017). Staphylococcus aureus biofilm: a complex developmental organism. Molecular Microbiology, 104(3), 365376. https://doi.org/10.1111/mmi.13634

Mootz, J. M., Benson, M. A., Heim, C. E., Crosby, H. A., Kavanaugh, J. S., Dunman, P. M., ... Horswill, A. R. (2015). Rot is a key regulator of Staphylococcus aureus biofilm formation. Molecular Microbiology, 96(2), 388-404. https://doi.org/10.1111/mmi.12943

Mozos, I. R. de L., Vergara-Irigaray, M., Segura, V., Villanueva, M., Bitarte, N., Saramago, M., ... Toledo-Arana, A. (2013). Base Pairing Interaction between 5'- and 3'-UTRs Controls icaR mRNA Translation in Staphylococcus aureus. PLoS Genetics, 9(12), e1004001. https://doi.org/10.1371/journal.pgen.1004001

Mrak, L. N., Zielinska, A. K., Beenken, K. E., Mrak, I. N., Atwood, D. N., Griffin, L. M., ... Smeltzer, M. S. (2012). saeRS and sarA Act Synergistically to Repress Protease Production and Promote Biofilm Formation in Staphylococcus aureus. PLoS ONE, 7(6), e38453. https://doi.org/10.1371/journal.pone.0038453

Muzamal, U., Gomez, D., Kapadia, F., \& Golemi-Kotra, D. (2014). Diversity of two-component systems: insights into the signal transduction mechanism by 
the Staphylococcus aureus two-component system GraSR. F1000Research, 3(0), 1-26. https://doi.org/10.12688/f1000research.5512.2

Novick, R. P. (2003). Autoinduction and signal transduction in the regulation of staphylococcal virulence. Molecular Microbiology, 48(6), 1429-1449. https://doi.org/10.1046/j.1365-2958.2003.03526.x

O'Gara, J. P. (2007). ica and beyond: biofilm mechanisms and regulation in Staphylococcus epidermidis and Staphylococcus aureus. FEMS Microbiology Letters, 270(2), 179-188. https://doi.org/10.1111/j.15746968.2007.00688.x

O'Toole, G., Kaplan, H. B., \& Kolter, R. (2000). Biofilm Formation as Microbial Development. Annual Review of Microbiology, 54(1), 49-79. https://doi.org/10.1146/annurev.micro.54.1.49

Otto, M. (2014). Staphylococcus aureus toxins. Current Opinion in Microbiology, 17, 32-37. https://doi.org/10.1016/j.mib.2013.11.004

Pelz, A., Wieland, K.-P., Putzbach, K., Hentschel, P., Albert, K., \& Götz, F. (2005). Structure and Biosynthesis of Staphyloxanthin from Staphylococcus aureus. Journal of Biological Chemistry, 280(37), 32493-32498. https://doi.org/10.1074/jbc.m505070200

Percival, S. L., Malic, S., Cruz, H., \& Williams, D. W. (2011). Introduction to Biofilms. In S. Percival, D. Knottenbelt, \& C. Cochrane (Eds.), Biofilms and Veterinary Medicine (pp. 41-68). Berlin, Heidelberg: Springer Berlin Heidelberg. https://doi.org/10.1007/978-3-642-21289-5_2

Percival, S., Walker, J., \& Hunter, P. (2000). Microbiological Aspects of Biofilms and Drinking Water.

Proft, T., \& Fraser, J. D. (2003). Bacterial superantigens. Clinical and Experimental Immunology, 133(3), 299-306. https://doi.org/10.1046/j.13652249.2003.02203.x

Rice, K. C., Murphy, E., Yang, S.-J., Bayles, K. W., Smeltzer, M. S., Projan, S. J., ... Dunman, P. M. (2006). Transcriptional profiling of a Staphylococcus aureus clinical isolate and its isogenic agr and sarA mutants reveals global differences in comparison to the laboratory strain RN6390. Microbiology, 152(10), 3075-3090. https://doi.org/10.1099/mic.0.29033-0

Rice, L. B. (2008). Federal Funding for the Study of Antimicrobial Resistance in Nosocomial Pathogens: No ESKAPE. The Journal of Infectious Diseases, 197(8), 1079-1081. https://doi.org/10.1086/533452

Römling, U., \& Amikam, D. (2006). Cyclic di-GMP as a second messenger. Current Opinion in Microbiology, 9(2), 218-228. https://doi.org/10.1016/j.mib.2006.02.010

Rooijakkers, S.H.M., van Wamel, W. J. B., Ruyken, M., van Kessel, K. P. M., \& van Strijp, J. A. G. (2005). Anti-opsonic properties of staphylokinase. 


Microbes and Infection, 7(3), 476-484.

https://doi.org/10.1016/j.micinf.2004.12.014

Rooijakkers, Suzan H M, Ruyken, M., Roos, A., Daha, M. R., Presanis, J. S., Sim, R. B., ... van Strijp, J. A. G. (2005). Immune evasion by a staphylococcal complement inhibitor that acts on C3 convertases. Nature Immunology, 6(9), 920-927. https://doi.org/10.1038/ni1235

Sadekuzzaman, M., Yang, S., Mizan, M. F. R. F. R., \& Ha, S. D. D. (2015). Current and Recent Advanced Strategies for Combating Biofilms. Comprehensive Reviews in Food Science and Food Safety, 14(4), 491-509. https://doi.org/10.1111/1541-4337.12144

Schiffmann, E., Corcoran, B. A., \& Wahl, S. M. (1975). N-formylmethionyl peptides as chemoattractants for leucocytes. Proceedings of the National Academy of Sciences, 72(3), 1059-1062. https://doi.org/10.1073/pnas.72.3.1059

Schwartz, K., Syed, A. K., Stephenson, R. E., Rickard, A. H., \& Boles, B. R. (2012). Functional Amyloids Composed of Phenol Soluble Modulins Stabilize Staphylococcus aureus Biofilms. PLoS Pathogens, 8(6), e1002744. https://doi.org/10.1371/journal.ppat.1002744

Sibbald, M. J. J. B., Ziebandt, A. K., Engelmann, S., Hecker, M., de Jong, A., Harmsen, H. J. M., ... van Dijl, J. M. (2006). Mapping the Pathways to Staphylococcal Pathogenesis by Comparative Secretomics. Microbiology and Molecular Biology Reviews, 70(3), 755-788. https://doi.org/10.1128/MMBR.00008-06

Somerville, G. A., \& Proctor, R. A. (2009). The Biology of Staphylococci. In K. B. Crossley, K. K. Jefferson, G. L. Archer, \& V. G. Fowler (Eds.), Staphylococci in Human Disease (pp. 1-18). Oxford, UK: Wiley-Blackwell. https://doi.org/10.1002/9781444308464.ch1

Stemerding, A. M., Köhl, J., Pandey, M. K., Kuipers, A., Leusen, J. H., Boross, P., ... van Strijp, J. A. G. (2013). Staphylococcus aureus Formyl Peptide Receptor-like 1 Inhibitor (FLIPr) and Its Homologue FLIPr-like Are Potent FcyR Antagonists That Inhibit IgG-Mediated Effector Functions. The Journal of Immunology, 191(1), 353-362. https://doi.org/10.4049/jimmunol.1203243

Stock, A. M., Robinson, V. L., \& Goudreau, P. N. (2000). Two-Component Signal Transduction. Annual Review of Biochemistry, 69(1), 183-215. https://doi.org/10.1146/annurev.biochem.69.1.183

Taglialegna, A., Navarro, S., Ventura, S., Garnett, J. A., Matthews, S., Penadés, J. R., ... Valle, J. (2016). Staphylococcal Bap Proteins Build Amyloid Scaffold Biofilm Matrices in Response to Environmental Signals. PLoS Pathogens, 12(6), 1-34. https://doi.org/10.1371/journal.ppat.1005711

Toledo-arana, A., Merino, N., Débarbouillé, M., Penadés, J. R., Lasa, I., Vergarairigaray, M., \& De, M. (2005). Staphylococcus aureus Develops an 
Alternative , ica- Independent Biofilm in the Absence of the arIRS TwoComponent System Staphylococcus aureus Develops an Alternative, icaIndependent Biofilm in the Absence of the arIRS Two-Component System $\dagger$. Journal of Bacteriology, 187(15), 5318-5329. https://doi.org/10.1128/jb.187.15.5318

Tong, S. Y. C., Davis, J. S., Eichenberger, E., Holland, T. L., \& Fowler, V. G. (2015). Staphylococcus aureus Infections: Epidemiology, Pathophysiology, Clinical Manifestations, and Management. Clinical Microbiology Reviews, 28(3), 603-661. https://doi.org/10.1128/cmr.00134-14

Valle, J., Toledo-Arana, A., Berasain, C., Ghigo, J.-M., Amorena, B., Penadés, J. R., \& Lasa, I. (2003). SarA and not $\sigma B$ is essential for biofilm development by Staphylococcus aureus. Molecular Microbiology, 48(4), 1075-1087. https://doi.org/10.1046/j.1365-2958.2003.03493.x

Verbrugh, H. A. (2009). Colonization with Staphylococcus aureus and the Role of Colonization in Causing Infection. In Staphylococci in Human Disease (pp. 253-271). Oxford, UK: Wiley-Blackwell. https://doi.org/10.1002/9781444308464.ch12

Vergara-Irigaray, M., Valle, J., Merino, N., Latasa, C., Garcia, B., Mozos, I. R. de los, ... Lasa, I. (2009). Relevant Role of Fibronectin-Binding Proteins in Staphylococcus aureus Biofilm-Associated Foreign-Body Infections. Infection and Immunity, 77(9), 3978-3991. https://doi.org/10.1128/iai.0061609

Villanueva, M., García, B., Valle, J., Rapún, B., Ruiz de los Mozos, I., Solano, C., ... Lasa, I. (2018). Sensory deprivation in Staphylococcus aureus. Nature Communications, 9(1), 523. https://doi.org/10.1038/s41467-018-02949-y

Vuong, C., Kocianova, S., Voyich, J. M., Yao, Y., Fischer, E. R., DeLeo, F. R., \& Otto, M. (2004). A Crucial Role for Exopolysaccharide Modification in Bacterial Biofilm Formation, Immune Evasion, and Virulence. Journal of Biological Chemistry, 279(52), 54881-54886. https://doi.org/10.1074/jbc.m411374200

Wertheim, H. F., Melles, D. C., Vos, M. C., van Leeuwen, W., van Belkum, A., Verbrugh, H. A., \& Nouwen, J. L. (2005). The role of nasal carriage in Staphylococcus aureus infections. The Lancet Infectious Diseases, 5(12), 751-762. https://doi.org/10.1016/S1473-3099(05)70295-4

Wilke, K. E., \& Carlson, E. E. (2013). All Signals Lost. Science Translational Medicine, 5(203), https://doi.org/10.1126/scitranslmed.3006670 203ps12-203ps12.

Woehl, J. L., Stapels, D. A. C., Garcia, B. L., Ramyar, K. X., Keightley, A., Ruyken, M., ... Geisbrecht, B. V. (2014). The Extracellular Adherence Protein from Staphylococcus aureus Inhibits the Classical and Lectin Pathways of Complement by Blocking Formation of the C3 Proconvertase. The Journal of Immunology, 193(12), 6161-6171. 
https://doi.org/10.4049/jimmunol.1401600

Yang, Y., \& Inouye, M. (1993). Requirement of Both Kinase and Phosphatase Activities of an Escherichia coli Receptor (Taz1) for Ligand-dependent Signal Transduction. Journal of Molecular Biology, 231(2), 335-342. https://doi.org/10.1006/jmbi.1993.1286

Zecconi, A., \& Scali, F. (2013). Staphylococcus aureus virulence factors in evasion from innate immune defenses in human and animal diseases. Immunology Letters, 150(1-2), 12-22. https://doi.org/10.1016/j.imlet.2013.01.004

Zhang, L., Jacobsson, K., Vasi, J., Lindberg, M., \& Frykberg, L. (1998). A second IgG-binding protein in Staphylococcus aureus. Microbiology, 144(4), 985991. https://doi.org/10.1099/00221287-144-4-985 
upna 
OBJETIVES 
upna 
The specific objectives of this thesis are:

1. Finding novel molecules capable of turning PIA/PNAG production into a lethal process for $S$. aureus.

2. Following a drug repurposing methodology, screen a collection of FDAapproved drug for inhibition of the GraRS two-component systems of $S$. aureus, using a singular strain that lacks the whole TCS machinery. 
A different slant in anti-biofilm drug discovery 


\section{Abstract}

The polysaccharide PIA/PNAG is one of the major components of staphylococcal biofilms. Contrary to what it might seem, production of PIA/PNAG does not always confer a selective advantage, proof of which are the multiple onoff mechanisms that regulate its expression. In this study, with the aim of finding novel molecules capable of turning PIA/PNAG production into a lethal process for $S$. aureus, we have performed a High Throughput Screening assay in which several PIA/PNAG overproducer strains and their icaADBC mutant counterparts were grown in the presence of a collection of marine extracts and compounds provided by the Spanish company BIOMAR. We have selected a sub-fraction (SF8) composed by malayamicin, lumichrome and soyasaponin that specifically inhibits the growth of those strains capable of producing PIA/PNAG-dependent biofilm. Furthermore, this study aims at an initial approach to characterize the molecular mechanism underlaying the selected extract. Results obtained up to date suggest that the inhibitory effect exerted by the sub-fraction is mediated by a post transcriptional icaC down regulation and protein $\mathrm{A}$ repression, among other high weight molecular proteins. 
upna 


\section{Introduction}

Conventional antibiotics fail to successfully treat biofilm-associated-chronic infections, being $S$. aureus one of the etiologic agents that is mostly perceived as a serious threat to human health. Since we are unfortunately immersed in the post-antibiotic era, current therapeutical measures tend to pursue the inhibition of biofilm formation and virulence factors instead of bacterial death (Jaśkiewicz, Neubauer, Kazor, Bartoszewska, \& Kamysz, 2019).

Over the last years, great progress in the eradication and dispersal of staphylococcal biofilms has been made, mostly helped by the gradually better understanding of the molecular mechanisms that govern such multicellular behavior. The principal anti-biofilm strategies under study today contemplate different fronts like the inhibition of attachment using small molecules like aryl rhodanines, chelators or silver ions and nanoparticles, disruption of the biofilm architecture through molecules like Cis-2-Decenoic acid or a mixture of Daminoacids dispersion, degradation of matrix component by enzymes like dispersin, DNase or other lytic enzymes encoded by bacteriophages, inhibition of quorum sensing, modification of Two-Component-Systems signalling pathways, or even the generation of a protective immune response via anti-biofilm vaccines (P. Y. Chung \& Toh, 2014; Verderosa, Dhouib, Fairfull-Smith, \& Totsika, 2019).

One of the major components of staphylococcal biofilms is the polysaccharide PIA/PNAG. The production of this high molecular weight polymer depends on the proteins encoded by the icaADBC intercellular adhesion locus, an operon that is subjected to strict regulation, both at transcriptional and posttranscriptional levels. Despite the undoubted role of this polysaccharide in staphylococcal persistence, adaptation and pathogenesis, production of PIA/PNAG does not always confer a selective advantage, proof of which are the on-off mechanisms like phase-variation that regulate its expression (Arciola, Campoccia, Ravaioli, \& Montanaro, 2015). Actually, when S. aureus is subjected to several subcultures, PIA/PNAG-negative phase variants quickly increased in 
number relative to PIA/PNAG over-expressers. Bearing this premise in mind, the rationale behind our approach here was that PIA/PNAG production might be considered as a bacterial "Achilles heel" and thus, over-synthesis and/or accumulation of PIA/PNAG-intermediate proteins-metabolites could become toxic or alternatively render a status of high susceptibility to antimicrobials. So, in our attempt to somehow look at the anti-biofilm paradigm from another perspective, we have carried out an alternative phenotypic, instead of targetfocused, drug discovery approach to find compounds that could specifically be lethal for those bacteria that were initiating the biofilm lifestyle. Indeed, phenotypic screenings, understood as testing molecules to see if they exert the desired effect on a cell, leaving the precise target or mechanism aside, are having something like a renascence these days, since, though they do not always lead to best-inclass drugs, they definitively entail some advantages for generating first-in class drugs (Swinney, 2013). Using a screening platform composed by PIA/PNAG overproducer strains and their ica $A D B C$ mutant counterparts, we have tested the capacity of a library of extracts and compounds of marine origin to specifically kill bacteria upon entering into biofilm-growth phase. The basis of the assay was as simple as selecting those molecules that were capable of exerting specific growth inhibition of PIA/PNAG positive strain but had hardly any effect on the PIA/PNAG negative ones.

The idea of using marine extracts and compounds in this study came as a result of a collaboration with the Spanish company Biomar. Though terrestrial plants and microorganisms are of global and paramount importance in drug discovery, marine biodiversity is assumed to be even higher, being nowadays conceived as a major source of high added value molecules for treating human diseases (Khazir, Mir, Mir, \& Cowan, 2013). Evidence of this conception is represented by the wide array of anti-staphylococcal compounds and extracts possessing antibacterial and/or anti-biofilm activities that have already been obtained from marine sponges and microbes (Balasubramanian, Harper, 
Chapter I. A different slant in anti-biofilm drug discovery

Shopsin, \& Torres, 2017; Gomes et al., 2014; Kildow, Conradie, \& Robson, 2012;

Palomo et al., 2013; Rahman \& Richardson, 2010; Stowe et al., 2011).

Though we have not yet been able to identify a singular compound capable of exerting a PIA/PNAG-dependent antibiotic effect, the present study describes the finding and characterization of a chemical subfraction obtained from a marine microbe, composed by Lumichrome, Soyasaponin and Malayamicin, that specifically inhibits those bacteria producing PIA/PNAG. Preliminary studies aimed at the understanding of the molecular mechanisms underlaying the effect of sub-fraction TA-15-A-A112CHV-F.9/10.SF8 indicate that post transcriptional regulation of ica operon and ica-conditional repression of proteinA and other (LPXTG) high molecular weight proteins could be crucial to exploit PIA/PNAGassociated fitness cost. 


\section{Results}

\section{High Throughput Screening platform}

In order to develop a robust phenotype-screening platform, we first tested the capacity of PIA/PNAG synthesis of nine previously characterized strains and selected strong biofilm formers that could be easily distinguishable from their icaADBC mutant counterparts. Upon characterizing their multicellular behaviour through a standard microtitter-plate protocol, three pairs of strains were selected: (I) the clinical isolate 15981 showing a strong PIA/PNAG-dependent biofilm production and its derivative PIA/PNAG defective mutant, (II) the clinical strain ISP479r, also capable of producing a polysaccharidic biofilm, and its derivative defective mutant and (III) $S$. aureus strain 132, together with the derivative mutant. This last strain was chosen due to its ability for producing a polysaccharidic or proteinaceous biofilm depending on the presence of high concentrations of salt or glucose respectively (Vergara-Irigaray, Valle, Merino, Latasa, Garcia, Mozos, et al., 2009).

In order to optimize the screening protocol, the effect of different temperatures $\left(28^{\circ} \mathrm{C}\right.$ and $\left.37^{\circ} \mathrm{C}\right)$ of incubation, initial inoculum $(1: 200,1: 100$ and $1: 40$ ) and incubation times (24h and $36 \mathrm{~h}$ ) was first examined. As shown in figure 1 , differences between biofilm positive and negative strains were especially notable when the assay was performed at $28^{\circ} \mathrm{C}$ for $36 \mathrm{~h}$. By contrast, incubation at $37^{\circ} \mathrm{C}$ for $24 \mathrm{~h}$ led to a more discriminative outcome when the proteinaceous biofilm formed by strain 132 was analyzed (figure 1). 
A

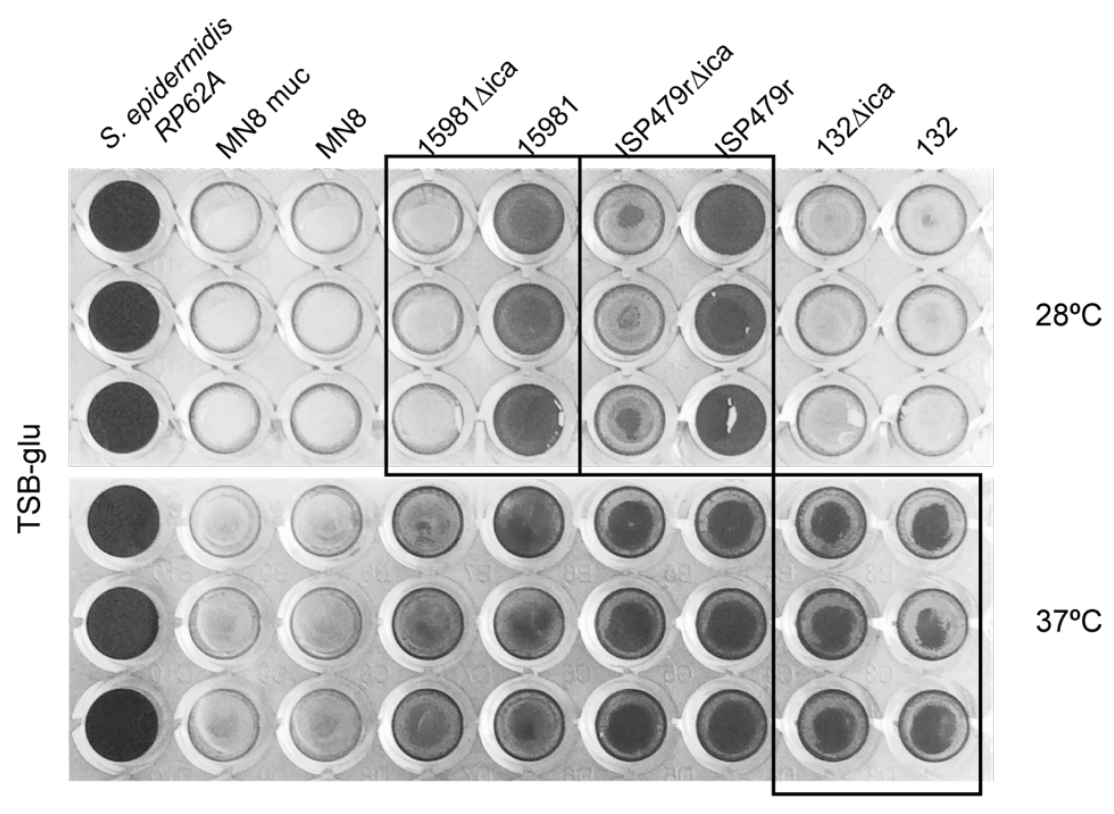

B

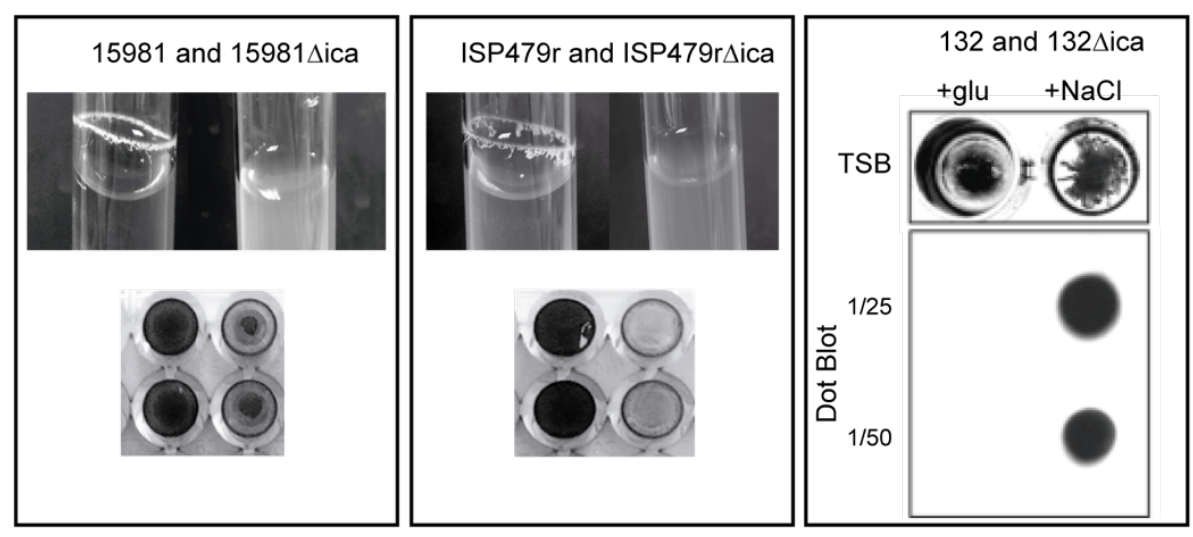

Figure 1. Anti-PIA/PNAG production screening platform. A) Quantification of the capacity of $S$. aureus and $S$. epidermidis strains to produce biofilm in 96-well polystyrene plates in TSB-glu at two different temperatures using crystal violet staining method. B) Biofilm phenotype in crystal tubes and 96-well plates shown by the three pairs of selected strains. 


\section{Screening and extract selection}

In collaboration with the company Biomar, the ability of more than 60,000 crude extracts and 10,000 natural compounds to affect $S$. aureus 15981 was assessed. Attending to the specific inhibition of biofilm formation or growth of the wild type strain, a first sub-collection of 29 extracts was generated.

The inhibitory effect of the 29 extracts was newly tested using the three pairs of clinical strains (15981, ISP479r, 132, together with the ica mutant strains) at two different concentrations (40 and $400 \mathrm{ng} / \mathrm{ml}$ ). This secondary screening enabled us to verify that the effect of the majority of selected extracts was rather variable and dependent on the genetic background. Furthermore, the sub collection of extracts tended to lead to a more tenuous outcome in this second screening round. In accordance to its anti-biofilm potential, five extracts were finally selected, four of them displaying an "orthodox" inhibitory effect on multicellular behaviour and one of them actually showing the desired specific antibiotic effect against the strains that produce PIA/PNAG (figure 2).

AA-AW-P-K005SPI: This extract exhibited a high anti-biofilm activity at the lower concentration, showing inhibition rates over the $50 \%$. Curiously, this effect was not exhibited when bacteria were exposed to the high dose $(400 \mathrm{ng} / \mathrm{ml})$, at which the biofilm formation was not reduced, or it was only decreased by a $20 \%$. Bacterial growth, whether ica operon was present or absent, remained unaffected by the presence of this extract.

HT-16-50-AA02, AA-99-B-L020GMA and AA-99-K023: These extracts presented anti-biofilm activity at the high concentration $(400 \mathrm{ng} / \mathrm{ml})$ without altering the biofilm formation at the low dose $(40 \mathrm{ng} / \mathrm{ml})$. Bacterial growth, independently of PIA/PNAG synthesis was not inhibited by the presence of the extracts.

TA-15-A-A112CHV: This extract was especially interesting and fitted with our goal since it showed antibiotic activity, being such growth inhibition accentuated on those strains capable of forming a PIA/PNAG-depending biofilm. 
A

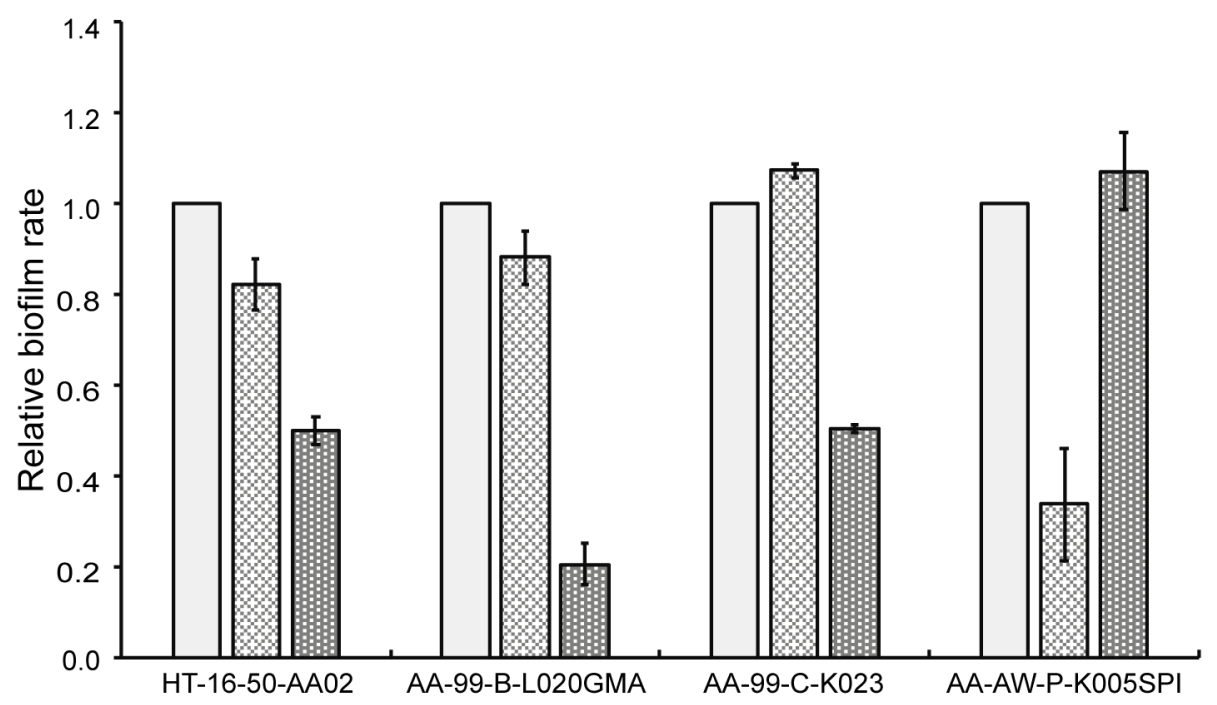

B

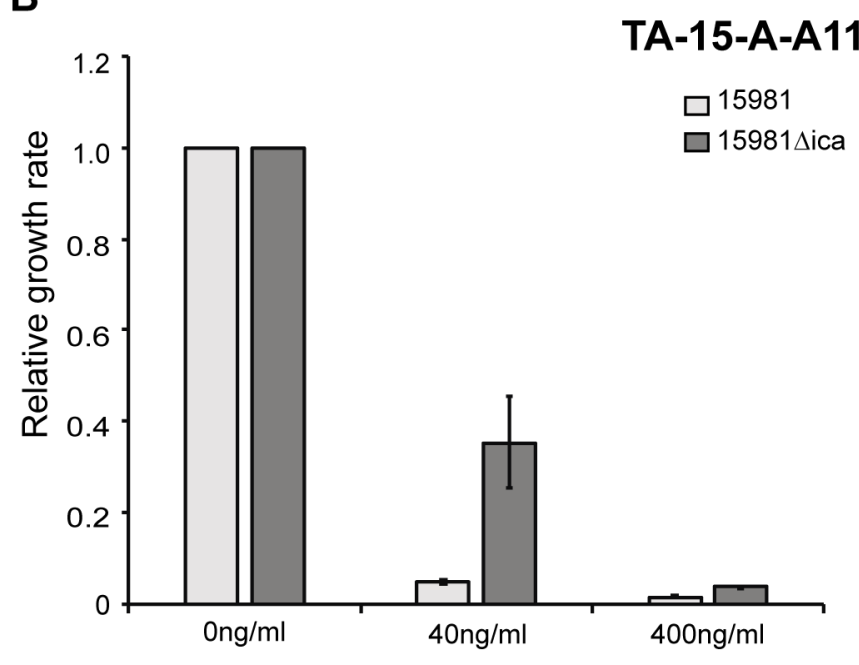

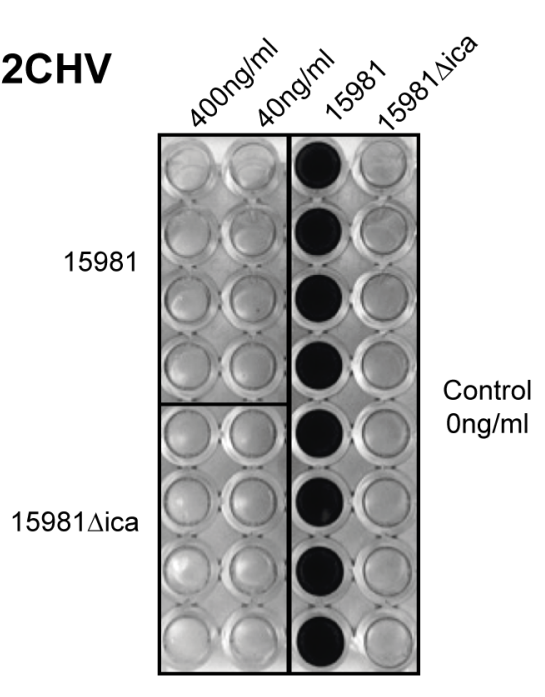

Figure 2. Secondary screening. A) Relative biofilm formation of $S$. aureus 15981 strain in the presence of selected extracts. B) Relative growth rate of $S$. aureus 15981 and 15981Dica strains in the presence of TA-15-A-A112CHV extract. Effect of this extract on biofilm formation is also illustrated. 
Chapter I. A different slant in anti-biofilm drug discovery

\section{Dose-response analysis}

Dose-response assessment is a critical step when it comes to evaluate how viable the following processes of fractionation and molecule identification steps might be. To further characterize the behavior of the previously selected extracts in this regard, 15981 and its ica minus derivative strain were exposed to a wide range of extract concentrations. These experiments were carried out using microtiter plates and $\mathrm{OD}_{600}$ values were subsequently measured.

As a result, it was found that extracts referred to as AA-99-B-L020GMA, AA99-C-K023 and TA-15-A-A112CHV provided a linear response (figures 3C, 3D and $3 E$ ). By contrast, in the case of the extract referred to as HT-16-50-AA02, it was noticeable that concentrations ranging from 4 to $32 \mathrm{ng} \mathrm{ml}^{-1}$ led to biofilm inhibition, even with 2-fold higher bacterial growth rates, but, unexpectedly, high dosages led to the opposite multicellular behaviour. Something similar was observed when different concentrations of AA-AW-P-K005SPI were tested; This extract displayed strong anti-biofilm activity from 4 to $32 \mathrm{ng} \mathrm{ml-1}$, but the effect was lost at higher concentrations (figure 3B). In view of these results, both HT16-50-AA02 and AA-AW-P-K005SPI were discarded when further investigation was planned. 
A

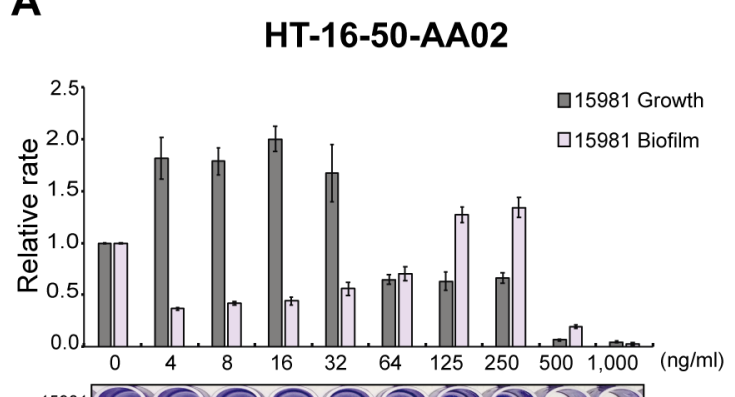

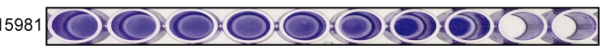

B

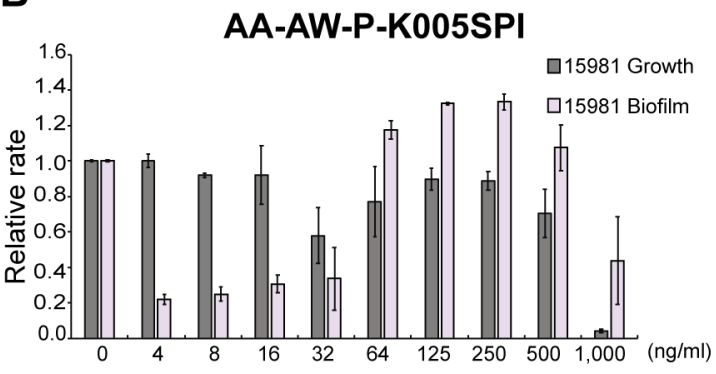

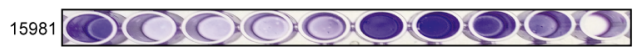

C

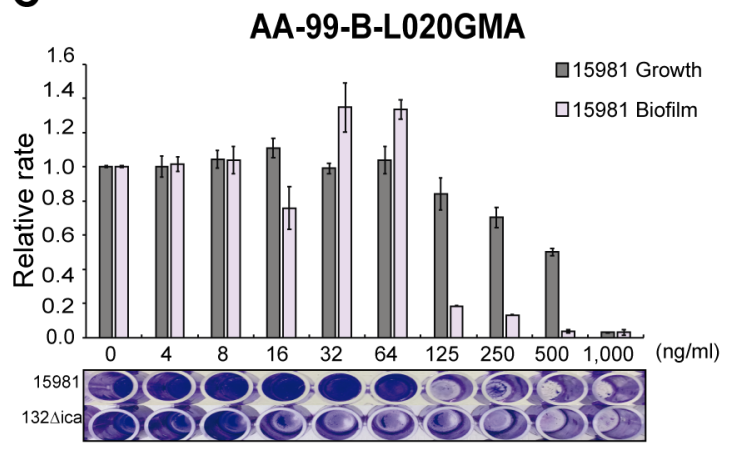

D

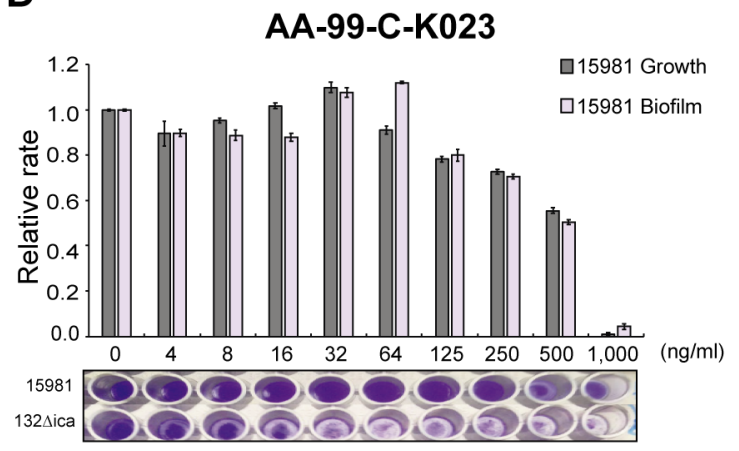

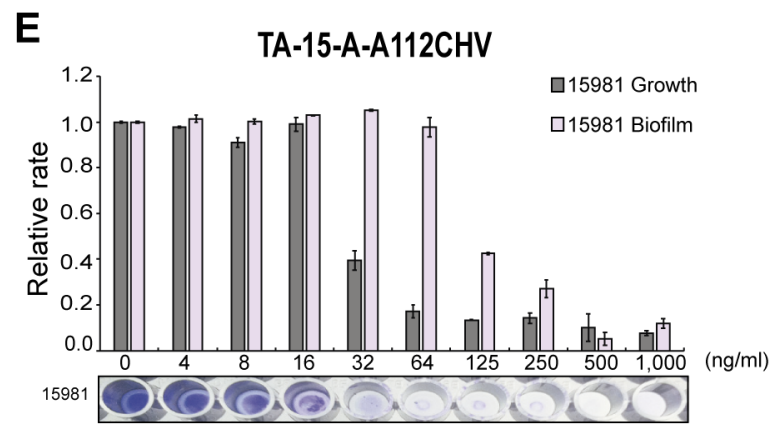

Figure 3. Dose response relationship. Graphics showing relative growth and biofilm rates of $S$. aureus 15981 strain in the presence of a concentration range up to $1000 \mathrm{ng} / \mathrm{ml}$ of (A) HT-16-50-AA02, (B) AA-AW-P-K005SPI, (C) AA-99-B-L020GMA, (D) AA-99-C-K023 or (E) TA-15-A-A112CHV. Corresponding crystal violet staining of resulting biofilm on polystyrene wells is also shown below each graphic. In the case of AA-99-B-L020GMA and AA-99-C-K023 extracts, the effect on a strictly proteinaceous biofilm, formed by $S$. aureus $132 \Delta$ ica strain, is additionally indicated. 
Chapter I. A different slant in anti-biofilm drug discovery

\section{Batch reproducibility analysis}

Once extracts referred to as HT-16-50-AA02 and AA-AW-P-K005SPI had been discarded due to lack of a dose-response relationship, the reproducibility between fermentation batches of AA-99-B-L020GMA, AA-99-C-K023 and TA-15A-A112CHV extracts were analysed. To do so, new batches were obtained from independent fermentation processes at Biomar facilities and S. aureus 15981 strain was simultaneously cultured in the presence of the old and new batches of each extract.

Unfortunately, the concentration needed to get the same anti-biofilm activity level with the new AA-99-B-L020GMA extract was significantly higher when compared to the original extract (figure 4A) and, curiously, new AA-99-C-K023 batch showed no activity at all (figure 4B). Hence, both extracts were discarded due to the lack of reproducibility between batches.

TA-15-A-A112CHV was the only extract whose independent batches displayed the same effect and thus its different effect over PIA/PNAG positive and negative genetic backgrounds was further analysed. With such purpose, both S. aureus 15981 and its ica lacking derivative were simultaneously tested in the presence of a wide range of concentrations of the extracts using a microtiter-plate growth assay. As shown in figure 4C, doses ranging from 32 to $64 \mathrm{ng} \mathrm{mL}^{-1}$ caused a very significant inhibition of the wild type strain, while the ica minus derivative hardly suffered a slight growth arrest. These results suggest that extract TA-15A-A112CHV exerts a specific antibiotic activity over PIA/PNAG producing cells. 
A

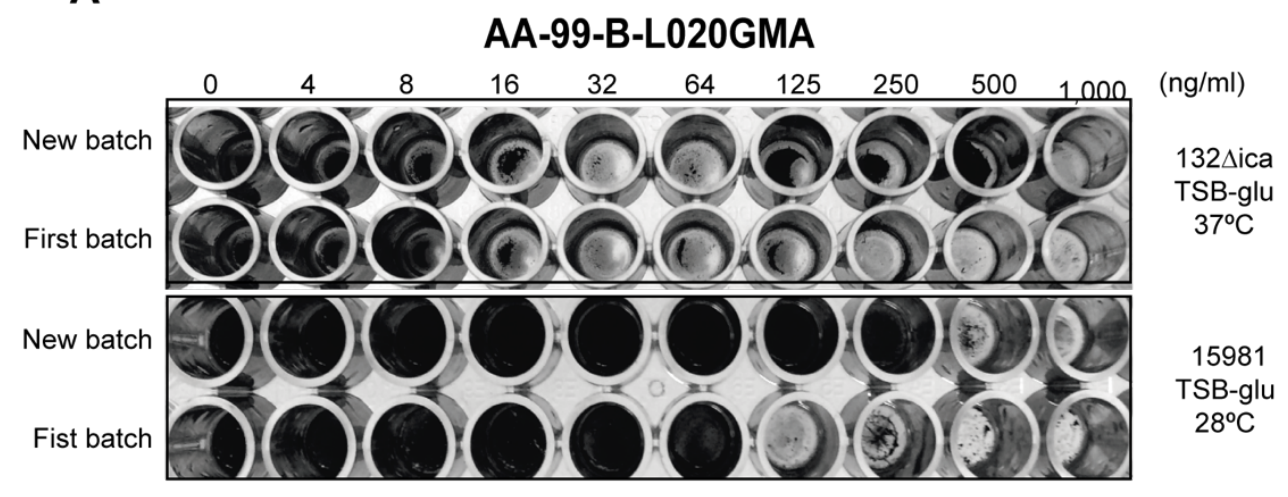

B

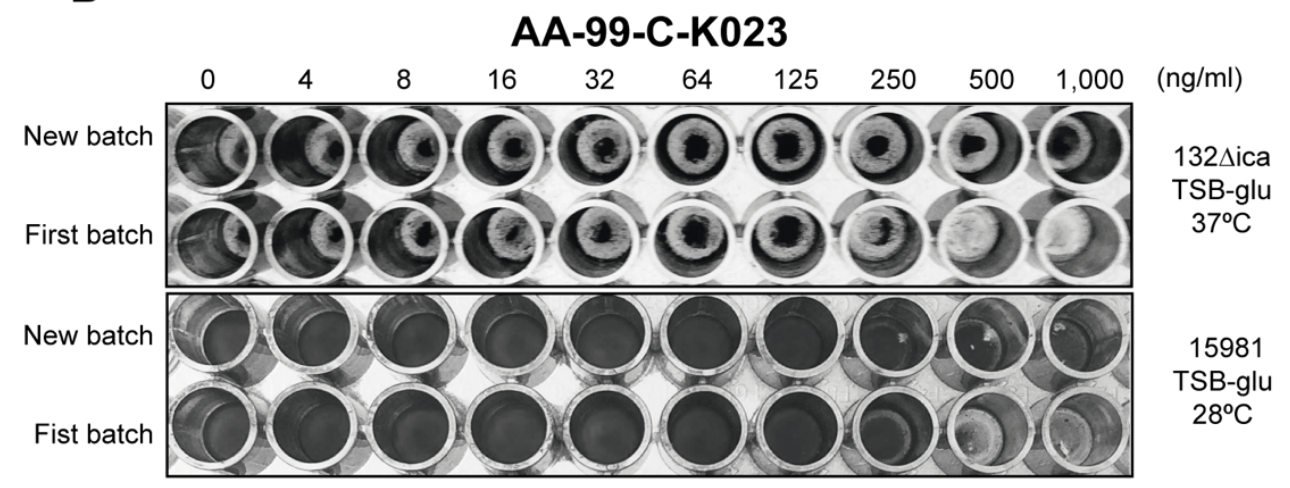

C

TA-15-A-A112CHV
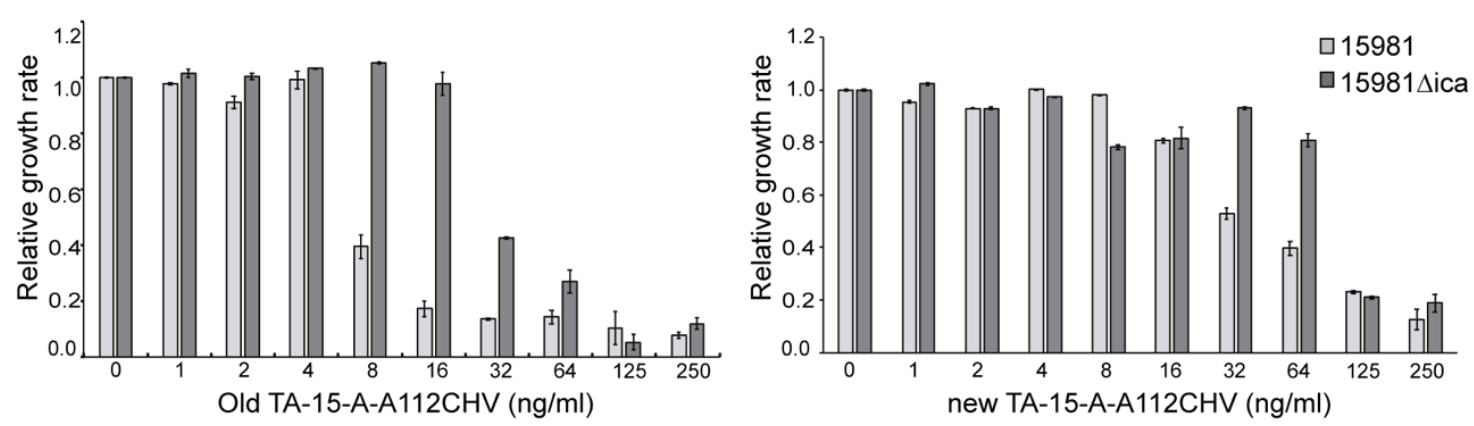

Figure 4. Analysis of fermentation batches reproducibility. Crystal violet staining of the biofilm formed by $S$. aureus 15981 and 132Aica strains in the presence of serial concentrations of two independent batches of $(A)$ AA-99-B-L20GMA and (B) AA-99-C-K023 extracts is shown. (C) Growth rates exhibited by $S$. aureus 15981 (light grey bars) and 15981 $\Delta$ ica (dark grey bars) strains in the presence of different concentrations of two independent batches of TA-15-A-A112CHV extract are plotted in graphics. 
Chapter I. A different slant in anti-biofilm drug discovery

\section{Characterization of TA-15-A-A112CHV}

\section{PIA/PNAG specificity:}

In order to determine the extent of PIA/PNAG specificity of this extract, we took advantage of the ability of strain $S$. aureus 132 to alternatively form a protein or polysaccharide-based matrix, depending on environmental conditions. To do so, an ordinary microtiter-plate growth test was performed using glucose or saltsupplemented TSB medium, to which serial dilutions of TA-15-A-A112CHV were added. In the first case the biofilm matrix would be primarily constituted by proteins whether the second condition leads to PIA/PNAG production. As shown in figure 5 , strain $S$. aureus 132 showed a higher degree of susceptibility to TA15-A-A112CHV in comparison to that previously showed by S. aureus 15981 and, according to our hypothesis, doses ranging between 2 and $8 \mathrm{ng} \mathrm{ml}^{-1}$ had a significant inhibitory effect when conditions favoured the production of PIA/PNAG but hardly affected those bacteria forming a protein-dependent biofilm. 


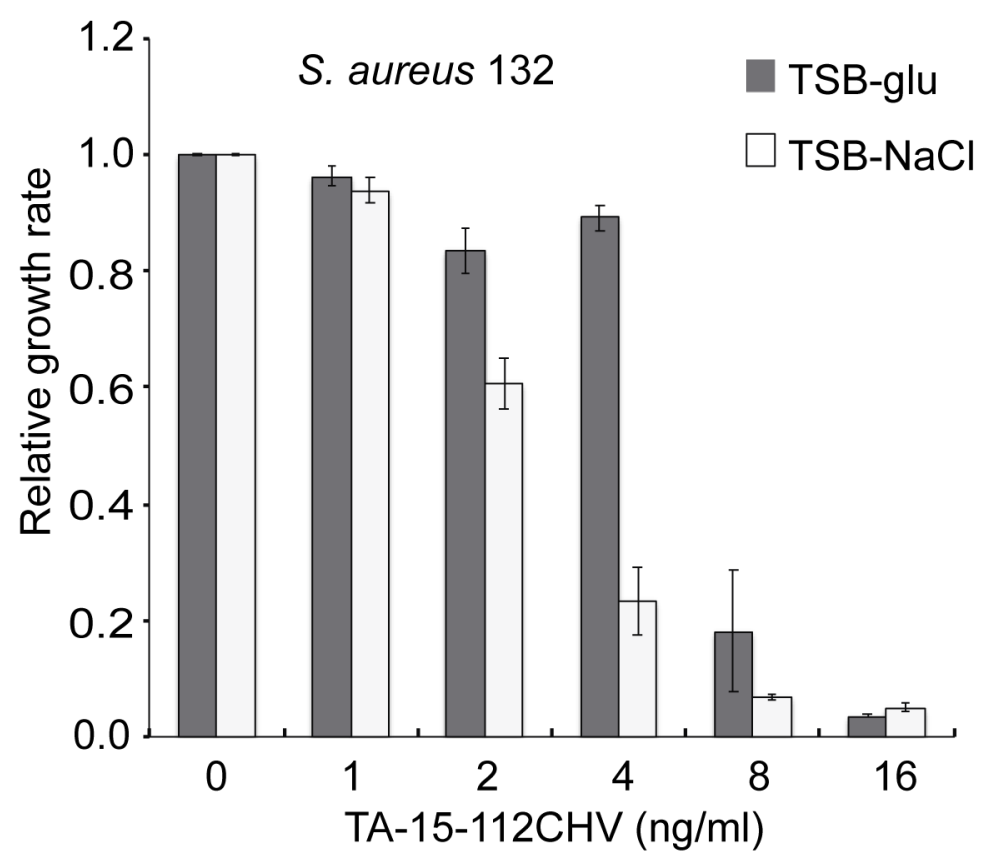

Figure 5. TA-15-A-A112CHV specificity over PIA/PNAG production. Growth rates exhibited by strain $S$. aureus 132 cultured in the presence of glucose, in order to obtain a proteinaceous matrix (grey bars), or salt, leading to a polysaccharidic biofilm (white bars), both in combination with TA-15-A-A112CHV extract at different concentrations is plotted in a graphic. 
Chapter I. A different slant in anti-biofilm drug discovery

\section{Fractions}

As a step forward in TA-15-A-A112CHV characterization, the team of Biomar chemists provided us with 10 extract fractions, whose PIA/PNAG-selective antibiotic activity was tested once again in different concentrations using a microtiter-plate growth assay. Results shown in figure 6 clearly evidenced that fraction $11 / 12$ (referred to as TA-15-A-A112CHV-F.11/12) contained the compound(s) responsible for the differential inhibitory effect.

Upon selecting TA-15-A-A112CHV-F.11/12 as the active fraction, an additional extraction step was carried out at Biomar facilities and 10 sub-fractions (referred to as TA-15-A-A112CHV-F.11/12.SF1 to TA-15-A-A112CHVF.11/12.SF10) were analysed applying the same methodology as described before. As a result, we obtained two sub-fractions (referred to as TA-15-AA112CHV-F.9/10.SF7 to TA-15-A-A112CHV-F.9/10.SF8) capable of exerting the PIA/PNAG-specific antibiotic effect. As shown in figure 6, SF8 displayed lower PIA/PNAG-differential MIC values, suggesting that this was actually the fraction that contained the active compound(s) or a higher concentration of it(them). In view of such an outcome, this fraction was newly analyzed through FAB mass spectrometry, obtaining three potential active compounds: (I) Soyasaponin, (II) Lumichrome and (III) Malayamicin. However, to our surprise, none of three compounds, under the conditions tested and whether alone or in different combinatory formulations, were capable to reproduce the effect exerted by SF8. 
A

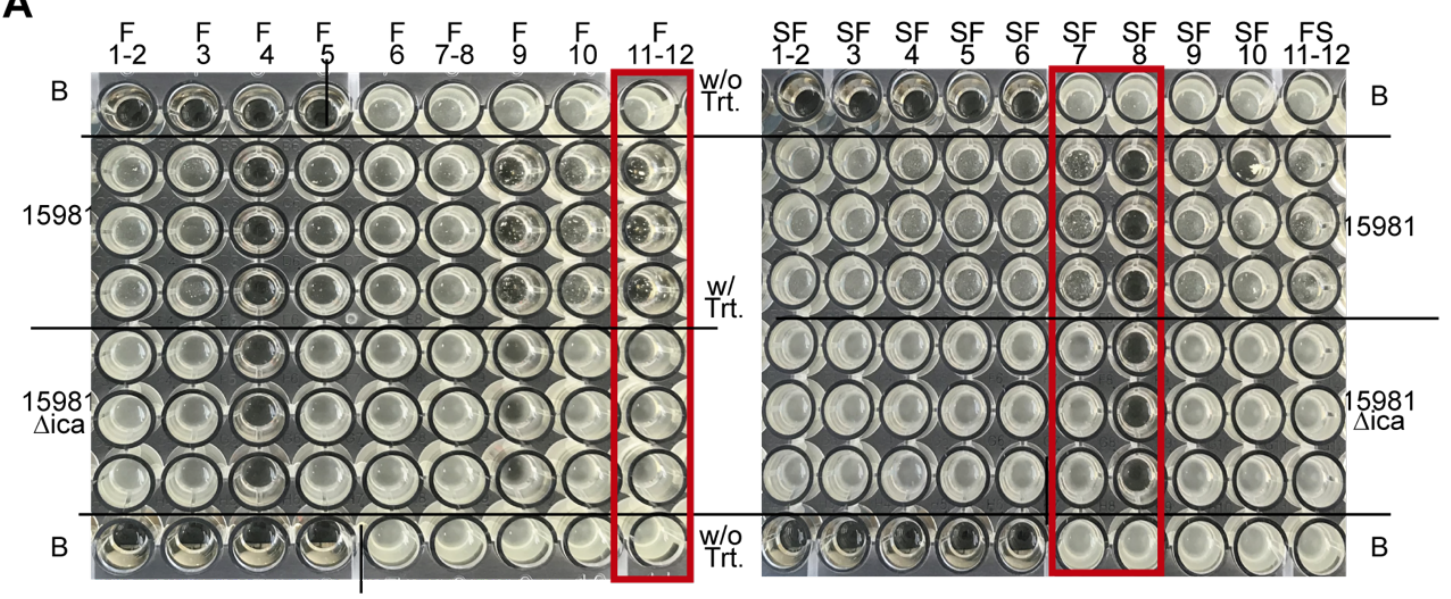

B

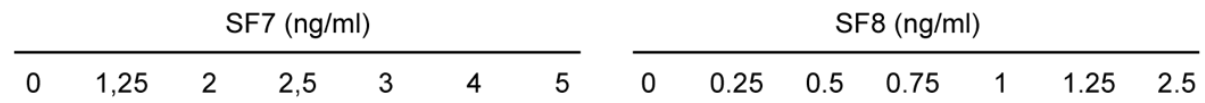

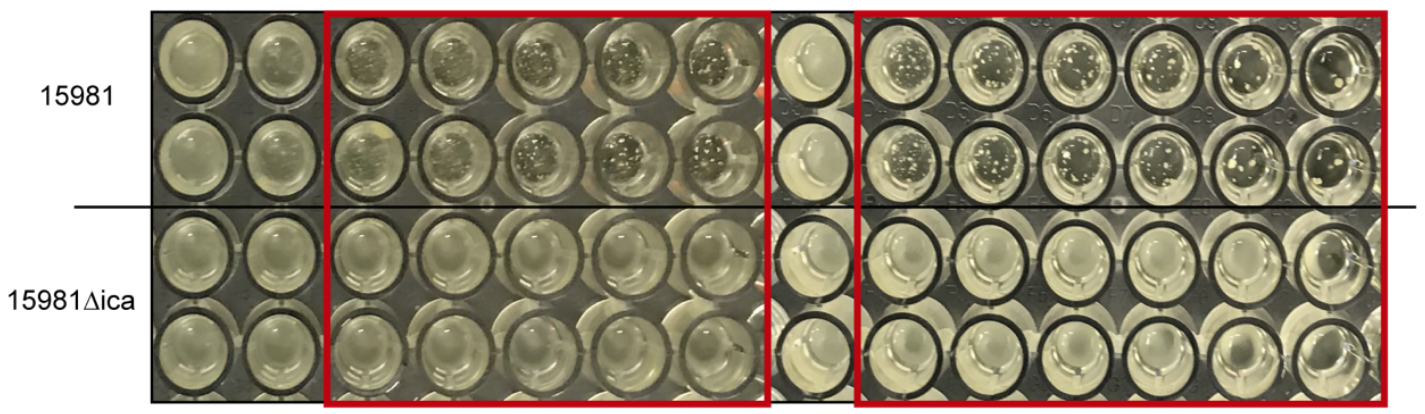

C

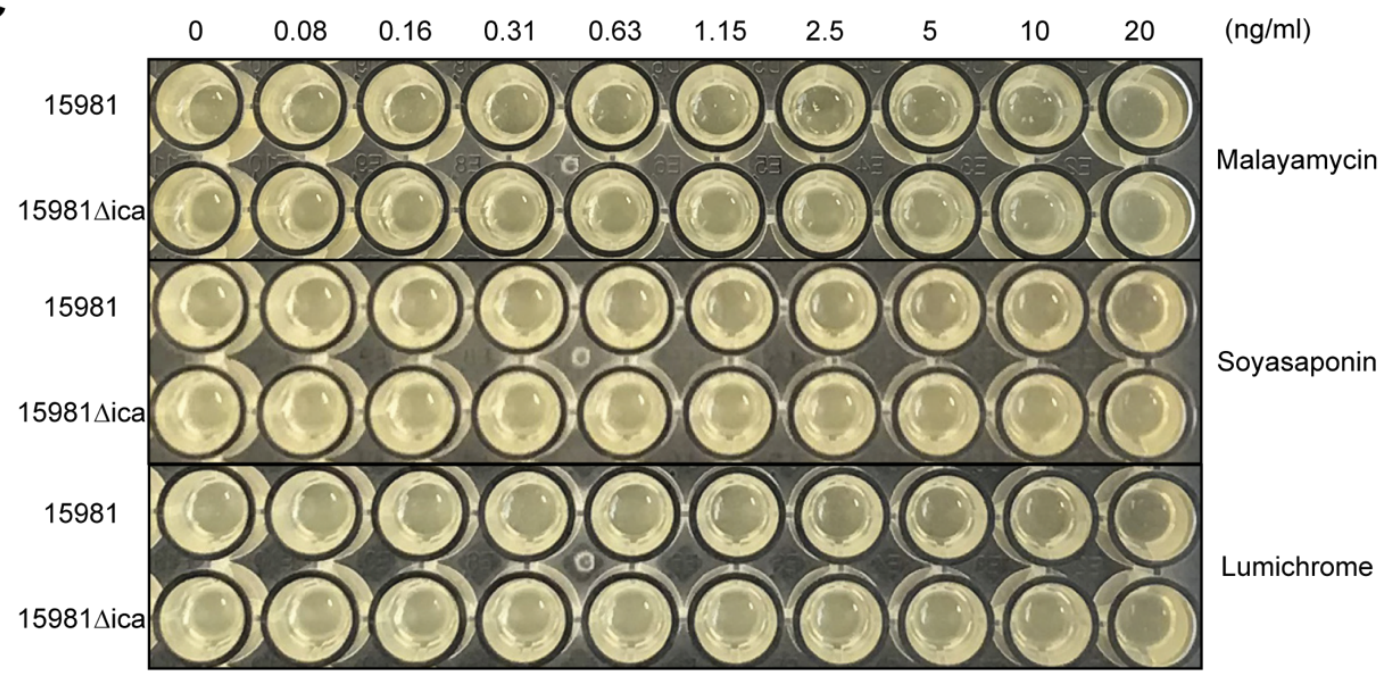

Figure 6. Fraction and sub-fraction screening. (A) Pictures of 96 well plates showing anti-PIA/PNAG activity of different TA-15-A-A112CHV fractions (left) and subfractions (right). Further analysis with (B) sub-fractions 7 and 8 and (C) compounds Malayamicinm, Soyasaponin and Lumichrome at different concentrations is also shown using the same layout. 


\section{Preliminary approach for understanding the molecular mechanisms underlaying PIA/PNAG-specific lethal effects}

In order to understand how PIA/PNAG synthesis machinery was responding to the presence of TA-15-A-A112CHV-F.9/10.SF8, both transcriptional and translational activities of ica operon were analyzed. Transcriptional characterization was carried out using a S. aureus 15981 strain derivative, previously transformed with a plasmid that harboured an icaA promoter-lacZ transcriptional fusion. S. aureus 15981 sica strain that contained the same reporter plasmid was used as a negative control. Curiously, measurements of beta galactosidase activity in the absence and presence of a sub-inhibitory concentration of SF8 did not differ significantly, while addition of Soyasaponin and Lumichrome resulted in a slight increased transcriptional activity of the operon responsible for PIA/PNAG synthesis (figure 7A).

On the other hand, translation of IcaC protein was assessed using the $S$. aureus 15981 wild type and ica minus derivative strains whose IcaC protein had been tagged with a 3XFlag epitope at its carboxi-terminal region. When these strains were grown in the presence of SF8 or its constituent compounds, the posttranscriptional effect of SF8 became evident, since IcaC protein was hardly detected via western blotting. Soyasaponin had a much less clear effect on icaC translation, while lumichrome seemed to lack any effect at this level. Nevertheless, this experiment allowed us to detect that SF8 makes the band corresponding to protein A disappear, but only in the case of the ica positive genetic background. Apart from protein A, and also restricted to the case of the strain capable of synthesizing PIA/PNAG, the protein profile analysed by coomassie staining obtained after the exposure to SF8 also lacked some highmolecular-weight proteins (figure 7).

Thus, these results suggest that SF8, but not its constituent compounds individually, exerts a post transcriptional inhibitory effect on ica operon expression, while is also capable of inhibiting the expression of Protein A and some other high molecular weight proteins. 
A

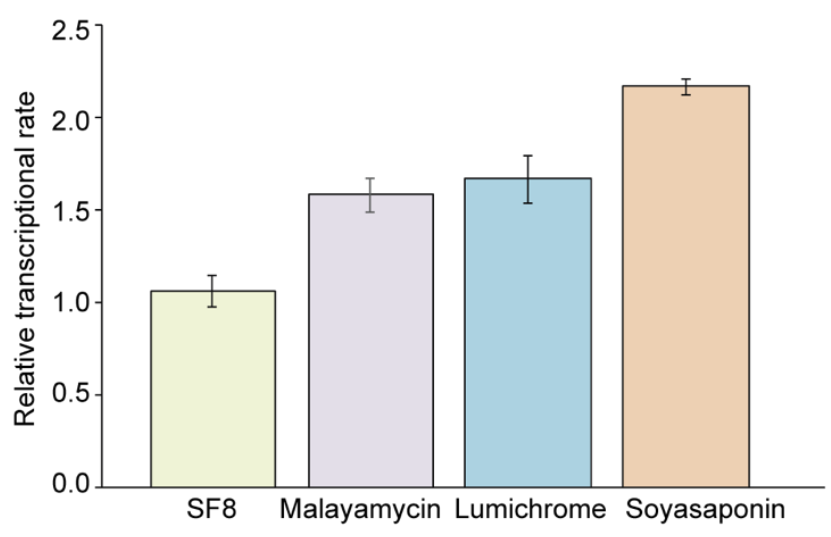

B
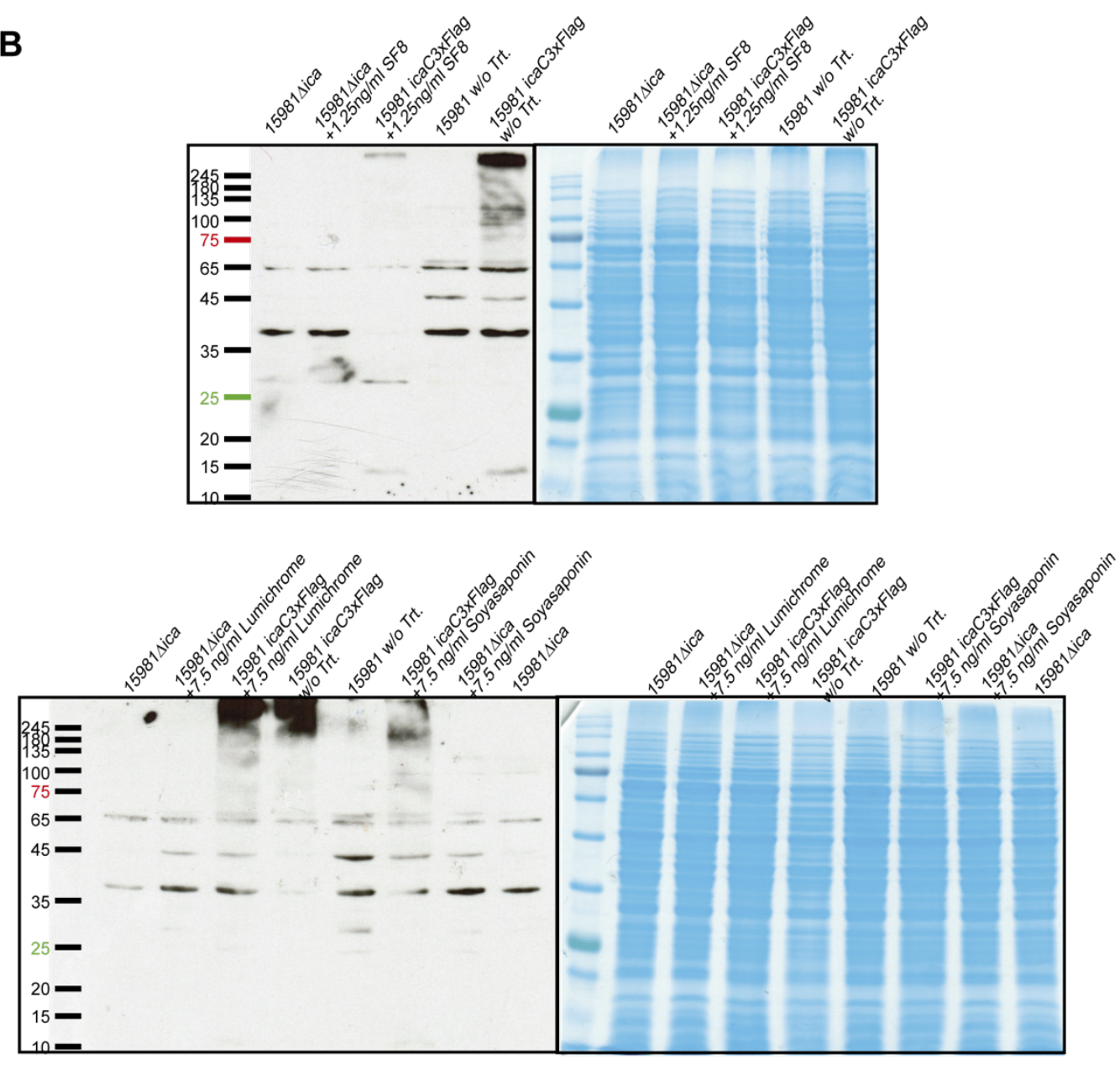

Figure 7. Transcriptional and translational activity of icaADBC operon. (A) Relative transcriptional of $i c a A$ gene and (B) IcaC protein expression in $S$. aureus 15981 strain grown in the presence of SF8 at $1,25 \mathrm{ng} / \mathrm{ml}$ or Malayamicin, Lumichrome and Soyasaponin at $7,25 \mathrm{ng} / \mathrm{ml}$ is presented. Transcriptional activities are plotted in a graphic in which beta galactosidase values given by a ica-promoter. lacZ fusion have been relativized to those showed by the wild type strain grown in the absence of any sub-fraction or compound. IcaC expression is illustrated via western blot images. Corresponding protein profiles stained with coomassie blue are also shown. 


\section{Discusion}

When it comes to anti-biofilm drug discovery, two main premises must be taken into account. First, the multiplicity of methods that can be used for studying biofilm growth might make difficult to choose the most reliable one; on the other hand, ordinary inhibition-based screenings enable rapid identification of the new drug candidates. However, this method might not be the most appropriate for particular in vitro growth pattern, such as the anchored or steady-state status found in biofilm matrixes (Jaśkiewicz et al., 2019).

With the aim of somehow overcoming these limitations and trying a different approach, we decided to focus on the contradictory nature of PIA/PNAG polysaccharide synthesis. Beyond doubt is the fact that this major component of the staphylococcal biofilm mediates virulence both through its contribution to matrix assembly and immune evasion. This is probably the main reason why evolutionary forces have definitively favoured the conservation and inter-species spread of the locus encoding it. However, evidence suggests that while PIA/PNAG might protect bacteria from the immune system under certain circumstances, it might also be the target for an effective immune response (Brooks \& Jefferson, 2014; Cerca et al., 2007; Maira-Litrán et al., 2012). In the same context, it has been shown that overproduction of the polysaccharide can entail a significative fitness cost and it is actually not infrequent to isolate PIA/PNAG negative revertant strains of $S$. aureus and $S$. epidermidis from patients (Brooks \& Jefferson, 2014; Juárez-Verdayes, Rodríguez-Martínez, Cancino-Diaz, \& Cancino-Diaz, 2013; Martin-Lopez et al., 2002). Behind all these phenomena there is a finely orchestrated regulatory system that includes repressors like IcaR, CodY or Sigma B and activators such as SarA or GraRS (Jefferson, Cramton, Götz, \& Pier, 2003; Majerczyk et al., 2008; Merino et al., 2009; Valle, Echeverz, \& Lasa, 2019; Valle et al., 2003) and even reversible mechanisms for truncation of ica operon mediated by the insertion of sequence element IS256 into icaA or icaC genes (Loessner, Dietrich, Dittrich, Hacker, \& 
Ziebuhr, 2002), or the Rec-A independent addition or subtraction of non-multiples of three repeat shifts in the icaC ORF (Brooks \& Jefferson, 2014). This extreme regulatory scenario has always prompted us to think that PIA/PNAG synthesis carries a "weakness" connotation, which could really be exploited to combat biofilm-associated infections.

S. aureus 15981 and ISPr strains have been extensively used as models for staphylococcal virulence, their multicellular behaviour is well characterized, and their sequence is available. S. aureus 132 is also a "veteran" strain, included in this platform due to its particular bivalent multicellular behaviour, which allows to differentiate those effects on protein-based biofilm from those dependent on polysaccharide production (Vergara-Irigaray, Valle, Merino, Latasa, Garcia, Ruiz de los Mozos, et al., 2009).

Why use marine natural extracts and compounds for the screening? While it is true that antimicrobial compounds from marine sources have not yet been developed into clinical trial phases, there are plenty of studies underscoring the great potential of marine microorganisms, especially those adaptable to extreme conditions like deep seabed, for the production of novel metabolites and antiinfectives like polyketides or cyclic peptides (Pereira et al., 2020). Thanks to a collaboration with the Spanish company Biomar, their AquaE and AquaC collections, containing more thant 1,000 compounds and 40,000 extracts respectively, were tested against $S$. aureus 15981 strain and its ica minus derivative.

As a result, from the first screening, 29 extracts were classified because showed potential for exerting a differential inhibition on PIA/PNAG positive strains. It was kind of disappointing, though not unexpected, the result obtained when these extracts were newly tested using the whole set of strains, since most of them showed a tenuous effect, which was also dependent on the genetic background. Upon applying this second screening step, five extracts were selected, two of which were additionally discarded due to the lack of doseresponse relationship. When batch reproducibility for the three remaining extracts 
Chapter I. A different slant in anti-biofilm drug discovery

was analyzed, only the new fermentation batch leading to extract TA-15-AA112CHV showed a consistent outcome. The BIOMAR team of chemical experts performed several TA-15-A-A112CHV fractionation and sub-fractionation steps, which allow us tu find out the SF8 from F9/10, which was capable of showing the inhibitory effect on PIA/PNAG positive strains growth without affecting the ica negative counterpart.

Mass spectrometry results indicated that SF8 was indeed composed by three compounds: Malayamicin, Lumichrome and Soyasaponin. To our knowledge, there is no available information about the effect of Malayamicin on microorganisms, except for a patent concerning the biocidal compounds Malayamicin and its isomer desmethylmalayamycin $A$, which show inhibitory effects on different fungi, virus and cancerous cells (https://patentscope.wipo.int/search/es/detail.jsfdocld=MX124710\&tab=NATION ALBIBLIO).

Lumichrome instead, is a riboflavin derivative which has been studied due to its capacity to behave as a signal for plant growth (Dakora, Matiru, \& Kanu, 2015) or activate LasR bacterial quorum sensing receptor (Rajamani et al., 2008). This molecule is also considered as a potential antibacterial agent due its photosensitizing effects (Bergh, Bruzell, Hegge, \& Tønnesen, 2015; Martins et al., 2008) but especially interesting is the recent work describing an approach very similar to ours in which lumichrome showed strong inhibitory activity against Staphylococcus aureus Sortase A, a transpeptidase responsible for anchoring surface proteins to the peptidoglycan cell wall, without affecting cell viability (B. Chung, Kwon, Shin, \& Oh, 2019). With regard to soyasaponin, this substance has been shown to exert synergistic effects on the antimicrobial activity of $\beta$-lactam antibiotics against $\beta$-lactamase-producing Staphylococcus aureus strains (Horie, Chiba, \& Wada, 2018).

Unfortunately, the desired biofilm-specific effect displayed by SF8 did not seem to rely on a unique compound, since, under the conditions tested and neither alone nor in different combinatory formulations, any of them was capable 
to reproduce the effect exerted by SF8. This results certainly opens up a more complicated scene for developing a clinically viable formulation. However, and with the aim of getting some knowledge about how it would be possible to reinforce the bacterial weakness associated to PIA/PNAG production, we thought it was worth analyzing the potential molecular mechanisms underlaying the observed effect. When transcriptional and translational effects on ica operon were tested, it became evident that SF8 was acting at a postranscriptional level, since bands corresponding to Ica protein complex practically disappeared from blot images. These same western blot assays offered an even more intriguing result, revealing that SF8 inhibits the expression of protein A and the activity of Ica operon is actually required for obtaining such effect. Protein A is a very common and relevant surface protein that binds Immunoglobulin $\mathrm{G}$ and simplifies bacterial transmission, allowing it to take hold of the host in a shorter space of time (Falugi, Kim, Missiakas, \& Schneewind, 2013; Winstel, Missiakas, \& Schneewind, 2018). Indeed, when the effect of lumichrome was assessed individually through western blot, a slight inhibitory effect on protein $A$ was obtained, reinforcing the previously mentioned observation made by Chung and colleagues (B. Chung et al., 2019). Apart from protein A, some other high molecular weight proteins were inhibited by SF8 exclusively in the ica positive genetic background, as stated by the protein profiles analysis via coomassie staining. These evidences have raised some crucial questions. Are those additionally inhibited proteins members of the LPXTG family? How is the inhibition of LPXTG proteins connected with Ica operon? In this regard, and since all post transcriptional silencing mechanisms depend on IcaC protein, would it be possible that accumulation of the other proteins encoded within the ica locus had an extra function and could mediate the effect exerted by SF8? This hypothesis has already been proposed by L. Brooks and K. Jeffersson (Brooks \& Jefferson, 2014). Up to date, we have no certain answers for such questions but studies to determine genome sequences of SF8-resistant clones are underway. Hopefully, though our work might not end up, or at least in a short-term basis, in a 
Chapter I. A different slant in anti-biofilm drug discovery

pharmaceutical formulation, elucidation of mechanisms underlaying PIA/PNAG collateral effects could pave the way to novel antimicrobial and antibiofilm therapies. 


\section{Experimental procedures}

\section{Bacterial strains, plasmids and culture media}

Bacterial strains and plasmids are listed in table 1 and table 2 respectively. Escherichia coli XL1blue strain was grown in LB broth and agar (Scharlau). Staphylococcus aureus strains were grown in trypticase soy broth (TSB) (VWR Chemicals), trypticase soy agar (TSA), trypticase soy broth with $0.25 \%$ of glucose (TSB-glu), Mueller Hinton (MH) (Pronadisa) and B2 medium (1\% casein hydrolysate, $2.5 \%$ yeast extract, $2.5 \% \mathrm{NaCl}, 0.1 \% \mathrm{~K}_{2} \mathrm{HPO}_{4}$, and $0.5 \%$ glucose $[\mathrm{w} / \mathrm{v}])$. When required for growth or selection, medium was supplemented with the appropriate antibiotic at the following concentrations: ampicillin (Am) $100 \mu \mathrm{g}$ $\mathrm{ml}^{-1}$, chloramphenicol (Clo) $10 \mathrm{\mu g} \mathrm{ml}^{-1}$ and $20 \mathrm{\mu g} \mathrm{ml}^{-1}$.

\section{DNA manipulations}

Plasmids were isolated using NucleoSpin $\circledast$ Plasmid kit (Macherey-Nagel) according to the manufacturer protocols.

Plasmids were transformed into Escherichia coli XL1Blue strain by electroporation and then introduced first into the restriction-deficient Staphylococcus aureus strain RN4220 using a previously described protocol (Lee, 1995), and transferred to other strains also by electroporation. S. aureus electro-competent cells were produced as described before (Schenk and Laddaga, 1992).

\section{Compounds and extracts libraries}

The compounds and extracts tested belongs to two libraries of the Spanish company Biomar. The first one is composed of 1,000 compounds obtained through the fermentation of marine microorganisms and by isolation of the pure compound. This library contains several natural products that are also presented in other libraries. However, the marine origin and the high taxonomic dereplication degree implemented for the microorganism selection, leads the presence of at least $25 \%$ of compounds that could be considered as new products. The second library consists in more than 60,000 crude extracts. These extracts are generated 
Chapter I. A different slant in anti-biofilm drug discovery

through the fermentation of marine microorganism in specific cultures designed by the company to promote the production of secondary metabolites, that are extracted in a cocktail of organic solvents developed to extract compound with a wide range of polarity.

\section{PIA/PNAG-dependent biofilm quantification assay}

The PIA/PNAG-depending biofilm-forming capacity was tested in microtiter wells as previously described (Heilmann et al., 1996).

Briefly, S. aureus strains (PIA/PNAG producer and PIA/PNAG defective strains simultaneously) were cultivated overnight in TSB-glu at $28^{\circ} \mathrm{C}$. The culture was diluted 1:40 in TSB-glu and supplemented with the appropriate crude extract or purified compound at the following concentration: extracts at $40 \mathrm{ng} \mathrm{ml}^{-1}$ and $400 \mathrm{ng} \mathrm{ml}^{-1}$ or compounds at $0.05 \mathrm{ng} \mathrm{ml}^{-1}, 0.5 \mathrm{ng} \mathrm{ml}^{-1}$ and $5 \mathrm{ng} \mathrm{ml}^{-1}$. 96-well polystyrene microtiter plates (BioLite Thermo Scientific) were inoculated with 200 $\mu \mathrm{l}$ of the previously prepared cell suspensions and the plates were incubated for $36 \mathrm{~h}$ at $28^{\circ} \mathrm{C}$. After the cultivation, to quantify the growth, the optical density at $650 \mathrm{~nm}\left(\mathrm{OD}_{650 \mathrm{~nm}}\right)$ was determined using a microplate reader (MultiSkan GO Thermo Scientific). Then, the wells were gently washed twice with water and airdried. The remaining surface absorbed cells or the individual wells were stained with crystal violet for $5 \mathrm{~min}$ at room temperature. Next, the microtiter plates were rinsed again twice with water, dried in an inverted position and photographed. To quantify the biofilm formed, the crystal violet-stained cells were resuspended in $200 \mu \mathrm{l}$ of ethanol-acetone $(80: 20 \mathrm{v} / \mathrm{v})$ solution and the optical density at $595 \mathrm{~nm}$ $\left(\mathrm{OD}_{595 \mathrm{~nm}}\right)$ was determined. Each assay was performed in triplicate and repeated at least three times.

\section{PIA/PNAG-independent biofilm quantification assay}

For quantification PIA/PNAG-independent biofilm-forming capacity, a test similar to that described for PIA/PNAG-dependent biofilm was used. Sterile 96well polystyrene microtiter plates from the same manufacturer (BioLite Thermo Scientific) were inoculated with $200 \mu \mathrm{l}$ of an overnight culture $\left(37^{\circ} \mathrm{C}\right.$ in TSB-glu) 
diluted 1: 40 in TSB-glu supplemented with the appropriate extract or compound at the identical concentrations. The plates were cultivated $24 \mathrm{~h}$ at $37^{\circ} \mathrm{C}$, and after the incubation the process was performed analogous to the process carried out for the PIA/PNAG-dependent assay. Each assay was performed in triplicate and repeated at least three times.

\section{Doses-response assay}

To confirm and to determine the potential of selected extracts and compounds (from the primary screening), chosen drugs were serially diluted from $1,000 \mathrm{ng} \mathrm{ml}^{-1}$ to $0 \mathrm{ng} \mathrm{ml}^{-1}$ into triplicate rows, and assayed with $S$. aureus 15981 and $15981 \Delta$ ica strains by the already described PIA/PNAG-dependent biofilm quantification assay.

\section{$\beta$-galactosidase assay}

To quantify ica $A D B C$ operon translation level overnight cultures were diluted 1:40 in TSB-glu supplemented with the appropriate concentration of each extract. 12-well plates were inoculated with $2 \mathrm{ml}$ of cells suspension and incubated for 36 h at $28^{\circ} \mathrm{C}$. S aureus strains were harvested by centrifuging $2 \mathrm{ml}$ of culture samples (2 min 20,000 g). Cells were resuspended in $1 \mathrm{ml}$ of $Z$ buffer (Jeffrey H. Miller, 1972 ) with $100 \mu \mathrm{l}$ of chloroform and $50 \mu \mathrm{l}$ of $0.1 \%$ of SDS, and lysed by incubation at $28{ }^{\circ} \mathrm{C}$ for $5 \mathrm{~min}$. Assay was performed as previously described and $\beta$ galactosidase specific activity was expressed as Miller units $\mathrm{OD}_{650 \mathrm{~nm}^{-1}}$ or as Miller units $\mathrm{g}$ of cells ${ }^{-1}$ (Jeffrey H. Miller, 1972). Briefly, to initiate the reaction $200 \mu \mathrm{l}$ of $4 \mathrm{mg} \mathrm{ml}^{-1}$ ortho-Nitrophenyl- $\beta$-galactoside (ONPG) was added to each sample, and when a faint yellow was observed the reaction was stopped adding $500 \mu \mathrm{l}$ of $1 \mathrm{M} \mathrm{Na} \mathrm{CO}_{3}$. Miller units were calculated as described previously attending to $\mathrm{OD}_{600 \mathrm{~nm}}, \mathrm{OD}_{420 \mathrm{~nm}}, \mathrm{OD}_{550 \mathrm{~nm}}$ and reaction time measurements (Li et al., 2012). All experiments were carried out in triplicate.

\section{SDS-PAGE and Western Blotting}

For detection of icaC translate level after the incubation with the extract or compound, an overnight culture of the 15981 icaC3xFlag strains was diluted 1:40 
in TSB-glu supplemented with the appropriate concentration of extract or compound and incubated for $36 \mathrm{~h}$ at $28^{\circ} \mathrm{C}$ in 12-well plates (Multiwell 12-Well FALCON). Two $\mathrm{ml}$ of bacterial cultures were centrifuged at 10,000 $\mathrm{g}$ for $1 \mathrm{~min}$, pellets were washed twice with PBS and resuspended in $100 \mu \mathrm{l}$ of lysis buffer (50mM Tris $\mathrm{HCl} \mathrm{pH} 7.4,250 \mathrm{mM} \mathrm{NaCl}, 0.5 \%$ Triton $\mathrm{X}-100,10 \%$ glycerol, $1 \mathrm{mM}$ DTT, PMSF) with $2 \mu$ of Lysostaphin $1 \mathrm{mg} \mathrm{ml}^{-1}$ (Sigma) and $3 \mu$ of Nuclease (Pierce) and incubated during $2 \mathrm{~h}$ at $37^{\circ} \mathrm{C}$. After the lysis step, the amount of protein was determined by BCA method (BCA Thermo Scientific) according to the manufacture's protocol. Protein concentration of different samples was equalized by adding phosphate-buffered saline (PBS). The protein samples were mixed with 1 volume of Laemmli buffer and denatured by boiled at $95^{\circ} \mathrm{C}$ for $5 \mathrm{~min}$. The samples were electrophoresed in $12 \%$ sodium dodecyl sulphate (SDS)polyacrylamide duplicated gels at $120 \mathrm{~V}$ for $2 \mathrm{~h}$.

One of each gel was stained with Coomassie (Gel Code ${ }^{T M}$ Blue safe protein stain Thermo Scientific) as loading control. The other was transferred onto Hybridization Nitrocellulose membrane (Millipore) by semi-dry electroblotting. Membranes were blocked overnight with $5 \%$ skimmed milk in PBS containing $0.1 \%$ of Tween 20 (Fisherbrand) and incubated with anti-FLAG antibodies labelled with phosphatase alkaline (Sigma) diluted 1:500 for $2 \mathrm{~h}$ at room temperature. 3XFLAG labelled IcaC protein was detected with the SuperSignal West Pico Chemiluminescent Substrate (Thermo Scientific) following the manufacture's recommendations.

\section{PIA/PNAG quantification}

Cell surface PIA/PNAG exopolysaccharide levels were quantified as previously described (Cramton et al., 1999; Mozos et al., 2013). Briefly, overnight cultures of the strains tested were diluted 1:40 in TSB-glu supplemented with the appropriate concentration of extract and $2 \mathrm{ml}$ of these cell suspensions were used to inoculate sterile 12-well polystyrene microtiter plates (FALCON). After $36 \mathrm{~h}$ of static incubation at $28{ }^{\circ} \mathrm{C}$, the same number of cells of each strain was 
resuspended in $50 \mu \mathrm{l}$ of $0.5 \mathrm{M}$ EDTA ( $\mathrm{pH}$ 8.0). Then, cells were incubated for 5 min at $100{ }^{\circ} \mathrm{C}$ and centrifuged $17,000 \mathrm{~g}$ for $5 \mathrm{~min}$. Each supernatant was incubated with $10 \mu \mathrm{l}$ of proteinase $\mathrm{K}$ at $20 \mathrm{mg} \mathrm{ml}^{-1}$ (Thermo Scientific) for $30 \mathrm{~min}$ at $37^{\circ} \mathrm{C}$. Next, $10 \mu \mathrm{l}$ of Tris-buffered saline $(20 \mathrm{mM}$ Tris- $\mathrm{HCl}, 150 \mathrm{mM} \mathrm{NaCl}$ [pH7.4]) containing $0.01 \%$ of bromophenol blue were added to each sample, and $5 \mu$ of each samples were spotted on a nitrocellulose membrane using a Bio-Dot microfiltration apparatus (Bio-Rad). The membrane was blocked overnight with 5 \% skimmed milk in PBS with $0.1 \%$ of Tween 20 , and incubated for $2 \mathrm{~h}$ with specific anti-PNAG antibodies diluted 1:10,000 (Maira-Litran et al., 2005). Bound antibodies were detected with peroxidase-conjugated goat anti-rabbit immunoglobulin $\mathrm{G}$ antibodies (Jackson ImmunoResearch Laboratories, Inc., West-grove, PA) diluted 1:10,000 and developed using the SuperSignal West Pico Chemiluminescence Substrate (Thermo Scientific). 
Chapter I. A different slant in anti-biofilm drug discovery

Table 1. Strains used in this study.

\begin{tabular}{|c|c|c|}
\hline Strain & Characteristics & Reference \\
\hline $\begin{array}{l}\text { Escherichia coli } \\
\text { XI1Blue }\end{array}$ & Cloning assay cell & (Stratagene) \\
\hline \multicolumn{3}{|c|}{ Staphylococcus aureus } \\
\hline RN4220 & $\begin{array}{l}\text { A mutant of S. aureus strain } 8325-4 \text { that } \\
\text { accepts foreign DNA }\end{array}$ & (Novick, 1990) \\
\hline 15981 & Clinical strain; biofilm positive; rsbU+ & $\begin{array}{l}\text { (Valle et al., } \\
\text { 2003) }\end{array}$ \\
\hline $15981 \Delta \mathrm{ica}$ & $\begin{array}{l}15981 \text { with deletion of the icaADBC } \\
\text { operon }\end{array}$ & $\begin{array}{l}\text { (Toledo-arana et } \\
\text { al., 2005) }\end{array}$ \\
\hline ISP479r & ISP479 with rsbU restored & $\begin{array}{l}\text { (Toledo-arana et } \\
\text { al., 2005) }\end{array}$ \\
\hline ISP479r $\Delta$ ica & $\begin{array}{l}\text { ISP479r with deletion of the icaADBC } \\
\text { operon }\end{array}$ & \\
\hline 132 & MRSA clinical strain; biofilm positive & $\begin{array}{l}\text { (Vergara-Irigaray, } \\
\text { Valle, Merino, } \\
\text { Latasa, Garcia, } \\
\text { Ruiz de los } \\
\text { Mozos, et al., } \\
\text { 2009) }\end{array}$ \\
\hline $132 \Delta \mathrm{ica}$ & $\begin{array}{l}132 \text { with deletion of the ica } A D B C \\
\text { operon }\end{array}$ & $\begin{array}{l}\text { (Vergara-Irigaray, } \\
\text { Valle, Merino, } \\
\text { Latasa, Garcia, } \\
\text { Ruiz de los } \\
\text { Mozos, et al., } \\
2009 \text { ) }\end{array}$ \\
\hline MN8 & Clinical strain. & $\begin{array}{l}\text { (Schlievert et al., } \\
\text { 1982) }\end{array}$ \\
\hline MN8 muc & Spontaneous mutant of MN8 & $\begin{array}{l}\text { (McKenney, } \\
\text { 1999) }\end{array}$ \\
\hline 15981 icaC3xFlag & $\begin{array}{l}15981 \text { strain carrying } 3 x \text { Flag tag epitope } \\
\text { at icaC }\end{array}$ & (Vergara, 2009) \\
\hline 15981 PicaA53 & $\begin{array}{l}15981 \text { strain carrying the } \\
\text { pSA14::PicaA53 plasmid }\end{array}$ & $\begin{array}{l}\text { (Mozos et al., } \\
2013 \text { ) }\end{array}$ \\
\hline $\begin{array}{l}15981 \Delta \text { ica } \\
\text { PicaA53 }\end{array}$ & $\begin{array}{l}15981 \triangle \text { ica strain carrying the } \\
\text { pSA14::PicaA53 plasmid }\end{array}$ & This study \\
\hline
\end{tabular}


Table 2. Plasmids used in this study.

\begin{tabular}{|l|l|l|}
\hline Plasmid & \multicolumn{3}{|c|}{} \\
\hline pSA14 & $\begin{array}{l}\text { Plasmid used for } \\
\text { transcriptional fusions } \\
\text { with E. coli lacZ }\end{array}$ & (Falord et al., 2011) \\
\hline pSA14::PicaA53 & $\begin{array}{l}\text { pSA14 containing icaA } \\
\text { promoter }\end{array}$ & (Mozos et al., 2013) \\
\hline
\end{tabular}




\section{References}

Arciola, C. R., Campoccia, D., Ravaioli, S., \& Montanaro, L. (2015). Polysaccharide intercellular adhesin in biofilm: structural and regulatory aspects. Cellular and Infection Microbiology, 5(February), 1-10. https://doi.org/10.3389/fcimb.2015.00007

Balasubramanian, D., Harper, L., Shopsin, B., \& Torres, V. J. (2017). Staphylococcus aureus pathogenesis in diverse host environments. Pathogens and Disease, 75(1), ftx005. https://doi.org/10.1093/femspd/ftx005

Bergh, V. J. V., Bruzell, E., Hegge, A. B., \& Tønnesen, H. H. (2015). Influence of formulation on photoinactivation of bacteria by lumichrome. Die Pharmazie, 70(9), 574-580. Retrieved from http://www.ncbi.nlm.nih.gov/pubmed/26492641

Brooks, J. L., \& Jefferson, K. K. (2014). Phase Variation of Poly-NAcetylglucosamine Expression in Staphylococcus aureus. PLoS Pathogens, 10(7), e1004292. https://doi.org/10.1371/journal.ppat.1004292

Cerca, N., Jefferson, K. K., Maira-Litrán, T., Pier, D. B., Kelly-Quintos, C., Goldmann, D. A., ... Pier, G. B. (2007). Molecular Basis for Preferential Protective Efficacy of Antibodies Directed to the Poorly Acetylated Form of

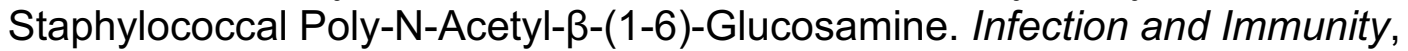
75(7), 3406-3413. https://doi.org/10.1128/IAI.00078-07

Chung, B., Kwon, O.-S., Shin, J., \& Oh, K.-B. (2019). Inhibitory Effects of Streptomyces sp. MBTH32 Metabolites on Sortase A and Sortase AMediated Cell Clumping of Staphylococcus aureus to Fibrinogen. Journal of Microbiology and Biotechnology, 29(10), 1603-1606. https://doi.org/10.4014/jmb.1906.06026

Chung, P. Y., \& Toh, Y. S. (2014). Anti-biofilm agents: recent breakthrough against multi-drug resistant Staphylococcus aureus. Pathogens and Disease, 70(3), 231-239. https://doi.org/10.1111/2049-632X.12141

Cramton, S. E., Gerke, C., Schnell, N. F., Nichols, W. W., \& Götz, F. (1999). The intercellular adhesion (ica) locus is present in Staphylococcus aureus and is required for biofilm formation. Infection and Immunity, 67(10), 5427-5433. Retrieved from http://www.ncbi.nlm.nih.gov/pubmed/10496925

Dakora, F. D., Matiru, V. N., \& Kanu, A. S. (2015). Rhizosphere ecology of lumichrome and riboflavin, two bacterial signal molecules eliciting developmental changes in plants. Frontiers in Plant Science, 6. https://doi.org/10.3389/fpls.2015.00700

Falord, M., Mäder, U., Hiron, A., Débarbouillé, M., \& Msadek, T. (2011). Investigation of the Staphylococcus aureus GraSR regulon reveals novel links to virulence, stress response and cell wall signal transduction 
Chapter I. A different slant in anti-biofilm drug discovery

$\begin{array}{llll}\text { pathways. } & \text { PLoS } & \text { ONE, } & \text { e21323. }\end{array}$

https://doi.org/10.1371/journal.pone.0021323

Falugi, F., Kim, H. K., Missiakas, D. M., \& Schneewind, O. (2013). Role of Protein $A$ in the Evasion of Host Adaptive Immune Responses by Staphylococcus aureus. MBio, 4(5). https://doi.org/10.1128/mBio.00575-13

Gomes, I. M., Marlow, M. A., Pinheiro, M. G., Freitas, M. de F. N. de, Fonseca, F. F., Cardoso, C. A. A., \& Aguiar-Alves, F. (2014). Risk factors for Staphylococcus aureus and methicillin-resistant $S$ aureus colonization among health care workers in pediatrics departments. American Journal of Infection Control, 42(8), 918-920. https://doi.org/10.1016/j.ajic.2014.05.009

Heilmann, C., Schweitzer, O., Gerke, C., Vanittanakom, N., Mack, D., \& Götz, F. (1996). Molecular basis of intercellular adhesion in the biofilm-forming Staphylococcus epidermidis. Molecular Microbiology, 20(5), 1083-1091. Retrieved from http://www.ncbi.nlm.nih.gov/pubmed/8809760

Horie, H., Chiba, A., \& Wada, S. (2018). Inhibitory effect of soy saponins on the activity of $\beta$-lactamases, including New Delhi metallo- $\beta$-lactamase 1 . Journal of Food Science and Technology, 55(5), 1948-1952. https://doi.org/10.1007/s13197-018-3091-4

Jaśkiewicz, M., Neubauer, D., Kazor, K., Bartoszewska, S., \& Kamysz, W. (2019). Antimicrobial Activity of Selected Antimicrobial Peptides Against Planktonic Culture and Biofilm of Acinetobacter baumannii. Probiotics and Antimicrobial Proteins, 11(1), 317-324. https://doi.org/10.1007/s12602-018-9444-5

Jefferson, K. K., Cramton, S. E., Götz, F., \& Pier, G. B. (2003). Identification of a 5-nucleotide sequence that controls expression of the ica locus in Staphylococcus aureus and characterization of the DNA-binding properties of IcaR. Molecular Microbiology, 48(4), 889-899. https://doi.org/10.1046/j.1365-2958.2003.03482.x

Jeffrey H. Miller. (1972). ß-galactosidase assay. In Cold Spring Harbor Laboratory (Ed.), Experiments in Molecular Genetics (pp. 352-355). NY.

Juárez-Verdayes, M. A., Rodríguez-Martínez, S., Cancino-Diaz, M. E., \& Cancino-Diaz, J. C. (2013). Peptidoglycan and muramyl dipeptide from Staphylococcus aureus induce the expression of VEGF-A in human limbal fibroblasts with the participation of TLR2-NFKB and NOD2-EGFR. Graefe's Archive for Clinical and Experimental Ophthalmology, 251(1), 53-62. https://doi.org/10.1007/s00417-012-2130-5

Khazir, J., Mir, B. A., Mir, S. A., \& Cowan, D. (2013). Natural products as lead compounds in drug discovery. Journal of Asian Natural Products Research, 15(7), 764-788. https://doi.org/10.1080/10286020.2013.798314

Kildow, B. J., Conradie, J. P., \& Robson, R. L. (2012). Nostrils of Healthy Volunteers Are Independent with Regard to Staphylococcus aureus 
Carriage. Journal of Clinical Microbiology, 50(11), 3744-3746. https://doi.org/10.1128/JCM.01488-12

Lee, J. C. (1995). Electrotransformation of Staphylococci. In J. A. Nickoloff (Ed.), Electroporation Protocols for Microorganisms (pp. 209-216). New Jersey: Humana Press. https://doi.org/10.1385/0-89603-310-4:209

Li, W., Zhao, X., Zou, S., Ma, Y., Zhang, K., \& Zhang, M. (2012). Scanning assay of $\beta$-galactosidase activity. Applied Biochemistry and Microbiology, 48(6), 603-607. https://doi.org/10.1134/S0003683812060075

Loessner, I., Dietrich, K., Dittrich, D., Hacker, J., \& Ziebuhr, W. (2002). Transposase-Dependent Formation of Circular IS256 Derivatives in Staphylococcus epidermidis and Staphylococcus aureus. Journal of Bacteriology, 184(17), 4709-4714. https://doi.org/10.1128/JB.184.17.47094714.2002

Maira-Litrán, T., Bentancor, L. V., Bozkurt-Guzel, C., O’Malley, J. M., CywesBentley, C., \& Pier, G. B. (2012). Synthesis and Evaluation of a Conjugate Vaccine Composed of Staphylococcus aureus Poly-N-Acetyl-Glucosamine and Clumping Factor A. PLoS ONE, 7(9), e43813. https://doi.org/10.1371/journal.pone.0043813

Maira-Litran, T., Kropec, A., Goldmann, D. a, \& Pier, G. B. (2005). Comparative Opsonic and Protective Activities of Staphylococcus aureus Conjugate Vaccines Containing Native or Deacetylated Staphylococcal Poly-N-Acetyl-(1-6)-Glucosamine. Infection and Immunity, 73(10), 6752-6762. https://doi.org/10.1128/iai.73.10.6752-6762.2005

Majerczyk, C. D., Sadykov, M. R., Luong, T. T., Lee, C., Somerville, G. A., \& Sonenshein, A. L. (2008). Staphylococcus aureus CodY Negatively Regulates Virulence Gene Expression. Journal of Bacteriology, 190(7), 2257-2265. https://doi.org/10.1128/JB.01545-07

Martin-Lopez, J. V., Perez-Roth, E., Claverie-Martin, F., Diez Gil, O., Batista, N., Morales, M., \& Mendez-Alvarez, S. (2002). Detection of Staphylococcus aureus Clinical Isolates Harboring the ica Gene Cluster Needed for Biofilm Establishment. Journal of Clinical Microbiology, 40(4), 1569-1570. https://doi.org/10.1128/JCM.40.4.1569-1570.2002

Martins, S. A. R., Combs, J. C., Noguera, G., Camacho, W., Wittmann, P., Walther, R., ... Behrens, A. (2008). Antimicrobial Efficacy of Riboflavin/UVA Combination (365 nm) In Vitro for Bacterial and Fungal Isolates: A Potential New Treatment for Infectious Keratitis. Investigative Opthalmology \& Visual Science, 49(8), 3402. https://doi.org/10.1167/iovs.07-1592

McKenney, D. (1999). Broadly Protective Vaccine for Staphylococcus aureus Based on an in Vivo-Expressed Antigen. Science, 284(5419), 1523-1527. https://doi.org/10.1126/science.284.5419.1523 
Merino, N., Toledo-Arana, A., Vergara-Irigaray, M., Valle, J., Solano, C., Calvo, E., ... Lasa, I. (2009). Protein A-mediated multicellular behavior in Staphylococcus aureus. Journal of Bacteriology, 191(3), 832-843. https://doi.org/10.1128/jb.01222-08

Mozos, I. R. de L., Vergara-Irigaray, M., Segura, V., Villanueva, M., Bitarte, N., Saramago, M., ... Toledo-Arana, A. (2013). Base Pairing Interaction between 5'- and 3'-UTRs Controls icaR mRNA Translation in Staphylococcus $\begin{array}{llll}\text { aureus. } & \text { PLoS Genetics, } & \text { 9(12), }\end{array}$ https://doi.org/10.1371/journal.pgen.1004001

Novick, R. P. (1990). Molecular biology of the staphylococci. VCH Publishers, 137.

Palomo, S., González, I., de la Cruz, M., Martín, J., Tormo, J., Anderson, M., ... Genilloud, O. (2013). Sponge-Derived Kocuria and Micrococcus spp. as Sources of the New Thiazolyl Peptide Antibiotic Kocurin. Marine Drugs, 11(12), 1071-1086. https://doi.org/10.3390/md11041071

Pereira, F., Almeida, J. R., Paulino, M., Grilo, I. R., Macedo, H., Cunha, I., ... Gaudêncio, S. P. (2020). Antifouling Napyradiomycins from Marine-Derived Actinomycetes Streptomyces aculeolatus. Marine Drugs, 18(1), 63. https://doi.org/10.3390/md18010063

Rahman, M. M., \& Richardson, A. (2010). Antibacterial activity of propolis and honey against Staphylococcus aureus and Escherichia coli. African Journal of Microbiology Research, 4(18), 1872-1878.

Rajamani, S., Bauer, W. D., Robinson, J. B., Farrow, J. M., Pesci, E. C., Teplitski, M., ... Phillips, D. A. (2008). The Vitamin Riboflavin and Its Derivative Lumichrome Activate the LasR Bacterial Quorum-Sensing Receptor. Molecular Plant-Microbe Interactions ${ }^{\circledR}, \quad 21(9), \quad$ 1184-1192. https://doi.org/10.1094/MPMI-21-9-1184

Schenk, S., \& Laddaga, R. A. (1992). Improved method for electroporation of Staphylococcus aureus. FEMS Microbiology Letters, 94(1-2), 133-138. https://doi.org/10.1111/j.1574-6968.1992.tb05302.x

Schlievert, P. M., Osterholm, M. T., Kelly, J. A., \& Nishimura, R. D. (1982). Toxin and enzyme characterization of Staphylococcus aureus isolates from patients with and without toxic shock syndrome. Annals of Internal Medicine, 96(6 Pt 2), 937-940. Retrieved from http://www.ncbi.nlm.nih.gov/pubmed/7091971

Stowe, S. D., Richards, J. J., Tucker, A. T., Thompson, R., Melander, C., \& Cavanagh, J. (2011). Anti-Biofilm Compounds Derived from Marine Sponges. Marine Drugs, 9(10), 2010-2035. https://doi.org/10.3390/md9102010

Swinney, D.C. (2013) Phenotypic vs. Target-Based Drug Discovery for First-in- 
Class Medicines. Clin Pharmacol Ther 93: 299-301 http://doi.wiley.com/10.1038/clpt.2012.236.

Toledo-arana, A., Merino, N., Débarbouillé, M., Penadés, J. R., Lasa, I., Vergarairigaray, M., \& De, M. (2005). Staphylococcus aureus Develops an Alternative, ica- Independent Biofilm in the Absence of the arIRS TwoComponent System Staphylococcus aureus Develops an Alternative, icaIndependent Biofilm in the Absence of the arIRS Two-Component System $\dagger$. Journal of Bacteriology, 187(15), 5318-5329. https://doi.org/10.1128/jb.187.15.5318

Valle, J., Echeverz, M., \& Lasa, I. (2019). $\sigma$ B Inhibits Poly- N -Acetylglucosamine Exopolysaccharide Synthesis and Biofilm Formation in Staphylococcus aureus. Journal of Bacteriology, 201(11). https://doi.org/10.1128/JB.0009819

Valle, J., Toledo-Arana, A., Berasain, C., Ghigo, J.-M., Amorena, B., Penadés, J. R., \& Lasa, I. (2003). SarA and not $\sigma B$ is essential for biofilm development by Staphylococcus aureus. Molecular Microbiology, 48(4), 1075-1087. https://doi.org/10.1046/j.1365-2958.2003.03493.x

Verderosa, A. D., Dhouib, R., Fairfull-Smith, K. E., \& Totsika, M. (2019). Nitroxide Functionalized Antibiotics Are Promising Eradication Agents against Staphylococcus aureus Biofilms. Antimicrobial Agents and Chemotherapy, 64(1). https://doi.org/10.1128/AAC.01685-19

Vergara-Irigaray, M., Valle, J., Merino, N., Latasa, C., Garcia, B., Mozos, I. R. de Ios, ... Lasa, I. (2009). Relevant Role of Fibronectin-Binding Proteins in Staphylococcus aureus Biofilm-Associated Foreign-Body Infections. Infection and Immunity, 77(9), 3978-3991. https://doi.org/10.1128/iai.0061609

Vergara-Irigaray, M., Valle, J., Merino, N., Latasa, C., Garcia, B., Ruiz de los Mozos, I., ... Lasa, I. (2009). Relevant Role of Fibronectin-Binding Proteins in Staphylococcus aureus Biofilm-Associated Foreign-Body Infections. Infection and Immunity, 77(9), 3978-3991. https://doi.org/10.1128/IAI.00616-09

Vergara, M. (2009). Study of the role of LPXTG proteins, wall teichoic acids and the global regulator Rot in the biofilm formation process of Staphylococcus aureus.

Winstel, V., Missiakas, D., \& Schneewind, O. (2018). Staphylococcus aureus targets the purine salvage pathway to kill phagocytes. Proceedings of the National Academy of Sciences, 115(26), 6846-6851. https://doi.org/10.1073/pnas.1805622115 


\section{CHAPTER II.}

Inhibiting the Two-Component System GraXRS with Verteporfin to combat Staphylococcus aureus infections 
upna 


\section{Abstract}

Infections caused by Staphylococcus aureus pose a serious and sometimes fatal health issue. With the aim of exploring a novel therapeutic approach, we chose GraXRS, a Two-Component System (TCS) that determines bacterial resilience against host innate immune barriers, as an alternative target to disarm $S$. aureus. Following a drug repurposing methodology, and taking advantage of a singular staphylococcal strain that lacks the whole TCS machinery but the target one, we screened 1.280 off-patent FDA-approved drug for GraXRS inhibition. Reinforcing the connection between this signaling pathway and redox sensing, we found that antioxidant and redox-active molecules were capable of reducing the expression of the GraXRS regulon. Among all the compounds, verteporfin (VER) was really efficient in enhancing PMN-mediated bacterial killing, while topical administration of such drug in a murine model of surgical wound infection significantly reduced the bacterial load. Experiments relying on the chemical mimicry existing between VER and heme group suggest that redox active residue C227 of GraS participates in the inhibition exerted by this FDAapproved drug. Based on these results, we propose VER as a promising candidate for sensitizing $S$. aureus that could be helpful to combat persistent or antibiotic-resistant infections. 
upna 


\section{Introduction}

Though the undeniable efficiency of anti-infective measures like vaccines and antimicrobials have made us believe that infectious diseases are nowadays under control, nothing could be further from the truth. An increasing number of studies alert that unless actions are taken, infections caused by antibioticresistant bacteria will kill an extra 10 million people a year worldwide by 2050 (Kelly and Davies, 2017).

Staphylococcus aureus is one of the bacterial species whose manage is especially challenging due to the emergence of methicillin-resistant (MRSA) strains. With a population-weighted mean of invasive MRSA strains of about $17 \%$ in terms of European prevalence (Rasigade et al., 2014), the major health care concern related to MRSA incidence lies in the limitations of currently approved treatments, which, in turn, leads to high rates of morbidity and mortality even in industrialized nations.

Despite of being an inoffensive colonizer of the nasal epithelium of one-third of the general population (Wertheim et al., 2005), Staphylococcus aureus might become a dangerous life-threatening pathogen when it defeats host immune system, crosses the epithelial barrier and get access to deeper tissues like blood, dermis, gastrointestinal tract, heart valves or bones (Wertheim et al., 2005; Balasubramanian et al., 2017). This biological versatility is based on a highly orchestrated regulation of circuits that sense a plethora of environmental signals and modulate gene expression for fine tuning crucial traits like cell-wall structure, biofilm formation or resistance to antibiotics. The core feature of such circuits is the two-component-signaling transduction system (TCS) (Stock et al., 2000), which is actually one of the most conserved and effective mechanisms in nature for coupling external stimuli and gene expression. In its most basic form, a canonical TCS normally consists of a membrane-bound histidine kinase and a cytosolic response regulator that, once phosphorylated, elicit appropriate 
changes in the cell by regulating gene expression, protein interactions, or enzymatic activity (Capra and Laub, 2012).

Over the last decade, the scientific community has gained in-depth knowledge of the genes affected by specific staphylococcal TCSs, giving rise to a vast body of bibliography and information about mutants in the respective sensor kinases, response regulators and auxiliary genes. Thus, the pivotal role of AgrCA and SaeRS TCSs on virulence gene expression or the involvement of BraRS and GraXRS in antibiotic resistance has been studied in great detail (Kawada-Matsuo et al., 2011; Falord et al., 2011; Boyle-Vavra et al., 2013; Haag and Bagnoli, 2015). Furthermore, since TCSs are a matter of life and death to bacteria and they are not present in host's cells, these regulatory pathways have always been listed as promising antibacterial targets. Precisely based on the assumption that solution to present-day therapeutic limitations might somehow lie on impairing the way Staphylococcus senses and integrates environmental stimuli, significant effort in the form of ambitious High Throughput Screenings (HTSs) and Structure-Based Virtual Screenings (SBVSs) has been done to find new molecules with inhibitory effects on staphylococcal sensor kinases (Bem et al., 2015). However, with few exceptions such as the molecule named walkmycin B (Okada et al., 2010), biochemical screens normally identify a high number of compounds acting through nonspecific inhibitory mechanisms and thus render non-viable drugs in terms of clinical application (Hilliard et al., 1999; Gotoh et al., 2010; Bem et al., 2015).

With the aim of designing a whole-cell drug discovery tool that could complement in silico docking and crystallographic analysis of kinase-ligands structure in TCS-targeting approaches, we decided to explore the potential of a recently developed staphylococcal strain that lacks the whole non-essential TCS machinery ( $\triangle X V$ strain) (Villanueva et al., 2018). Among all the TCSs whose individual contribution to a specific $S$. aureus phenotype has been defined, and based on its overall responsibility for resistance to host defenses like 
polymorphonuclear cells (PMNs) or cationic antimicrobial peptides, we selected GraXRS as a candidate of therapeutic target (Kraus et al., 2008; Falord et al., 2011; Yang et al., 2012; Cheung et al., 2014; Chaili et al., 2016). Additional evidence supporting our choice was given by a recent work showing that $S$. aureus uses this regulatory system to sense and adapt to the acidified phagolysosome in macrophages (Flannagan et al., 2018), but also by several previous studies unveiling the potential of GraXRS to impact the bacterial capacity to colonize and survive on aortic valves in a rabbit endocarditis infection model (Cheung et al., 2014) or to play a crucial function in a murine model of systemic infection (Kraus et al., 2008). Most of these preceding articles conclude that mechanisms underlying GraXRS activity are related with changes in bacterial surface charge via its target downstream gene $m p r F$ and the operon ditABCD (Falord et al., 2011; Yang et al., 2012; Muzamal et al., 2014; Cheung et al., 2014).

In this study, we have used the $S$. aureus strain deprived of fifteen TCS (Villanueva et al., 2018) and isogenic derivatives containing exclusively the GraXRS TCS as a whole-cell platform to identify drugs that specifically target this signaling pathway. Upon evaluating the GraXRS-blocking activity of 1280 FDAapproved off-patent drugs, we found that molecules with antioxidant activity as acetylsalicylic acid, ascorbic acid, the porphyrin derivative verteporfin, or the flavonoid hesperidin, are capable of inhibiting the activity of GraXRS-dependent promoters. Among all the compounds, only verteporfin made a significant contribution to the susceptibility of $S$. aureus to human PMNs-mediated killing and rendered lower levels of bacterial colonization when its effect was assessed using an in vivo murine model. Though further analysis is needed to fully understand the precise molecular targets of verteporfin, data presented in this work suggest that the redox-active cysteine of GraS is required for this molecule to exert its inhibiting effect. Altogether, our results enlighten the potential of verteporfin as a supplement and(or) alternative antimicrobial therapy and provide 
Chapter II: Inhibiting the TCS GraXRS with Vertepofin

evidence that this compound could be included in a recently described category of drugs known as "Potential Drugs for Repurposing against Infectious Agents". 
upna 


\section{Results}

\section{Design and validation of a GraXRS-focused screening platform}

With the aim of designing a highly specific GraXRS-targeting screening assay, we first restored the GraXRS TCS into the chromosome of $S$. aureus $\triangle X V$ strain, which only contains the essential WalKS TCS system in its genome. The resulting $S$. aureus $\triangle \mathrm{XV}$ Gra-RES strain, together with the corresponding $S$. aureus MW2 wild type strain and the single GraXRS mutant derivative, were transformed with two different reporter plasmids in which lacZ expression depends on the GraXRS-regulated promoters of mprF and dltX(Falord et al., 2011). As shown in figure 1, transcriptional activity of reporter genes was barely detectable in the GraXRS deficient strains (single and multiple $\triangle X V$ mutants), whereas $m p r F$ and dltX-based reporter constructs were highly induced in the GraXRS containing strains (wild type and $\triangle X V$ GraRES). As an additional test for evaluating the behavior of the reporter strain-set, positive response of the GraXRS-dependent promoters to the presence of sublethal concentrations of colistin was also analyzed. Noticeably, and confirming the concept of TCS as selfsufficient modules previously envisioned (Villanueva et al., 2018), lacZ expression driven by dltX promoter was essentially equal in the wild type and graXRS restored genetic backgrounds. This result validates both the use of the GraXRS restored strain and dltXP::lacZ transcriptional fusion for high-throughputscreening designs aimed at the discovery of GraXRS-blocking drugs and molecules. 
A

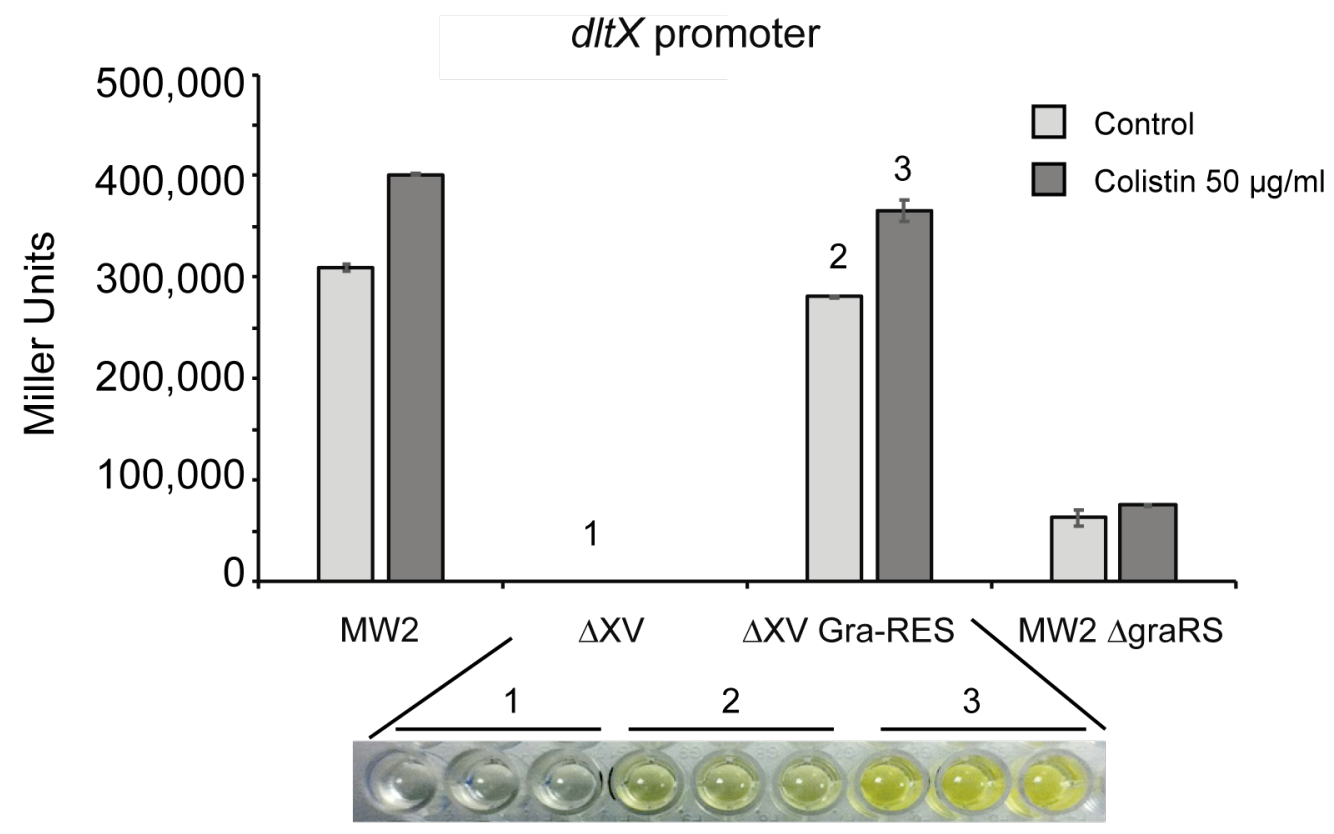

B

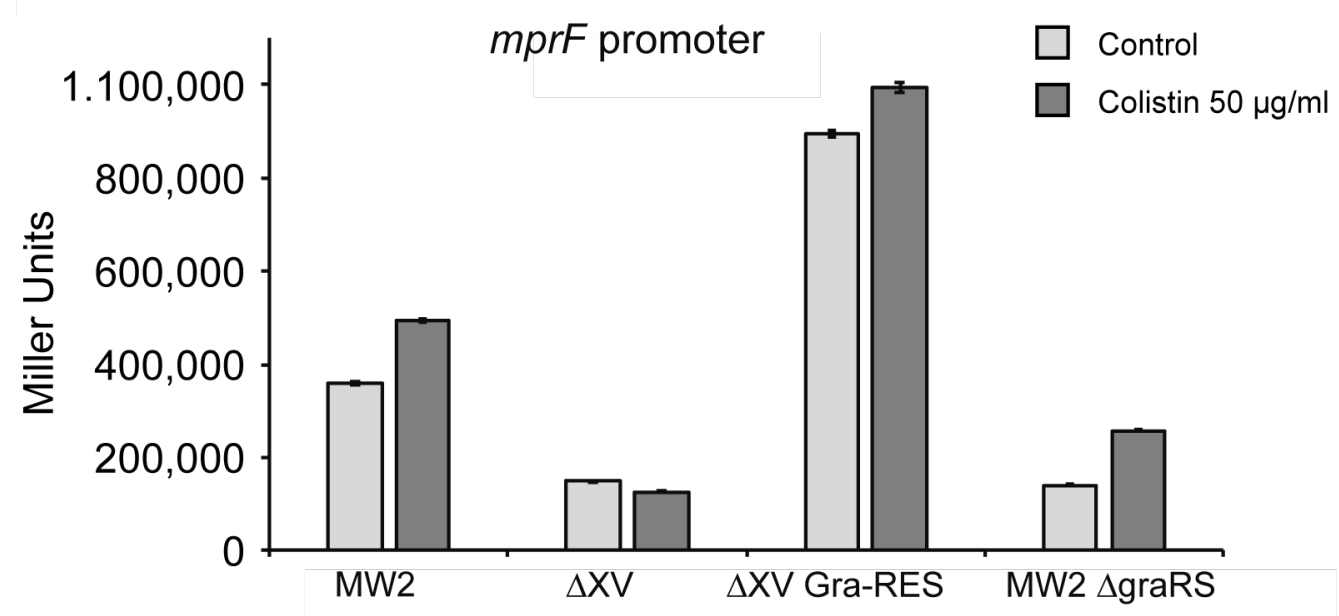

Figure 1. Validation of GraXRS-dependent transcriptional fusions. Graphic illustration of GraXRS-dependent activity of (A) dltX and (B) $m p r F$ promoters in $S$. aureus MW2 wild type, $\triangle \mathrm{XV}, \triangle \mathrm{XV}$ Gra-RES and $\triangle \mathrm{graRS}$ strains. Transcriptional activity in TSB medium (light grey bars) and TSB supplemented with colistin $50 \mu \mathrm{g} / \mathrm{ml}$ (dark grey bars) is presented. Means and standard deviations values are shown from at least three independent experiments. A visual example showing different degrees of GraXRS activity ((1) $\triangle X V$, (2) $\triangle X V$ Gra-RES and (3) $\triangle X V$ Gra-RES in the presence of colistin) in the 96-well format is also shown. 


\section{Primary and secondary screenings}

From the initial screening of the 1.280 drugs included in the Prestwick library (http://www.prestwickchemical.com/libraries-screening-lib-pcl.html), we selected 77 compounds that led to reduced activity of dltX promoter by more than $55 \%$ as determined by beta-galactosidase activity. Because the intention of this work was to repurpose those FDA-approved drugs that specifically targeted GraXRSmediated signaling pathway, and this TCS has been shown to be crucial for bacterial growth under acidic conditions (Villanueva et al., 2018), the capacity of the selected compounds to affect $\mathrm{OD}_{600}$ values at $\mathrm{pH}$ 5,5 was tested, expecting a significant growth arrest in the presence of GraXRS-blocking compounds. Following a similar approach, the dose-response behavior of selected compounds was evaluated. To do so, both bacterial growth and ditxP transcriptional activity were quantitatively assessed in the presence of variable concentrations, ranging from 0 to $20 \mu \mathrm{M}$, of selected drugs (figure $2 \mathrm{C}$ ).

In order to reinforce the involvement of GraXRS TCS in the phenotypic outcomes rendered by the drugs to be chosen, their ability to down regulate the GraXRS-dependent alternative $m p r F$ promoter was considered as an additional selective criterion.

To verify the specificity of GraXRS for the selected compounds, we restored a different TCS, saeRS, into the $\triangle \mathrm{XV}$ genome. In this case, the reporter lacZ gene was transcriptionally fused to sec4 promoter, which has previously described as part of SaeRS regulon (Liu et al., 2016). No shift in the transcription levels of sec4P::lacZ fusion appeared when $\triangle \mathrm{XV}$ Sae-RES were incubated in the presence of each selected compound.

Finally, and though equivalency between wild type and GraXRS restored strains in terms of GraXRS-mediated sensing had been previously validated, the possibility that other TCSs or derived circuits absent on $\triangle \mathrm{XV}$ Gra-RES could somehow affect dlt $X$ transcriptional activity was considered. In order to address 
this issue, the MW2 wild type strain was transformed with the dltX-derived reporter plasmid and beta-galactosidase activity was measured in the absence and presence of mentioned compounds.

As shown in figure 2, the whole consecutive screening process significantly restricted the number of active compounds from almost 80 to 5 . Acetylsalicylic acid (ASA), hesperidin (HES), ascorbic acid (VITC), verteporfin (VER) and troglitazone (TGZ) were capable of inhibiting bacterial growth under acidic conditions, affected mprFP activity negatively and exerted a suppressing effect on ditXP in the wild type genetic background. Among this final group of drugs, TGZ displayed an additional negative impact on SaeRS, and thus was firstly considered as a potential multi-target drug. However, since this molecule was withdrawn in 2000 due to high risk of hepatotoxicity, only ASA, HES, VITC and VER were contemplated as real candidates for therapeutic reposition. Curiously, though these four compounds show no common (known) pharmacological features, they are all chemically classified as redox-active drugs. 

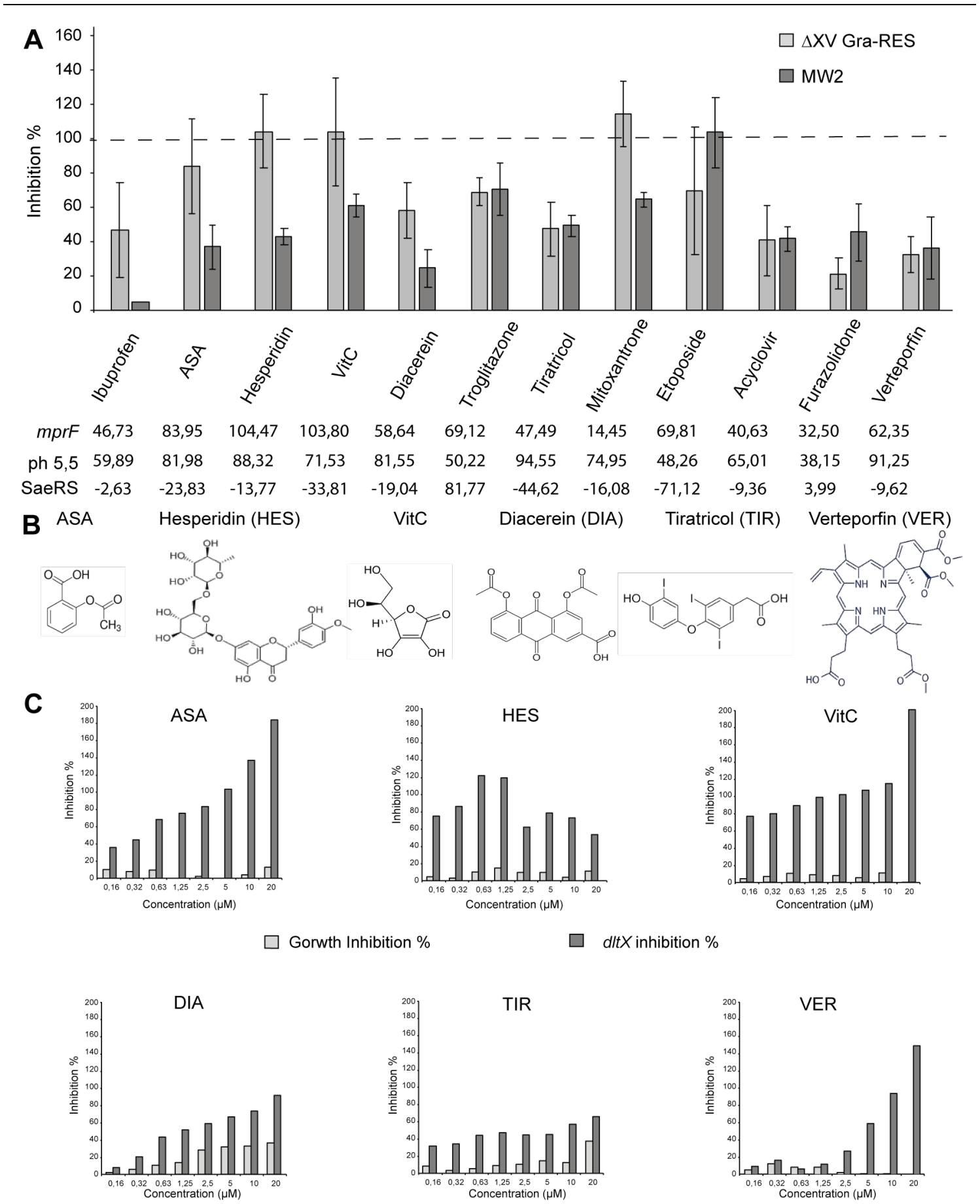

Figure 2. Screening results. (A) Graphic illustration of GraXRS-dependent activity of dltX promoter in the presence of selected drugs $(10 \mu \mathrm{M})$ in $\mathrm{S}$. aureus $\triangle \mathrm{XV}$ Gra-RES (light gray bars) and MW2 wild type strains (dark grey bars). Data are presented as relative M.U. values obtained in the absence of any compound for $S$. aureus $\triangle \mathrm{XV}$ Gra-RES and MW2 wild type strains respectively. Values exceeding $100 \%$ correspond to those cases where the observed transcriptional activity is lower to that showed by $\triangle \mathrm{XV}$ and/or bacterial growth is inhibited. Standard deviations values correspond to at least three independent experiments. Results regarding additional selection criteria including the repression of the GraXRS-dependent alternative mprF promoter, significative inhibition of wild type strain under acidic growth conditions $(\mathrm{pH} \mathrm{5,5)}$ and transcriptional co-inhibition of the SaeRS-dependent sec4 promoter are presented. (B) Structure of selected drugs included in drug bank profiles (https://www.drugbank.ca) is shown. (C) Graphic illustration of Dose Dependency profiles in terms of dltX inhibition exhibited by selected compounds. Data are presented as relative M.U. values obtained in the absence of any compound for $S$. aureus $\triangle X V$ Gra-RES (dark grey bars). Relative percentage of survival in the presence of increasing doses of compounds is also included (light grey bars). 
In vitro effect of selected compounds: Phagocytosis and killing of S. aureus by human PMNs

Deepening into the anti-virulence potential of selected drugs, we next proceeded with an in vitro assay in which the bacterial susceptibility to phagocytosis and killing by human polymorphonuclear cells was assessed. Considering that GraXRS has been shown to have a pivotal role for $S$. aureus to resist PMN attack (Flannagan et al., 2018), we isolated this cellular fraction from peripheral human blood and the effect of ASA, HES, VITC and VER on MW2 susceptibility to these immune cells was assessed. In all cases the process was boosted by opsonic antibodies naturally present in human sera due to unavoidable exposure to $S$. aureus. After incubating PMNs-S. aureus MW2 suspensions for 30 minutes in the absence or presence of the four selected compounds (5 $\mu \mathrm{M}$ each), removal of extracellular bacteria via gentamicin exposure, and subsequent lysis of eukaryotic cells at basic $\mathrm{pH}$, bacterial viability was estimated via plate counting. Data shown in figure 3 prompted us to conclude that the presence of ASA, HES and VITC caused a slight increase in the sensitivity to PMN attack, while the effect of VER on reducing the number of surviving intracellular bacteria was substantially obvious and statistically significant (figure 3). As a result, from this in vitro approach, we chose VER as the sole candidate to proceed with the next assays. 


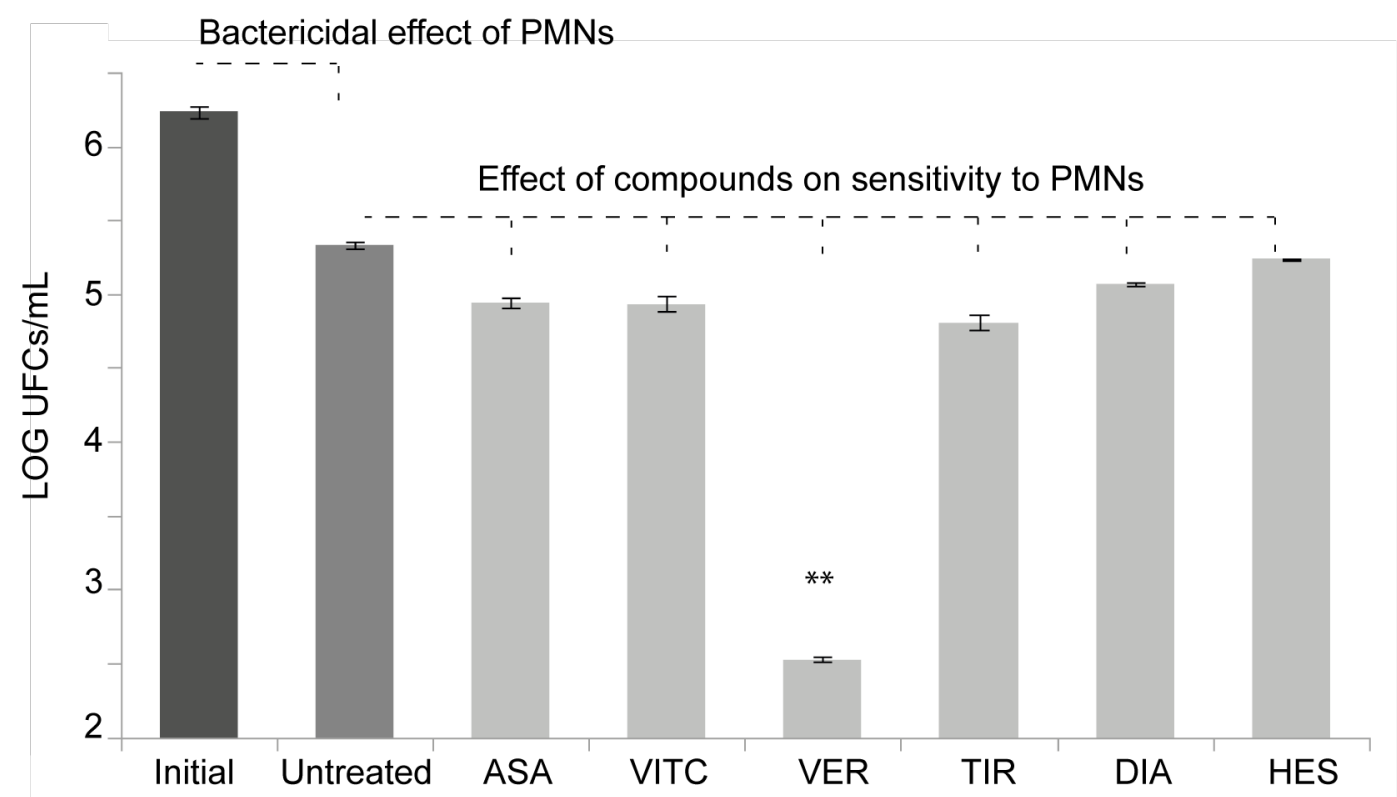

Figure 3. Effect of selected drugs in the susceptibility to phagocytosis and killing by human PMNs. Graphical scheme of bacterial counts expressed as log values after incubating PMNs and S. aureus MW2 wild type suspensions for 30 min in the presence or absence of four selected compounds (5 $\mu \mathrm{M}$ each), subsequent gentamicin treatments and lysis of eukaryotic cells (see Materials and Methods section). Means and standard deviations are presented, illustrating the bactericidal effect of PMNs and the additional contribution of ASA, VITC, VER, TIR, DIA and HES. In the case of VER, two asterisks denote an associated $p$ value of 0,006 when ANOVA and Tukey's pairwise post hoc tests were applied according to prior normality and homoscedasticity tests. 


\section{Effect of Verteporfin in a murine model of wound infection}

Following on from the in vitro testing, we next evaluated VER using the murine model of wound (or surgical site) infection. In this in vivo approach, a silk suture contaminated with $S$. aureus MW2 or MW2 $\Delta g r a X R S$ strain $\left(4,5 \times 10^{5} \mathrm{CFUs}\right.$ $\mathrm{cm}^{-1}$ ) was used for sewing up a previous incision on the back of the mice. VER was topically applied 2 and 24 hours after suture implantation using hydrogelbased formulations that contained either no active ingredient or the porphyrin under study at a low $(0,125 \mathrm{mg} / \mathrm{kg})$ or a high $(2,5 \mathrm{mg} / \mathrm{kg})$ dose. Assessment of the infection was performed by counting viable bacteria in tissue homogenates that were obtained upon animal euthanasia, 24 hours after the last treatment.

As shown in figure 4 , the significantly lower quantity of viable bacteria present in tissue samples that had been infected with the GraXRS deficient strain unveiled the critical role of this TCS in surgical wound infections. When the effect of VER was assessed, data showed that topical administration of this drug significantly reduced the bacterial load in a dose-dependent manner. Noticeably, application of VER at a low dose led to a similar degree of bacterial colonization to that followed by the implantation of sutures that had been contaminated with the GraXRS lacking strain. While such a result reinforces the potential of VER as a GraXRS inhibitory drug, its specificity is suggested by the fact that the observed outcome after treatment of wounds infected with the wild type strain is certainly evident, but it becomes almost imperceptible in the case of $\Delta g r a X R S$-associated infection. Equally certain, however, is that high doses of VER could exert a GraXRS-independent and/or antibiotic effect. 


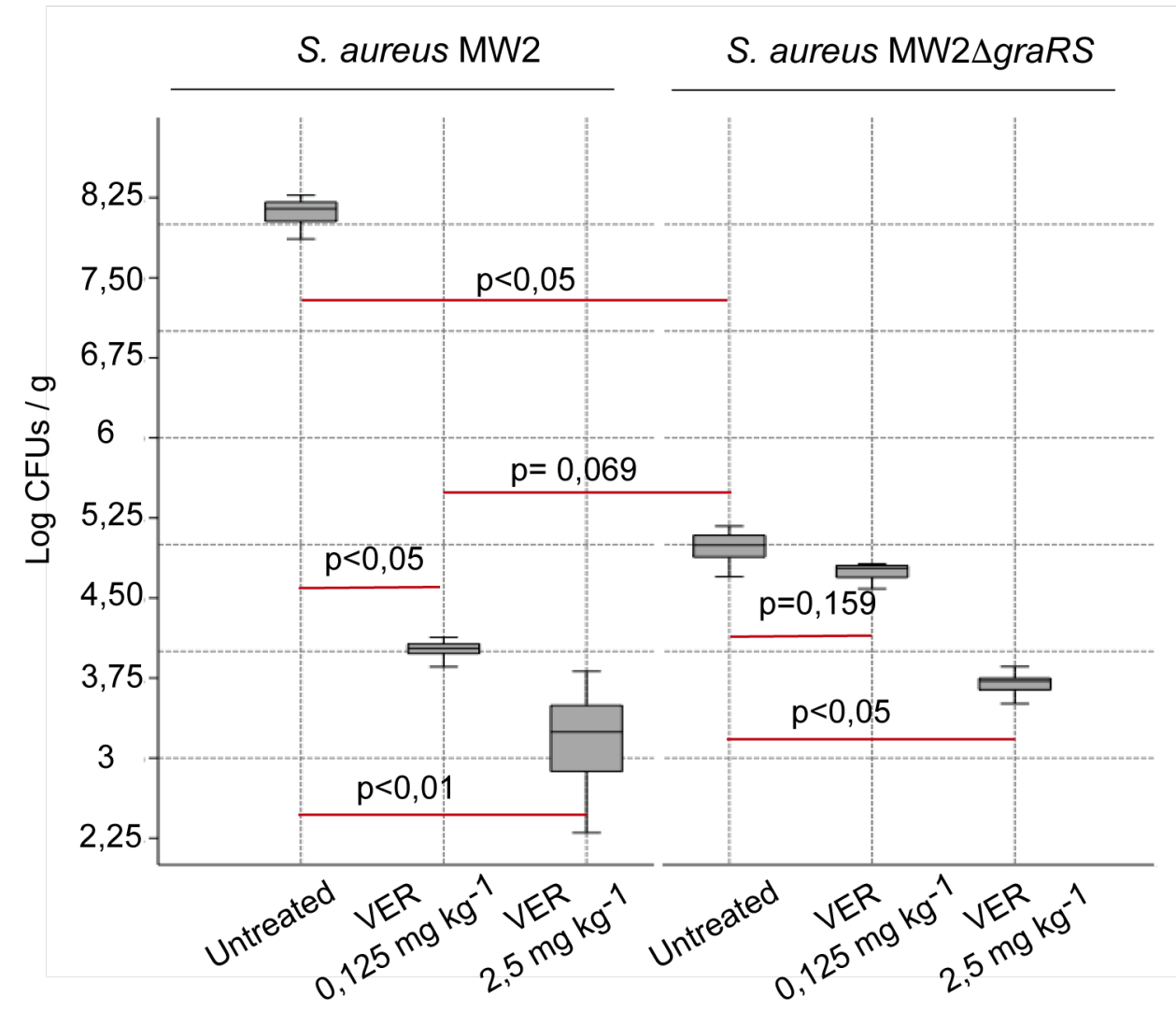

Figure 4. Effect of VER in a murine model of surgical wound infection. BOX-PLOT illustration (PAST statistical package) of bacterial counts expressed as log values per gram of wound tissue homogenates. Different treatments include the topical administration of hydrogel-based formulations with two doses $(0,125$ and $2,5 \mathrm{mg} \mathrm{kg}-1)$ of VER, 2 and 24 hours after making an incision that was immediately infected with a surgical suture contaminated with $4 \times 10^{5}$ CFUs of $S$. aureus MW2 wild type or $\triangle$ graRS strain. Hydrogel without any active pharmaceutical ingredient was applied to control mice. All the animals were euthanized 24 hours after the last treatment. Apart from visual interpretation in accordance to IQR overlapping, data were statistically analyzed via Kruskal-Wallis and post hoc Mann-Whitney test. Corrected p-values corresponding to relevant post hoc statistical comparisons are also shown. 


\section{Exploring the mechanistic basis of verteporfin}

Because VER is a tetradentate chelating porphyrin(Eales et al., 2018) that might be involved in redox sensing, just like heme complex, and such molecules are normally sensed through thiol-based switches, we also analyzed the contribution of the single redox-active cysteine present in GraS, C227, to VER effect (Shimizu et al., 2019). To do so, C227 was mutated to S or A in $\Delta$ XV GraRES background and transcriptional activity of dltXP in the resulting $\triangle X V$ GraRES S(C227-S) and $\triangle X V$ Gra-RES S(C227-A) strains was measured. An additional strain in which GraS H129 amino acid, the residue that undergoes phosphorylation upon activation of the kinase, had been mutated to $Q$ was also constructed and included as a reference of complete GraXRS inactivation. As shown in figure $5 \mathrm{~A}$, data verified that replacement of cysteine by another residue had a negative impact on GraXRS activity, being such an outcome dependent on the polarity of the substituted amino acid. Thus, C227-A (non-polar) GraS isoform led to a lower degree of transcriptional activity of $\operatorname{dlt} X P$ in comparison to that showed by the isoform in which $\mathrm{C} 227$ had been mutated to the polar amino acid serine. In accordance with this observation, bacterial growth arrest under acidic conditions, a phenotype that strictly reflects GraXRS status, also showed dependence on the mutation polarity (fig. 5B). When the effect of VER was assessed, transcriptional data revealed that GraXRS repression led by mutations was far from being as drastic as the one achieved by VER (fig. 5A), discarding the possibility of considering the $\mathrm{C} 227$ redox switch as the exclusive mechanism underlying VER effect. However, impairment of the signaling via C227 resulted in the insensitivity to VER, fact that suggests that intermolecular cysteine-disulfidebond formation is required, though not entirely, for VER to have a blocking GraXRS-dependent effect. 


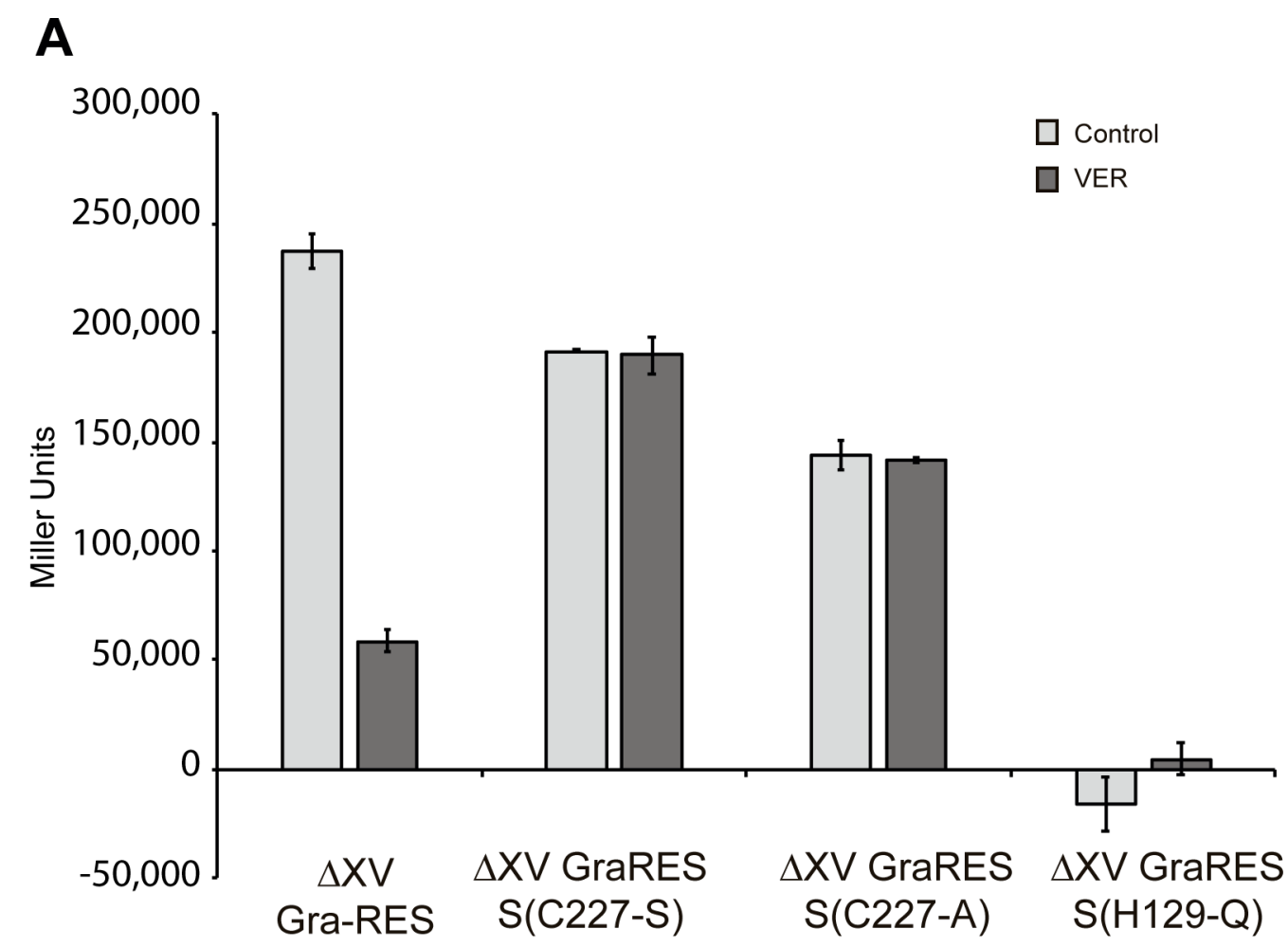

B

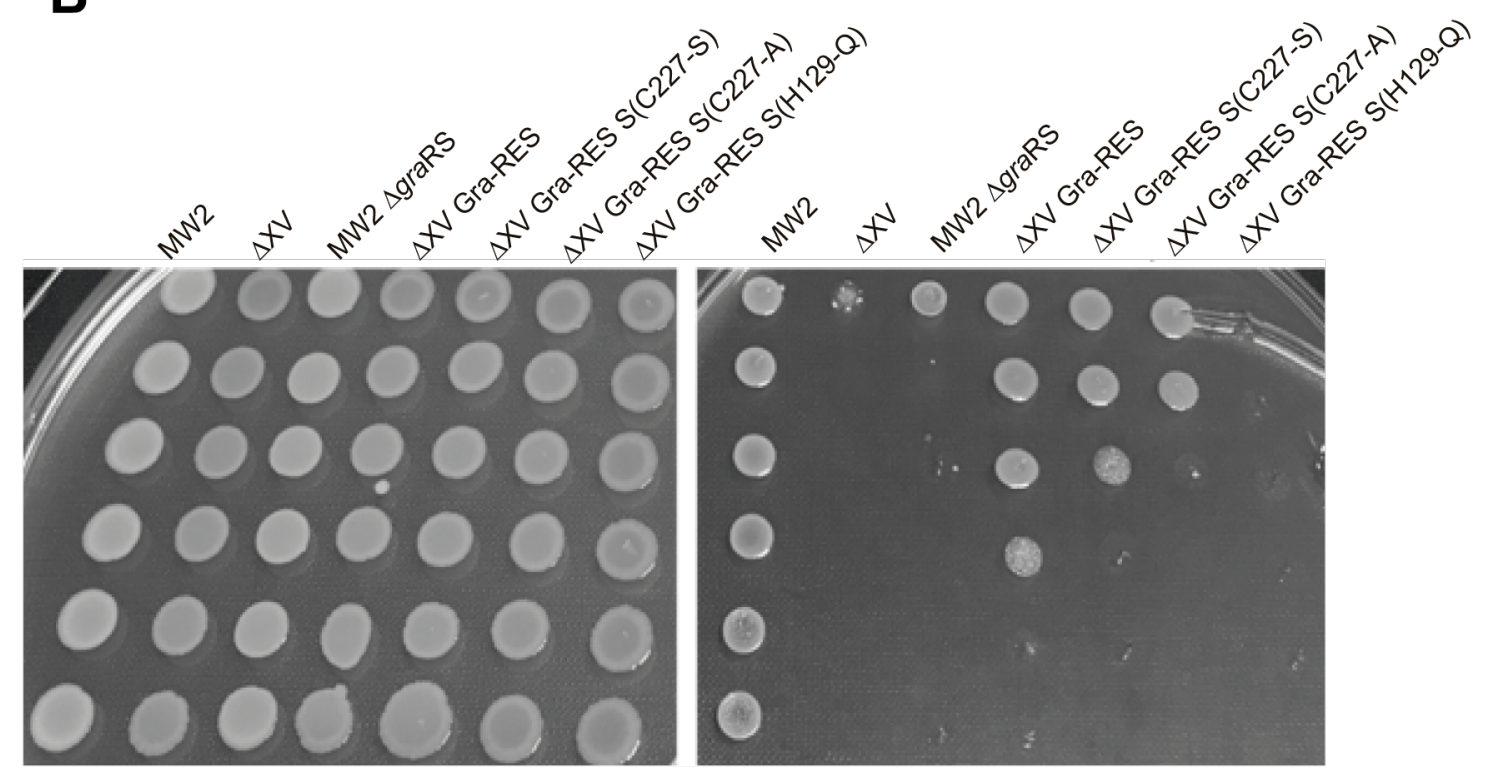

$\mathrm{pH} 7$

$\mathrm{pH} 4,5$

Figure 5. C227-mediated redox switch involvement in the sensitizing effect exerted by VER. (A) Transcriptional activity of GraXRS-dependent dltX promoter in S. aureus $\triangle X V$ Gra-RES, $\triangle X V$ Gra-RES S(C227-S), $\triangle X V$ Gra-RES S(C227-A) and $\triangle X V$ Gra-RES $S(H 129-\mathrm{Q})$ strains is illustrated both in the presence (dark grey bars) or absence (light gray bars) of VER $(10 \mu \mathrm{M})$. Means and standard deviations values are shown form at least three independent experiments. (B) Pictures illustrating the capacity of serially-diluted suspensions of bacterial strains $S$. aureus MW2 wild type, $\triangle X V, \triangle$ graRS, $\triangle X V$ Gra-RES, $\triangle X V$ Gra-RES $S(C 227-S), \Delta X V$ Gra-RES S(C227-A) and $\triangle X V$ Gra-RES S(H129-Q) to grow in neutral (left) and acidified (right) TSA medium are also included in this figure. 


\section{Discussion}

Current strategies aimed at antimicrobial discovery prioritize innovative concepts like alternative molecular mechanisms of action, new natural product sources, pro-drugs, or even approved compounds that were originally intended for other therapeutic indications, as it is the case of the present work (Statement of Antimicrobial drug discovery, EASAC-2014 (van der Meer et al., 2014)). Particularly speaking of $S$. aureus, and discarding the essential TCS WalKR/S as the antibiotic target per excelence, continuous efforts are being made toward the discovery of inhibitors of TCS involved in virulence and biofilm formation (for review (Thangamani et al., 2016; Kong et al., 2016; Yeo et al., 2018)). Impairment of these non-essential biological pathways has the advantage of requiring a lower plasmatic dose compared with a MIC, reducing the tendency to resistance and minimizing side effects on neutral and beneficial microbiota that colonize treated human or animal hosts (Thangamani et al., 2015). Up to date, several novel and previously approved drugs with the capacity to exert an inhibitory effect on Agr, SaeRS, and ArIRS TCSs have been described (for review (Thangamani et al., 2016; Kong et al., 2016; Yeo et al., 2018)) but, to our knowledge, GraXRS had never been considered as a target for disarming $S$. aureus. The involvement of this TCS in the resistance to antimicrobial peptides and macrophages had already been envisioned in several occasions (Li et al., 2007; Falord et al., 2011; Falord et al., 2012), but it has just been recently proven that GraXRS is entirely responsible for the response to $\mathrm{pH}$ inside acidified macrophage phagolysosomes (Flannagan et al., 2018; Villanueva et al., 2018). These premises led us to consider GraXRS as a clear target to counteract $S$. aureus response to innate host immunity and impede replication of the pathogen in the acute stage of systemic infection.

Taking advantage of the $S$. aureus strain that lacks its complete sensorial TCS network (Villanueva et al., 2018), we developed a series of reporter strains that could be helpful for selecting compounds capable of blocking transcriptional 
activity of the GraXRS-dependent dltX promoter. Working with $\triangle \mathrm{XV}$ Gra-RES strain gave us the opportunity to perform a bioassay where bacterial sensing entirely depends on GraXRS (and WalkRS), thus reducing the probability of selecting off-target drug candidates. Proof of this last claim is the fact that among selected drugs, only one of them (Troglitazone) displayed a GraXRS-SaeRS multi target effect.

At the time of deciding the type of compound to be tested for the identification of GraXRS inhibitors, we, as many other researchers, opted for the drugrepurposing approach. This strategy is based on the identification of "off" antimicrobial targets for drugs that were approved for other clinical diseases (Thangamani et al., 2015), hence bypassing the financial and regulatory barriers that have to be overcome to bring a drug to market. At present day, this concept of repurposing has gained renewed interest and a novel category of drugs known as "Potential Drugs for Repurposing against Infectious Agents" is exponentially thriving (Miró-Canturri et al., 2019) By way of example, the old antimalarial drug chloroquine is being tested as SARS-CoV-2 inhibitor (Gautret et al., 2020). Though the precise mechanistic basis of their effect remains to be completely elucidated, current candidate PDRIAs targeting $S$. aureus SaeRS and/or AgrTCSs are floxuridine, streptozotocin and diflunisal (Khodaverdian et al., 2013; Hendrix et al., 2016; Yeo et al., 2018).

The screening methodology applied here consisted in the analysis of changes in dltXP transcriptional activity, followed by several consecutive steps where additional criteria like the effect on an alternative GraXRS-dependent promoter, TCS-selectivity, or the determination of bacterial growth in the presence of selected drugs under acidic conditions were applied. The overall process ended up in the selection of five candidate drugs: acetylsalicylic acid (ASA), hesperidin (HES), ascorbic acid (VITC), verteporfin (VER) and troglitazone (TGZ). Curiously, all compounds are classified as redox-active drugs. While ASA, HES, VITC and TGZ are commonly sorted as antioxidant 
molecules, VER can induce oxidative stress through the production of free radicals or be alternatively combined with soluble metals and display a redox potential similar to that showed by the heme complex (Eales et al., 2018). These observations are in agreement with the previously unveiled connection between GraXRS and oxidative stress, evidenced by the deciphering of the GraXRS regulon and the proved essentiality of this TCS in staphylococcal resistance to redox compounds like paraquat or $\mathrm{H}_{2} \mathrm{O}_{2}$ (Falord et al., 2011). Furthermore, a recent RNA-seq transcriptomic approach has just corroborated the involvement of GraXRS, collectively with VraSR, SaeRS, MgrA, SigB or Fur, in the cell response to thiol-oxidative stress (Loi et al., 2018; Loi et al., 2019).

After proving that VER was the only compound really capable of sensitizing bacteria against the effect of human PMNs, this compound was further examined using a murine model of surgical wound infection. This model has been previously used to assess the effect of systemic and topical antimicrobial agents, finding a close correlation with efficacy in clinical trials with human subjects. Noticeably, our results provided further evidence concerning the critical role of GraXRS in skin and wound infections and insinuated a pharmaceutical potential of VER as a novel local treatment for $S$. aureus infections. Since bacterial count after the infection with the wild type strain and subsequent treatment with $0,125 \mathrm{mg} \mathrm{kg}^{-1}$ of VER was quite similar to that proceeding from the infection with a GraXRS negative strain, the effect exerted by the porphyrin derivative seems to be highly dependent on the activity of this TCS.

When the possible path(s) of how VER inhibits the activity of GraXRS was envisaged, we thought of VER as a heme-like porphyrin capable of binding iron in different oxidation states (Eales et al., 2018). Recent transcriptomic studies conducted with the constitutively-active forms of staphylococcal kinases have unveiled the involvement of GraXRS in the regulation of heme synthase $A$ (MW_RS05355; (Rapun-Araiz et al., 2020)), fact that led us to attach importance to the chemical mimicry between both molecules. Since porphyrins are normally 
involved in thiol-based molecular switches (Shimizu et al., 2019), the unique potentially redox-active residue in GraS, C227, was considered a potential molecular target of VER. To address this question, the impact of C227 mutations to $S$ and $A$ on GraXRS activity and VER sensitivity was assessed. To our knowledge, the results achieved in this work by punctual mutations of C227 have evidenced for the first time that this cytosol-located redox-active residue actually participates in GraS kinase activity. This line of reasoning, which has support from studies that have characterized other bacterial kinases like AcrB (Malpica et al., 2004), showed that GraS degree of silencing depended on the polar nature of the amino acid that substituted C227 and suggested the involvement of this redox-switch as a potential molecular target concerning VER effect. However, and though $\mathrm{C} 227$ substitutions led to insensitivity to VER, the inhibitory outcome yielded by mutations was not as drastic as the one achieved by exposure to VER, suggesting that additional molecular paths must be involved in this process. An additional candidate that might be considered is Stk1, the unique serinethreonine kinase which cross-phosphorylates GraR (Fridman et al., 2013) and shows homology with OXR1, one of the recently discovered mammalian target of VER that, curiously, is also related to oxidative stress (AIAmri et al., 2018). However, in accordance with Fridman et al (Fridman et al., 2013), we have verified that both Stk1 and GraS-mediated phosphorylation on GraR as T128, T130, T149 and D51 respectively are equally required for full dltX expression (data not shown), fact that seriously complicates the use of our reporter systems when it comes to holding Stk1 accountable for intervening on VER effect.

Could VER be considered a viable antimicrobial candidate? Though we are fully aware that further in vitro and in silico studies helping to understand the whole molecular scenario underlaying VER effect and alternative in vivo approaches or definition of strategic dosages are some pending issues to claim a novel anti-virulence pharmaceutical indication for VER, we are convinced that this drug presents some strengths, apart from those inherent to anti-virulence 
drugs, that might be worth considering. In terms of pharmacology, for instance, VER excretion is dependent on hepatic function, while many antibiotics primarily undergo elimination via kidney filtration. Thus, VER could be administered to patients suffering from kidney disease, or to those who were being concomitantly treated with antibiotics that are prone to cause nephrotoxicity (e.g. vancomycin) (Elyasi et al., 2012). On the other hand, though side effects associated to parenteral administration of VER include hypersensitivity reactions or blood pressure alteration, these symptoms have lower mean severity ratings in comparison to those showed by many antibiotics (ema.europa.eu/Find medicine/Human medicines/European public assessment reports). Finally, taking into account that we have also observed that VER-containing topical formulations are effective and that further studies might confirm that chemical mimicry between porphyrin derivatives and heme group could actually be harnessed for disarming $S$. aureus, our results may be considered as a step forward in re-proposing VER as a plausible alternative in combating antimicrobial resistance. 


\section{Material and Methods}

\section{Bacterial strains, plasmids, oligonucleotides and culture media}

Bacterial strains, plasmids and oligonucleotides (purchased to IDT) are listed in table 1, table 2 and table 3 respectively. Escherichia coli XL1blue strain was grown in LB broth and LB agar. Staphylococcus aureus strains were grown on trypticase soy broth (TSB), trypticase soy agar (TSA), trypticase soy broth with $0.2 \%$ of glucose (TSB-glu), Mueller Hinton (MH) and B2 medium (1\% casein hydrolysate, $2.5 \%$ yeast extract, $2.5 \% \mathrm{NaCl}, 0.1 \% \mathrm{~K}_{2} \mathrm{HPO}_{4}$, and $0.5 \%$ glucose $[w / v])$. When required for growth or selection, medium was supplemented with 5Bromo-4-Chloro-3-Indolyl $\beta$-D-Galactopyranoside (XGal) and/or the appropriate antibiotic at the following concentrations: erythromycin (Eri) $10 \mathrm{\mu g} \mathrm{ml}^{-1}$, ampicillin (Am) $100 \mathrm{\mu g} \mathrm{ml}^{-1}$, chloramphenicol (Clo) $10 \mathrm{\mu g} \mathrm{ml}^{-1}$ and $20 \mathrm{\mu g} \mathrm{ml}^{-1}$.

\section{DNA manipulations}

Plasmids were purified using NucleoSpin Plasmid kit (Macherey-Nagel) according to the protocol provided by the manufacturer. PCR fragments and enzymatic reactions were purified using GeneJET Gel Extraction and DNA Cleanup Micro Kit (Thermo Scientific). FastDigest restriction enzymes, Rapid DNA ligation kit, Dreamtaq DNA polymerase and Phusion DNA polymerase were supplied by Thermo Scientific and used according to provided instructions. Sequence verification of PCR-amplified products and plasmid constructions was performed by Stab Vida. Transformation of Staphylococcus aureus was performed following previously standardized protocols (Schenk and Laddaga, 1992; Lee, 1995).

\section{Allelic exchange of chromosomal genes}

To generate markerless deletions, two fragments of at least $500 \mathrm{bp}$ that flanked upstream (primers A and B, table 3 ) and downstream fragments (primers $\mathrm{C}$ and $\mathrm{D}$, table 3 ) of the region to be deleted were amplified by PCR. Amplified 
products were digested using the corresponding restriction enzymes (table 3), purified and cloned by ligation into pMAD shuttle vector. To restore individual TCSs into XV chromosome, a fragment containing the two flanking regions used to generate the deletion (Villanueva et al., 2018) and the original TCS sequence were amplified by PCR using chromosomal DNA from MW2 strain as template and oligonucleotide pair gra or sae 1-3. For restoration of the TCS with single amino acid substitutions at C227, graRS was amplified using MW2 chromosomal DNA as template and a two-step PCR protocol. First, the oligonucleotides $\mathrm{A}$ and $\mathrm{G}$ or $\mathrm{H}$ were used for generating two overlapping PCR products, while a second amplification step with $A$ and $D$ oligonucleotides using both purified PCR products as templates generated graRS S(C227-A) and graRS $S(C 227-S)$ isoforms. Such DNA fragments were purified, digested with the corresponding enzymes (see Table 3 ) and inserted by ligation into the pMAD shuttle vector (Arnaud et al., 2004). Homologous recombination experiments were performed as previously described (Valle et al., 2003). Final plasmidless erythromycin sensitive white colonies were tested by PCR using primers $E$ and $F$ (Table 3).

\section{Reporter plasmid construction}

pSA14 was used for the construction of different reporter plasmids. Promoter regions of mprF, dltX and sec 4 were amplified by PCR using oligonucleotides described in table 3. PCR fragments were purified and cloned into pSA14 through restriction enzymes to generate transcriptional fusion with lacZ. GraRSdependent reporter plasmids were transformed via electroporation into $S$. aureus MW2, MW2 $\Delta$ graXRS, $\Delta \mathrm{XV}, \Delta \mathrm{XV}$ Gra-RES and $\Delta \mathrm{XV}$ Gra-RES $\Delta$ graX, while plasmid harboring Sae-dependent sec4 promoter was inserted into MW2, $\triangle \mathrm{XV}$ and $\triangle \mathrm{XV}$ Sae-RES strains. To analyze mprF, dltX and sec4 expression, ON cultures were chemically lysed beta-galactosidase activity was measured. 


\section{High throughput beta-galactosidase-based screening}

Screening of the 1280 off-patent FDA-approved drugs in Prestwick Chemical drug library (Prestwick Chemical) was based in a method for beta-galactosidase assays in 96 well plates. Working solutions of the compounds were prepared in $50 \mu \mathrm{l}$ of sterile distilled-deionized water at a concentration of $20 \mu \mathrm{M}$, and combined with $50 \mu$ of a 1:30 dilution on 2x TSB medium of an overnight (ON) culture of $S$. aureus strains, thus generating $100 \mu \mathrm{l}$ of 1:60 cell dilution on $1 \mathrm{x}$ TSB at a final concentration of $10 \mu \mathrm{M}$ of each drug. Plates were incubated during 24 $\mathrm{h}$ at $37^{\circ} \mathrm{C}$ and, upon incubation, $\mathrm{OD}_{600 \mathrm{~nm}}$ was measured (Multiskan Go; Thermo Scientific). Bacterial cells were subsequently lysed by the addition of $100 \mu$ well- $^{-}$ ${ }^{1}$ of $Z$ buffer supplemented with lysostaphin $\left(0.5 \mathrm{mg} \mathrm{ml}^{-1}\right)$ during 2 hours at $37^{\circ} \mathrm{C}$; Next, $30 \mu \mathrm{l}$ well-1 of Ortho-Nitrophenyl-beta-galactoside (ONPG, $4 \mathrm{mg} \mathrm{ml}^{-1}$ ) was added and, when required, the reaction was stopped with $100 \mu$ well $^{-1}$ of $1 \mathrm{M}$ $\mathrm{Na}_{2} \mathrm{CO} 3$. $\mathrm{OD}_{420}$ and $\mathrm{OD}_{550}$ values were finally recorded for Miller Units calculation. Untreated reporter $\triangle \mathrm{XV}$-GraRES and $\triangle \mathrm{XV}$ strains were included in every plate as internal controls. Experiments were carried out in triplicate

\section{Phagocytosis and killing of S. aureus by human PMNs}

Phagocytosis and killing of $S$. aureus by human neutrophils in presence of selected compounds was determined as described before (Peschel et al., 2001). Polymorphonuclear cells (PMNs) were isolated from healthy human heparinizeddefibrinated blood (Seralab Logistics) using Ficoll-Plaque PREMIUM (GEHealthcare) according to manufacturer's protocol and resuspended at a final concentration of $1 \times 10^{7} \mathrm{PMNs} \mathrm{ml}^{-1}$ in HBSS supplemented with human serum. $S$. aureus strains were cultured to the early stationary phase and $10 \mathrm{ml}$ of culture were centrifuged, washed twice with sterile PBS and resuspended in Hank's Balanced Salt Solution (HBSS) supplemented with human serum at a final concentration of $4 \times 10^{5}$ bacteria $\mathrm{ml}^{-1}$. Finally, $0.2 \mathrm{ml}$ of PMNs solution was mixed with $0.2 \mathrm{ml}$ of $S$. aureus solution and $600 \mu$ of HBSS supplemented with human 
serum. Compounds were added at a final concentration of $5 \mu \mathrm{M}$. After incubation at $37^{\circ} \mathrm{C}$ for 30 minutes, each sample was treated with gentamicin $100 \mathrm{mg} \mathrm{ml}^{-1}$ and then $100 \mu$ l of each mixture were added to $1 \mathrm{ml}$ of $\mathrm{pH} 11$ solution. Finally, serial dilutions were plated on TSA to determine the number of colony-forming units (CFU) in presence of the different compounds. All data were referred to initial CFU number.

\section{Mouse infections models}

The experimental animal study was reviewed and approved by the "Comité de Ética, Experimentación Animal y Bioseguridad" of the Universidad de Navarra-Centro de Investigación Médica Aplicada (CIMA). Work was carried out at the CIMA animal facility under the principles and guidelines described in the "European Directive 86/609/EEC" for the protection of animals used for experimental purposes. Six-week-old female swiss mice (20-25 g) were obtained from ENVIGO and confined in groups of 6 animals.

The model was performed as previously described (McRipley and Whitney, 1976). Briefly, $10 \mathrm{~cm}$ fragments of commercial brailed silk (TC-15, Lorca Marín) were contaminated with $4 \times 10^{6} \mathrm{CFU} \mathrm{cm}^{-1}$ of $S$. aureus MW2 or $S$. aureus MW2 $\operatorname{graXRS}$ strains by immersion for 30 minutes. Fragments were then blotted- dried. One day prior to the experiment, the interscapular skin was shaved using a sharp razor. On the day of the infection, superficial wounds were produced on the exposed back surface though a longitudinal midline incision of $2 \mathrm{~cm}$ approximately. The skin of either side of the incision was retracted, and the wound was infected by stitching it with contaminated suture and a suturing needle. Wounds were topically treated $1 \mathrm{~h}$ and $8 \mathrm{~h}$ after infection with approximately $100 \mu \mathrm{l}$ of hydrogel formulations containing 0,125 and 2,5 mg/100 $\mu l$. The hydrogel base without any active substance was applied in the control group. Treatments were repeated 24 hours after infection and mice were sacrificed $24 \mathrm{~h}$ after the last application. Finally, the wounded tissue was 
Chapter II: Inhibiting the TCS GraXRS with Vertepofin

resected, homogenized in PBS, and dilution series of homogenates was plated on TSB agar for enumeration of CFU (output). After an overnight incubation at $37^{\circ} \mathrm{C}, \mathrm{CFU}$ gr of tissue ${ }^{-1}$ were calculated and expressed as $\log _{10}$.

\section{Statistical analysis}

Data generated by PMN-mediated killing assay were compared using ANOVA, applying Tukey's pairwise as post hoc test. Data obtained from the bacterial counts in the murine model were treated and compared using KruskalWallis test, Mann-Whitney pairwise and Dunn's post hoc tests. All tests were twosided, and the significance level was $5 \%$. The statistical analysis was performed with Past and R softwares. 
Table 1 Strains used in this study

\begin{tabular}{|c|c|c|}
\hline Strain & Characteristics & Reference \\
\hline \multicolumn{3}{|l|}{ Escherichia coli } \\
\hline XI1Blue & $\begin{array}{l}\text { Cloning strain (recA1 endA1 gyrA96 } \\
\text { thi-1 hsdR17 supE44 relA1 lac [F' } \\
\text { proAB laclqZ } \Delta \text { M15 Tn10 (Tetr)]) }\end{array}$ & Stratagene \\
\hline \multicolumn{3}{|c|}{ Staphylococcus aureus } \\
\hline RN4220 & $\begin{array}{lll}\text { Restriction } & \text { deficient } & \text { transformation } \\
\text { recipient } & & \\
\end{array}$ & (Novick, 1990) \\
\hline MW2 & $\begin{array}{l}\text { Community-acquired strain of MRSA } \\
\text { isolated in } 1998 \text { in North Dakota, USA. }\end{array}$ & (Baba et al., 2002) \\
\hline MW2 2 graRS & Markerless mutation of graRS genes & $\begin{array}{l}\text { (Villanueva et al., } \\
\text { 2018) }\end{array}$ \\
\hline$\Delta \mathrm{XV}$ & $\begin{array}{l}\text { MW2 } \Delta \text { hptRS } \Delta l y t S R \quad \Delta g r a R S \quad \Delta s a e R S \\
\Delta M W 1208-M W 1209 \quad \Delta a r l R S \quad \Delta s r r A B \\
\Delta p h o P R \quad \Delta y h c S R \quad \Delta v r a S R \quad \Delta a g r B D C A \\
\Delta k d p D E \Delta h s R S \Delta n r e B C \Delta b r a R S\end{array}$ & $\begin{array}{l}\text { (Villanueva et al., } \\
\text { 2018) }\end{array}$ \\
\hline$\triangle \mathrm{XV}$ Gra-RES & Restored $\Delta \mathrm{XV}:$ :graRS strain & This study \\
\hline $\begin{array}{ll}\Delta X V & \text { Gra-RES } \\
\mathrm{S}(\mathrm{C} 227-\mathrm{A}) & \\
\end{array}$ & $\begin{array}{l}\text { Restored } \triangle \mathrm{XV}:: \text { graRS strain with } \mathrm{C} 227-\mathrm{A} \\
\text { single amino acid substitution in GraS }\end{array}$ & This study \\
\hline $\begin{array}{ll}\Delta X V & \text { Gra-RES } \\
\mathrm{S}(\mathrm{C} 2227-\mathrm{S}) & \\
\end{array}$ & $\begin{array}{l}\text { Restored } \triangle \mathrm{XV}:: \text { graRS strain with } \mathrm{C} 227-\mathrm{S} \\
\text { single amino acid substitution in GraS }\end{array}$ & This study \\
\hline $\begin{array}{ll}X \mathrm{XV} & \text { Gra-RES } \\
\mathrm{S}(\mathrm{H} 129-\mathrm{Q}) & \\
\end{array}$ & $\begin{array}{l}\text { Restored } \Delta \mathrm{XV}: \text { :graRS with H129-Q single } \\
\text { amino acid substitution in GraS }\end{array}$ & This study \\
\hline$\Delta \mathrm{XV}$ Gra-RES $\Delta g r a \mathrm{X}$ & $\begin{array}{l}\text { Markerless mutation of graX in } \triangle \mathrm{XV} \text { Gra- } \\
\text { RES strain }\end{array}$ & This study \\
\hline$\triangle \mathrm{XV}$ Sae-RES & Restored $\Delta X V::$ saeRS strain & This study \\
\hline MW2 mprFp & MW2 carrying pSA14::mprFp; Eri ${ }^{\mathrm{R}}$ & This study \\
\hline MW2 dltXp & MW2 carrying pSA14::dltXp; Eri $^{\mathrm{R}}$ & This study \\
\hline MW2 sec4p & MW2 carrying pSA14::sec $4 p$; Eri ${ }^{\mathrm{R}}$ & This study \\
\hline$\Delta \mathrm{XV} m p r \mathrm{Fp}$ & $\Delta \mathrm{XV}$ carrying pSA14::mprFp; $\mathrm{Eri}^{\mathrm{R}}$ & This study \\
\hline$\Delta \mathrm{XV}$ dlt Xp & $\Delta X \mathrm{X}$ carrying pSA14::dltXp; Eri ${ }^{\mathrm{R}}$ & This study \\
\hline$\Delta X V \sec 4 p$ & $\Delta \mathrm{XV}$ carrying pSA14::sec4p; Eri ${ }^{\mathrm{R}}$ & This study \\
\hline$\triangle \mathrm{XV}$ Gra-RES $m p r F p$ & $\begin{array}{l}\text { Restored } \triangle \mathrm{XV}:: \text { graRS strain carrying } \\
\text { pSA14::mprFp; Eri }\end{array}$ & This study \\
\hline$\Delta \mathrm{XV}$ Gra-RES dltXp & $\begin{array}{l}\text { Restored } \Delta \mathrm{XV}:: \text { graRS strain carrying } \\
\text { pSA14::dltXp; Eri }\end{array}$ & This study \\
\hline MW2 $\Delta g r a \mathrm{RS}$ mprFp & $\begin{array}{l}\text { MW2 } \Delta g r a \mathrm{RS} \text { carrying pSA14::mprFp } \\
\text { Eri }^{\mathrm{R}}\end{array}$ & This study \\
\hline MW2 $\Delta g r a \mathrm{RS}$ dltXp & MW2 $\Delta$ graRS carrying pSA14::dltXp Eri ${ }^{\mathrm{R}}$ & This study \\
\hline$\Delta X V$ Sae-RES $\sec 4 p$ & $\begin{array}{l}\text { Restored } \quad \Delta X V:: \text { SaeRS } \\
\text { pSA14::sec4p Eri }\end{array}$ & This study \\
\hline
\end{tabular}


Table 2. Plasmid used in this study

\begin{tabular}{|l|l|l|}
\hline Plasmid & Characteristics & References \\
\hline pMAD & $\begin{array}{l}\text { E. coli }- \text { S. aureus shuttle vector with a } \\
\text { thermosensitive origin of replication used for } \\
\text { allelic replacement }\end{array}$ & (Arnaud et al., 2004) \\
\hline pMAD::graRES & $\begin{array}{l}\text { pMAD plasmid containing the allele for } \\
\text { chromosomal restoration of graRS TCS }\end{array}$ & This study \\
\hline pMAD::saeRES & $\begin{array}{l}\text { pMAD plasmid containing the allele for } \\
\text { chromosomal restoration of saeRS TCS }\end{array}$ & This study \\
\hline pMAD:: $\Delta g r a X$ & $\begin{array}{l}\text { pMAD plasmid containing the allele for } \\
\text { markerless deletion of graX gene }\end{array}$ & This study \\
\hline pMAD::graRES & $\begin{array}{l}\text { pMAD plasmid containing the allele for } \\
\text { chromosomal restoration of graRS S(C227-A) } \\
\text { isoform }\end{array}$ & This study \\
\hline pMAD::graRES & $\begin{array}{l}\text { pMAD plasmid containing the allele for } \\
\text { chromosomal restoration of graRS S(C227-S) } \\
\text { isoform }\end{array}$ & This study \\
\hline pMAD::graRES & $\begin{array}{l}\text { pMAD plasmid containing the allele for } \\
\text { chromosomal restoration of graRS S(H120-Q) } \\
\text { isoform }\end{array}$ & This study \\
\hline pSA14 & $\begin{array}{l}\text { pM4 derivative carrying the promoterless E.coli } \\
\text { lacZ gene for constructing transcriptional } \\
\text { fusions }\end{array}$ & (Falord et al., 2011) \\
\hline pSA14::mprFp & pSA14 containing the mprF promoter region & (Falord et al., 2011) \\
\hline pSA14::dltXp & pSA14 containing the dltX promoter region & This study \\
\hline pSA14::sec4p & pSA14 containing the sec4 promoter region & This study \\
\hline
\end{tabular}

Table 3. Oligonucleotides used in this study

\begin{tabular}{|l|l|}
\hline $\begin{array}{l}\text { Oligonucleotide } \\
\text { Restoration of } \\
\text { TCS }\end{array}$ & \\
\hline gra-E & GGGCCATAAAAAGCCTCCAG \\
\hline gra-F & GTAGCTTCCGACTTGTGAGCC \\
\hline gra-A (EcoRI) & CCGGGAGCTCGAATTCCAAATAGATATTGCTGTATTCTTTATCGACCCAAC \\
\hline gra-D (BamHI) & GGGCGATATCGGATCCAACGCCACCTAAAACACTTTGTACAC \\
\hline G C227A Rv & CTAATAATCATACGGCACCATTTTATATC \\
\hline H C227A Fwd & GATATAAAATGGTGCCGTATGATTATTAG \\
\hline G C227S Rv & TCTAATAATCATACGAGACCATTTTATATC \\
\hline H C227S Fwd & AGATATAAAATGGTCTCGTATGATTATTAG \\
\hline G H129-Q Rv & GTTTTTATGTCTTGCACAAATTCTG \\
\hline H H129-Q Fwd & CAGAATTTGTGCAAGACATAAAAAC \\
\hline sae-E & AGTACAATTTGATGATGGTGTTGGTG \\
\hline sae-F & GATTTCACAGCACCCCTAGC \\
\hline sae-A (BamHI) & GGGCGATATCGGATCCCAAAAGGGTTATTTGAATGGATAGGC \\
\hline
\end{tabular}


Chapter II: Inhibiting the TCS GraXRS with Vertepofin

\begin{tabular}{|c|c|}
\hline sae-D (Notl) & CCATGGCATGCATCGCTGTTCACATAACACTACAAATCGC \\
\hline $\operatorname{graX} \mathrm{A}(\mathrm{Bg} \mid \mathrm{ll})$ & CACAGATCTGGTTGGTTATTGAGTGGTACATTTG \\
\hline graX B (Xhol) & CACCTCGAGCTAAAATACTCCTTTAAACTGTAACC \\
\hline graX C (Xhol) & CACCTCGAGGGTGATATGGATGCAAATAC \\
\hline graX D & GGAGGATCCTTTCGATTTGATTTTTTTTGGTAATAAG \\
\hline graX E & GTTGTTATGCGATTCTGATACAAG \\
\hline graX F & TGTTTCGATTGCACTATCCATAC \\
\hline \multicolumn{2}{|l|}{$\begin{array}{l}\text { Reporter } \\
\text { construction }\end{array}$} \\
\hline pSA14-Fw & TGGAATTGTGAGCGGATAAC \\
\hline pSA14-Rv & CTCTTCGCTATTACGCCAG \\
\hline mprFp-Fw (Pstl) & CTGCTGCAGTATAGATAACCATATTGTTC \\
\hline $\begin{array}{l}\text { mprFp-Rv } \\
\text { (BamHI) }\end{array}$ & GGAGGATCCTGATTCATTTTTTCACATCA \\
\hline dltXp-Fw (Pstl) & GGCTGCAGGCGCTGATGATAATTCAATAA \\
\hline dltXp-Rv (BamHI) & CGGGATCCGATTTCATATTGCACCTCTTAAAG \\
\hline sec4p-Fw (Pstl) & GGCTGCAGGAGTGTGAATATATAAACAATG \\
\hline $\begin{array}{l}\text { sec4p-Rv } \\
\text { (BamHI) }\end{array}$ & GCGGATCCTTATTCATTTTTATCTCCTTC \\
\hline $\begin{array}{l}\text { mprFp-GFP-Fw } \\
\text { (Sall) }\end{array}$ & GTCGTCGACGTATAGATAACCATATTGTTC \\
\hline $\begin{array}{l}\text { mprFp-GFP-Rv } \\
\text { (Kpnl) }\end{array}$ & GGTGGTACCTGATTCATTTTTTCACATCA \\
\hline \multicolumn{2}{|l|}{$\begin{array}{l}\text { Complementatio } \\
\text { n plasmid }\end{array}$} \\
\hline graR Fw (Kpnl) & GGGGTACCTCGAGAATGATATTGGGTGATATGG \\
\hline graR Rv (EcoRI) & GGGAATTCCAAATTATTCATGAGCCATATA \\
\hline
\end{tabular}




\section{References}

AlAmri, M.A., Kadri, H., Alderwick, L.J., Jeeves, M., and Mehellou, Y. (2018) The Photosensitising Clinical Agent Verteporfin Is an Inhibitor of SPAK and OSR1 Kinases. ChemBioChem

19: 2072-2080 http://doi.wiley.com/10.1002/cbic.201800272.

Arnaud, M., Chastanet, A., and Debarbouille, M. (2004) New Vector for Efficient Allelic Replacement in Naturally Nontransformable, Low-GC-Content, GramPositive Bacteria. Appl Environ Microbiol 70: 6887-6891 http://www.ncbi.nlm.nih.gov/pmc/articles/PMC525206/.

Baba, T., Takeuchi, F., Kuroda, M., Yuzawa, H., Aoki, K., Oguchi, A., et al. (2002) Genome and virulence determinants of high virulence community-acquired MRSA. Lancet 359: 1819-1827 http://dx.doi.org/10.1016/S01406736(02)08713-5.

Balasubramanian, D., Harper, L., Shopsin, B., and Torres, V.J. (2017) Staphylococcus aureus pathogenesis in diverse host environments. Pathog Dis 75: ftx005 https://academic.oup.com/femspd/articlelookup/doi/10.1093/femspd/ftx005.

Bem, A.E., Velikova, N., Pellicer, M.T., Baarlen, P. van, Marina, A., and Wells, J.M. (2015) Bacterial Histidine Kinases as Novel Antibacterial Drug Targets. ACS Chem Biol 10: 213-224 https://pubs.acs.org/doi/10.1021/cb5007135.

Boyle-Vavra, S., Yin, S., Jo, D.S., Montgomery, C.P., and Daum, R.S. (2013) $\mathrm{VraT/YvqF}$ is required for methicillin resistance and activation of the VraSR regulon in Staphylococcus aureus. Agencia Eur Medicam 57: 83-95.

Capra, E.J., and Laub, M.T. (2012) Evolution of Two-Component Signal Transduction Systems. Annu Rev Microbiol 66: 325-347 http://www.annualreviews.org/doi/10.1146/annurev-micro-092611-150039.

Chaili, S., Cheung, A.L., Bayer, A.S., Xiong, Y.Q., Waring, A.J., Memmi, G., et al. (2016) The GraS Sensor in Staphylococcus aureus Mediates Resistance to Host Defense Peptides Differing in Mechanisms of Action. Infect Immun 84: 459-466 http://iai.asm.org/content/84/2/459.abstract.

Cheung, A.L., Bayer, A.S., Yeaman, M.R., Xiong, Y.Q., Waring, A.J., Memmi, G., et al. (2014) Site-Specific Mutation of the Sensor Kinase GraS in Staphylococcus aureus Alters the Adaptive Response to Distinct Cationic Antimicrobial Peptides. Infect Immun 82: 5336-5345 http://iai.asm.org/lookup/doi/10.1128/IAI.02480-14.

Eales, K.L., Wilkinson, E.A., Cruickshank, G., Tucker, J.H.R., and Tennant, D.A. (2018) Verteporfin selectively kills hypoxic glioma cells through iron-binding and increased production of reactive oxygen species. Sci Rep 8: 14358 https://doi.org/10.1038/s41598-018-32727-1. 
Elyasi, S., Khalili, H., Dashti-Khavidaki, S., and Mohammadpour, A. (2012) Vancomycin-induced nephrotoxicity: mechanism, incidence, risk factors and special populations. A literature review. Eur J Clin Pharmacol 68: 1243-1255 https://doi.org/10.1007/s00228-012-1259-9.

Falord, M., Karimova, G., Hiron, A., and Msadek, T. (2012) GraXSR Proteins Interact with the VraFG ABC Transporter To Form a Five-Component System Required for Cationic Antimicrobial Peptide Sensing and Resistance in Staphylococcus aureus. Antimicrob Agents Chemother 56: 1047-1058 http://aac.asm.org/lookup/doi/10.1128/AAC.05054-11.

Falord, M., Mäder, U., Hiron, A., Débarbouillé, M., and Msadek, T. (2011) Investigation of the Staphylococcus aureus GraSR regulon reveals novel links to virulence, stress response and cell wall signal transduction pathways. PLoS One 6: e21323 http://dx.plos.org/10.1371/journal.pone.0021323.

Flannagan, R.S., Kuiack, R.C., McGavin, M.J., and Heinrichs, D.E. (2018) Staphylococcus aureus Uses the GraXRS Regulatory System To Sense and Adapt to the Acidified Phagolysosome in Macrophages. MBio 9: 561 http://mbio.asm.org/lookup/doi/10.1128/mBio.01143-18.

Fridman, M., Williams, G.D., Muzamal, U., Hunter, H., Siu, K.W.M.W.M., and Golemi-Kotra, D. (2013) Two Unique Phosphorylation-Driven Signaling Pathways Crosstalk in Staphylococcus aureus to Modulate the Cell-Wall Charge: Stk1/Stp1 Meets GraSR. Biochemistry 52: 7975-7986 https://pubs.acs.org/doi/10.1021/bi401177n.

Gautret, P., Lagier, J.-C., Parola, P., Hoang, V.T., Meddeb, L., Mailhe, M., et al. (2020) Hydroxychloroquine and azithromycin as a treatment of COVID-19: results of an open-label non-randomized clinical trial. Int J Antimicrob Agents 105949

http://www.sciencedirect.com/science/article/pii/S0924857920300996.

Gotoh, Y., Eguchi, Y., Watanabe, T., Okamoto, S., Doi, A., and Utsumi, R. (2010) Two-component signal transduction as potential drug targets in pathogenic bacteria. Curr Opin Microbiol 13: 232-239 https://linkinghub.elsevier.com/retrieve/pii/S1369527410000135.

Haag, A.F., and Bagnoli, F. (2015) The Role of Two-Component Signal Transduction Systems in Staphylococcus aureus Virulence Regulation. In Life Science Journal. pp. 145-198 http://link.springer.com/10.1007/82_2015_5019.

Hendrix, A.S., Spoonmore, T.J., Wilde, A.D., Putnam, N.E., Hammer, N.D., Snyder, D.J., et al. (2016) Repurposing the Nonsteroidal Anti-inflammatory Drug Diflunisal as an Osteoprotective, Antivirulence Therapy for Staphylococcus aureus Osteomyelitis. Antimicrob Agents Chemother 60: 5322-5330 http://aac.asm.org/lookup/doi/10.1128/AAC.00834-16. 
Hilliard, J.J., Goldschmidt, R.M., Licata, L., Baum, E.Z., and Bush, K. (1999) Multiple mechanisms of action for inhibitors of histidine protein kinases from bacterial two-component systems. Antimicrob Agents Chemother 43: 16931699.

Kawada-Matsuo, M., Yoshida, Y., Nakamura, N., and Komatsuzawa, H. (2011) Role of two-component systems in the resistance of Staphylococcus aureus to antibacterial agents. Virulence 2: 427-430.

Kelly, R., and Davies, S.C. (2017) Tackling antimicrobial resistance globally. Med J Aust 207: 371-373 https://onlinelibrary.wiley.com/doi/abs/10.5694/mja17.00865.

Khodaverdian, V., Pesho, M., Truitt, B., Bollinger, L., Patel, P., Nithianantham, S., et al. (2013) Discovery of Antivirulence Agents against MethicillinResistant Staphylococcus aureus. Antimicrob Agents Chemother 57: 36453652 http://aac.asm.org/lookup/doi/10.1128/AAC.00269-13.

Kong, C., Neoh, H., and Nathan, S. (2016) Targeting Staphylococcus aureus Toxins: A Potential form of Anti-Virulence Therapy. Toxins (Basel) 8: 72 http://www.mdpi.com/2072-6651/8/3/72.

Kraus, D., Herbert, S., Kristian, S.A., Khosravi, A., Nizet, V., Götz, F., and Peschel, A. (2008) The GraRS regulatory system controls Staphylococcus aureus susceptibility to antimicrobial host defenses. BMC Microbiol 8: 85 http://bmcmicrobiol.biomedcentral.com/articles/10.1186/1471-2180-8-85.

Lee, J.C. (1995) Electrotransformation of Staphylococci. In Electroporation Protocols for Microorganisms. Nickoloff, J.A. (ed.). Humana Press, New Jersey. pp. 209-216 https://doi.org/10.1385/0-89603-310-4:209.

Li, M., Cha, D.J., Lai, Y., Villaruz, A.E., Sturdevant, D.E., and Otto, M. (2007) The antimicrobial peptide-sensing system aps of Staphylococcus aureus. Mol Microbiol 66: 1136-1147 http://doi.wiley.com/10.1111/j.13652958.2007.05986.x.

Liu, Q., Yeo, W.-S., and Bae, T. (2016) The SaeRS Two-Component System of Staphylococcus aureus. Genes (Basel) 7: 81 http://www.mdpi.com/20734425/7/10/81.

Loi, V. Van, Busche, T., Tedin, K., Bernhardt, J., Wollenhaupt, J., Huyen, N.T.T., et al. (2018) Redox-Sensing Under Hypochlorite Stress and Infection Conditions by the Rrf2-Family Repressor HypR in Staphylococcus aureus. Antioxid Redox Signal 29: 615-636 http://www.liebertpub.com/doi/10.1089/ars.2017.7354.

Loi, V. Van, Huyen, N.T.T., Busche, T., Tung, Q.N., Gruhlke, M.C.H., Kalinowski, J., et al. (2019) Staphylococcus aureus responds to allicin by global Sthioallylation - Role of the Brx/BSH/YpdA pathway and the disulfide 
reductase MerA to overcome allicin stress. Free Radic Biol Med 139: 55-69 https://linkinghub.elsevier.com/retrieve/pii/S0891584919305118.

Malpica, R., Franco, B., Rodriguez, C., Kwon, O., and Georgellis, D. (2004) Identification of a quinone-sensitive redox switch in the ArcB sensor kinase. Proc Natl Acad Sci 101: 13318-13323 http://www.pnas.org/cgi/doi/10.1073/pnas.0403064101.

McRipley, R.J., and Whitney, R.R. (1976) Characterization and Quantitation of Experimental Surgical-Wound Infections Used to Evaluate Topical Antibacterial Agents. Antimicrob Agents Chemother 10: 38-44 http://aac.asm.org/cgi/doi/10.1128/AAC.10.1.38.

Meer, J.W.M. van der, Fears, R., Davies, D.S.C., and Meulen, V. ter (2014) Antimicrobial innovation: combining commitment, creativity and coherence. Nat Rev Drug Discov 13: 709-710 https://doi.org/10.1038/nrd4448.

Miró-Canturri, A., Ayerbe-Algaba, R., and Smani, Y. (2019) Drug Repurposing for the Treatment of Bacterial and Fungal Infections. Front Microbiol 10: 41 https://www.frontiersin.org/article/10.3389/fmicb.2019.00041/full.

Muzamal, U., Gomez, D., Kapadia, F., and Golemi-Kotra, D. (2014) Diversity of two-component systems: insights into the signal transduction mechanism by the Staphylococcus aureus two-component system GraSR. F1000Research 3: 1-26 http://f1000research.com/articles/3-252/v2.

Novick, R.P. (1990) Molecular biology of the staphylococci. VCH Publ 1-37.

Okada, A., Igarashi, M., Okajima, T., Kinoshita, N., Umekita, M., Sawa, R., et al. (2010) Walkmycin B targets WalK (YycG), a histidine kinase essential for bacterial cell growth. J Antibiot (Tokyo) 63: 89-94 http://www.nature.com/articles/ja2009128.

Peschel, A., Jack, R.W., Otto, M., Collins, L.V., Staubitz, P., Nicholson, G., et al. (2001) Staphylococcus aureus Resistance to Human Defensins and Evasion of Neutrophil Killing via the Novel Virulence Factor Mprf Is Based on Modification of Membrane Lipids with I-Lysine. J Exp Med 193: 1067-1076 https://rupress.org/jem/article/193/9/1067/39353/Staphylococcus-aureusResistance-to-Human.

Rapun-Araiz, B., Haag, A.F., Cesare, V. De, Gil, C., Dorado-Morales, P., Penades, J.R., and Lasa, I. (2020) Systematic Reconstruction of the Complete Two-Component Sensorial Network in Staphylococcus aureus. mSystems 5 https://msystems.asm.org/content/5/4/e00511-20.

Rasigade, J.-P., Dumitrescu, O., and Lina, G. (2014) New epidemiology of Staphylococcus aureus infections. Clin Microbiol Infect 20: 587-588 https://linkinghub.elsevier.com/retrieve/pii/S1198743X14611435. 
Schenk, S., and Laddaga, R.A. (1992) Improved method for electroporation of Staphylococcus aureus. FEMS Microbiol Lett 94: 133-138 https://doi.org/10.1111/j.1574-6968.1992.tb05302.x.

Shimizu, T., Lengalova, A., Martínek, V., and Martínková, M. (2019) Heme: emergent roles of heme in signal transduction, functional regulation and as catalytic centres. Chem Soc Rev 48: 5624-5657 http://dx.doi.org/10.1039/C9CS00268E.

Stock, A.M., Robinson, V.L., and Goudreau, P.N. (2000) Two-Component Signal Transduction. Annu Rev Biochem 69: 183-215 http://www.annualreviews.org/doi/10.1146/annurev.biochem.69.1.183.

Thangamani, S., Mohammad, H., Abushahba, M.F.N., Sobreira, T.J.P., and Seleem, M.N. (2016) Repurposing auranofin for the treatment of cutaneous staphylococcal infections. Int $J$ Antimicrob Agents 47: 195-201 https://linkinghub.elsevier.com/retrieve/pii/S0924857916000121.

Thangamani, S., Mohammad, H., Younis, W., and Seleem, M. (2015) Drug Repurposing for the Treatment of Staphylococcal Infections. Curr Pharm Des 21: 2089-2100 http://www.eurekaselect.com/openurl/content.php?genre=article\&issn=1381 $-6128 \&$ volume $=21 \&$ issue $=16 \&$ spage $=2089$.

Valle, J., Toledo-Arana, A., Berasain, C., Ghigo, J.-M., Amorena, B., Penadés, J.R., and Lasa, I. (2003) SarA and not $\sigma B$ is essential for biofilm development by Staphylococcus aureus. Mol Microbiol 48: 1075-1087 http://doi.wiley.com/10.1046/j.1365-2958.2003.03493.x.

Villanueva, M., García, B., Valle, J., Rapún, B., Ruiz de los Mozos, I., Solano, C., et al. (2018) Sensory deprivation in Staphylococcus aureus. Nat Commun 9: 523 http://dx.doi.org/10.1038/s41467-018-02949-y.

Wertheim, H.F., Melles, D.C., Vos, M.C., Leeuwen, W. van, Belkum, A. van, Verbrugh, H.A., and Nouwen, J.L. (2005) The role of nasal carriage in Staphylococcus aureus infections. Lancet Infect Dis 5: 751-762 https://linkinghub.elsevier.com/retrieve/pii/S1473309905702954.

Yang, S.-J., Bayer, A.S., Mishra, N.N., Meehl, M., Ledala, N., Yeaman, M.R., et al. (2012) The Staphylococcus aureus Two-Component Regulatory System, GraRS, Senses and Confers Resistance to Selected Cationic Antimicrobial Peptides. Infect Immun 80: 74-81 http://iai.asm.org/lookup/doi/10.1128/IAI.05669-11.

Yeo, W.-S., Arya, R., Kim, K.K., Jeong, H., Cho, K.H., and Bae, T. (2018) The FDA-approved anti-cancer drugs, streptozotocin and floxuridine, reduce the virulence of Staphylococcus aureus. Sci Rep 8: 2521 http://www.nature.com/articles/s41598-018-20617-5. 
upna 
Just as the scientific community predicted the possibility of a coronavirus pandemic many years ago (Morse et al., 2012), there is substantial evidence that antimicrobial resistance poses a great threat to animal and human health, which definitively can not be ignored any longer. Paradoxically, and with no intention to demonize them, pharmaceutical companies are curtailing anti-infective research programs. Why is this happening? A number of social and economical factors make antimicrobials less attractive from a business point of view these days. For instance, the aging of population has shifted drug discovery projects towards drugs for treating chronic conditions that mostly affect elderly such as hypercholesterolemia, hypertension or arthritis. These medications are normally long-term used, while antibiotics are commonly restricted to short-term treatments. In addition, the large number of commercial antibiotics already available and the global preconceived notion that antibiotics must be inexpensive result in a very high level of market competition. Medical community does not contribute to make antimicrobial-drug-discovery the "goose that lays golden eggs" for pharma companies either, since first-line use of newly developed antimicrobials is normally reserved for extreme resistance cases, thus negatively impacting sales.

We are confident that small spin-off and biotech companies might help to fill the gap in anti-infective research created by big pharma withdrawal and thus Recombina is committed to the innovation and technology that could put a tiny grain of sand in the AMR crisis.

\section{Chapter I}

With the previously mentioned objective in mind, we first attempted to find a novel molecule of marine origin that could enhance the negative effects, understood as toxic accumulation of intermediary metabolites or proteins, that over production of the major staphylococcal biofilm polysaccharide might entail. Though we have not yet been able to identify a singular compound capable of 
Future prospects

exerting a PIA/PNAG-dependent antibiotic effect, we found that a subfraction obtained from the fermentation of a marine microbe, composed by Lumichrome, Soyasaponin and Malayamicin, specifically inhibits those bacteria producing PIA/PNAG. Preliminary studies aimed at the understanding of the molecular mechanisms underlaying the effect of sub-fraction TA-15-A-A112CHVF.9/10.SF8 indicate that post transcriptional regulation of ica operon and icaconditional repression of Protein A and other high molecular weight proteins could be crucial to exploit PIA/PNAG-associated fitness cost. Thus, next experimental steps that are currently being evaluated include the identification of those high molecular weight proteins that are missing from proteic profiles when bacteria are cultured in the presence of sub-inhibitory concentrations of SF8. Given the precedent work unveiling the negative effect of Lumichrome on sortase A (Chung et al, 2019), we are also planing to study the effect of SF8 in the strain S. aureus $15981 \Delta s r t A$. If this anchoring factor is indeed a target for SF8, mutant strain should show a lower susceptibility to this compound mixture. Additionally, we find quite attractive the previously formulated hypothesis that, since IcaC is normally the target for phase variation in PIA/PNAG production and its lack confers an advantage under poor nutrient conditions in comparison to the loss of the entire operon, other proteins encoded within the ica locus could have some other function (Brooks and Jefferson, 2014). Are IcaA or IcaD, for instance, involved in SF8 effect? To address this question, we have some experiments in mind, including the construction and analysis of individual complemented and epitopetagged lca-derivatives.

Apart from SrtA and Ica operon, and with the aim of having a global picture of the effect exerted by SF8, and at the same time going deeper into the mechanisms that could trigger lethality when PIA/PNAG is produced, we are considering the possibility of getting the resources to perform single-step and multi-step resistance studies. These approaches, which have recently been used to propose a new class of synthetic retinoids as effective antibiotics against 
bacterial persisters (Kim et al., 2018), involve the formation of resistant mutant clones in one exposure or over many passages (subcultures) in the presence of the antimicrobial agent. We could then not only evaluate the frequency of resistant clones to SF8, but also find the type of mutations via whole genome sequencing, thus inferring the molecular basis underlaying PIA/PNAG associated fitness cost and, luckily, novel targets for antibiotic drug-discovery.

As an alternative to single and multi-step resistance experiments, it could also be of huge help to apply an inverse approach and perform an automated hightroughput staphylococcal killing assay. Using the Nebraska Transposon Mutant Library, to name an example, which is a collection of strains containing mutant derivatives of USA300 LAC in which individual genes have been disrupted by the insertion of the mariner Tn bursa aurealis, we could identify those mutants that are resistant to SF8 and therefore characterize its molecular targets.

\section{Chapter II}

Though the harsh truth is that only three clinical studies with repurposed drugs have been performed or are currently underway (Miró-Canturri et al., 2019), we continue being enthusiastic about the concept of drug repurposing. Thanks to a unique genetic tool like $S$. aureus $\Delta X V$ (Villanueva et al., 2018), we have found that Verteporfin, a drug that is normally prescribed for macular degeneration, is capable of blocking GraXRS Two-Component-System. Behaving like an antivirulence compound, Verteporfin was really efficient in enhancing PMN-mediated bacterial killing, while topical administration of such drug in a murine model of surgical wound infection significantly reduced the bacterial load. In this regard, future experiments supporting the new novel antimicrobial therapeutical indication of Verteporfin must be undertaken. It would be very intriguing to study the effect of this drug using an animal model that did not show an intrinsic resistance to $S$ aureus, mimicking human susceptibility to this pathogen. This could be case of a rabbit skin-infection model using the host-adapted ST121 strain (Viana et al., 2015), which was indeed the approach that revealed how 
crucial the TCS GraXRS is when it comes to staphylococal virulence. Besides, since galenic formulation of drugs might have a great impact on their therapeutical effect, it would also be worth exploring new cream and ointment bases, or even its combination with topical antibiotics like mupirocin.

Could another porphyrin derivative display and improved GraXRS-blocking effect? We believe so. Porphyrins have already been clinically considered for antimicrobial photodynamic therapy due to their capacity to generate highly reactive radicals, but our study suggests that they might possess other biological properties that do not depend on light activation. Since these molecules show important pharmaceutical advantages like the relatively low in vitro and in vivo toxicity, a reasonable clearance time from the body, amphiphilicity and ability for numerous chemical modifications, a high binding affinity to cellular components (membranes, proteins, DNA) and a more than reasonable "therapeutic window" whereby they can kill bacteria but do not harm cultured human cells (AmosTautua et al., 2019), we are currently considering the possibility of analyzing the GraXRS-blocking potential of other porphyrins like Porfimer sodium, Bacteriocholorophyll A, N-Methylmesoporphyrin, Protoporphyrin, Siroheme or Ferrohem.

Experiments relying on the chemical mimicry existing between Verteporfin and heme group have suggested that redox active residue GraS C227 participates in the inhibition exerted by this FDA-approved drug. Though it is a matter of basic research, it could also be fascinating to understand how this residue mediates GraXRS activity. As described before, we found that replacement of cysteine by another residue had a negative impact on GraXRS activity, being such an outcome dependent on the polarity of the substitute amino acid. Thus, C227-A (non polar) GraS isoform led to a lower degree of transcriptional activity of dltXP in comparison to that showed by the isoform in which $\mathrm{C} 227$ had been mutated to the polar amino acid serine. These results have prompted us to hypothesize that, in terms hydrogen-bonding potential, the 
reduced form of cysteine could behave in a similar way to that showed by serine. Alanine, by contrast, lacks the hydrogen-bonding potential and thus has a higher impact on the transcriptional activity of the GraXRS-dependent promoter. Our reasoning is that serine retains the ability to form hydrogen-bonds independently of the redox status, leading to a constant state of activation, while alanine causes the opposite effect, being nonreactive (also independently of redox conditions) and simulating the oxidized constant off-mode. To certainly prove these hypotheses, we should perform in vitro experiments in which the phosphorylation of the purified forms of GraS and its C227-A and C227-S derivatives in the presence of Verteporfin, oxidant and reducing agents would be assessed.

Finally, the same approach applied here to find GraXRS-targeting molecules might be used with any $\triangle \mathrm{XV}$ derivative that had been restored with a single TCS. We are confident that such valuable in vivo tools could be an extraordinary complement to in silico and in vitro screens aimed at finding histidine kinase inhibitors. 


\section{References}

Amos-Tautua, B., Songca, S., and Oluwafemi, O. (2019) Application of Porphyrins in Antibacterial Photodynamic Therapy. Molecules 24: 2456 https://www.mdpi.com/1420-3049/24/13/2456.

Brooks, J.L., and Jefferson, K.K. (2014) Phase Variation of Poly-NAcetylglucosamine Expression in Staphylococcus aureus. PLoS Pathog 10: e1004292 http://dx.plos.org/10.1371/journal.ppat.1004292.

Chung, B., Kwon, O.-S., Shin, J., and Oh, K.-B. (2019) Inhibitory Effects of Streptomyces sp. MBTH32 Metabolites on Sortase A and Sortase AMediated Cell Clumping of Staphylococcus aureus to Fibrinogen. J Microbiol Biotechnol 29: 1603-1606 http://www.jmb.or.kr/journal/view.html?doi=10.4014/jmb.1906.06026.

Kim, W., Zhu, W., Hendricks, G.L., Tyne, D. Van, Steele, A.D., Keohane, C.E., et al. (2018) A new class of synthetic retinoid antibiotics effective against bacterial persisters. Nature 103-107 http://www.nature.com/articles/nature26157.

Miró-Canturri, A., Ayerbe-Algaba, R., and Smani, Y. (2019) Drug Repurposing for the Treatment of Bacterial and Fungal Infections. Front Microbiol 10: 41 https://www.frontiersin.org/article/10.3389/fmicb.2019.00041/full.

Morse, S.S., Mazet, J.A., Woolhouse, M., Parrish, C.R., Carroll, D., Karesh, W.B., et al. (2012) Prediction and prevention of the next pandemic zoonosis. Lancet 380: https://linkinghub.elsevier.com/retrieve/pii/S0140673612616845.

Viana, D., Ward, M., Viana, D., Comos, M., Mcadam, P.R., Ward, M.J., et al. (2015) A single natural nucleotide mutation alters bacterial pathogen host tropism A single natural nucleotide mutation alters bacterial pathogen host tropism. .

Villanueva, M., García, B., Valle, J., Rapún, B., Ruiz de los Mozos, I., Solano, C., et al. (2018) Sensory deprivation in Staphylococcus aureus. Nat Commun 9: 523 http://dx.doi.org/10.1038/s41467-018-02949-y. 
CONCLUSIONES 
upna 
1. Recombina SL dispone de una plataforma que permite realizar cribados fenotípicos de forma sencilla y económica para la identificación tanto de compuestos anti-biofilm como de aquellos capaces de afectar específicamente a las cepas productoras del polisacárido PIA/PNAG.

2. Una subfracción (SF8) de un extracto procedente de la fermentación de un microorganismo marino inhibe específicamente el crecimiento de cepas de $S$. aureus productoras de PIA/PNAG, sin afectar a aquellas incapaces de producirlo. Este resultado valida la posibilidad de potenciar los efectos colaterales que conlleva la producción del polisacárido PIA/PNAG como potencial estrategia terapéutica antimicrobiana.

3. La sub-fracción 8 (SF8) contiene los principios activos Lumichrome, Malayamicina y Soyasaponina. Ninguno de ellos es individualmente capaz de mostrar la actividad que observamos en el extracto y sus correspondientes fracciones o subfracciones.

4. La sub-fracción 8 (SF8) inhibe la expresión de inhibe la expresión de IcaC, proteína $\mathrm{A}$ y otras proteínas de alto peso molecular, siendo este efecto dependiente de la funcionalidad del operón icaADBC.

5. La cepa $S$. aureus MW2 $\triangle \mathrm{XV}$ y sus derivados restaurados en cada uno de los sistemas de dos componentes no esenciales representan un sistema in vivo idóneo para los cribados de compuestos capaces de bloquear sistemas de dos componentes como GraXRS. 
6. El fármaco Verteporfina, prescrito hasta el momento para el tratamiento de la degeneración macular, es capaz de bloquear el sistema de dos componentes GraXRS.

7. La aplicación tópica de una formulación en base al fármaco Verteporfina es capaz de disminuir significativamente la carga bacteriana en un modelo murino de infección de sutura quirúrgica y reduce la capacidad de Staphylococcus aureus para evadir el efecto letal de los polimorfonucleares en la sangre.

8. El residuo redox- activo cisteína 227 (C227) del dominio catalítico del sensor GraS está implicado, al menos parcialmente, en el efecto inhibidor que ejerce el compuesto Verteporfin sobre el sistema GraXRS.

9. El medicamento Verteporfin podría incluirse en la lista de medicamentos cuya indicación terapéutica está siendo repropuesta para el tratamiento de infecciones asociadas al patógeno $S$. aureus. 
CONCLUSIONS 
upna 
1. Recombina SL has developed a platform that enables rapid and inexpensive phenotypic high throughput screenings aimed at the identification of antibiofilm compounds and those that specifically inhibit PIA/PNAG producer strains.

2. A chemical sub-fraction proceeding from the fermentation of a marine microorganisms specifically inhibits PIA/PNAG producer strains but does not affect their PIA/PNAG negative derivatives. These results validate the hypothesis of considering the reinforcement of negative collateral effects entailed by PIA/PNAG production as a novel antimicrobial therapeutical approach.

3. Sub-fraction 8 (SF8) is composed by Lumichrome, Malayamicin and Soyaponin. Any of these molecules, when tested individually, is capable of reproducing the activity shown by the original extract or their fractions and sub-fractions.

4. Sub-fraction 8 (SF8) exerts a post transcriptional effect on icaADBC operon, inhibiting IcaC protein translation, also inhibits the expression of protein $A$ and other high-molecular-weight protein, being such an outcome dependent on icaADBC functionality.

5. S. aureus $\Delta \mathrm{XV}$ and its derivative strains in which a single nonessential Two Component System has been restored are highly valuable in vivo tools for high troughput screenings aimed at finding molecules capable of targeting Two Component Systems like GraXRS.

6. Verteporfin, a drug that has been prescribed for the treatment of macular degeneration up to date, blocks GraXRS Two Component System. 
Conclusions

7. Topical application of a formulation based on the drug Verteporfin is capable of significantly reducing the bacterial load in a murine model of surgical infection and reduces the ability of Staphylococcus aureus to evade the lethal effect of polymorphonuclear cells in the blood.

8. The redox-active residue cysteine 227 (C227) located in the catalytic domain of GraS is involved, at least partially, in the GraXRS-blocking effect exerted by Verteporfin.

9. Verteporfin is a patent-free FDA-approved drug which could be considered as a novel candidate to be repurposed for anti-S. aureus therapeutical interventions. 
Anexo I

ANEXO I 


\section{Supplementary Information}

\section{Table S1. Data obtained from the HTS}

\begin{tabular}{|c|c|c|c|}
\hline Name & Therapeutic effect & $\begin{array}{l}\text { \% GraXRS } \\
\text { inhibition }\end{array}$ & $\begin{array}{l}\text { \% Growth } \\
\text { inhibition }\end{array}$ \\
\hline Neomycin sulfate & Antibacterial & 180,15 & 39,79 \\
\hline Promazine hydrochloride & Antipsychotic & $-455,16$ & 56,7 \\
\hline Econazole nitrate & Antifungal & 173,73 & 50,6 \\
\hline Ascorbic acid & $\begin{array}{l}\text { Antioxidant CNS Stimulant } \\
\text { Hemostatic }\end{array}$ & 132 & 18,77 \\
\hline Chlorphensin carbamate & Muscle relaxant & 117,88 & 8,82 \\
\hline Hesperidin & $\begin{array}{l}\text { Anti-haemorrhoids } \\
\text { Antineoplastic Antioxidant }\end{array}$ & 115,43 & 9,86 \\
\hline Nicergoline & Anti-ischemic vasodilator & 108,5 & 49,62 \\
\hline Nalbuphine hydrochloride & analgesic & 99,03 & 50,25 \\
\hline Acetylsalicylic acid & $\begin{array}{l}\text { Analgesic Anti-inflammatory } \\
\text { Antipyretic }\end{array}$ & 89,91 & 8 \\
\hline Ornidazole & $\begin{array}{l}\text { Antibacterial antiparasitic } \\
\text { antiprotozoal }\end{array}$ & 89,65 & 25,16 \\
\hline Tazobactam & Antibacterial & $-383,54$ & 60,19 \\
\hline Clomiphene citrate $(Z, E)$ & & 85,25 & 53,63 \\
\hline Streptomycin sulfate & Antibacterial & 83,29 & 29,18 \\
\hline Troglitazone & Antidiabetic anti-inflammatory & 79,86 & 48,71 \\
\hline Daunorubicin hydrochloride & Antibacterial antineoplastic & 70,01 & 30,82 \\
\hline Thioridazine hydrochloride & Antipsychotic & 67,57 & $-26,73$ \\
\hline Oxantel pamoate & Antihelmintic & 66,59 & 6,44 \\
\hline Cefazolin sodium salt & Antibacterial & $-1702,12$ & 95,61 \\
\hline Triclabendazole & Antihelmintic & 64,07 & 2,36 \\
\hline $\begin{array}{r}\text { Scopolamin-N-oxide } \\
\text { hydrobromide }\end{array}$ & Antispastic mydriatic & 63,42 & $-1,86$ \\
\hline $\begin{array}{r}\text { Tiratricol, 3,3',5- } \\
\text { triiodothyroacetic acid }\end{array}$ & $\begin{array}{l}\text { Antihypothyroid } \\
\text { hypocholesterolemic }\end{array}$ & 60,48 & 34,92 \\
\hline Amidopyrine & $\begin{array}{l}\text { Analgesic anti-inflammatory } \\
\text { antipyretic }\end{array}$ & 59,64 & 32,77 \\
\hline Aminocaproic acid & Antifibrionolytic Hemostatic & 58,89 & 8,78 \\
\hline $\begin{array}{r}\text { Trimethobenzamide } \\
\text { hydrochloride }\end{array}$ & Antiemetic & 55,32 & $-15,5$ \\
\hline Azaguanine-8 & Antineoplastic & 53,86 & 4,14 \\
\hline Orphenadrine hydrochloride & Antihistaminic antiparkinsonian & 47,19 & $-7,04$ \\
\hline Sulindac & $\begin{array}{l}\text { nalgesic } \\
\text { antypyretic }\end{array}$ & 45,8 & $-14,37$ \\
\hline Busulfan & Antineoplastic & 43,69 & 29,62 \\
\hline Flavoxate hydrochloride & Antispastic & 43,25 & 2,87 \\
\hline Monensin sodium salt & Antibacterial & 70,62 & 80,76 \\
\hline Hyoscyamine (L) & Antiemetic antispastic mydriatic & 42,71 & 7,27 \\
\hline
\end{tabular}




\begin{tabular}{|c|c|c|c|}
\hline Name & Therapeutic effect & $\begin{array}{l}\text { \% GraXRS } \\
\text { inhibition }\end{array}$ & $\begin{array}{l}\text { \% Growth } \\
\text { inhibition }\end{array}$ \\
\hline Diacerein & Antiarthritic & 42,06 & 15,85 \\
\hline Amisulpride & Antipsychotic & $-310,8$ & 55,94 \\
\hline Cefpodoxime proxetil & Antibacterial & $-306,94$ & 72,71 \\
\hline Demeclocycline hydrochloride & Antibacterial & $-69,98$ & 89,49 \\
\hline Amitryptiline hydrochloride & Antidepressant & 41,03 & $-40,03$ \\
\hline Piretanide & Antihypertensive Diuretic & 39,78 & $-2,32$ \\
\hline Amprolium hydrochloride & anticoccidial antiparasitic & 38,28 & $-13,2$ \\
\hline Ethosuximide & Anticonvulsant & 37,08 & 26,96 \\
\hline Paclitaxel & Antineoplastic & 36,91 & 38,02 \\
\hline Diazoxide & $\begin{array}{l}\text { Antidiuretic antihypertensive } \\
\text { vasodilator }\end{array}$ & 36,44 & 37,36 \\
\hline Valproic acid & Anticonvulsant & 36,39 & 5,2 \\
\hline Phenelzine sulfate & Antidepressant & 36,16 & 33,49 \\
\hline Verteporfin & & 33,95 & 30,24 \\
\hline Imipramine hydrochloride & Antidepressant & 32,51 & $-27,35$ \\
\hline Clebopride maleate & Antiemetic Antispastic & 31,2 & 30,25 \\
\hline Azacytidine-5 & Antineoplastic & 30,95 & 49,41 \\
\hline Adiphenine hydrochloride & Antispastic & 30,73 & $-16,78$ \\
\hline Sildenafil & $\begin{array}{ll}\text { Antihypertensive } & \text { Erectile } \\
\text { dysfunction treatment }\end{array}$ & 30,69 & 20 \\
\hline Carprofen & Anti-inflammatory & 30,38 & 24,96 \\
\hline Chlorpheniramine maleate & $\begin{array}{l}\text { Antihistaminic antitussive } \\
\text { sedative }\end{array}$ & 29,77 & 50,15 \\
\hline Hydralazine hydrochloride & Antihypertensive & 28,62 & 22,14 \\
\hline Prednisone & $\begin{array}{l}\text { Anti-inflammatory antipruritic } \\
\text { Immunosuppressant }\end{array}$ & 27,07 & $-22,18$ \\
\hline Acetazolamide & $\begin{array}{l}\text { Anticonvulsant antiglaucoma } \\
\text { diuretic }\end{array}$ & 26,95 & $-8,17$ \\
\hline Prednicarbate & Anti-inflammatory & 26,56 & $-2,42$ \\
\hline Clotrimazole & Antibacterial antifungal & 26,55 & 15,35 \\
\hline Todralazine hydrochloride & Antihypertensive & 25,89 & $-34,39$ \\
\hline (-)-Emtricitabine & antiviral & $-257,79$ & 56,73 \\
\hline Alexidine dihydrochloride & Antibacterial & 36,85 & 94,38 \\
\hline Riluzole hydrochloride & Antipastic Neuroprotectant & 25,89 & 23,66 \\
\hline Chloropyramine hydrochloride & Antihistaminic & 25,54 & $-4,78$ \\
\hline Diphemanil methylsulfate & Antispastic antiulcer & 25,17 & $-19,33$ \\
\hline Isoflupredone acetate & Anti-inflammatory & 23,83 & $-3,75$ \\
\hline Ketoconazole & Antifungal & 23,57 & 29,91 \\
\hline Diethylstilbestrol & & 23,25 & 35,06 \\
\hline Proglumide & Antiulcer & 22,66 & $-0,42$ \\
\hline Dicumarol & Anticoagulant & $-523,22$ & 74,71 \\
\hline
\end{tabular}




\begin{tabular}{|c|c|c|c|}
\hline Name & Therapeutic effect & $\begin{array}{l}\text { \% GraXRS } \\
\text { inhibition }\end{array}$ & $\begin{array}{l}\text { \% Growth } \\
\text { inhibition }\end{array}$ \\
\hline Desonide & Antipsoriatic & 20,05 & $-0,61$ \\
\hline Merbromin & Antibacterial & $-3277,68$ & 92,27 \\
\hline Verapamil hydrochloride & Antihypertensive & 19,94 & 35,51 \\
\hline Acyclovir & Antiviral & 19,72 & 28,55 \\
\hline Cisatracurium besylate & Muscle relaxant & 19,72 & $-6,16$ \\
\hline Disulfiram & Antabuse effect & 19,14 & 46,42 \\
\hline Cefprozil & Antibacterial & 18,36 & 7,81 \\
\hline Tolfenamic acid & Analgesic anti-inflammatory & 18,25 & 33,52 \\
\hline Etomidate & Anesthetic Hypnotic & 18,05 & 3,23 \\
\hline Tioconazole & Antifungal & 17,7 & 54,75 \\
\hline Nitrofurantoin & Antibacterial & 17,5 & 26,14 \\
\hline Pemetrexed disodium & Antienoplastic & 16,84 & $-0,68$ \\
\hline Carbinoxamine maleate salt & Antihistaminic & 16,48 & $-2,82$ \\
\hline Silodosin & Antihypertenisve & 16,33 & 0,44 \\
\hline Sulconazole nitrate & Antifungal & 82,06 & 72,66 \\
\hline Brompheniramine maleate & $\begin{array}{l}\text { Antihistaminic } \\
\text { antitussive }\end{array}$ & 15,57 & 26,91 \\
\hline Mitoxantrone dihydrochloride & Antineoplastic & 15,07 & 23,47 \\
\hline Oxymetazoline hydrochloride & $\begin{array}{l}\text { Nasal decongestant } \\
\text { vasoconstrictor }\end{array}$ & 14,94 & 39,45 \\
\hline Penciclovir & Antiviral & 14,8 & 30,79 \\
\hline Dibucaine & Local anesthetic & 14,78 & $-14,63$ \\
\hline Spectinomycin dihydrochloride & Antibacterial & 14,51 & $-1,78$ \\
\hline Cytarabine & Antineoplastic & $-241,17$ & 58,32 \\
\hline Furazolidone & & 14 & 12,21 \\
\hline Moxalactam disodium salt & Antibacterial & $-692,97$ & 97,01 \\
\hline S-(+)-ibuprofen & Analgesic Anti-inflammatory & 12,89 & 15,15 \\
\hline Auranofin & Analgesic & 104,81 & 96,32 \\
\hline Indapamide & Antihypertensive diuretic & 12,74 & 42,6 \\
\hline Hydrochlorothiazide & antihypertensive diuretic & 12,24 & $-6,91$ \\
\hline Metformin hydrochloride & anorectic antidiabetic antilipmic & 11,91 & 5,61 \\
\hline Sulmazole & Cardiotonic & 11,79 & 5,44 \\
\hline Oxybenzone & & 11,03 & $-5,77$ \\
\hline Valsartan & Vasodilator Antihypetensive & 10,84 & $-3,63$ \\
\hline Repaglinide & Antidiabetic & 10,38 & 4,34 \\
\hline Gallamine triethiodide & Muscle relaxant & 10,12 & 21,75 \\
\hline Nefopam hydrochloride & Analgesic & 9,68 & 40,78 \\
\hline Raltitrexed & Antineoplastic & 9,63 & $-3,86$ \\
\hline Suprofen & Analgesic Anti-inflammatory & 9,36 & 13,93 \\
\hline
\end{tabular}




\begin{tabular}{|c|c|c|c|}
\hline Name & Therapeutic effect & $\begin{array}{l}\text { \% GraXRS } \\
\text { inhibition }\end{array}$ & $\begin{array}{l}\text { \% Growth } \\
\text { inhibition }\end{array}$ \\
\hline Thyroxine (L) & $\begin{array}{l}\text { Antihypothyroid antilipemic } \\
\text { hypocholesterolemic }\end{array}$ & 9,33 & 13,73 \\
\hline Tacrine hydrochloride & CNS Stimulant & 8,78 & 22,66 \\
\hline Sulbactam & Antibacterial & 8,61 & 4,65 \\
\hline Edrophonium chloride & Anti-fatigue & 8,56 & 24,75 \\
\hline Brimonidine L-Tartrate & Antiglaucoma & 8,43 & 2,22 \\
\hline Guanethidine sulfate & $\begin{array}{l}\text { Antihypertensive } \\
\text { anesthetic }\end{array}$ & 8,05 & 4,75 \\
\hline Tridihexethyl chloride & Antispastic & 6,59 & $-1,83$ \\
\hline Mefenamic acid & $\begin{array}{l}\text { Analgesic anti-inflammatory } \\
\text { antipyretic }\end{array}$ & 6,5 & 17,94 \\
\hline Ethynylestradiol 3-methyl ether & & 6,39 & 14,47 \\
\hline Penbutolol sulfate & $\begin{array}{l}\text { Antianginal Antiarrhythmic } \\
\text { Antihyperensive }\end{array}$ & 6,29 & 4,36 \\
\hline Lithocholic acid & Cholangogue Choleretic & 6,06 & 25,71 \\
\hline Novobiocin sodium salt & Antibacterial & 113,09 & 83,58 \\
\hline Antimycin A & Antibacterial antifungal & 5,46 & 45,65 \\
\hline Clobutinol hydrochloride & Antitusive & $-227,43$ & 58,87 \\
\hline Dichlorphenamide & Antiglaucoma & 5,35 & $-1,62$ \\
\hline Zoxazolamine & $\begin{array}{lll}\text { Antigout } & \text { Muscle } & \text { relaxant } \\
\text { Uricosuric } & & \\
\end{array}$ & 5,22 & 6 \\
\hline Clinafloxacin & Antibacterial & 62,07 & 77,42 \\
\hline Trimipramine maleate salt & Antidepressant & 5,03 & $-2,92$ \\
\hline Piromidic acid & Antibactierial & 4,87 & 1,47 \\
\hline Allantoin & Antipsoriatic Vilnerary & 3,48 & $-5,66$ \\
\hline $\begin{array}{r}\text { Nafcillin sodium salt } \\
\text { monohydrate }\end{array}$ & Antibacterial & $-488,7$ & 96,58 \\
\hline Hydroxyzine dihydrochloride & antihitaminic & 3,28 & 46,1 \\
\hline Rofecoxib & Anti-inflammatory & 2,98 & 8,5 \\
\hline Dipyridamole & $\begin{array}{l}\text { Anticoagulant antiplatelet } \\
\text { vasodilator }\end{array}$ & 2,31 & 45,14 \\
\hline $\begin{array}{r}\text { Phenylpropanolamine } \\
\text { hydrochloride }\end{array}$ & $\begin{array}{l}\text { Antihypotensive } \quad \text { Nasal } \\
\text { Decongestant Vasoconstrictor }\end{array}$ & 2,3 & 17,48 \\
\hline Miconazole & Antifungal & 2,1 & 53,1 \\
\hline Milnacipran hydrochloride & Antidepressant Analgesic & 2,07 & 4,57 \\
\hline Dilazep dihydrochloride & Antiplatelet vasodilator & 1,74 & 14,01 \\
\hline $\begin{array}{r}\text { Amiloride hydrochloride } \\
\text { dihydrate }\end{array}$ & antihypertensive diuretic & 1,7 & $-4,42$ \\
\hline Chlorzoxazone & Anticonvulsant Muscle relaxant & 1,69 & 23,43 \\
\hline Canrenoic acid potassium salt & Antihypertensive diuretic & 1,47 & 49,88 \\
\hline Roxithromycin & Antibacterial & 107,08 & 81,98 \\
\hline Methazolamide & Antiglaucoma Diuretic & 1,41 & $-2,55$ \\
\hline Bisoprolol fumarate & $\begin{array}{l}\text { Antianginal Antiarrhythmic } \\
\text { Antihypertensive }\end{array}$ & 1,11 & 10,04 \\
\hline
\end{tabular}




\begin{tabular}{|c|c|c|c|}
\hline Name & Therapeutic effect & $\begin{array}{l}\text { \% GraXRS } \\
\text { inhibition }\end{array}$ & $\begin{array}{l}\text { \% Growth } \\
\text { inhibition }\end{array}$ \\
\hline Atracurium besylate & Curarizing & 0,78 & -4 \\
\hline Sulfamethoxypyridazine & Antibacterial & 0,78 & 11,18 \\
\hline Haloprogin & Antifungal & 0,46 & 47,63 \\
\hline Tyloxapol & Mucolytic & 0,15 & $-3,13$ \\
\hline Oxyphenbutazone & Anti-inflammatory & $-0,11$ & 1,48 \\
\hline Troxipide & Antiulcer & $-0,67$ & 3,9 \\
\hline Gestrinone & Contraceptive & $-0,95$ & $-4,9$ \\
\hline Methyldopa (L,-) & Antihypertensive & $-1,5$ & 23,67 \\
\hline Ubenimex & $\begin{array}{l}\text { Antineoplastic } \\
\text { Immunomodulator }\end{array}$ & $-1,83$ & 8,18 \\
\hline Indinavir sulfate & Antiviral & $-2,1$ & 12,26 \\
\hline Pyrithyldione & Hypnotic Sedative & $-2,36$ & $-0,49$ \\
\hline Loracarbef & Antibacterilal & -208 & 64,86 \\
\hline Etoposide & Antineoplatic & $-2,42$ & 31,84 \\
\hline Gemfibrozil & $\begin{array}{l}\text { Hypocholesterolemic lipid- } \\
\text { lowering }\end{array}$ & $-2,79$ & 31,14 \\
\hline Testosterone propionate & Anabolic & $-3,23$ & 9,71 \\
\hline Albendazole & Antihelmintic antiparasitic & $-4,56$ & 12,37 \\
\hline Doxapram hydrochloride & Analeptic Eupneic & $-4,89$ & 5,08 \\
\hline Idebenone & Antineoplastic & $-5,13$ & 7,44 \\
\hline Amorolfine hydrochloride & Antifungal & $-6,16$ & 8,28 \\
\hline Meglumine & $\begin{array}{l}\text { Antileishmanial } \quad \text { Antiseptic } \\
\text { Expectorant }\end{array}$ & $-6,55$ & $-2,24$ \\
\hline Metronidazole & $\begin{array}{l}\text { Antiamebic antibacterial } \\
\text { antiprotozoal }\end{array}$ & $-6,87$ & 43,47 \\
\hline Flufenamic acid & $\begin{array}{l}\text { Analgesic anti-inflammatory } \\
\text { antipytetic }\end{array}$ & $-7,92$ & 35,14 \\
\hline Trifluoperazine dihydrochloride & Antiemetic antipsychotic & $-8,18$ & 12,76 \\
\hline Carbamazepine & $\begin{array}{l}\text { Analgesic } \\
\text { antidiuretic }\end{array}$ & $-9,02$ & 15,35 \\
\hline Denatonium benzoate & & $-9,11$ & $-2,3$ \\
\hline Esmolol hydrochloride & Antiarrhythmic & $-9,52$ & 3,08 \\
\hline Carbachol & Antihypertenisve Vasodilator & $-9,83$ & 8,81 \\
\hline Pravastatin & Antilipemic & $-10,01$ & 17,7 \\
\hline Ketanserin tartrate hydrate & Antihypertensive Vasodilator & $-10,37$ & 0,68 \\
\hline Carbenoxolone disodium salt & Antiulcer & $-10,37$ & 31,75 \\
\hline Digoxigenin & & $-10,63$ & $-1,84$ \\
\hline Quinethazone & Antihypertensive Diuretic & -11 & 8,13 \\
\hline Rabeprazole Sodium salt & Antiulcer & $-11,03$ & 12,15 \\
\hline Amlexanox & $\begin{array}{l}\text { Anti-inflammatory } \\
\text { Immunomodulator }\end{array}$ & $-11,48$ & 6,07 \\
\hline Fulvestrant & Antineoplastic & $-11,92$ & 37,59 \\
\hline (+) -Levobunolol hydrochloride & Antiglaucoma & $-11,94$ & 12,79 \\
\hline
\end{tabular}




\begin{tabular}{|c|c|c|c|}
\hline Name & Therapeutic effect & $\begin{array}{l}\text { \% GraXRS } \\
\text { inhibition }\end{array}$ & $\begin{array}{l}\text { \% Growth } \\
\text { inhibition }\end{array}$ \\
\hline Morantel tartrate & Antihelmintic & $-11,95$ & 5,28 \\
\hline Fludarabine & Antineoplastic & -12 & 44,86 \\
\hline Phentolamine hydrochloride & Antihypertensive vasodilator & $-12,39$ & 33,97 \\
\hline Estradiol Valerate & Contraceptive & $-12,79$ & 39,05 \\
\hline Didanosine & Antiviral & $-12,87$ & 35,22 \\
\hline Rosiglitazone Hydrochloride & Antidiabetic & $-13,02$ & 22,84 \\
\hline Scopolamine hydrochloride & Antiemetic & $-13,14$ & 7,33 \\
\hline Lorglumide sodium salt & Antiulcer & $-13,48$ & 18,92 \\
\hline Etanidazole & Antineoplastic chemosensitizer & $-13,95$ & 5,37 \\
\hline Fenbufen & $\begin{array}{l}\text { Analgesic anti-inflammatory } \\
\text { antipytetic }\end{array}$ & $-14,14$ & 43,62 \\
\hline Hexetidine & Antifungal antiseptic & $-14,41$ & 3,16 \\
\hline Sulfaguanidine & Antibacterial & $-14,59$ & $-8,92$ \\
\hline Pentobarbital & Anesthetic hypnotic sedative & $-14,62$ & 2,31 \\
\hline Enalapril maleate & Antihypertensive & $-14,88$ & 12,35 \\
\hline Dienestrol & & $-15,46$ & 11,33 \\
\hline Nifedipine & $\begin{array}{l}\text { Antianginal antihypertensive } \\
\text { vasodilator }\end{array}$ & $-15,96$ & 20,06 \\
\hline Bacitracin & Antibacterial & $-566,7$ & 95,46 \\
\hline Gemifloxacin mesylate & Antibacterial & 56,18 & 88,42 \\
\hline Lynestrenol & Contraceptive & $-16,03$ & 49,14 \\
\hline Mepivacaine hydrochloride & Local anesthetic & $-16,23$ & 15,16 \\
\hline Nomifensine maleate & Antidepressant & $-16,29$ & 54,22 \\
\hline Moroxidine hydrochloride & Antiviral & $-16,63$ & 33,73 \\
\hline Liranaftate & Antifungal & $-17,29$ & $-3,87$ \\
\hline Prochlorperazine dimaleate & Antiemetic Antiphychotic & $-17,54$ & 31,07 \\
\hline Cladribine & Antineoplastic & $-190,03$ & 56,17 \\
\hline Iopromide & Contrastant & $-17,55$ & 11,66 \\
\hline Promethazine hydrochloride & Antihistaminic Sedative & $-17,87$ & 2,94 \\
\hline Iopamidol & Contrastant & $-17,94$ & 13,36 \\
\hline Fluphenazine dihydrochloride & Antipsychotic & -18 & 22,94 \\
\hline Azilsartan kamedoxomil & Antihypertensive & $-18,15$ & 52,25 \\
\hline Bemegride & CNS Stimulant & $-18,76$ & $-4,01$ \\
\hline Clofilium tosylate & Antirrhythmic & $-19,04$ & 1,63 \\
\hline Thonzonium bromide & Antiseptic & $-1906,98$ & 97,79 \\
\hline Deoxycorticosterone & Anti-inflammatory & $-19,28$ & 15,63 \\
\hline Meprylcaine hydrochloride & Local anesthetic & $-19,37$ & 18,81 \\
\hline lobenguane sulfate & Antineoplastic & $-19,44$ & 10,03 \\
\hline Danazol & Anabolic antigonadotropin & $-19,49$ & 48,35 \\
\hline
\end{tabular}




\begin{tabular}{|c|c|c|c|}
\hline Name & Therapeutic effect & $\begin{array}{l}\% \text { GraXRS } \\
\text { inhibition }\end{array}$ & $\begin{array}{l}\% \text { Growth } \\
\text { inhibition }\end{array}$ \\
\hline Crotamiton & Antipruritic & $-20,88$ & 5,88 \\
\hline Niacin & Antilipemic Vasodilator & $-21,64$ & 0,13 \\
\hline Canrenone & Diuretic & $-21,66$ & $-2,78$ \\
\hline Zalcitabine & Antiviral & $-21,74$ & 17,05 \\
\hline Lamivudine & Antiviral & $-184,31$ & 57,07 \\
\hline Simvastatin & Antilipemic & $-21,83$ & 21,03 \\
\hline Ambroxol hydrochloride & Expectorant Mucolytic & $-21,95$ & 47,43 \\
\hline Anastrozole & Antineoplastic & $-22,14$ & 9,61 \\
\hline Xylometazoline hydrochloride & $\begin{array}{ll}\text { Nasal } & \text { decongestant } \\
\text { vasoconstrictor } & \end{array}$ & $-22,18$ & 42,41 \\
\hline Pyrantel tartrate & Antihelmintic & $-23,18$ & 26,85 \\
\hline Benzthiazide & Antihypertensive Diuretic & $-23,29$ & 16,11 \\
\hline Piperacetazine & Antipsychotic & $-23,5$ & 4,93 \\
\hline Loperamide hydrochloride & Antidiarrheal & $-24,09$ & 46,02 \\
\hline Pergolide mesylate & Antiparkinsonian & $-24,87$ & 36,71 \\
\hline Sulfadimethoxine & Antibacterial & $-24,87$ & 10,97 \\
\hline $\begin{array}{r}\text { Dehydroisoandosterone 3- } \\
\text { acetate }\end{array}$ & & $-24,89$ & 24,58 \\
\hline Cefaclor hydrate & Antibacterial & $-25,06$ & 20,33 \\
\hline Isoxsuprine hydrochloride & Vasodilator & $-25,12$ & 15,33 \\
\hline Algestone acetophenide & $\begin{array}{l}\text { Contraceptive } \\
\text { inflammatory }\end{array}$ & $-25,44$ & 16,35 \\
\hline Mephentermine hemisulfate & $\begin{array}{l}\text { Antihypotensive } \\
\text { Vasoconstrictor }\end{array}$ & $-25,67$ & $-0,93$ \\
\hline Nevirapine & Antiviral & $-25,98$ & 2,05 \\
\hline Idoxuridine & Antiviral & -26 & 28,24 \\
\hline Paromomycin sulfate & Antiamebic Antibacterial & $-26,04$ & 38,02 \\
\hline Sotalol hydrochloride & $\begin{array}{l}\text { Antianginal Antiarrhythmic } \\
\text { Antihypertenisve }\end{array}$ & $-26,15$ & 0,64 \\
\hline Dosulepin hydrochloride & Antidepressant CNS stimulant & $-26,53$ & 6,63 \\
\hline Sulfadoxine & Antibacterial & $-26,59$ & 23,44 \\
\hline Azaperone & Antipsychotic Sedative & $-26,7$ & 11,73 \\
\hline Eprosartan mesylate & Antihypertenisve & $-27,69$ & 17,46 \\
\hline Raloxifene hydrochloride & & $-175,94$ & 55,81 \\
\hline Bupropion hydrochloride & Antidepressant & $-27,97$ & 17,82 \\
\hline Entacapone & Antiparkinsonian & $-28,06$ & 10,82 \\
\hline Enilconazole & Antifungal & $-28,16$ & 7,65 \\
\hline Procarbazine hydrochloride & Antineoplastic & $-28,47$ & 14,3 \\
\hline Buspirone hydrochloride & & $-28,49$ & 8,38 \\
\hline Methacycline hydrochloride & Antibacterial & 91,59 & 88,74 \\
\hline Floxuridine & Antineoplastic Antiviral & 119 & 73,49 \\
\hline
\end{tabular}




\begin{tabular}{|c|c|c|c|}
\hline Name & Therapeutic effect & $\begin{array}{l}\text { \% GraXRS } \\
\text { inhibition }\end{array}$ & $\begin{array}{l}\text { \% Growth } \\
\text { inhibition }\end{array}$ \\
\hline Amiprilose hydrochloride & Immunomodulator & $-28,69$ & 20,28 \\
\hline Propantheline bromide & Antispastic & $-28,71$ & 15,62 \\
\hline Indatraline hydrochloride & Antidepressant & $-28,82$ & 9,43 \\
\hline Zolmitriptan & & $-29,48$ & 16,44 \\
\hline Fentiazac & Anti-inflammatory & $-29,49$ & 28,52 \\
\hline Sulfamethoxazole & Antibacterial & $-29,88$ & 50,57 \\
\hline Carbetapentane citrate & $\begin{array}{l}\text { Antispastic Antitussive Local } \\
\text { anesthetic }\end{array}$ & $-29,89$ & 35,12 \\
\hline Trimebutine & Antispastic & $-30,3$ & 8,05 \\
\hline Dimethadione & Anticonvulsant & $-31,02$ & 14,78 \\
\hline Reserpine & Antipsychotic & $-31,21$ & 25,06 \\
\hline Dolasetron mesilate & Antiemetic & $-31,24$ & 4,27 \\
\hline (R)-Propranolol hydrochloride & $\begin{array}{l}\text { Antianginal Antiarrhythmic } \\
\text { Antihyperensive }\end{array}$ & $-31,26$ & 20,01 \\
\hline Balsalazide Sodium & Anti-inflammatory & $-31,32$ & 13,93 \\
\hline Nelfinavir mesylate & Antiviral Antineoplastic & $-31,57$ & 8,27 \\
\hline Darifenacin hydrobromide & & $-31,57$ & 2,75 \\
\hline $\begin{array}{r}\text { Meclofenamic acid sodium salt } \\
\text { monohydrate }\end{array}$ & Anti-inflammatory antipytetic & $-31,62$ & 37,53 \\
\hline Pepstatin A & Antiviral & $-31,76$ & 18,42 \\
\hline Decamethonium bromide & Muscle relaxant & $-31,98$ & 3,55 \\
\hline Nicotinamide & & $-32,25$ & 12,17 \\
\hline Bezafibrate & $\begin{array}{l}\text { Antilipemic } \\
\text { Hypocholesterolemic Lipid- } \\
\text { lowering }\end{array}$ & $-32,54$ & 34,48 \\
\hline Tolmetin sodium salt dihydrate & Anti-inflammatory & $-33,03$ & 29,83 \\
\hline Ciprofibrate & Hypocholesterolemic & $-33,08$ & 26,47 \\
\hline Lofepramine & $\begin{array}{l}\text { Antidepressant } \quad \text { Anxiolytic } \\
\text { Sedative }\end{array}$ & $-33,56$ & 13,79 \\
\hline loversol & Contrastant & $-33,78$ & 13,59 \\
\hline Flurbiprofen & Analgesic Anti-inflammatory & $-34,07$ & 36,26 \\
\hline Delavirdine & & $-34,25$ & 9,57 \\
\hline Althiazide & Antihypertensive & $-34,36$ & 3,74 \\
\hline Metolazone & Antihypertensive diuretic & $-34,4$ & 49,31 \\
\hline Nicorandil & Antianginal vasodilator & $-34,45$ & 50,28 \\
\hline Alfuzosin hydrochloride & Vasodilator & $-34,51$ & 8,73 \\
\hline Ranolazine & Antianginal & $-34,64$ & 18,65 \\
\hline Mesalamine & Anti-inflammatory & $-35,03$ & 17,32 \\
\hline (R)-(+)-Atenolol & $\begin{array}{l}\text { Antianginal Antiarrhythmic } \\
\text { Antihypertenisve }\end{array}$ & $-35,64$ & 15,89 \\
\hline Antipyrine & $\begin{array}{l}\text { Analgesic anti-inflammatory } \\
\text { antipyretic }\end{array}$ & $-35,85$ & 19,66 \\
\hline Benzylpenicillin sodium & Antibacterial & $-161,88$ & 57,51 \\
\hline
\end{tabular}




\begin{tabular}{|c|c|c|c|}
\hline Name & Therapeutic effect & $\begin{array}{l}\text { \% GraXRS } \\
\text { inhibition }\end{array}$ & $\begin{array}{l}\text { \% Growth } \\
\text { inhibition }\end{array}$ \\
\hline Hydroflumethiazide & antihypertensive diuretic & $-36,07$ & 34,12 \\
\hline Sertaconazole nitrate & Antibacterial Antifungal & $-36,3$ & 28,45 \\
\hline Articaine hydrochloride & Anesthetic & $-36,58$ & 6,06 \\
\hline Clidinium bromide & Antispastic & $-36,79$ & 21,1 \\
\hline Baclofen $(R, S)$ & $\begin{array}{l}\text { Antispastic, muscle relaxant } \\
\text { alcohol addiction treatment }\end{array}$ & $-36,9$ & 31,34 \\
\hline Megestrol acetate & Antineoplastic Contraceptive & $-37,15$ & 11,31 \\
\hline Sulfanilamide & Antibacterial & $-37,2$ & 1,39 \\
\hline Indoprofen & Analgesic Anti-inflammatory & $-37,21$ & 18,34 \\
\hline Donepezil hydrochloride & $\begin{array}{l}\text { Anti-Alzheimer Antipsychotic } \\
\text { CNS Stimulant }\end{array}$ & $-37,59$ & 20,14 \\
\hline Serotonin hydrochloride & CNS stimulant & $-38,31$ & 3,06 \\
\hline Flucloxacillin sodium & Antibacterial & $-873,24$ & 96,33 \\
\hline Norethynodrel & Contraceptive & $-38,4$ & 25,25 \\
\hline Mecamylamine hydrochloride & Antihypertensive & $-38,43$ & 18,72 \\
\hline Carbimazole & Antihyperthyroid & $-158,16$ & 60,16 \\
\hline Ethionamide & Antibacterial & $-38,71$ & 20,1 \\
\hline Droperidol & Antipsychotic & $-39,45$ & 30,66 \\
\hline Alprenolol hydrochloride & $\begin{array}{l}\text { Antianginal antiarrhythmic } \\
\text { antihypertensive }\end{array}$ & $-39,6$ & 20,27 \\
\hline Colistin sulfate & Antibacterial & $-40,03$ & 7,24 \\
\hline Rivastigmine & & $-40,28$ & 18,34 \\
\hline Deflazacort & $\begin{array}{l}\text { Anti-inflammatory } \\
\text { Immunosuppressant }\end{array}$ & $-40,63$ & 30,15 \\
\hline Chicago sky blue 6B & & $-40,83$ & 12,46 \\
\hline Mafenide hydrochloride & Antibacterial antiseptic & $-41,09$ & 25,49 \\
\hline Dorzolamide hydrochloride & Antiglaucoma Antihypertensive & $-41,49$ & 23,9 \\
\hline Clioquinol & $\begin{array}{l}\text { Antiamebic } \\
\text { Antiseptic }\end{array}$ & $-41,7$ & 12,03 \\
\hline Vecuronium bromide & Muscle relaxant & $-42,01$ & 38,56 \\
\hline Levofloxacin & Antibacterial & $-18,19$ & 84,78 \\
\hline Rebamipide & Antiulcer & $-42,04$ & $-2,32$ \\
\hline Mianserine hydrochloride & Antidepressant anxiolytic & $-42,11$ & 54,9 \\
\hline Fenoldopam & Antihypertenisve Vasodilator & $-42,15$ & 16,48 \\
\hline Nylidrin & Vasodilator & $-42,16$ & 19,62 \\
\hline Procaine hydrochloride & Local anesthetic & $-42,26$ & 24,61 \\
\hline Saquinavir mesylate & Antiviral & $-42,73$ & 18,75 \\
\hline Fluocinolone acetonide & Anti-inflammatory & $-42,78$ & 29,68 \\
\hline Vatalanib & Antineoplastic & $-42,79$ & 13,83 \\
\hline Itraconazole & Antifungal & $-43,49$ & 7,03 \\
\hline Dapsone & Antibacterial antimalarial & $-43,51$ & 27,04 \\
\hline
\end{tabular}




\begin{tabular}{|c|c|c|c|}
\hline Name & Therapeutic effect & $\begin{array}{l}\text { \% GraXRS } \\
\text { inhibition }\end{array}$ & $\begin{array}{l}\text { \% Growth } \\
\text { inhibition }\end{array}$ \\
\hline Toremifene & Antineoplastic & $-43,53$ & 15,8 \\
\hline Topiramate & Anticonvulsant Antimigraine & $-43,96$ & 24,78 \\
\hline Tribenoside & & $-43,97$ & 27,84 \\
\hline Butoconazole nitrate & Antibacterial antifungal & $-44,13$ & 36,77 \\
\hline Phenethicillin potassium salt & Antibacterial & $-44,54$ & 26,1 \\
\hline Histamine dihydrochloride & Antineoplastic Analgesic & $-44,94$ & 17,03 \\
\hline Nomegestrol acetate & Contraceptive & $-45,08$ & 15,32 \\
\hline Isopyrin hydrochloride & $\begin{array}{l}\text { Analgesic Anti-inflammatory } \\
\text { antipyretic }\end{array}$ & $-45,41$ & 0,1 \\
\hline Pancuronium bromide & Muscle relaxant & $-45,42$ & 8,38 \\
\hline Glibenclamide & Antidiabetic & $-45,58$ & 19,29 \\
\hline Acetylsalicylsalicylic acid & $\begin{array}{l}\text { Analgesic anticoagulant anti- } \\
\text { inflammatory }\end{array}$ & $-45,9$ & 52,71 \\
\hline S(-)Eticlopride hydrochloride & & $-46,05$ & 19,06 \\
\hline Fenbendazole & Antihelmintic & $-46,46$ & 42,38 \\
\hline Dropropizine $(R, S)$ & Antitussive & $-46,68$ & 23,53 \\
\hline Nialamide & Antidepressant & $-46,77$ & 23,53 \\
\hline Oxalamine citrate salt & $\begin{array}{l}\text { Anti-inflammatory Antispastic } \\
\text { Antitussive }\end{array}$ & $-47,48$ & 24,45 \\
\hline Eserine hemisulfate salt & Antiglaucoma & $-47,65$ & 8,28 \\
\hline Benperidol & Antipsychotic & $-47,77$ & 4,37 \\
\hline (-)-Isoproterenol hydrochloride & Bronchodilator Vasodilator & $-48,08$ & 25,75 \\
\hline Pentylenetetrazole & Analeptic CNS stimulant & $-48,36$ & 29,53 \\
\hline Ethoxzolamide & Antiglaucoma Antiulcer Diuretic & $-48,82$ & 11,04 \\
\hline Nifenazone & $\begin{array}{l}\text { Analgesic anti-inflammatory } \\
\text { antipytetic }\end{array}$ & $-48,87$ & 41,43 \\
\hline Pheniramine maleate & $\begin{array}{l}\text { Antihistaminic antitussive } \\
\text { sedative }\end{array}$ & $-49,13$ & 21,16 \\
\hline Neostigmine bromide & Anti-fatigue & $-49,28$ & 41,43 \\
\hline Metyrapone & & $-49,42$ & 16,42 \\
\hline Amphotericin B & Antibacterial antifungal & $-49,42$ & 17,85 \\
\hline Hexestrol & Antineoplastic & $-49,77$ & 34,27 \\
\hline Clocortolone pivalate & Anti-inflammatory & $-49,88$ & 15,29 \\
\hline Nefazodone hydrochloride & Antidepressant & $-50,74$ & 37,07 \\
\hline D-cycloserine & Antibacterial & $-50,91$ & 29,21 \\
\hline loxaglic acid & Contrastant & $-50,93$ & 27,16 \\
\hline Cilnidipine & Antihypertensive & $-51,4$ & 47,94 \\
\hline Procyclidine hydrochloride & $\begin{array}{l}\text { Antiparkinsonian } \\
\text { relaxant }\end{array}$ & $-51,89$ & 31,5 \\
\hline Dicyclomine hydrochloride & Antispastic & $-52,29$ & 30,98 \\
\hline Ethaverine hydrochloride & Antispastic & $-52,31$ & 27,27 \\
\hline Avermectin B1 & Antihelmintic & $-52,87$ & 52,15 \\
\hline
\end{tabular}




\begin{tabular}{|c|c|c|c|}
\hline Name & Therapeutic effect & $\begin{array}{l}\text { \% GraXRS } \\
\text { inhibition }\end{array}$ & $\begin{array}{l}\% \text { Growth } \\
\text { inhibition }\end{array}$ \\
\hline Diclofenac sodium & Anti-inflammatory & $-138,18$ & 60,5 \\
\hline Ketoprofen & $\begin{array}{l}\text { Analgesic anti-inflammatory } \\
\text { antipytetic }\end{array}$ & $-53,21$ & 36,49 \\
\hline Bicalutamide & Antineoplastic & $-53,59$ & 22,13 \\
\hline Naftifine hydrochloride & Antifungal & $-53,66$ & 37,86 \\
\hline Mefexamide hydrochloride & CNS Stimulant & $-53,78$ & 48,05 \\
\hline Tazarotene & Antipsoriatic antiacne & $-53,78$ & 12,37 \\
\hline $\begin{array}{r}\text { N-Acetyl-DL-homocysteine } \\
\text { Thiolactone }\end{array}$ & Expectorant & $-53,91$ & $-2,78$ \\
\hline Idazoxan hydrochloride & Antiparkinsonian Antipsychotic & -54 & 19,96 \\
\hline Itopride & & $-54,1$ & 10,52 \\
\hline Ethambutol dihydrochloride & Antibacterial & $-54,17$ & 33,98 \\
\hline Loxapine succinate & Antipsychotic anxiolytic & $-54,31$ & 42,15 \\
\hline Ronidazole & $\begin{array}{ll}\text { Antibacterial } & \text { Antiprotozoal } \\
\text { Antitrichomonal } & \end{array}$ & $-54,42$ & 26,93 \\
\hline Celecoxib & Anti-inflammatory & $-55,09$ & 35,82 \\
\hline Estrone & & $-55,22$ & 27,77 \\
\hline Bethanechol chloride & & $-55,47$ & 36,84 \\
\hline Iopanoic acid & Contrastant & $-55,73$ & 47,98 \\
\hline Panthenol (D) & Anti-alopecia & $-55,74$ & 26,13 \\
\hline Nafronyl oxalate & $\begin{array}{l}\text { Anti-ischemic } \quad \text { Antispastic } \\
\text { Vasodilator }\end{array}$ & $-55,77$ & 41,61 \\
\hline Mexiletine hydrochloride & Antirrhythmic local anesthetic & $-55,78$ & 15,94 \\
\hline Levalbuterol hydrochloride & Antiasthmatic Bronchodilator & $-56,2$ & 34 \\
\hline Acarbose & Antidiabetic & $-56,2$ & 13,37 \\
\hline Glutethimide, para-amino & Antineoplastic & $-56,24$ & 13 \\
\hline Atorvastatin & & $-56,45$ & 26,4 \\
\hline Enalaprilat dihydrate & Antihypertenisve & $-56,69$ & 17,43 \\
\hline lodixanol & Contrastant & $-56,77$ & 26,9 \\
\hline Sarafloxacin & Antibacterial & 50,98 & 78,47 \\
\hline Rifabutin & Antibacterial & $-263,66$ & 94,54 \\
\hline Apramycin & Antibacterial & $-57,08$ & 24,34 \\
\hline 4-aminosalicylic acid & Antibacterial Antifungal & $-57,38$ & 32,03 \\
\hline Estramustine & Antineoplastic & $-57,75$ & 28,39 \\
\hline Perindopril & Antihypertenisve & $-57,86$ & 35,66 \\
\hline Quinapril hydrochloride & Antihypertensive & $-58,34$ & 37,86 \\
\hline Bufexamac & $\begin{array}{l}\text { Analgesic anti-inflammatory } \\
\text { antipyretic }\end{array}$ & $-58,36$ & $-0,36$ \\
\hline Primaquine diphosphate & Antimalarial & $-58,57$ & 19,87 \\
\hline Mirtazapine & Antidepressant & $-58,58$ & 18,26 \\
\hline Benzoxiquine & Antiseptic & $-58,6$ & 26,12 \\
\hline
\end{tabular}




\begin{tabular}{|c|c|c|c|}
\hline Name & Therapeutic effect & $\begin{array}{l}\text { \% GraXRS } \\
\text { inhibition }\end{array}$ & $\begin{array}{l}\text { \% Growth } \\
\text { inhibition }\end{array}$ \\
\hline Acetaminophen & Analgesic Antipyretic & $-58,62$ & 30,78 \\
\hline Nadifloxacin & Antibacterial & 19,1 & 91,49 \\
\hline Fluvoxamine maleate & Antidepressant CNS Stimulant & $-58,62$ & 20,82 \\
\hline Viomycin sulfate & Antibacterial & $-58,64$ & 21,3 \\
\hline Anthralin & Antipsoriatic & $-58,7$ & 35,17 \\
\hline Mevastatin & Hypocholesterolemic & $-58,74$ & 7,12 \\
\hline Triamterene & antihypertensive diuretic & $-58,8$ & 33,33 \\
\hline Atropine sulfate monohydrate & Antispastic mydriatic & $-58,8$ & 10,64 \\
\hline Stavudine & Antiviral & $-59,02$ & 42,59 \\
\hline Cefepime hydrochloride & Antibacterial & $-627,3$ & 96,49 \\
\hline Rifaximin & Antibacterial & $-73,94$ & 94,16 \\
\hline Fluvastatin sodium salt & Antilipemic & $-59,17$ & 21,35 \\
\hline Selegiline hydrochloride & Antiparkinsonian & $-59,32$ & 8,09 \\
\hline Valdecoxib & Antiarthritic Anti-inflammatory & $-59,55$ & 23,53 \\
\hline Doxycycline hydrochloride & Antibacterial & 103,15 & 89,58 \\
\hline Carbadox & Antibacterial & $-128,95$ & 68,09 \\
\hline Fleroxacin & Antibacterial & 71,83 & 75,89 \\
\hline Clavulanate potassium salt & Antibacterial & $-182,94$ & 69,76 \\
\hline Nalmefene hydrochloride & & $-59,61$ & 29,23 \\
\hline Ethopropazine hydrochloride & Antiparkinsonian & $-60,17$ & 37,18 \\
\hline Perospirone & Antipsychotic & $-60,17$ & 23,07 \\
\hline Pyridostigmine iodide & & $-60,19$ & 7,04 \\
\hline Levocabastine hydrochloride & Antihistaminic & $-60,46$ & 13,11 \\
\hline Adamantamine fumarate & Antiviral & $-60,47$ & 14,13 \\
\hline Homatropine hydrobromide $(R, S)$ & Antispastic mydriatic & $-60,49$ & 23,02 \\
\hline locetamic acid & Contrastant & $-60,5$ & 31,59 \\
\hline Antipyrine, 4-hydroxy & & $-60,54$ & 29,84 \\
\hline Acebutolol hydrochloride & $\begin{array}{l}\text { Antianginal antiarrhythmic } \\
\text { antihypertensive }\end{array}$ & $-60,61$ & 21,49 \\
\hline Benoxinate hydrochloride & Local anesthetic & $-61,1$ & 17,15 \\
\hline Urosiol & & $-61,13$ & 18,36 \\
\hline Imatinib & Antineoplastic & $-61,16$ & 17,69 \\
\hline Oxethazaine & Local anesthetic & $-61,6$ & 27,72 \\
\hline Spironolactone & Diuretic & $-62,18$ & 47,47 \\
\hline Diphenhydramine hydrochloride & antihitaminic & $-62,3$ & 26,15 \\
\hline Cefdinir & Antibacterial & $-543,28$ & 96,98 \\
\hline Phenothiazine & $\begin{array}{l}\text { Antipsychotic } \\
\text { Antimigraine }\end{array}$ & $-62,33$ & 23,09 \\
\hline Nabumetone & Analgesic Anti-inflammatory & $-62,68$ & 15,39 \\
\hline
\end{tabular}




\begin{tabular}{|c|c|c|c|}
\hline Name & Therapeutic effect & $\begin{array}{l}\% \text { GraXRS } \\
\text { inhibition }\end{array}$ & $\begin{array}{l}\text { \% Growth } \\
\text { inhibition }\end{array}$ \\
\hline Formoterol fumarate & Antiasthmatic & $-62,82$ & 21,37 \\
\hline Montelukast & Antiasthmatic & $-62,85$ & 41,46 \\
\hline Butacaine & Anesthetic & $-62,86$ & 36,75 \\
\hline Etilefrine hydrochloride & Vasoconstrictor & $-62,93$ & 29,33 \\
\hline Nicardipine hydrochloride & Antianginal Antihypertensive & $-62,98$ & 36,03 \\
\hline Cyproterone acetate & Antineoplastic Contraceptive & $-63,04$ & 31,66 \\
\hline Flucytosine & Antifungal & $-63,07$ & 24,9 \\
\hline Ceftibuten & Antibacterial & $-63,6$ & 43,19 \\
\hline Captopril & Antihypertensive vasodilator & $-63,65$ & 32,62 \\
\hline Triclosan & $\begin{array}{l}\text { Antibacterial } \\
\text { Antiseptic }\end{array}$ & 66,77 & 92,54 \\
\hline Enoxacin & Antibacterial & 59,74 & 75,6 \\
\hline Prothionamide & Antibacterial & $-63,98$ & 23,13 \\
\hline Latanoprost & Antiglaucoma & $-64,27$ & 35,04 \\
\hline Pramipexole dihydrochloride & Antiparkinsonian & $-64,32$ & 24,22 \\
\hline Flumethasone pivalate & Anti-inflammatory & $-64,7$ & 21,65 \\
\hline Telmisartan & Antihypertensive & $-122,3$ & 56,98 \\
\hline Trapidil & Vasodilator & $-64,79$ & 25,38 \\
\hline Ticarcillin sodium & Antibacterial & $-65,01$ & 39,96 \\
\hline Gliclazide & Anticoagulant antidiabetic & $-65,1$ & 20,94 \\
\hline 2-Aminobenzenesulfonamide & Diuretic & $-65,24$ & 26,23 \\
\hline Sparfloxacin & Antibacterial & 93,31 & 77,7 \\
\hline Palonosetron hydrochloride & Antiemetic & $-65,67$ & 24,35 \\
\hline Clarithromycin & Antibacterial & $-78,27$ & 78,85 \\
\hline Trimeprazine tartrate & $\begin{array}{l}\text { Antihistaminic } \quad \text { Antipruritic } \\
\text { Sedative }\end{array}$ & $-65,67$ & 36,24 \\
\hline Ezetimibe & Hypocholesterolemic & $-65,89$ & 30,12 \\
\hline Sertraline & Antidepressant CNS Stimulant & $-65,92$ & 27,77 \\
\hline Pantoprazole sodium & Antiulcer & $-65,93$ & 25,01 \\
\hline Azithromycin & Antibacterial & 47,23 & 76,8 \\
\hline Pioglitazone & & $-65,94$ & 49,33 \\
\hline lodipamide & Contrastant & -66 & 22,47 \\
\hline Trichlormethiazide & Antihypertensive Diuretic & $-66,22$ & 34,42 \\
\hline Bromperidol & Antipsychotic & $-66,5$ & 24,11 \\
\hline Chloramphenicol & Antibacterial & $-66,59$ & 31,82 \\
\hline Ritonavir & Antiviral & $-66,76$ & 23,43 \\
\hline Oxymetholone & Anabolic & $-66,77$ & 30,74 \\
\hline Gatifloxacin & Antibacterial & 46,56 & 85,07 \\
\hline Prazosin hydrochloride & Antihyperensive & $-66,79$ & 41,03 \\
\hline
\end{tabular}




\begin{tabular}{|c|c|c|c|}
\hline Name & Therapeutic effect & $\begin{array}{l}\text { \% GraXRS } \\
\text { inhibition }\end{array}$ & $\begin{array}{l}\text { \% Growth } \\
\text { inhibition }\end{array}$ \\
\hline Gemcitabine & Antineoplastic & 16,91 & 77,03 \\
\hline Equilin & & $-67,5$ & 31,04 \\
\hline Anagrelide & Thrombolytic & $-67,62$ & 27,36 \\
\hline Amrinone & & $-67,72$ & 23,98 \\
\hline Bucladesine sodium salt & & $-67,95$ & 27,44 \\
\hline Sulfacetamide sodic hydrate & Antibacterial Antipsoriatic & $-68,19$ & 31,39 \\
\hline Chlorpromazine hydrochloride & $\begin{array}{l}\text { Antiemetic antihypertensive } \\
\text { antipsychotic }\end{array}$ & $-68,2$ & 21,73 \\
\hline Hexachlorophene & Antiseptic & $-89,63$ & 96,86 \\
\hline Ampicillin trihydrate & Antibacterial & $-68,37$ & 51,2 \\
\hline Moxifloxacin & Antibacterial & 81,62 & 85,18 \\
\hline Pralidoxime chloride & & $-68,46$ & 32,36 \\
\hline Rufloxacin & Antibacterial & 185,42 & 78,28 \\
\hline Methocarbamol & Analgesic muscle relaxant & $-68,77$ & 37,24 \\
\hline Doxylamine succinate & $\begin{array}{l}\text { Anti-anorectic } \\
\text { antihitaminic }\end{array}$ & $-69,42$ & 31,34 \\
\hline Nitrendipine & Antihypertenisve & $-69,5$ & 20,56 \\
\hline Pyrvinium pamoate & & $-69,57$ & 47,75 \\
\hline Betazole hydrochloride & Diagnostic & $-69,68$ & 34,62 \\
\hline Ibudilast & Anti-inflammatory & $-69,76$ & 26,66 \\
\hline Fosfosal & Analgesic & $-70,02$ & 27,64 \\
\hline Ampiroxicam & Anti-inflammatory Analgesic & $-70,56$ & 20,67 \\
\hline Pinacidil & Antihypertensive vasodilator & $-70,78$ & 23,63 \\
\hline Guanabenz acetate & Antihypertensive & $-70,81$ & 49,39 \\
\hline Chlormadinone acetate & Antineoplastic & $-70,86$ & 22,71 \\
\hline Ifenprodil tartrate & Vasodilator & $-71,29$ & $-2,74$ \\
\hline Flurandrenolide & Anti-inflammatory antipruritic & $-71,6$ & 7,16 \\
\hline Enrofloxacin & Antibacterial & 57,64 & 79,49 \\
\hline Aceclofenac & Analgesic anti-inflammatory & $-71,63$ & 47,77 \\
\hline Pindolol & $\begin{array}{l}\text { Antianginal antiarrhythmic } \\
\text { antiglaucoma }\end{array}$ & $-71,65$ & 16,73 \\
\hline Piracetam & CNS stimulant & $-71,74$ & 32,16 \\
\hline Proparacaine hydrochloride & Anesthetic & $-71,74$ & 16,25 \\
\hline Butalbital & Hypnotic sedative & $-71,9$ & 30,64 \\
\hline Capecitabine & Antineoplastic & $-72,51$ & 36,58 \\
\hline Theophylline monohydrate & $\begin{array}{l}\text { Bronchodilator CNS Stimulant } \\
\text { Diuretic }\end{array}$ & $-72,58$ & 17,5 \\
\hline Carvedilol & Antihypertensive & $-73,15$ & 38,7 \\
\hline Tolcapone & Antiparkinsonian & $-153,68$ & 80,96 \\
\hline Naphazoline hydrochloride & $\begin{array}{l}\text { Nasal Decongestant } \\
\text { Vasoconstrictor }\end{array}$ & $-73,21$ & 31,21 \\
\hline
\end{tabular}




\begin{tabular}{|c|c|c|c|}
\hline Name & Therapeutic effect & $\begin{array}{l}\text { \% GraXRS } \\
\text { inhibition }\end{array}$ & $\begin{array}{l}\text { \% Growth } \\
\text { inhibition }\end{array}$ \\
\hline Vardenafil & Erectile dysfunction treatment & $-73,5$ & 30,48 \\
\hline Cromolyn disodium salt & $\begin{array}{l}\text { Antiasthmatic } \\
\text { inflammatory }\end{array}$ & $-73,73$ & 36,78 \\
\hline Pirenzepine dihydrochloride & Antiulcer & $-73,78$ & 53,32 \\
\hline Methiazole & Antihelmintic & $-74,31$ & 35,26 \\
\hline Astemizole & Antihistaminic & $-74,53$ & 45,44 \\
\hline Nitazoxanide & Antiprotozoal & $-156,12$ & 67,85 \\
\hline Levodopa & Antiparkinsonian & $-74,56$ & 32,69 \\
\hline Propoxycaine hydrochloride & Anesthetic & $-74,69$ & 35,08 \\
\hline $\begin{array}{r}\text { Hexamethonium dibromide } \\
\text { dihydrate }\end{array}$ & Antihypertensive & $-74,88$ & 38,01 \\
\hline Pipemidic acid & Antibacterial & -75 & 31,5 \\
\hline Pidotimod & Immunostimulant & $-75,19$ & 30,25 \\
\hline Retinoic acid & Keratolytic & $-75,34$ & 31,67 \\
\hline Meticrane & antihypertensive diuretic & $-75,48$ & 30,78 \\
\hline Diflunisal & $\begin{array}{l}\text { Analgesic anti-inflammatory } \\
\text { antipyretic }\end{array}$ & $-75,59$ & 36,34 \\
\hline Formestane & Antineoplastic & $-75,81$ & 37,55 \\
\hline Salmeterol & Bronchodilator & $-76,08$ & 35,89 \\
\hline Furaltadone hydrochloride & Antibacterial & $-76,32$ & 42,27 \\
\hline Benfluorex & $\begin{array}{lll}\text { Anorectic } & \text { Antidiabetic } & \text { CNS } \\
\text { Stimulant } & & \\
\end{array}$ & $-76,34$ & 48,19 \\
\hline (-)-Eseroline fumarate salt & Analgesic & $-76,36$ & 38,77 \\
\hline Tolazoline hydrochloride & Vasodilator & $-76,63$ & 29,47 \\
\hline Sulfaphenazole & Antibacterial & $-76,71$ & 33,25 \\
\hline Betaxolol hydrochloride & Antiglaucoma Antihypertensive & $-77,05$ & 33,04 \\
\hline Cefuroxime axetil & Antibacterial & $-292,99$ & 81,47 \\
\hline Doxazosin mesylate & Antihypertensive & $-77,09$ & 32,45 \\
\hline Thiocolchicoside & Antispastic muscle relaxant & $-77,1$ & 25,35 \\
\hline Deferoxamine mesylate & Chelating & $-77,6$ & 11,92 \\
\hline (-) -Levobunolol hydrochloride & Antiglaucoma & $-77,83$ & 32,28 \\
\hline Oxfendazol & & $-77,96$ & 22,73 \\
\hline Dofetilide & Antiarrhythmic & $-77,98$ & 28,67 \\
\hline Isradipine & Antianginal Antihypertenisve & $-78,27$ & 28,94 \\
\hline Besifloxacin hydrochloride & Antibacterial & 3,54 & 93,13 \\
\hline Ritodrine hydrochloride & Tocolytic & $-78,27$ & 33,08 \\
\hline GBR 12909 dihydrochloride & Antidepressant & $-78,44$ & 40,62 \\
\hline Benzydamine hydrochloride & $\begin{array}{l}\text { Analgesic anti-inflammatory } \\
\text { antipyretic }\end{array}$ & $-78,45$ & 21,55 \\
\hline $\begin{array}{r}\text { Naltrexone hydrochloride } \\
\text { dihydrate }\end{array}$ & Analgesic & $-78,65$ & 44,74 \\
\hline Methotrimeprazine maleat salt & Analgesic antiemetic sedative & $-78,73$ & 24,75 \\
\hline
\end{tabular}




\begin{tabular}{|c|c|c|c|}
\hline Name & Therapeutic effect & $\begin{array}{l}\text { \% GraXRS } \\
\text { inhibition }\end{array}$ & $\begin{array}{l}\text { \% Growth } \\
\text { inhibition }\end{array}$ \\
\hline Moxisylyte hydrochoride & $\begin{array}{l}\text { Erectile dysfunction treatment } \\
\text { vasodilator }\end{array}$ & $-78,87$ & 32,03 \\
\hline Tolbutamide & Antidiabetic & $-79,31$ & 42,04 \\
\hline Methicillin sodium & & $-108,81$ & 61,23 \\
\hline Ethacrynic acid & Diuretic & $-79,47$ & 36,71 \\
\hline Minoxidil & $\begin{array}{l}\text { Anti-alopecia antihypertensive } \\
\text { vasodilator }\end{array}$ & $-79,54$ & 23,87 \\
\hline Trimethadione & Anticonvulsant antiepileptic & $-79,69$ & 26,49 \\
\hline Viloxazine hydrochloride & Antidepressant & $-80,39$ & 31,41 \\
\hline Beclomethasone dipropionate & Anti-inflammatory & $-80,42$ & 33,68 \\
\hline Methylhydantoin-5-(L) & Anticonvulsant & $-80,74$ & 32,02 \\
\hline Nandrolone & Antianemic & $-80,83$ & 25,62 \\
\hline Isotretinoin & Keratolytic & $-80,84$ & 39,59 \\
\hline Tolterodine tartrate & Muscle relaxant & $-81,01$ & 29,02 \\
\hline Isoxicam & $\begin{array}{l}\text { Analgesic anti-inflammatory } \\
\text { antipyretic }\end{array}$ & $-81,11$ & 34,02 \\
\hline Methylhydantoin-5-(D) & & $-81,23$ & 39,9 \\
\hline Ramipril & Antihypertensive & $-81,32$ & 39,43 \\
\hline Nadolol & Antianginal Antihypertensive & $-81,57$ & 28,71 \\
\hline Darunavir & & $-81,92$ & 27,33 \\
\hline Fenspiride hydrochloride & Antitussive bronchodilator & $-82,49$ & 35,5 \\
\hline Lamotrigine & Anticonvulsant & $-82,56$ & 34,85 \\
\hline Eszopiclone & Hypnotic & $-82,74$ & 30,69 \\
\hline Biperiden hydrochloride & Antiparkinsonian & $-82,74$ & 27,8 \\
\hline Amiodarone hydrochloride & Antianginal Antiarrhythmic & $-82,98$ & 39,24 \\
\hline Isosorbide mononitrate & Antianginal & $-83,08$ & 38,07 \\
\hline Racepinephrine hydrochloride & Bronchodilator Vasoconstrictor & $-83,27$ & 40,22 \\
\hline Hemicholinium bromide & Curarizing & $-83,5$ & 22,9 \\
\hline Cyclopenthiazide & Antihypertensive Diuretic & $-83,52$ & 30,86 \\
\hline Ganciclovir & Antiviral & $-83,68$ & 35,7 \\
\hline Theobromine & Bronchodilator Diiuretic & $-83,79$ & 18,3 \\
\hline 6-Furfurylaminopurine & & $-83,79$ & 30,55 \\
\hline Gabapentin & Anticonvulsant & $-83,82$ & 32,52 \\
\hline Valacyclovir hydrochloride & Antiviral & $-83,86$ & 29,66 \\
\hline Felbamate & Antiepileptic & $-83,9$ & 25,32 \\
\hline Acitretin & Antipsoriatic & $-83,94$ & 37,88 \\
\hline Methantheline bromide & Antispastic & $-84,06$ & 36,12 \\
\hline Aliskiren hemifumarate & Antihypertensive & $-84,08$ & 51,77 \\
\hline Abacavir Sulfate & Antiviral & $-84,24$ & 25,36 \\
\hline Dehydrocholic acid & Choleretic & $-84,61$ & 43,92 \\
\hline
\end{tabular}




\begin{tabular}{|c|c|c|c|}
\hline Name & Therapeutic effect & $\begin{array}{l}\% \text { GraXRS } \\
\text { inhibition }\end{array}$ & $\begin{array}{l}\text { \% Growth } \\
\text { inhibition }\end{array}$ \\
\hline Sulfadiazine & Antibacterial & $-84,96$ & 35,72 \\
\hline Aminophylline & $\begin{array}{l}\text { Bronchodilator CNS Stimulant } \\
\text { Diuretic }\end{array}$ & $-85,43$ & 33,71 \\
\hline Sulfamonomethoxine & Antibacterial & $-85,49$ & 34,48 \\
\hline Lacosamide & Analgesic & $-85,65$ & 42,45 \\
\hline Azacyclonol & Antipychotic & $-85,74$ & 49,8 \\
\hline Trifluridine & Antiviral & $-85,96$ & 40,26 \\
\hline Tranylcypromine hydrochloride & Antidepressant & $-85,97$ & 39,35 \\
\hline Oxaprozin & Analgesic Anti-inflammatory & $-86,02$ & 38,05 \\
\hline Chlorpropamide & Antidiabetic & $-86,19$ & 30,69 \\
\hline Aprepitant & Antiemetic & $-86,3$ & 25,16 \\
\hline Etodolac & $\begin{array}{l}\text { Analgesic anti-inflammatory } \\
\text { antiplatelet }\end{array}$ & $-86,55$ & 7,19 \\
\hline Remoxipride Hydrochloride & Antipsychotic & $-86,75$ & 33,14 \\
\hline (S)-Naproxen & $\begin{array}{l}\text { Analgesic anti-inflammatory } \\
\text { antipyretic }\end{array}$ & $-86,89$ & 27,44 \\
\hline Sibutramine hydrochloride & & $-86,95$ & 27,39 \\
\hline Altrenogest & Progestogen & $-87,03$ & 26,53 \\
\hline Minaprine dihydrochloride & Anti-Alzheimer antidepressant & $-87,05$ & 23,96 \\
\hline Milrinone & Vasodilator & $-87,12$ & 36,15 \\
\hline Guanfacine hydrochloride & Antihypertensive & $-87,5$ & 27,84 \\
\hline Niclosamide & Antihelmintic & 116,07 & 90,79 \\
\hline Raclopride & & $-87,61$ & 19,36 \\
\hline Lidocaine hydrochloride & Antiarrhythmic local anesthetic & $-87,63$ & 28,02 \\
\hline Camptothecine $(S,+)$ & Antineoplastic & $-87,69$ & 42,31 \\
\hline Isometheptene mucate & Antimigraine Vasoconstrictor & $-87,95$ & 32,75 \\
\hline Timolol maleate salt & $\begin{array}{ll}\text { Antianginal } & \text { Antiarrhythmic } \\
\text { Antiglaucoma } & \\
\end{array}$ & $-87,98$ & 34,73 \\
\hline Heptaminol hydrochloride & $\begin{array}{l}\text { Analeptic Positive inotropic } \\
\text { Vasodilator }\end{array}$ & $-88,19$ & 31,1 \\
\hline Zoledronic acid hydrate & Antiosteoporosis & $-88,21$ & 27,42 \\
\hline $\begin{array}{r}R(-) \text { Apomorphine hydrochloride } \\
\text { hemihydrate }\end{array}$ & Antiparkinsonian emetic & $-88,26$ & 45,85 \\
\hline Dexfenfluramine hydrochloride & Anorectic & $-88,3$ & 21,82 \\
\hline Pentetic acid & Chelating Radioprotectant & $-88,51$ & 36,08 \\
\hline Ciclesonide & & $-89,18$ & 34,19 \\
\hline Nimesulide & Anti-inflammatory & $-89,45$ & 41,47 \\
\hline Xamoterol hemifumarate & & $-89,65$ & 31,65 \\
\hline Procainamide hydrochloride & $\begin{array}{l}\text { Antiarrhythmic Local anesthetic } \\
\text { Vasodilator }\end{array}$ & $-89,87$ & 38,31 \\
\hline Avobenzone & Cytoprotectant & $-89,94$ & 22,53 \\
\hline Alcuronium chloride & Muscle relaxant & $-90,3$ & 21,55 \\
\hline
\end{tabular}




\begin{tabular}{|c|c|c|c|}
\hline Name & Therapeutic effect & $\begin{array}{l}\text { \% GraXRS } \\
\text { inhibition }\end{array}$ & $\begin{array}{l}\text { \% Growth } \\
\text { inhibition }\end{array}$ \\
\hline Flutamide & Antineoplastic & $-90,34$ & 35,22 \\
\hline Benzonatate & Antitussive Local anesthetic & $-90,44$ & 36,13 \\
\hline Mebendazole & Antihelmintic & $-90,46$ & 45,43 \\
\hline Piperidolate hydrochloride & Antispastic & $-90,49$ & 30,25 \\
\hline Mupirocin & & 697,49 & 90,55 \\
\hline Nocodazole & Antineoplastic & $-90,59$ & 38,69 \\
\hline Amcinonide & Anti-inflammatory & $-90,6$ & 37,23 \\
\hline Pregabalin & Anticonvulsant Anxiolytic & -91 & 26,29 \\
\hline Meclozine dihydrochloride & $\begin{array}{l}\text { Antiemetic antihistaminic } \\
\text { sedative }\end{array}$ & $-91,05$ & 40,88 \\
\hline Urapidil hydrochloride & Antihypertenisve Vasodilator & $-91,15$ & 32,12 \\
\hline $\begin{array}{r}\text { (+)-Isoproterenol (+)-bitartrate } \\
\text { salt }\end{array}$ & $\begin{array}{l}\text { Antiasthmatic Bronchodilator } \\
\text { Vasodilator }\end{array}$ & $-91,3$ & 37,05 \\
\hline Ethamivan & Analeptic CNS stimulant & $-91,36$ & 24,39 \\
\hline Alverine citrate salt & Antispastic & $-91,4$ & 43,1 \\
\hline Lansoprazole & Antiulcer & $-91,51$ & 40,13 \\
\hline Pentamidine isethionate & $\begin{array}{l}\text { Antifungal antiparasitic } \\
\text { antiprotozoal }\end{array}$ & $-91,52$ & 21,99 \\
\hline Nateglinide & Antidiabetic & $-91,59$ & 33,72 \\
\hline Luteolin & Expectorant & $-91,67$ & 33,09 \\
\hline Tropicamide & Mydriatic & $-91,82$ & 35,29 \\
\hline Cyclobenzaprine hydrochloride & Muscle relaxant & $-92,37$ & 48,86 \\
\hline Chenodiol & Cholagogue Choleretic & $-92,42$ & 31,17 \\
\hline Azatadine maleate & Antihistaminic & $-92,53$ & 27,1 \\
\hline Pivampicillin & Antibacterial & $-92,59$ & 35,73 \\
\hline Gefitinib & Antineoplastic & $-92,64$ & 1,49 \\
\hline Amyleine hydrochloride & Local anesthetic & $-92,66$ & 36,21 \\
\hline Lovastatin & Hypocholesterolemic & $-92,78$ & 28,42 \\
\hline Ceftazidime pentahydrate & Antibacterial & $-92,88$ & 34,64 \\
\hline Proguanil hydrochloride & Antimalarial & $-93,07$ & 37,02 \\
\hline Thiamphenicol & Antibacterial & $-93,09$ & 36,43 \\
\hline Nimodipine & Vasodilator & $-93,27$ & 34,19 \\
\hline Homoveratrylamine & Antihypertenisve & $-93,71$ & 30,75 \\
\hline Etifenin & Chemosensitizer & $-93,83$ & 27,42 \\
\hline Prenylamine lactate & $\begin{array}{l}\text { Antianginal } \\
\text { vasodilator }\end{array}$ & $-94,3$ & 30,27 \\
\hline Zonisamide & Anticonvulsant & $-94,41$ & 23,1 \\
\hline Domperidone & Antiemetic & $-94,59$ & 21,74 \\
\hline Benserazide hydrochloride & Antiparkinsonian & $-94,79$ & 37,55 \\
\hline Parbendazole & & $-94,9$ & 49,73 \\
\hline Irbesartan & Antihypertensive & $-95,26$ & 37,24 \\
\hline
\end{tabular}




\begin{tabular}{|c|c|c|c|}
\hline Name & Therapeutic effect & $\begin{array}{l}\text { \% GraXRS } \\
\text { inhibition }\end{array}$ & $\begin{array}{l}\text { \% Growth } \\
\text { inhibition }\end{array}$ \\
\hline Terbinafine & Antifungal & $-95,4$ & 36,77 \\
\hline Nelarabine & & $-95,62$ & 38,72 \\
\hline Actarit & $\begin{array}{l}\text { Anti-inflammatory } \\
\text { Immunomodulator }\end{array}$ & $-95,89$ & 28,16 \\
\hline Nisoxetine hydrochloride & Antidepressant & $-95,97$ & 34,42 \\
\hline Epirizole & $\begin{array}{l}\text { Analgesic anti-inflammatory } \\
\text { antipyretic }\end{array}$ & -96 & 37,42 \\
\hline Diltiazem hydrochloride & $\begin{array}{l}\text { antianginal antiarrhythmic } \\
\text { antihypertensive }\end{array}$ & $-96,14$ & 39,91 \\
\hline Methylatropine nitrate & Antispastic Mydriatic & $-96,35$ & 34,09 \\
\hline Dioxybenzone & & $-96,59$ & 32,33 \\
\hline Paroxetine Hydrochloride & Antidepressant CNS Stimulant & $-96,65$ & 39,8 \\
\hline Olopatadine hydrochloride & Antihistaminic & $-96,78$ & 45,99 \\
\hline Salbutamol & Bronchodilator tocodytic & $-97,15$ & 40,99 \\
\hline Stanozolol & & $-97,38$ & 45,23 \\
\hline Levamisole hydrochloride & $\begin{array}{l}\text { Antihelmintic } \\
\text { immunomodulator }\end{array}$ & $-97,76$ & 33,22 \\
\hline $\begin{array}{r}\text { Metoclopramide } \\
\text { monohydrochloride }\end{array}$ & Antiemetic & $-97,78$ & 38,72 \\
\hline Ciclopirox ethanolamine & Antibacterial antifungal & $-97,82$ & 31,43 \\
\hline Picotamide monohydrate & $\begin{array}{l}\text { Anticoagulant } \\
\text { thrombolytic }\end{array}$ & $-97,92$ & 52,93 \\
\hline Vorinostat & Antineoplastic & $-97,99$ & 38,43 \\
\hline Clorsulon & Antihelmintic & $-98,09$ & 30,75 \\
\hline Benidipine hydrochloride & Antihypertenisve & $-98,21$ & 29,82 \\
\hline Azlocillin sodium salt & Antibacterial & $-98,29$ & 52,04 \\
\hline Naftopidil dihydrochloride & Antihypertensive & $-98,74$ & 29,35 \\
\hline Fluocinonide & Anti-inflammatory & $-98,74$ & 26,58 \\
\hline Tolnaftate & Antifungal & $-99,07$ & 22,7 \\
\hline Diprophylline & $\begin{array}{l}\text { Analeptic } \\
\text { bronchodilator }\end{array}$ & $-99,35$ & 40,88 \\
\hline Lodoxamide & Antihistaminic & $-99,4$ & 33,28 \\
\hline Ziprasidone Hydrochloride & Antipsychotic & $-99,56$ & 24,78 \\
\hline Propafenone hydrochloride & Antiarrhythmic & $-99,76$ & 26,43 \\
\hline Cimetidine & Antiulcer & $-99,96$ & 36,06 \\
\hline Hymecromone & Muscle relaxant & $-100,21$ & 36,05 \\
\hline $\begin{array}{r}\text { Ciprofloxacin hydrochloride } \\
\text { monohydrate }\end{array}$ & Antibacterial antiprotozoal & 318,88 & 75,9 \\
\hline Oxolinic acid & Antibacterial & $-100,69$ & 43,75 \\
\hline Oxprenolol hydrochloride & $\begin{array}{l}\text { Antianginal Antiarrhythmic } \\
\text { Antihyperensive }\end{array}$ & $-100,83$ & 35,25 \\
\hline Imiquimod & Antiviral & $-100,93$ & 36,27 \\
\hline Yohimbine hydrochloride & $\begin{array}{l}\text { Erectile dysfunction treatment } \\
\text { vasodilator }\end{array}$ & $-100,93$ & 29,93 \\
\hline
\end{tabular}




\begin{tabular}{|c|c|c|c|}
\hline Name & Therapeutic effect & $\begin{array}{l}\text { \% GraXRS } \\
\text { inhibition }\end{array}$ & $\begin{array}{l}\text { \% Growth } \\
\text { inhibition }\end{array}$ \\
\hline Sulfathiazole & Antibacterial & $-101,05$ & 34,61 \\
\hline Famotidine & Antiulcer & $-101,11$ & 44,08 \\
\hline Flunisolide & Anti-inflammatory & $-101,16$ & 4,99 \\
\hline Fexofenadine hydrochloride & Antihistaminic & $-101,24$ & 43,72 \\
\hline Estriol & & $-102,31$ & 41,82 \\
\hline Fluticasone propionate & Anti-inflammatory Vasodilator & $-102,34$ & 39,35 \\
\hline Isocarboxazid & Antidepressant & $-102,59$ & 29,68 \\
\hline Iproniazide phosphate & $\begin{array}{l}\text { Antidepressant } \\
\text { antihypertensive }\end{array}$ & $-102,6$ & 46,73 \\
\hline Diflorasone Diacetate & $\begin{array}{l}\text { Anti-inflammatory antipruritic } \\
\text { antipsoriatic }\end{array}$ & $-102,95$ & 39,56 \\
\hline Isoconazole & Antibacterial antifungal & 157,84 & 71,03 \\
\hline Terfenadine & Antihistaminic antipruritic & $-103,02$ & 47,57 \\
\hline Cefotaxime sodium salt & Antibacterial & 904,42 & 93,91 \\
\hline Tetracycline hydrochloride & Antibacterial & 507,2 & 89,84 \\
\hline Fluspirilen & Antipsychotic & $-103,03$ & 42,46 \\
\hline Allopurinol & & $-103,15$ & 32,74 \\
\hline Imidurea & Antifungal & $-103,25$ & 40,84 \\
\hline Diloxanide furoate & Antiamebic & $-103,3$ & 32,57 \\
\hline Amfepramone hydrochloride & & $-103,32$ & 48,19 \\
\hline (R)-Duloxetine hydrochloride & & $-103,38$ & 39,02 \\
\hline Clindamycin hydrochloride & Antibacterial & 821,87 & 91,69 \\
\hline Lymecycline & Antibacterial & $-103,49$ & 38,55 \\
\hline Protriptyline hydrochloride & Antidepressant & $-103,57$ & 38,31 \\
\hline Norgestimate & & $-103,62$ & 49,57 \\
\hline Rasagiline & Antiparkinsonian & $-103,68$ & 31,41 \\
\hline Flubendazol & & $-103,69$ & 30,94 \\
\hline Chlorhexidine & Antibacterial antiseptic & 1668,32 & 97,77 \\
\hline Sertindole & Antipsychotic & $-103,79$ & 21,36 \\
\hline Chlortetracycline hydrochloride & Antiamecib antibacterial & 512,98 & 92,51 \\
\hline Tamoxifen citrate & Antineoplastic & 63,72 & 61,04 \\
\hline Clopidogrel & Antiplatelet & $-104,24$ & 36,31 \\
\hline Cefoxitin sodium salt & Antibacterial & $-83,74$ & 70,78 \\
\hline Dihydrostreptomycin sulfate & Antibacterial & 277,27 & 85,53 \\
\hline Gentamicine sulfate & Antibacterial & 440,04 & 76,9 \\
\hline Erythromycin & Antibacterial anti-inflammatory & 723,07 & 91,66 \\
\hline Chloroxine & & 349,51 & 78,59 \\
\hline Phenprobamate & $\begin{array}{l}\text { Muscle relaxant } \\
\text { Anticonvulsant }\end{array}$ & $-104,39$ & 25,62 \\
\hline Josamycin & Antibacterial & 557,7 & 93,87 \\
\hline
\end{tabular}




\begin{tabular}{|c|c|c|c|}
\hline Name & Therapeutic effect & $\begin{array}{l}\text { \% GraXRS } \\
\text { inhibition }\end{array}$ & $\begin{array}{l}\% \text { Growth } \\
\text { inhibition }\end{array}$ \\
\hline Aminopurine, 6-benzyl & & $-105,16$ & 38,6 \\
\hline Tiaprofenic acid & $\begin{array}{l}\text { Analgesic anti-inflammatory } \\
\text { antipyretic }\end{array}$ & $-105,17$ & 30,97 \\
\hline Diatrizoic acid dihydrate & Contrastant & $-105,35$ & 32,5 \\
\hline Tulobuterol & Bronchodilator & $-105,41$ & 38,81 \\
\hline Clemizole hydrochloride & $\begin{array}{l}\text { Antibacterial } \\
\text { antihistaminic }\end{array}$ & $-105,59$ & 51,25 \\
\hline Liothyronine & & $-105,65$ & 37,42 \\
\hline Pyrimethamine & Antimalarial antiprotozoal & $-105,74$ & 42,48 \\
\hline $\begin{array}{r}\text { Phenoxybenzamine } \\
\text { hydrochloride }\end{array}$ & Antihypertensive & $-106,01$ & 37,37 \\
\hline Methenamine & Antibacterial & $-106,04$ & 43,48 \\
\hline Felodipine & Antianginal antihypertensive & $-106,4$ & 22,71 \\
\hline Acetohexamide & Antidiabetic & $-106,41$ & 32,62 \\
\hline Tolazamide & Antidiabetic & $-106,51$ & 21,64 \\
\hline Losartan & Antihypertensive & $-107,01$ & 49,19 \\
\hline Ethynodiol diacetate & Contraceptive & $-107,42$ & 39,56 \\
\hline Benztropine mesylate & Antiparkinsonian & $-107,54$ & 43,26 \\
\hline Pyrazinamide & Antibacterial & $-107,58$ & 31,43 \\
\hline Clozapine & Antiparkinsonian Antipsychotic & $-107,6$ & 30,24 \\
\hline Tocainide hydrochloride & Anesthetic Antiarrhythmic & $-107,7$ & 41,15 \\
\hline Oxandrolone & & $-107,76$ & 40,12 \\
\hline (S)-propranolol hydrochloride & $\begin{array}{l}\text { Antianginal Antiarrhythmic } \\
\text { Antihyperensive }\end{array}$ & $-107,94$ & 42,55 \\
\hline Cephalosporanic acid, 7-amino & Antibacterial & $-108,02$ & 32,48 \\
\hline (+,-)-Synephrine & Vasoconstrictor & $-108,06$ & 36,68 \\
\hline Molindone hydrochloride & Antipsychotic & $-108,12$ & 19,77 \\
\hline (S)-(-)-Cycloserine & Antibacterial & $-108,83$ & 39,52 \\
\hline Pridinol methanesulfonate salt & Antiparkinsonian & $-109,03$ & 28,88 \\
\hline Pivmecillinam hydrochloride & Antibacterial & $-109,08$ & 39,11 \\
\hline Docetaxel & Antineoplastic & $-109,08$ & 48,65 \\
\hline Phensuximide & Anticonvulsant & $-109,72$ & 43,66 \\
\hline Phthalylsulfathiazole & Antibacterial & $-109,99$ & 34,43 \\
\hline Monobenzone & & $-110,36$ & 36,89 \\
\hline Nilvadipine & Antianginal antihypertensive & $-110,36$ & 14,19 \\
\hline Cloxacillin sodium salt & Antibacterial & $-3481,68$ & 97,96 \\
\hline Carteolol hydrochloride & Antiglaucoma antihypertensive & $-110,36$ & 30,27 \\
\hline Propidium iodide & Antibacterial & $-110,43$ & 25,42 \\
\hline Spaglumic acid & Antiallergic Vasodilator & $-110,68$ & 47,2 \\
\hline Levopropoxyphene napsylate & Analgesic Antitussive & $-110,78$ & 41,3 \\
\hline
\end{tabular}




\begin{tabular}{|c|c|c|c|}
\hline Name & Therapeutic effect & $\begin{array}{l}\text { \% GraXRS } \\
\text { inhibition }\end{array}$ & $\begin{array}{l}\text { \% Growth } \\
\text { inhibition }\end{array}$ \\
\hline Meropenem & Antibacterial & $-77,35$ & 65,94 \\
\hline Tegaserod maleate & Gastreoprokinetic & $-110,93$ & 24,89 \\
\hline Sulfisoxazole & Antibacterial & $-110,98$ & 38,48 \\
\hline Phenindione & Anticoagulant & $-111,13$ & 36,21 \\
\hline Nifuroxazide & Antibacterial & $-111,21$ & 23,26 \\
\hline Bephenium hydroxynaphthoate & & $-111,71$ & 33,83 \\
\hline Gliquidone & Antidiabetic & $-111,74$ & 38,57 \\
\hline Niflumic acid & $\begin{array}{l}\text { Analgesic anti-inflammatory } \\
\text { antipyretic }\end{array}$ & $-111,81$ & 33,92 \\
\hline Ropivacaine hydrochloride & Anesthetic & $-112,36$ & 30,12 \\
\hline Haloperidol & Antiemetic antipsychtotic & $-112,51$ & 45,81 \\
\hline Lomerizine hydrochloride & Antimigraine & $-112,59$ & 35,98 \\
\hline $\begin{array}{r}\text { Amodiaquin dihydrochloride } \\
\text { dihydrate }\end{array}$ & Anti-inflammatory antimalarial & $-112,61$ & 28,5 \\
\hline Fosinopril & Antihypertenisve & $-112,67$ & 44,87 \\
\hline Posaconazole & Antifungal & $-112,7$ & 32,09 \\
\hline Clonixin Lysinate & Analgesic Antifungal & $-112,72$ & 46,78 \\
\hline Perphenazine & Antiemetic antipsychotic & $-112,76$ & 45,76 \\
\hline Ticlopidine hydrochloride & Anticoagulant antiplatelet & $-112,99$ & 36,58 \\
\hline Ambrisentan & Antihypertensive & $-113,24$ & 37,48 \\
\hline Phenylbutazone & Anti-inflammatory & $-113,26$ & 38,76 \\
\hline Butylparaben & Antifungal & $-113,53$ & 30,11 \\
\hline Griseofulvin & Antifungal anti-inflammatory & $-114,03$ & 44,62 \\
\hline Phenformin hydrochloride & Antidiabetic & $-114,06$ & 41,65 \\
\hline Nilutamide & Antineoplastic & $-114,32$ & 32,66 \\
\hline Nystatine & Antifungal & $-114,5$ & 43,69 \\
\hline Glipizide & Antidiabetic & $-114,93$ & 40,32 \\
\hline Cyproheptadine hydrochloride & $\begin{array}{l}\text { Antihistaminic } \\
\text { sedative }\end{array}$ & $-115,61$ & 49,45 \\
\hline Tripelennamine hydrochloride & Antihistaminic & -116 & 43,21 \\
\hline Risedronic acid monohydrate & Antiosteoporosis & $-116,41$ & 27,68 \\
\hline Adapalene & Keratolytic Anti-inflammatory & $-116,43$ & 43,29 \\
\hline Etoricoxib & Analgesic anti-inflammatory & $-116,53$ & 32,73 \\
\hline Norfloxacin & Antibacterial & 85,65 & 78,14 \\
\hline Cloperastine hydrochloride & Antitussive & $-116,69$ & 25,72 \\
\hline Dopamine hydrochloride & Antihypertensive & $-116,73$ & 33,91 \\
\hline Trimetazidine dihydrochloride & antischemic & $-116,78$ & 31,21 \\
\hline Sulfasalazine & Antibacterial anti-inflammatory & $-116,96$ & 31,18 \\
\hline Ethoxyquin & Antifungal & $-117,13$ & 26,14 \\
\hline Clobetasol propionate & Anti-inflammatory & $-117,17$ & 30,31 \\
\hline
\end{tabular}




\begin{tabular}{|c|c|c|c|}
\hline Name & Therapeutic effect & $\begin{array}{l}\text { \% GraXRS } \\
\text { inhibition }\end{array}$ & $\begin{array}{l}\text { \% Growth } \\
\text { inhibition }\end{array}$ \\
\hline Homosalate & Radioprotectant & $-117,23$ & 38,83 \\
\hline Moxonidine & Antihypertenisve & $-117,33$ & 38,39 \\
\hline Toltrazuril & Anticoccidial & $-117,4$ & 44,7 \\
\hline Pentolinium bitartrate & Antihypertensive & $-117,49$ & 47,71 \\
\hline Amethopterin $(R, S)$ & $\begin{array}{l}\text { Anti-inflammatory } \\
\text { Antineoplastic } \\
\text { Immunosuppressant }\end{array}$ & $-117,98$ & 47,44 \\
\hline Olmesartan & Antihypertensive & $-118,17$ & 40,86 \\
\hline Trimethoprim & Antibacterial antimalarial & $-118,56$ & 42,83 \\
\hline Terbutaline hemisulfate & $\begin{array}{l}\text { Antiasthmatic Bronchodilator } \\
\text { Muscle relaxant }\end{array}$ & $-118,57$ & 8,47 \\
\hline Telenzepine dihydrochloride & Antiulcer & $-118,62$ & 32,14 \\
\hline Ofloxacin & Antibacterial & 71,59 & 81,8 \\
\hline Lomefloxacin hydrochloride & Antibacterial & 102,61 & 77,55 \\
\hline N6-methyladenosine & Antineoplastic & $-118,68$ & 33,69 \\
\hline Azapropazone & Analgesic Anti-inflammatory & $-118,81$ & 35,82 \\
\hline Flumequine & Antibacterial & $-118,91$ & 52,63 \\
\hline Propylthiouracil & Antihyperthyroid & $-118,96$ & 31,86 \\
\hline Aminacrine & Antiseptic & $-118,97$ & 36,7 \\
\hline N-Acetyl-L-leucine & Antivertigo & $-118,98$ & 34,65 \\
\hline Ipriflavone & Antiosteoporosis & $-119,09$ & 32,83 \\
\hline Mitotane & Antineoplatic & $-119,35$ & 41,41 \\
\hline Rizatriptan benzoate & Antimigraine Vasoconstrictor & $-119,46$ & 28,48 \\
\hline Felbinac & Analgesic Anti-inflammatory & $-119,71$ & 28,67 \\
\hline Halofantrine hydrochloride & Antimalarial & $-119,74$ & 45,21 \\
\hline Ketorolac tromethamine & $\begin{array}{l}\text { Analgesic Anti-inflammatory } \\
\text { Antipyretic }\end{array}$ & $-119,81$ & 34,37 \\
\hline Diclazuril & & $-119,9$ & 49,72 \\
\hline Digitoxigenin & Cardiotonic & $-119,97$ & 35,71 \\
\hline Aceclidine Hydrochloride & Antiglaucoma & $-120,09$ & 36,35 \\
\hline Fluoxetine hydrochloride & Antidepressant & $-120,33$ & 30,18 \\
\hline Guaiacol & Expectorant & $-120,38$ & 38,02 \\
\hline Alosetron hydrochloride & Antidiarrheal & $-120,4$ & 39 \\
\hline Flunixin meglumine & $\begin{array}{l}\text { Analgesic Anti-inflammatory } \\
\text { antipyretic }\end{array}$ & $-120,55$ & 40,91 \\
\hline $\begin{array}{r}\text { Adenosine 5'-monophosphate } \\
\text { monohydrate }\end{array}$ & Antiarrhythmic & $-120,6$ & 42,89 \\
\hline Debrisoquin sulfate & Antihypertensive & $-120,95$ & 29,24 \\
\hline Terconazole & Antifungal & $-120,95$ & 28,43 \\
\hline Molsidomine & $\begin{array}{l}\text { Antianginal } \\
\text { antiplatelet }\end{array}$ & $-121,21$ & 31,94 \\
\hline Naloxone hydrochloride & Opioate antidote & $-121,46$ & 44,9 \\
\hline
\end{tabular}




\begin{tabular}{|c|c|c|c|}
\hline Name & Therapeutic effect & $\begin{array}{l}\text { \% GraXRS } \\
\text { inhibition }\end{array}$ & $\begin{array}{l}\text { \% Growth } \\
\text { inhibition }\end{array}$ \\
\hline Tomoxetine hydrochloride & & $-121,53$ & 27,37 \\
\hline Trolox & Antioxidant & $-121,9$ & 32,46 \\
\hline Norcyclobenzaprine & Antiulcer & $-122,49$ & 36,27 \\
\hline Cilostazol & Anticoagulant & $-122,51$ & 27,06 \\
\hline Ethinylestradiol & Contraceptive & $-122,84$ & 36,57 \\
\hline Cyclopentolate hydrochloride & & $-122,89$ & 48,17 \\
\hline Cefadroxil & Antibacterial & $-122,95$ & 43,38 \\
\hline Modafinil & CNS stimulant & $-123,16$ & 34,62 \\
\hline Olanzapine & Antipsychotic & $-123,22$ & 40,68 \\
\hline Trazodone hydrochloride & Antidepressant & $-123,48$ & 24,86 \\
\hline Acenocoumarol & anticoagulant & $-123,53$ & 37,99 \\
\hline Bepridil hydrochloride & $\begin{array}{l}\text { Antianginal Antiarrhythmic } \\
\text { Antihypotensive }\end{array}$ & $-123,74$ & 44,03 \\
\hline Meptazinol hydrochloride & Analgesic & $-123,91$ & 32,49 \\
\hline Tiabendazole & Antihelmintic & $-123,96$ & 37,85 \\
\hline Bifonazole & Antifungal & $-124,19$ & 49 \\
\hline Chloroquine diphosphate & $\begin{array}{l}\text { Anti-inflammatory antimalarial } \\
\text { antiprotozoal }\end{array}$ & $-124,37$ & 34,34 \\
\hline $\begin{array}{r}\text { Quinidine hydrochloride } \\
\text { monohydrate }\end{array}$ & Antiarrhythmic antimalarial & $-124,42$ & 24,25 \\
\hline Diethylcarbamazine citrate & Antihelmintic & $-124,57$ & 37,81 \\
\hline Alprostadil & $\begin{array}{l}\text { Erectile Dysfunction treatment } \\
\text { Vasodilator }\end{array}$ & $-124,66$ & 39,34 \\
\hline Methyldopate hydrochloride & Antihypertensive & $-124,75$ & 24,35 \\
\hline Ozagrel hydrochloride & Antianginal & $-124,78$ & 31,72 \\
\hline Progesterone & Progestogen & $-125,25$ & 35,51 \\
\hline EPIA/PNAGndrosterone & Anabolic & $-125,94$ & 39,83 \\
\hline Camylofine chlorhydrate & & $-126,38$ & 35,61 \\
\hline Aminohippuric acid & & $-126,73$ & 27,79 \\
\hline Spiperone & Antipsychotic & 54,85 & 69,33 \\
\hline Nifurtimox & & -127 & 41,36 \\
\hline Triflupromazine hydrochloride & $\begin{array}{l}\text { Antiemetic } \\
\text { anxiolytic }\end{array}$ & $-127,23$ & 39,11 \\
\hline Melatonin & $\begin{array}{l}\text { Anticonvulsant } \\
\text { immunostimulant }\end{array}$ & $-127,29$ & 42,79 \\
\hline Omeprazole & Antiulcer & $-127,53$ & 31,84 \\
\hline Zotepine & Antipsychotic & $-128,12$ & 30,6 \\
\hline Nizatidine & Antiulcer & $-128,13$ & 42,05 \\
\hline Budesonide & Anti-inflammatory & $-128,25$ & 34,65 \\
\hline (R) -Naproxen sodium salt & Anti-inflammatory & $-128,4$ & 23,73 \\
\hline (+,-)-Octopamine hydrochloride & & $-129,2$ & 38,1 \\
\hline Artemisinin & Antimalarial & $-129,28$ & 32,52 \\
\hline
\end{tabular}




\begin{tabular}{|c|c|c|c|}
\hline Name & Therapeutic effect & $\begin{array}{l}\% \text { GraXRS } \\
\text { inhibition }\end{array}$ & $\begin{array}{l}\text { \% Growth } \\
\text { inhibition }\end{array}$ \\
\hline Alfadolone acetate & Anesthetic & $-129,58$ & 40,79 \\
\hline Prilocaine hydrochloride & Local anesthetic & $-129,98$ & 43,77 \\
\hline Moricizine hydrochloride & Antiarrhythmic & $-130,23$ & 40,5 \\
\hline Lincomycin hydrochloride & Antibacterial & 193,73 & 91,33 \\
\hline Sulpiride & $\begin{array}{l}\text { Antidepressant } \\
\text { antipsychotic }\end{array}$ & $-130,36$ & 35,25 \\
\hline Clofibrate & Antilipemic & $-130,53$ & 46,06 \\
\hline Fluconazole & Antifungal & $-130,61$ & 37,78 \\
\hline Ribavirin & Antiviral & $-130,84$ & 35,17 \\
\hline Oxytetracycline dihydrate & Antibacterial & $-16,96$ & 62,92 \\
\hline Bendroflumethiazide & Antihypertensive diuretic & $-130,92$ & 40,66 \\
\hline Bromocryptine mesylate & Antiparkinsonian & $-130,94$ & 45,21 \\
\hline Dibenzepine hydrochloride & Antidepressant & $-131,21$ & 25,23 \\
\hline Chlorothiazide & Antihypertensive diuretic & $-131,94$ & 30,24 \\
\hline Methoxamine hydrochloride & $\begin{array}{l}\text { Antihypotensive } \\
\text { vasoconstrictor }\end{array}$ & $-132,01$ & 39,04 \\
\hline Tinidazole & Antiamebic Antibacterial & $-132,05$ & 30,76 \\
\hline Corticosterone & $\begin{array}{l}\text { Anti-inflammatory } \\
\text { immunosuppressant }\end{array}$ & $-132,28$ & 41,04 \\
\hline Minocycline hydrochloride & Antibacterial & 127,99 & 90,93 \\
\hline Adrenosterone & & $-132,47$ & 31,12 \\
\hline Mifepristone & Abortifacient & $-132,58$ & 26,3 \\
\hline Loteprednol etabonate & Anti-inflammatory & $-132,82$ & 42,24 \\
\hline Candesartan & Antihypertensive & $-132,93$ & 39,9 \\
\hline Mephenytoin & Anticonvulsant & $-133,02$ & 40,9 \\
\hline Piperacillin sodium salt & Antibacterial & $-133,23$ & 48,29 \\
\hline Chlormezanone & Anxiolytic Muscle relaxant & $-133,27$ & 38,18 \\
\hline Fendiline hydrochloride & Antianginal & $-133,84$ & 26,42 \\
\hline Ondansetron Hydrochloride & Antianemic & $-134,08$ & 38,4 \\
\hline Piribedil hydrochloride & Antiparkinsonian Vasodilator & $-134,34$ & 34,7 \\
\hline Primidone & Anticonvulsant & $-134,9$ & 42,18 \\
\hline Cefoperazone dihydrate & Antibacterial & 415,31 & 83,3 \\
\hline Memantine Hydrochloride & $\begin{array}{l}\text { Anti-Alzheimer } \\
\text { Antiparkinsonian Antispastic }\end{array}$ & -135 & 35,15 \\
\hline Carbidopa & Antiparkinsonian & $-135,14$ & 40,14 \\
\hline Cyclizine hydrochloride & antihistaminic & $-135,37$ & 32,87 \\
\hline Alfaxalone & Anesthetic & $-135,65$ & 34,76 \\
\hline Lopinavir & Antiviral & $-135,79$ & 24,13 \\
\hline Aztreonam & Antibacterial & $-135,83$ & 48,79 \\
\hline Ethamsylate & Antiplatelet Hemostatic & $-136,4$ & 44,76 \\
\hline
\end{tabular}




\begin{tabular}{|c|c|c|c|}
\hline Name & Therapeutic effect & $\begin{array}{l}\text { \% GraXRS } \\
\text { inhibition }\end{array}$ & $\begin{array}{l}\text { \% Growth } \\
\text { inhibition }\end{array}$ \\
\hline Etofylline & $\begin{array}{ll}\text { Antispastic } & \text { Bronchodilator } \\
\text { Cardiotonic } & \end{array}$ & $-136,54$ & 38,06 \\
\hline Phentermine hydrochloride & & $-136,67$ & 36,62 \\
\hline Hycanthone & Antihelmintic Antiparasitic & $-136,75$ & 40,49 \\
\hline Tibolone & & -137 & 48,6 \\
\hline Altretamine & Antineoplastic & $-137,25$ & 40,74 \\
\hline Triflusal & Anticoagulant antiplatelet & $-137,66$ & 38,19 \\
\hline Anethole-trithione & Choleretic & $-137,71$ & 42,82 \\
\hline Mefloquine hydrochloride & Antimalarial & $-138,02$ & 49,41 \\
\hline Meloxicam & Anti-inflammatory & $-138,12$ & 40,13 \\
\hline Bretylium tosylate & $\begin{array}{l}\text { Anesthetic Antiarrhythmic } \\
\text { Antihypertenisve }\end{array}$ & $-138,12$ & 44,37 \\
\hline Thiorphan & Antidiarrheal & $-138,31$ & 29,8 \\
\hline 1,8-Dihydroxyanthraquinone & Laxative Antiemetic & $-52,31$ & 60,06 \\
\hline Thioperamide maleate & Antiemetic & $-138,85$ & 38,19 \\
\hline Aripiprazole & Antipsychotic & $-138,9$ & 43,34 \\
\hline Amoxapine & Antidepressant antipsychotic & $-139,29$ & 48,46 \\
\hline Pilocarpine nitrate & Antiglaucoma & $-139,73$ & 44,71 \\
\hline $\begin{array}{r}\text { Dextromethorphan } \\
\text { hydrobromide monohydrate }\end{array}$ & antitussive & $-139,74$ & 36,97 \\
\hline Mesoridazine besylate & Antipsychotic & $-141,03$ & 36,99 \\
\hline Acefylline & CNS stimulant & $-141,37$ & 23,22 \\
\hline Sulfamethizole & Antibacterial & $-141,44$ & 34,52 \\
\hline Vigabatrin hydrochloride & Anticonvulsant antiepileptic & $-142,42$ & 29,39 \\
\hline Propofol & Anesthetic Sedative & $-142,44$ & 43,98 \\
\hline Dihydroergotamine tartrate & Antimigraine & $-142,53$ & 42,19 \\
\hline Rimantadine Hydrochloride & Antiviral & $-143,38$ & 34,95 \\
\hline Lidoflazine & Antiarrhythmic & $-143,66$ & 34,88 \\
\hline Alfacalcidol & Antiosteoporosis & $-143,72$ & 39,73 \\
\hline Sulfinpyrazone & Antiplatelet uricosuric & $-143,9$ & 28,41 \\
\hline Bromhexine hydrochloride & Expectorant & $-144,22$ & 39,94 \\
\hline Sulfaquinoxaline sodium salt & Antibacterial & $-144,43$ & 39,65 \\
\hline Dinoprost trometamol & Oxytocic & $-144,43$ & 36,91 \\
\hline Misoprostol & Antiulcer & $-144,65$ & 50,57 \\
\hline Dimaprit dihydrochloride & & $-144,8$ & 41,03 \\
\hline Mebeverine hydrochloride & Antispastic & $-144,87$ & 28,48 \\
\hline Pirlindole mesylate & Antidepressant & $-146,43$ & 38,55 \\
\hline Zomepirac sodium salt & Anti-inflammatory & $-147,45$ & 33,24 \\
\hline Rimexolone & Anti-inflammatory & $-147,58$ & 40,8 \\
\hline Erlotinib & Antineoplastic & $-147,91$ & 35,07 \\
\hline
\end{tabular}




\begin{tabular}{|c|c|c|c|}
\hline Name & Therapeutic effect & $\begin{array}{l}\text { \% GraXRS } \\
\text { inhibition }\end{array}$ & $\begin{array}{l}\% \text { Growth } \\
\text { inhibition }\end{array}$ \\
\hline Asenapine maleate & Antipsychotic & $-148,15$ & 39,29 \\
\hline $\begin{array}{r}\text { Metaproterenol sulfate, } \\
\text { orciprenaline sulfate }\end{array}$ & Bronchodilator & $-148,44$ & 33,5 \\
\hline Niridazole & $\begin{array}{l}\text { Antihelmintic } \\
\text { antiprotozoal }\end{array}$ & $-148,46$ & 43,94 \\
\hline lohexol & Contrastant & $-148,59$ & 34,99 \\
\hline Clofazimine & Antibacterial & 273,41 & 81,3 \\
\hline Tolvaptan & Antihypertensive diuretic & $-148,71$ & 36,42 \\
\hline Mephenesin & $\begin{array}{l}\text { Anticonvulsant local anesthetic } \\
\text { muscle relaxant }\end{array}$ & $-149,28$ & 49,28 \\
\hline Fursultiamine Hydrochloride & Anti-Alzheimer & $-149,3$ & 45,09 \\
\hline Fusidic acid sodium salt & Antibacterial & 361,06 & 91,91 \\
\hline Benzathine benzylpenicillin & Antibacterial & $-149,39$ & 51,81 \\
\hline Dexrazoxane hydrochloride & Chemoprotectant & $-149,51$ & 39,66 \\
\hline Methylergometrine maleate & Hemostatic Oxytocic & $-150,28$ & 37,45 \\
\hline Risperidone & Antipsychotic & $-151,26$ & 41,65 \\
\hline Lofexidine & Antihypertensive & $-151,52$ & 36,39 \\
\hline Gabexate mesilate & Anticoagulant & $-151,66$ & 36,7 \\
\hline Nitrocaramiphen hydrochloride & & $-151,96$ & 41,55 \\
\hline Dequalinium dichloride & Antibacterial Antiseptic & $-131,97$ & 78,57 \\
\hline Pentoxifylline & Bronchodilator Vasodilator & $-153,1$ & 34,83 \\
\hline Thalidomide & Hypnotic Immunosuppressant & $-153,59$ & 40,23 \\
\hline Exemestane & Antineoplastic & $-155,08$ & 42,38 \\
\hline Letrozole & Antineoplatic & $-155,32$ & 40,66 \\
\hline Oxybutynin chloride & Antispastic & $-155,46$ & 32,53 \\
\hline Kanamycin A sulfate & Antibacterial & 698,91 & 74,53 \\
\hline Amikacin hydrate & Antibacterial & 1163,39 & 92,93 \\
\hline Atovaquone & Antimalarial antiprotozoal & $-155,49$ & 36,03 \\
\hline $\begin{array}{r}\text { Butylscopolammonium ( } \mathrm{n}-) \\
\text { bromide }\end{array}$ & Antispastic & $-155,52$ & 38,85 \\
\hline Metoprolol-(+,-) (+)-tartrate salt & $\begin{array}{l}\text { Antiarrhythmic } \\
\text { antihypertensive }\end{array}$ & $-156,17$ & 40,62 \\
\hline Flunarizine dihydrochloride & Anticonvulsant vasodilator & $-156,22$ & 31,21 \\
\hline Cortisol acetate & Anti-inflammatory & $-156,38$ & 32,87 \\
\hline Metaraminol bitartrate & $\begin{array}{l}\text { Antihypotensive } \\
\text { vasoconstrictor }\end{array}$ & $-156,42$ & 50,72 \\
\hline Oxiconazole Nitrate & Antifungal & $-156,94$ & 39,13 \\
\hline Tenoxicam & $\begin{array}{l}\text { Analgesic anti-inflammatory } \\
\text { antipyretic }\end{array}$ & $-157,27$ & 37,85 \\
\hline Glimepiride & Antidiabetic & $-157,36$ & 37,38 \\
\hline Tigecycline & & $-157,71$ & 30,04 \\
\hline Amifostine & & $-157,96$ & 42,07 \\
\hline
\end{tabular}




\begin{tabular}{|c|c|c|c|}
\hline Name & Therapeutic effect & $\begin{array}{l}\text { \% GraXRS } \\
\text { inhibition }\end{array}$ & $\begin{array}{l}\text { \% Growth } \\
\text { inhibition }\end{array}$ \\
\hline Pizotifen malate & $\begin{array}{l}\text { Antihistaminic Antimigraine } \\
\text { Sedative }\end{array}$ & $-158,08$ & 40,75 \\
\hline Metixene hydrochloride & Antiparkinsonian antispastic & $-158,81$ & 27,38 \\
\hline Nifekalant & Antiarrhythmic & $-159,2$ & 42,17 \\
\hline Khellin & $\begin{array}{l}\text { Antispastic } \\
\text { vasodilator }\end{array}$ & $-159,36$ & 48,51 \\
\hline Dipivefrin hydrochloride & Antiglaucoma & $-159,69$ & 31,15 \\
\hline Pargyline hydrochloride & $\begin{array}{l}\text { Antidepressant } \\
\text { antihypertensive }\end{array}$ & $-160,04$ & 47,24 \\
\hline Caffeine & CNS Stimulant & $-160,13$ & 43,44 \\
\hline Paliperidone & Antipsychotic & $-160,21$ & 44,17 \\
\hline Brinzolamide & Antiglaucoma Diuretic & $-160,6$ & 40,06 \\
\hline Chlorprothixene hydrochloride & Antiemetic Antipsychotic & $-160,78$ & 38,82 \\
\hline Etofenamate & Anti-inflammatory & $-161,47$ & 48,49 \\
\hline Pimozide & Antipsychotic & $-36,39$ & 66,56 \\
\hline Pronethalol hydrochloride & $\begin{array}{l}\text { Antianginal Antiarrhythmic } \\
\text { Antihypertenisve }\end{array}$ & $-161,74$ & 36,26 \\
\hline Moclobemide & Antidepressant & $-161,82$ & 39,05 \\
\hline Dantrolene sodium salt & Muscle relaxant & $-162,15$ & 31,34 \\
\hline Fluorometholone & Anti-inflammatory & $-162,37$ & 27,17 \\
\hline Vinpocetine & $\begin{array}{l}\text { CNS Stimulant } \\
\text { Neuroprotectant Vasodilator }\end{array}$ & $-35,51$ & 67,13 \\
\hline Lisinopril & Antihypertensive vasodilator & $-162,45$ & 32,05 \\
\hline Calcipotriene & Antipsoriatic & $-162,61$ & 54,39 \\
\hline Fomepizole & & $-162,62$ & 38,87 \\
\hline Probucol & $\begin{array}{l}\text { Antilipermic } \\
\text { Hypocholesterolemic }\end{array}$ & $-163,46$ & 37,5 \\
\hline Zuclopenthixol dihydrochloride & Antipsychotic Antiviral Sedative & $-163,49$ & 42,58 \\
\hline Zardaverine & Bronchodilator & $-163,57$ & 40,74 \\
\hline Levonordefrin & Vasoconstrictor & $-164,58$ & 35,06 \\
\hline Pefloxacine & Antibacterial & 40,67 & 68,21 \\
\hline Praziquantel & Antihelmintic & $-165,02$ & 25,44 \\
\hline Torsemide & Antihypertensive Diuretic & $-165,09$ & 44,22 \\
\hline Granisetron & Antiemetic & $-166,09$ & 52,05 \\
\hline Maprotiline hydrochloride & Antidepressant Anxiolytic & $-166,35$ & 41,55 \\
\hline Loratadine & Antihistaminic & $-167,11$ & 36,6 \\
\hline Azathioprine & $\begin{array}{l}\text { Antineoplastic } \\
\text { immunosuppressant }\end{array}$ & $-167,21$ & 50,85 \\
\hline Cyanocobalamin & Analgesic & $-167,36$ & 45,44 \\
\hline Flecainide acetate & Antiarrhythmic & $-168,09$ & 38,99 \\
\hline Dicloxacillin sodium salt hydrate & Antibacterial & 119,67 & 81,21 \\
\hline Famciclovir & Antiviral & $-168,18$ & 48,74 \\
\hline Miglitol & Antidiabetic & $-168,28$ & 40,92 \\
\hline
\end{tabular}




\begin{tabular}{|c|c|c|c|}
\hline Name & Therapeutic effect & $\begin{array}{l}\text { \% GraXRS } \\
\text { inhibition }\end{array}$ & $\begin{array}{l}\text { \% Growth } \\
\text { inhibition }\end{array}$ \\
\hline Deptropine citrate & $\begin{array}{l}\text { Antihistaminic Bronchodilator } \\
\text { Vasodilator }\end{array}$ & $-168,93$ & 49,42 \\
\hline Cyclosporin A & Immunosuppressant & $-169,41$ & 39,86 \\
\hline Antazoline hydrochloride & Antihistaminic sedative & $-31,51$ & 68,68 \\
\hline 5-fluorouracil & Antineoplastic & $-31,36$ & 70,27 \\
\hline Tracazolate hydrochloride & Anticonvulsant Sedative & $-169,77$ & 39,01 \\
\hline Cinoxacin & Antibacterial & $-170,3$ & 39,83 \\
\hline Nebivolol hydrochloride & Antihypertensive & $-170,57$ & 47,84 \\
\hline Medrysone & Anti-inflammatory & $-170,79$ & 41,82 \\
\hline Ibandronate sodium & Antiosteoporosis & $-171,09$ & 36,43 \\
\hline Bupivacaine hydrochloride & Local anesthetic & $-171,16$ & 36,61 \\
\hline Carbarsone & Antiamebicantiprotozoal & $-171,23$ & 41,43 \\
\hline Linezolid & Antibacterial & 93,91 & 62,09 \\
\hline Fenoterol hydrobromide & Bronchodilator tocolytic & $-171,75$ & 36,57 \\
\hline Meclocycline sulfosalicylate & Antibacterial & 87,48 & 77,44 \\
\hline Chlorthalidone & Antihypertensive Diuretic & $-172,61$ & 39,4 \\
\hline Melengestrol acetate & & -173 & 46,59 \\
\hline Pipenzolate bromide & Antispastic & $-173,25$ & 41,84 \\
\hline Ceforanide & Antibacterial & $-20,07$ & 69,45 \\
\hline Oxcarbazepine & Anticonvulsant & $-173,28$ & 44,74 \\
\hline Cefixime & Antibacterial & $-63,52$ & 67,49 \\
\hline Pirenperone & & $-173,75$ & 38,83 \\
\hline $\begin{array}{r}\text { Mebhydroline 1,5- } \\
\text { naphtalenedisulfonate }\end{array}$ & Antihistaminic & $-173,84$ & 47,01 \\
\hline Tosufloxacin hydrochloride & Antibacterial & $-59,88$ & 78,57 \\
\hline Methylprednisolone, 6-alpha & $\begin{array}{l}\text { Anti-inflammatory } \\
\text { Immunosuppressant }\end{array}$ & $-173,92$ & 38,12 \\
\hline Rifapentine & Antibacterial & 101,55 & 78,07 \\
\hline $\begin{array}{r}\text { Zimelidine dihydrochloride } \\
\text { monohydrate }\end{array}$ & Antidepressant & $-28,25$ & 55,63 \\
\hline Mometasone furoate & Anti-inflammatory & $-174,08$ & 38,79 \\
\hline Closantel & Antihelmintic antiparasitic & 141,43 & 75,63 \\
\hline Bisacodyl & Laxative & $-174,76$ & 38,82 \\
\hline Tegafur & Antineoplastic & $-175,65$ & 46,24 \\
\hline Trimetozine & Sedative & $-176,09$ & 37,52 \\
\hline Streptozotocin & Antineoplastic & $-176,31$ & 40,9 \\
\hline Glycopyrrolate & Antispastic & $-176,37$ & 41,35 \\
\hline Triprolidine hydrochloride & Antihistaminic sedative & $-177,47$ & 29,17 \\
\hline Cinnarizine & $\begin{array}{l}\text { Antihistaminic } \quad \text { antivertigo } \\
\text { sedative }\end{array}$ & $-26,35$ & 69,62 \\
\hline Indomethacin & $\begin{array}{l}\text { Analgesic anti-inflammatory } \\
\text { antipyretic }\end{array}$ & $-177,56$ & 35,46 \\
\hline
\end{tabular}




\begin{tabular}{|c|c|c|c|}
\hline Name & Therapeutic effect & $\begin{array}{l}\text { \% GraXRS } \\
\text { inhibition }\end{array}$ & $\begin{array}{l}\text { \% Growth } \\
\text { inhibition }\end{array}$ \\
\hline Zaleplon & Hypnotic sedative & $-178,45$ & 46,15 \\
\hline Isosorbide dinitrate & Antianginal & $-178,87$ & 26,98 \\
\hline Halcinonide & Anti-inflammatory antipruritic & $-179,07$ & 35,06 \\
\hline Cefotiam hydrochloride & Antibacterial & $-1007,95$ & 95,38 \\
\hline Betahistine mesylate & Vasodilator & $-179,43$ & 36,15 \\
\hline Azelastine hydrochloride & Antihistaminic & $-180,09$ & 41,22 \\
\hline Ribostamycin sulfate salt & Antibacterial & $-180,56$ & 47,77 \\
\hline Dobutamine hydrochloride & $\begin{array}{l}\text { Analeptic Cardiotonic Positive } \\
\text { inotropic }\end{array}$ & $-180,61$ & 38,91 \\
\hline Folinic acid calcium salt & Antianemic & $-180,72$ & 40,09 \\
\hline Bosentan & Vasodilator & $-180,86$ & 53,39 \\
\hline Diperodon hydrochloride & Local anesthetic & $-180,87$ & 34,04 \\
\hline Alendronate sodium & Antiosteoporosis & $-180,91$ & 29,58 \\
\hline Ibutilide fumarate & Antiarrhythmic & $-181,04$ & 27,87 \\
\hline Acetylcysteine & Mucolytic & $-181,64$ & 45,19 \\
\hline Levetiracetam & Anticonvulsant & $-182,71$ & 24,87 \\
\hline Desloratadine & Antihistaminic & $-22,83$ & 62 \\
\hline Cetirizine dihydrochloride & Antihistaminic antipruritic & $-182,79$ & 37,78 \\
\hline Amlodipine & Antihypertensive & $-183,03$ & 40,87 \\
\hline Vancomycin hydrochloride & Antibacterial & $-820,38$ & 95,15 \\
\hline Clofibric acid & Antilipemic & $-183,34$ & 42,53 \\
\hline Finasteride & Anti-alopecia antineoplastic & $-184,05$ & 32,97 \\
\hline Phenacetin & Analgesic antipyretic & $-185,28$ & 39,03 \\
\hline Cisapride & Gastroprokinetic & $-185,94$ & 40,33 \\
\hline Betamethasone & $\begin{array}{l}\text { Anti-inflammatory Antipruritic } \\
\text { Immunosuppressant }\end{array}$ & $-186,53$ & 39,25 \\
\hline Clorgyline hydrochloride & Antidepressant & $-187,19$ & 43,51 \\
\hline Dacarbazine & Antineoplastic & $-187,32$ & 45,14 \\
\hline Metrizamide & Contrastant & $-188,45$ & 44,17 \\
\hline Zaprinast & Erectil dysfunction treatment & $-188,96$ & 39,8 \\
\hline Lacidipine & Antihypertensive & $-188,97$ & 43,85 \\
\hline Quetiapine hemifumarate & Antipsychotic & $-189,06$ & 54,02 \\
\hline Imipenem & Antibacterial & $-1799,83$ & 97,05 \\
\hline Methiothepin maleate & Antipsychotic & $-189,16$ & 48,36 \\
\hline Pramoxine hydrochloride & Local anesthetic & $-189,79$ & 40,71 \\
\hline Biotin & & $-189,81$ & 40,82 \\
\hline Clenbuterol hydrochloride & $\begin{array}{l}\text { Antiasthmatic } \text { Bronchodilator } \\
\text { Tocolytic }\end{array}$ & $-189,88$ & 44,23 \\
\hline Diphenidol hydrochloride & Antiemetic antivertigo & $-189,94$ & 30,46 \\
\hline Chlorotrianisene & Antineoplastic & -190 & 43,91 \\
\hline
\end{tabular}




\begin{tabular}{|c|c|c|c|}
\hline Name & Therapeutic effect & $\begin{array}{l}\text { \% GraXRS } \\
\text { inhibition }\end{array}$ & $\begin{array}{l}\text { \% Growth } \\
\text { inhibition }\end{array}$ \\
\hline Tetramisole hydrochloride & $\begin{array}{l}\text { Antihelmintic antiparasitic } \\
\text { immunomodulator }\end{array}$ & $-190,8$ & 37,06 \\
\hline Ropinirole hydrochloride & Antiparkinsonian & $-190,86$ & 42,74 \\
\hline Dronedarone hydrochloride & Antiarrhythmic & -191 & 41,63 \\
\hline Galanthamine hydrobromide & $\begin{array}{l}\text { Analgesic anti-alzheimer anti- } \\
\text { fatigue }\end{array}$ & $-191,3$ & 44,44 \\
\hline Mesna & Chemoprotectant & $-191,31$ & 47,78 \\
\hline $\begin{array}{r}\text { Roxatidine Acetate } \\
\text { hydrochloride }\end{array}$ & Antiulcer & $-191,43$ & 43,96 \\
\hline Thiostrepton & Antibacterial & 10,1 & 91,31 \\
\hline Nitrofural & Antibacterial & $-191,59$ & 38,05 \\
\hline Fenofibrate & $\begin{array}{l}\text { Hypocholesterolemic Lipid- } \\
\text { lowering Uricosuric }\end{array}$ & $-191,6$ & 35,52 \\
\hline Rifampicin & Antibacterial & $-360,18$ & 92,86 \\
\hline THIP Hydrochloride & sedative & $-191,79$ & 38,76 \\
\hline Clomipramine hydrochloride & Antidepressant & $-191,8$ & 32,4 \\
\hline Tropisetron hydrochloride & Antiemetic & $-192,25$ & 36,97 \\
\hline (S)-(-)-Atenolol & $\begin{array}{l}\text { Antianginal antiarrhythmic } \\
\text { antihypertensive }\end{array}$ & $-192,32$ & 39,47 \\
\hline Thiethylperazine dimalate & Antiemetic Antivertigo & $-192,36$ & 50,1 \\
\hline Flumethasone & Anti-inflammatory & $-192,38$ & 45,47 \\
\hline Grepafloxacin & & 82,7 & 82,91 \\
\hline Furosemide & Antihypertensive Diuretic & $-192,43$ & 35,68 \\
\hline D,L-Penicillamine & Analgesic & $-193,14$ & 31,31 \\
\hline $\begin{array}{r}\text { Fenoprofen calcium salt } \\
\text { dihydrate }\end{array}$ & Anti-inflammatory & $-193,33$ & 41,23 \\
\hline Clemastine fumarate & antihistaminic & $-193,36$ & 38,14 \\
\hline Zidovudine, AZT & Antiviral & $-193,49$ & 36,62 \\
\hline Vidarabine & Antiviral & $-193,53$ & 46,46 \\
\hline Cefotetan & Antibacterial & $-194,65$ & 49,78 \\
\hline Pimethixene maleate & $\begin{array}{l}\text { Antihistaminci antitussive } \\
\text { Bronchodilator }\end{array}$ & $-195,39$ & 29,95 \\
\hline Carisoprodol & $\begin{array}{l}\text { Analgesic antipyretic muscle } \\
\text { relaxant }\end{array}$ & $-195,66$ & 47,09 \\
\hline Probenecid & Antigout uricosuric & $-195,72$ & 35,28 \\
\hline Benzocaine & Local anesthetic & $-195,88$ & 15,71 \\
\hline Tobramycin & Antibacterial & $-485,01$ & 87,09 \\
\hline Isoetharine mesylate salt & Bronchodilator & $-196,04$ & 36,65 \\
\hline Tiapride hydrochloride & antipsychotic & $-196,81$ & 40,91 \\
\hline Pemirolast potassium & $\begin{array}{l}\text { Anti-inflammatory Antipruritic } \\
\text { Antihistaminic }\end{array}$ & $-197,24$ & 41,37 \\
\hline Isopropamide iodide & Antiulcer & $-197,74$ & 43,01 \\
\hline Amprenavir & Antiviral & $-198,04$ & 40,69 \\
\hline
\end{tabular}




\begin{tabular}{|c|c|c|c|}
\hline Name & Therapeutic effect & $\begin{array}{l}\text { \% GraXRS } \\
\text { inhibition }\end{array}$ & $\begin{array}{l}\text { \% Growth } \\
\text { inhibition }\end{array}$ \\
\hline Pyrilamine maleate & $\begin{array}{l}\text { Antihistaminic } \\
\text { antitussive }\end{array}$ & $-198,32$ & 40,25 \\
\hline Bacampicillin hydrochloride & Antibacterial & $-199,63$ & 43,09 \\
\hline Fenipentol & Choleretic & $-200,02$ & 42,45 \\
\hline Acamprosate calcium & & $-200,52$ & 47,87 \\
\hline Methapyrilene hydrochloride & Antihistaminic Sedative & $-201,74$ & 36,89 \\
\hline Sisomicin sulfate & Antibacterial & $-8,89$ & 57,15 \\
\hline Ipsapirone & & $-202,19$ & 49,37 \\
\hline Tenatoprazole & Antiulcer & $-202,4$ & 40,53 \\
\hline Carmofur & Antineoplastic & $-7,88$ & 58,75 \\
\hline Cefpiramide & Antibacterial & $-7,51$ & 60,64 \\
\hline Topotecan & Antineoplastic & $-203,08$ & 53,57 \\
\hline Sulfabenzamide & Antibacterial & $-203,71$ & 29,17 \\
\hline Voriconazole & Antifungal & $-203,78$ & 47,27 \\
\hline Cefsulodin sodium salt & Antibacterial & $-5,82$ & 65,88 \\
\hline Nisoldipine & Antianginal antihypertensive & $-205,35$ & 35,05 \\
\hline Metergoline & Antiprolactin & $-206,31$ & 46,57 \\
\hline Pregnenolone & Anabolic anti-inflammatory & $-207,03$ & 39,31 \\
\hline Suloctidil & Antiplatelet vasodilator & $-207,41$ & 41,52 \\
\hline Alizapride hydrochloride & Antiemetic & $-207,57$ & 44,25 \\
\hline Clopamide & Antihypertensive Diuretic & $-207,72$ & 47,01 \\
\hline Leflunomide & Immunosuppressant & $-208,18$ & 32,32 \\
\hline Thioguanosine & Antineoplastic & $-208,21$ & 41,13 \\
\hline Methacholine chloride & & $-208,69$ & 42,28 \\
\hline Aniracetam & Anti-alzheimer & $-209,7$ & 48,9 \\
\hline Cortisone & $\begin{array}{l}\text { Anti-inflammatory } \\
\text { Immunosuppressant }\end{array}$ & $-210,96$ & 40,33 \\
\hline Beta-Escin & Antineoplastic diuretic & $-211,18$ & 42,73 \\
\hline Butenafine Hydrochloride & Antifungal & $-211,75$ & 53,9 \\
\hline Norethindrone & Contraceptive & $-212,05$ & 39,33 \\
\hline Sulfachloropyridazine & Antibacterial & $-212,2$ & 34,6 \\
\hline Androsterone & Anabolic & $-212,35$ & 37,25 \\
\hline Acetopromazine maleate salt & $\begin{array}{l}\text { Antiemetic } \quad \text { antipsychotic } \\
\text { antitussive }\end{array}$ & $-212,97$ & 41,38 \\
\hline Bambuterol hydrochloride & Bronchodilator Tocolytic & $-213,37$ & 36,56 \\
\hline Prednisolone & $\begin{array}{l}\text { Anti-inflammatory } \\
\text { Immunosuppressant }\end{array}$ & $-214,55$ & 40,16 \\
\hline Bimatoprost & Antiglaucoma & $-214,63$ & 40,86 \\
\hline Practolol & Antianginal Antihypertensive & $-215,33$ & 35,43 \\
\hline Dyclonine hydrochloride & Local anesthetic & $-215,84$ & 37,99 \\
\hline Etretinate & Antipsoriatic & $-217,14$ & 46,43 \\
\hline
\end{tabular}




\begin{tabular}{|c|c|c|c|}
\hline Name & Therapeutic effect & $\begin{array}{l}\text { \% GraXRS } \\
\text { inhibition }\end{array}$ & $\begin{array}{l}\text { \% Growth } \\
\text { inhibition }\end{array}$ \\
\hline Buflomedil hydrochloride & Vasodilator & $-217,14$ & 43,52 \\
\hline Guaifenesin & Bronchodilator expectorant & $-218,14$ & 46,77 \\
\hline Amoxicillin & Antibacterial & $-218,73$ & 48,36 \\
\hline Ethisterone & Contraceptive & $-218,88$ & 35,33 \\
\hline Glafenine hydrochloride & Analgesic & $-219,16$ & 38,27 \\
\hline Efavirenz & Antiviral & $-219,95$ & 48,65 \\
\hline Fludrocortisone acetate & Anti-inflammatory antipruritic & $-220,48$ & 37,57 \\
\hline Argatroban & Anticoagulant & $-220,79$ & 44,69 \\
\hline Pitavastatin calcium & Hypocholesterolemic & $-221,75$ & 47,2 \\
\hline Hydroxychloroquine sulfate & Antimalarial & $-222,05$ & 48,01 \\
\hline Papaverine hydrochloride & $\begin{array}{l}\text { Antispastic antitussive erectile } \\
\text { dysfunction treatment }\end{array}$ & $-222,84$ & 46,71 \\
\hline Proadifen hydrochloride & Local anesthetic & $-224,52$ & 45,55 \\
\hline Spiramycin & Antibacterial & 6,02 & 65,82 \\
\hline Escitalopram oxalate & Antidepressant & $-224,95$ & 39,74 \\
\hline Benzamil hydrochloride & Antihypertensive diuretic & $-225,18$ & 35,27 \\
\hline Estradiol-17 beta & Antigonadotropin & $-225,5$ & 45,32 \\
\hline Zafirlukast & Antiasthmatic & 97,7 & 76,25 \\
\hline Zopiclone & Hypnotic sedative & $-225,91$ & 47,08 \\
\hline Pranlukast & Antiasthmatic & $-227,03$ & 38,21 \\
\hline Clonidine hydrochloride & $\begin{array}{l}\text { Analgesic antihypotensive } \\
\text { sedative }\end{array}$ & 7,96 & 58,79 \\
\hline Labetalol hydrochloride & Antihypotensive & $-227,54$ & 39,22 \\
\hline Hydrocortisone base & Anti-inflammatory & $-228,11$ & 42,38 \\
\hline Guanadrel sulfate & Antihypertenisve & $-228,59$ & 45,51 \\
\hline Dydrogesterone & Progestogen & $-228,84$ & 45,82 \\
\hline Cycloheximide & Antibacterial & $-230,46$ & 42,63 \\
\hline Isoniazid & Antibacterial & $-231,26$ & 25,29 \\
\hline Tirofiban hydrochloride & Antiplatelet & $-231,86$ & 49,29 \\
\hline Oxibendazol & & $-233,13$ & 52,06 \\
\hline Mizolastine & & $-235,15$ & 47,3 \\
\hline Tetracaïne hydrochloride & & $-235,34$ & 39,39 \\
\hline Picrotoxinin & Analeptic & -237 & 40,42 \\
\hline Dimenhydrinate & $\begin{array}{l}\text { Antiemetic } \\
\text { antivertigo }\end{array}$ & $-239,52$ & 40,87 \\
\hline Terazosin hydrochloride & Antihypertensive & $-239,59$ & 44,48 \\
\hline Vincamine & CNS Stimulant Vasodilator & $-239,9$ & 34,95 \\
\hline Meclofenoxate hydrochloride & CNS Stimulant & $-239,98$ & 45,96 \\
\hline Xylazine & Analgesic sedative & $-240,09$ & 54,4 \\
\hline Dexamethasone acetate & $\begin{array}{l}\text { Anti-inflammatory } \\
\text { immunosuppressant }\end{array}$ & $-240,22$ & 42,34 \\
\hline
\end{tabular}




\begin{tabular}{|c|c|c|c|}
\hline Name & Therapeutic effect & $\begin{array}{l}\text { \% GraXRS } \\
\text { inhibition }\end{array}$ & $\begin{array}{l}\text { \% Growth } \\
\text { inhibition }\end{array}$ \\
\hline Doxepin hydrochloride & $\begin{array}{l}\text { Anticonvulsant antidepressant } \\
\text { antipruritic }\end{array}$ & $-240,65$ & 37,76 \\
\hline Disopyramide & Antiarrhythmic & $-240,7$ & 34,42 \\
\hline Doxorubicin hydrochloride & $\begin{array}{l}\text { Antibacterial antineoplastic } \\
\text { immunosuppressant }\end{array}$ & 14,31 & 61,8 \\
\hline Tizanidine hydrochloride & Muscle relaxant & $-241,2$ & 51,82 \\
\hline Butamben & Anesthetic & $-241,28$ & 48,68 \\
\hline Sulfamerazine & Antibacterial & $-241,28$ & 39,67 \\
\hline Podophyllotoxin & Antiviral & $-241,42$ & 47,82 \\
\hline Bumetanide & Diuretic & $-241,45$ & 36,21 \\
\hline Trioxsalen & & $-242,77$ & 42,13 \\
\hline Florfenicol & Antibacterial & 15,77 & 66,02 \\
\hline Fipexide hydrochloride & Anti-fatigue CNS stimulant & 16,02 & 62,49 \\
\hline Digoxin & Cardiotonic & $-243,64$ & 47,02 \\
\hline Sulfamethazine sodium salt & Antibacterial & $-243,86$ & 46,28 \\
\hline Methimazole & & $-244,16$ & 48,79 \\
\hline Norgestrel-(-)-D & Contraceptive & $-244,58$ & 48,39 \\
\hline Acemetacin & Anti-inflammatory & $-245,1$ & 39,07 \\
\hline Pinaverium bromide & Antipastic & $-745,12$ & 93,96 \\
\hline Nortriptyline hydrochloride & Antidepressant CNS stimulant & $-245,81$ & 36,4 \\
\hline Benfotiamine & & $-246,03$ & 40,17 \\
\hline Benazepril hydrochloride & Antihypertensive & $-246,13$ & 52,78 \\
\hline Diosmin & & $-247,64$ & 54,83 \\
\hline Hexylcaine hydrochloride & Anesthetic & $-248,37$ & 45,8 \\
\hline Temozolomide & Antineoplastic & $-249,74$ & 48,89 \\
\hline Celiprolol hydrochloride & Antianginal antihypertensive & $-249,89$ & 51,28 \\
\hline Dimethisoquin hydrochloride & Antipruritic lical anesthetic & $-252,01$ & 53,39 \\
\hline Drofenine hydrochloride & Antispastic & $-252,06$ & 43,32 \\
\hline Emedastine & Antihistaminic & $-252,44$ & 51,39 \\
\hline Sulfameter & Antibacterial & $-253,12$ & 43,16 \\
\hline Desipramine hydrochloride & Antidepressant CNS Stimulant & $-253,36$ & 45,93 \\
\hline Ketotifen fumarate & Antihistaminic & $-254,34$ & 35,52 \\
\hline Acipimox & Antilipemic & $-256,89$ & 53,12 \\
\hline Colchicine & Antigout Anti-inflammatory & $-257,58$ & 44,38 \\
\hline Folic acid & & $-259,46$ & 51,71 \\
\hline Citalopram Hydrobromide & Antidepressant & $-260,3$ & 35,94 \\
\hline Pranoprofen & Anti-inflammatory & $-260,41$ & 47,6 \\
\hline Demecarium bromide & Antiglaucoma & $-265,08$ & 53,76 \\
\hline Pyridoxine hydrochloride & & $-266,05$ & 53,65 \\
\hline
\end{tabular}




\begin{tabular}{|c|c|c|c|}
\hline Name & Therapeutic effect & $\begin{array}{l}\% \text { GraXRS } \\
\text { inhibition }\end{array}$ & $\begin{array}{l}\text { \% Growth } \\
\text { inhibition }\end{array}$ \\
\hline Thioproperazine dimesylate & Antiemetic antipsychotic & 27,55 & 56,28 \\
\hline Lanatoside C & Cardiotonic & $-269,8$ & 39,07 \\
\hline Mercaptopurine & Immunosuppressant & $-272,06$ & 53,63 \\
\hline Reboxetine mesylate & Antidepressant & $-272,43$ & 50,71 \\
\hline Mepenzolate bromide & Antispastic antiulcer & $-274,45$ & 40,21 \\
\hline Nalidixic acid sodium salt & Antibacterial & $-274,99$ & 41,26 \\
\hline Suxibuzone & $\begin{array}{l}\text { Analgesic anti-inflammatory } \\
\text { antipyretic }\end{array}$ & $-275,31$ & 40,27 \\
\hline Racecadotril & Antidiarrheal & $-275,67$ & 54,96 \\
\hline Dirithromycin & Antibacterial & 32,47 & 69,13 \\
\hline Triamcinolone & $\begin{array}{l}\text { Anti-inflammatory } \\
\text { immunosuppressant }\end{array}$ & $-276,79$ & 43,59 \\
\hline Venlafaxine & Antidepressant & $-278,74$ & 49,73 \\
\hline Phenazopyridine hydrochloride & Analgesic & $-279,32$ & 49,57 \\
\hline Estropipate & & $-286,23$ & 39,89 \\
\hline $\begin{array}{r}\text { Tetraethylenepentamine } \\
\text { pentahydrochloride }\end{array}$ & Antilipemic & $-290,81$ & 41,19 \\
\hline Oxacillin sodium & Antibacterial & $-2146,59$ & 96,8 \\
\hline Tranilast & Antiallergic & $-291,5$ & 52,04 \\
\hline $\begin{array}{r}\text { Trihexyphenidyl-D,L } \\
\text { Hydrochloride }\end{array}$ & Antiparkinsonian & $-298,84$ & 42,47 \\
\hline Alclometasone dipropionate & Anti-inflammatory & $-305,4$ & 45,83 \\
\hline Dipyrone & $\begin{array}{l}\text { Analgesic } \\
\text { antipyretic }\end{array}$ & $-306,55$ & 33,48 \\
\hline $\begin{array}{r}\text { Homochlorcyclizine } \\
\text { dihydrochloride }\end{array}$ & Antihistaminic sedative & $-306,56$ & 39,22 \\
\hline Benzethonium chloride & Antibacterial antiseptic & $-316,26$ & 49,84 \\
\hline Mirabegron & & $-320,08$ & 45,79 \\
\hline Sumatriptan succinate & Antimigraine & $-323,76$ & 46,63 \\
\hline Doxofylline & Bronchodilator & $-325,87$ & 46,56 \\
\hline Perhexiline maleate & Antianginal & $-326,3$ & 39,93 \\
\hline Sulfapyridine & Antibacterial & $-330,79$ & 48,84 \\
\hline Tetrahydrozoline hydrochloride & $\begin{array}{ll}\text { Nasal } & \text { decongestant } \\
\text { vasoconstrictor }\end{array}$ & $-337,86$ & 44,24 \\
\hline Piroxicam & $\begin{array}{l}\text { Analgesic anticoagulant anti- } \\
\text { inflammatory }\end{array}$ & $-337,96$ & 36,5 \\
\hline Zileuton & Antiasthmatic & $-341,85$ & 44,19 \\
\hline Cefmetazole sodium salt & Antibacterial & $-2413,38$ & 97,12 \\
\hline Tylosin & Antibacterial & 45,13 & 85,17 \\
\hline $\begin{array}{r}\text { Quinacrine dihydrochloride } \\
\text { hydrate }\end{array}$ & $\begin{array}{l}\text { Antihelmintic antileishmanial } \\
\text { antimalarial }\end{array}$ & 59,1 & 62,81 \\
\hline Thiamine hydrochloride & Immunostimulant & $-346,43$ & 43,69 \\
\hline Bromopride & Antiemetic & $-349,22$ & 49,43 \\
\hline Ethotoin & Anticonvulsant & $-350,77$ & 50,03 \\
\hline
\end{tabular}


Anexo I

\begin{tabular}{|c|c|c|c|}
\hline Name & Therapeutic effect & $\begin{array}{l}\% \text { GraXRS } \\
\text { inhibition }\end{array}$ & $\begin{array}{l}\text { \% Growth } \\
\text { inhibition }\end{array}$ \\
\hline Warfarin & Anticoagulant & $-352,58$ & 45,34 \\
\hline Famprofazone & Analgesic antipyretic & -353 & 46,62 \\
\hline $\begin{array}{r}\text { 3-alpha-Hydroxy-5-beta- } \\
\text { androstan-17-one }\end{array}$ & & $-353,82$ & 40,87 \\
\hline Irsogladine maleate & Antiulcer & $-354,28$ & 40,84 \\
\hline Opipramol dihydrochloride & Antidepressant antipsychotic & $-355,1$ & 44,38 \\
\hline Ivermectin & Antihelmintic antiparasitic & 81,94 & 68,9 \\
\hline Epirubicin hydrochloride & Antineoplastic & 83,01 & 60,93 \\
\hline Succinylsulfathiazole & Antibacterial & $-362,6$ & 46,99 \\
\hline Pempidine & Antihypotenisve vasodilator & $-371,17$ & 46,07 \\
\hline Methyl benzethonium chloride & Antibacterial & $-1322,89$ & 96,66 \\
\hline $\begin{array}{r}\text { Irinotecan hydrochloride } \\
\text { trihydrate }\end{array}$ & Antineoplastic & $-387,09$ & 42,15 \\
\hline Midodrine hydrochloride & Antihypertensive & $-392,31$ & 37,84 \\
\hline Tramadol hydrochloride & Analgesic & $-410,34$ & 49,33 \\
\hline Cephalothin sodium salt & Antibacterial & $-972,09$ & 94,62 \\
\hline Cefuroxime sodium salt & Antibacterial & $-837,14$ & 87,29 \\
\hline Ranitidine hydrochloride & Antiulcer & $-413,31$ & 35,38 \\
\hline Ampyrone & $\begin{array}{l}\text { Analgesic anticoagulant anti- } \\
\text { inflammatory }\end{array}$ & $-418,54$ & 39,74 \\
\hline Secnidazole & Antiamebic & $-418,93$ & 48,42 \\
\hline Benzbromarone & $\begin{array}{l}\text { Antianginal } \\
\text { Antispastic }\end{array}$ & 131,47 & 56,37 \\
\hline Tranexamic acid & Hemostatic & $-428,99$ & 37,53 \\
\hline Chlorcyclizine hydrochloride & antihistaminic & $-434,53$ & 54,63 \\
\hline Diphenylpyraline hydrochloride & $\begin{array}{l}\text { Antihistaminic } \\
\text { sedative }\end{array}$ & $-488,99$ & 50,6 \\
\hline Troleandomycin & Antibacterial & 289,19 & 76,05 \\
\hline
\end{tabular}

